ORNL/TM-12960

OAK RIDGE

NATIONAL

LABORATORY

MARTIN MARIETTA
Carbonate and Citric Acid Leaching of Uranium from UraniumContaminated Soils: Pilot-Scale Studies (Phase II)

\author{
J. H. Wilson \\ R. Chernikoff \\ W. D. DeMarco \\ C. W. Francis \\ L. L. Stebbins
}


This report has been reproduced directly from the best available copy.

Available to DOE and DOE contractors from the Office of Scientific and Technical Information, P.O. Box 62, Oak Ridge, TN 37831; prices available from (615) 576-8401, FTS 626-8401.

Available to the public from the National Technical Information Service, U.S. Department of Commerce, 5285 Port Royal Rd., Springfield, VA 22161.

This report was prepared as an account of work sponsored by an agency of the United States Government. Neither the United States Government nor any agency thereof, nor any of their employees, makes any warranty, express or implied, or assumes any legal liability or responsibility for the accuracy, completeness, or usefulness of any information, apparatus, product, or process disclosed, or represents that its use would not infringe privately owned rights. Reference herein to any specific commercial product, process, or service by trade name, trademark, manufacturer, or otherwise, does not necessarily constitute or imply its endorsement, recommendation, or favoring by the United States Government or any agency thereof. The views and opinions of authors expressed herein do not necessarily state or reflect those of the United States Government or any agency thereof. 


\title{
CARBONATE AND CITRIC ACID LEACHING OF URANIUM FROM URANIUM-CONTAMINATED SOILS: PILOT-SCALE STUDIES (PHASE II)
}

\author{
J. H. Wilson \\ R. Chernikoff* \\ W. D. DeMarco* \\ C. W. Francis ${ }^{\dagger}$ \\ L. L. Stebbins ${ }^{*}$ \\ ${ }^{*}$ FERMCO, Fernald, Ohio \\ ${ }^{\dagger}$ Environmental Sciences Division
}

Date Published: October 1995

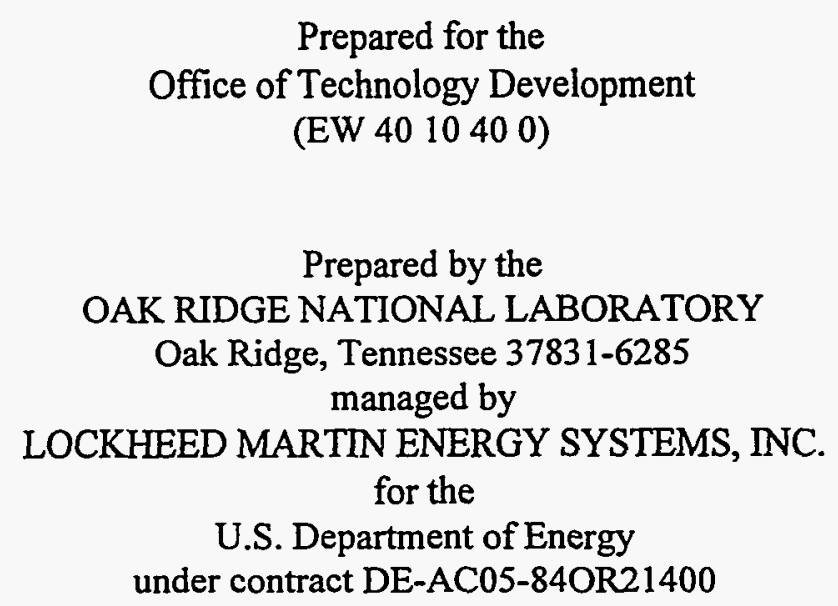




\section{DISCLAIMER}

Portions of this document may be illegible in electronic image products. Images are produced from the best available original document. 


\section{CONTENTS}

LIST OF FIGURES $\ldots \ldots \ldots \ldots \ldots \ldots \ldots \ldots \ldots \ldots \ldots \ldots \ldots \ldots \ldots \ldots \ldots$

LIST OF TABLES $\ldots \ldots \ldots \ldots \ldots \ldots \ldots \ldots \ldots \ldots \ldots \ldots \ldots \ldots \ldots \ldots \ldots \ldots \ldots \ldots \ldots$

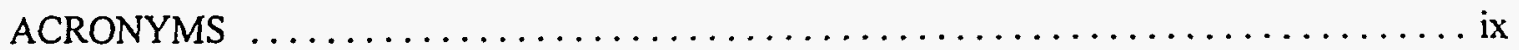

PROJECT PARTICIPANTS LIST $\ldots \ldots \ldots \ldots \ldots \ldots \ldots \ldots \ldots \ldots \ldots \ldots \ldots \ldots \ldots \ldots \ldots \ldots$

EXECUTIVE SUMMARY $\ldots \ldots \ldots \ldots \ldots \ldots \ldots \ldots \ldots \ldots \ldots \ldots \ldots \ldots \ldots \ldots \ldots \ldots \ldots \ldots \ldots$

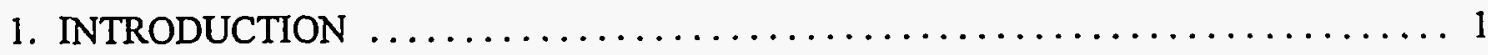

1.1 DOCUMENT PURPOSE . . . . . . . . . . . . . . . . . . . . . . . 1

1.2 INTEGRATED DEMONSTRATION PROJECT DESCRIPTION . . . . . . . . . 1

1.3 HOST SITE DESCRIPTION AND NEED FOR URANIUM REMEDIATION $\ldots \ldots 3$

2. PROJECT OBJECTIVE AND STRATEGY $\ldots \ldots \ldots \ldots \ldots \ldots \ldots \ldots \ldots \ldots \ldots \ldots \ldots$

3. TREATABILITY SOIL DESCRIPTION $\ldots \ldots \ldots \ldots \ldots \ldots \ldots \ldots \ldots \ldots \ldots \ldots$

3.1 SEWAGE TREATMENT PLANT/WASTE INCINERATOR AREA

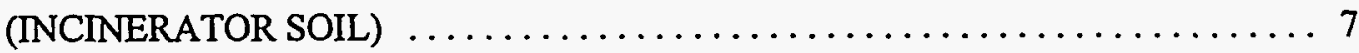

3.2 PLANT 1 PAD (STORAGE PAD SOIL) $\ldots \ldots \ldots \ldots \ldots \ldots \ldots \ldots \ldots \ldots \ldots \ldots$

3.3 SOIL PREPARATION $\ldots \ldots \ldots \ldots \ldots \ldots \ldots \ldots \ldots \ldots \ldots \ldots \ldots \ldots \ldots \ldots \ldots$

4. FERNALD PILOT-SCALE TEST UNIT $\ldots \ldots \ldots \ldots \ldots \ldots \ldots \ldots \ldots \ldots \ldots \ldots \ldots \ldots \ldots$

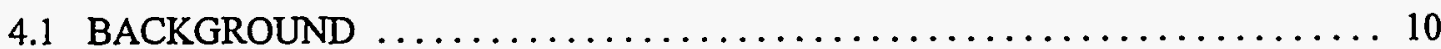

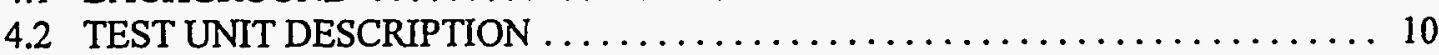

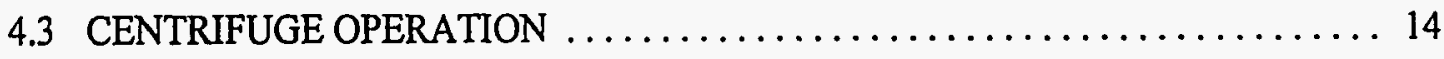

5. SUMMARY OF EXPERIMENTAL AND SAMPLING PLANS $\ldots \ldots \ldots \ldots \ldots \ldots \ldots$

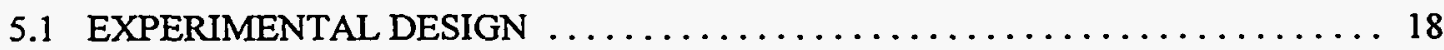

5.2 SAMPLING AND ANALYSIS PLAN AND PROCESS DATA ACQUISITION . . 21

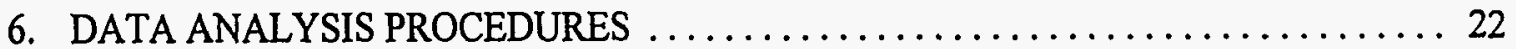

6.1 MATERIAL BALANCE AND REACTOR KINETICS CALCULATIONS . . . . . 22

6.2 STATISTICAL ANALYSIS PROCEDURES $\ldots \ldots \ldots \ldots \ldots \ldots \ldots \ldots \ldots \ldots$

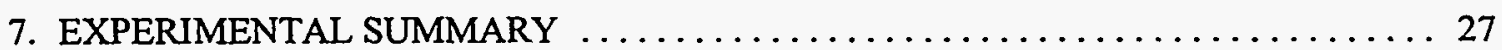

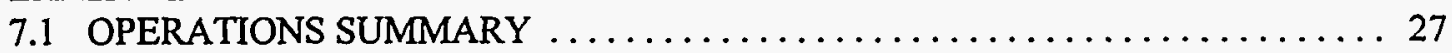

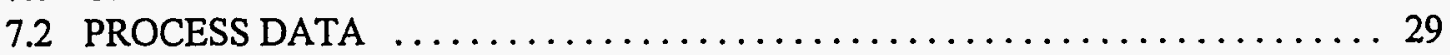

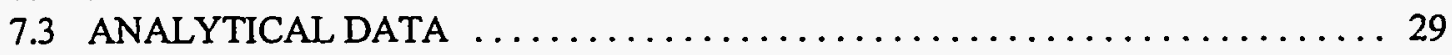

8. RESULTS OF DATA ANALYSIS AND DISCUSSION $\ldots \ldots \ldots \ldots \ldots \ldots \ldots \ldots \ldots$

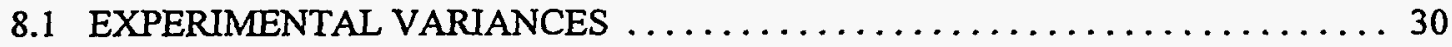




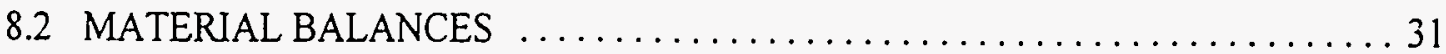

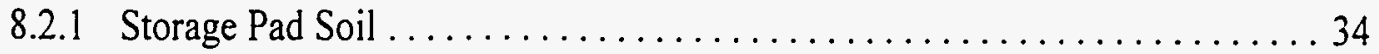

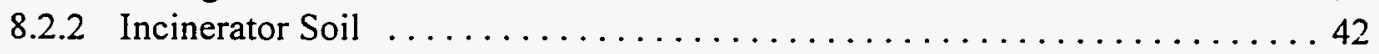

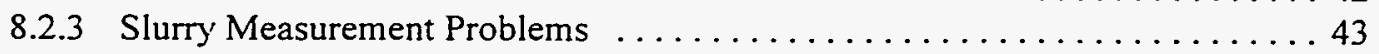

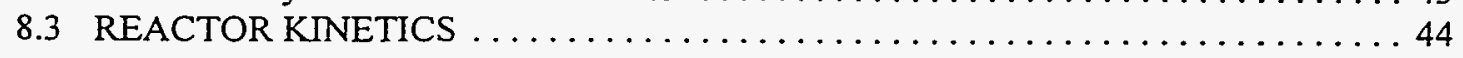

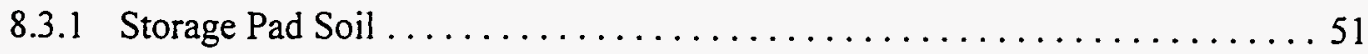

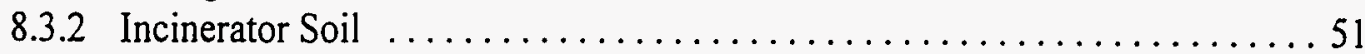

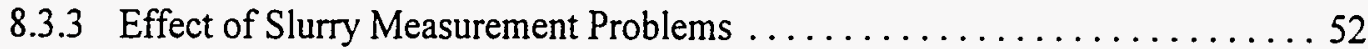

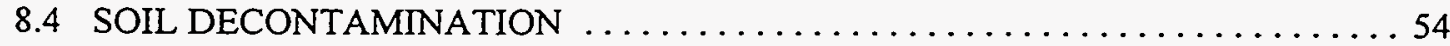

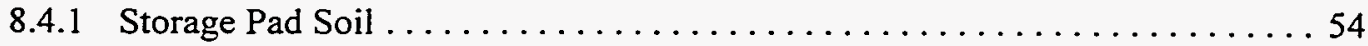

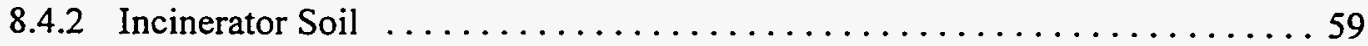

9. RESULTS OF TESTS CARRIED OUT AT "OPTIMUM" CONDITIONS $\ldots \ldots \ldots \ldots 6$

9.1 BASIS FOR EXPERIMENTAL CONDITIONS $\ldots \ldots \ldots \ldots \ldots \ldots \ldots \ldots \ldots \ldots$

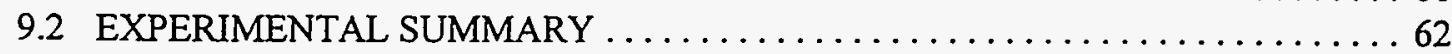

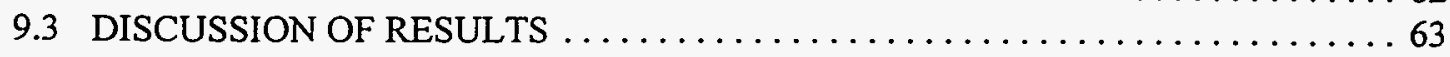

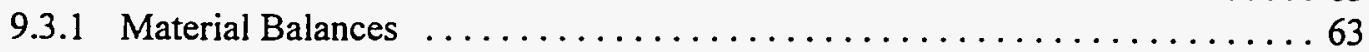

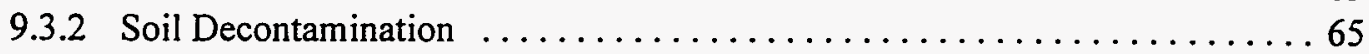

9.3.3 Decontamination of Trommel Oversize $\ldots \ldots \ldots \ldots \ldots \ldots \ldots \ldots \ldots$

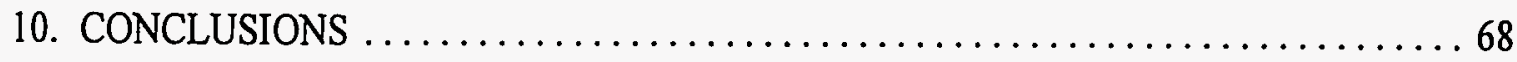

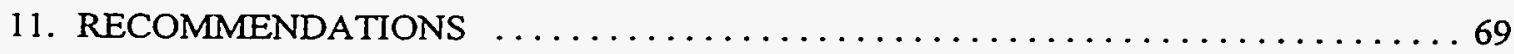

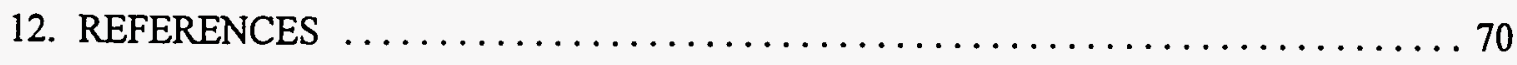

APPENDIX A-PROCESS FLOW SHEETS $\ldots \ldots \ldots \ldots \ldots \ldots \ldots \ldots \ldots \ldots \ldots \ldots \ldots$

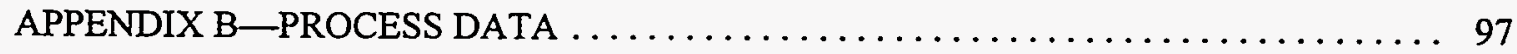

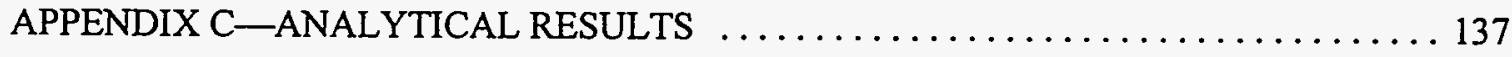

APPENDIX D—DETAILED MATERIAL BALANCES $\ldots \ldots \ldots \ldots \ldots \ldots \ldots \ldots \ldots$ 


\section{LIST OF FIGURES}

Figure

Page

1 Process flow diagram of soil leaching test unit used for Phase II $\ldots \ldots \ldots \ldots \ldots \ldots \ldots$

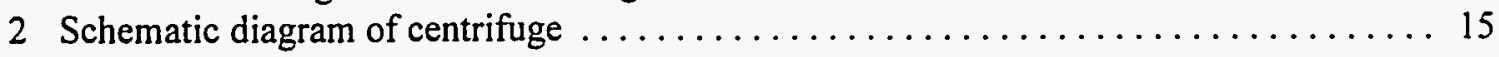

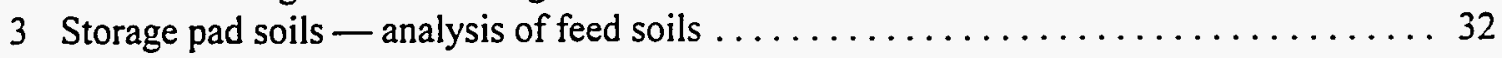

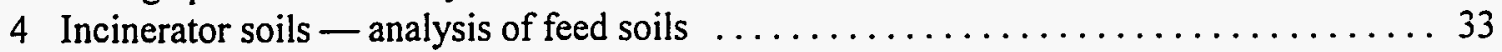

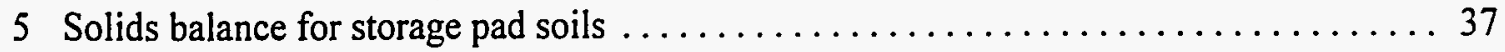

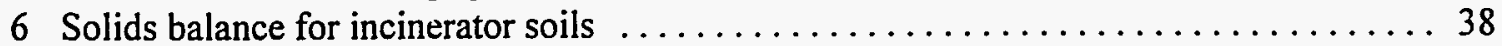

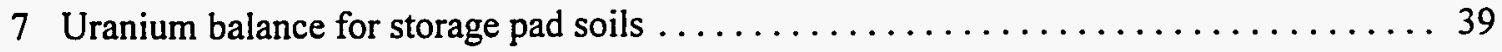

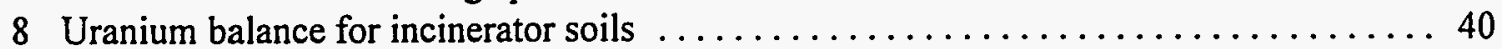

9 Storage pad soils - uranium concentration in reactor solution vs time $\ldots \ldots \ldots \ldots . \ldots 4$

10 Incinerator soils - uranium concentration in reactor solution vs time . . . . . . . . 46

11 Storage pad soils - percent uranium decontamination in reactor vs time $\ldots \ldots \ldots \ldots 48$

12 Incinerator soils - percent uranium decontamination in reactor vs time . . . . . . . 49

13 Storage pad soil tests - uranium concentration in treated soil ............... 57

14 Incinerator soil tests - uranium concentration in treated soil $\ldots \ldots \ldots \ldots \ldots \ldots \ldots$ 


\section{LIST OF TABLES}

Table

Page

1 Summary of conditions for Phase II batch tests $\ldots \ldots \ldots \ldots \ldots \ldots \ldots \ldots \ldots$

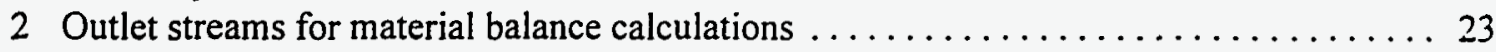

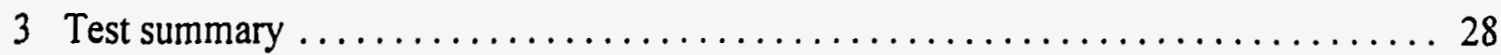

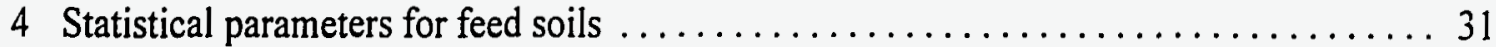

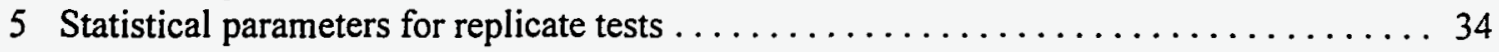

6 Solids and uranium material balances for storage pad soil tests $\ldots \ldots \ldots \ldots \ldots \ldots \ldots$

7 Solids and uranium material balances for incinerator soil tests $\ldots \ldots \ldots \ldots \ldots \ldots \ldots \ldots$

8 Soil decontamination results for storage pad soil tests $\ldots \ldots \ldots \ldots \ldots \ldots \ldots \ldots \ldots$

9 Soil decontamination results for incinerator soil tests $\ldots \ldots \ldots \ldots \ldots \ldots \ldots \ldots \ldots \ldots$

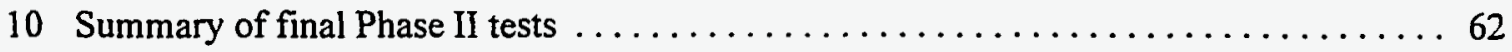

11 Solids and uranium material balances for final Phase II tests $\ldots \ldots \ldots \ldots \ldots \ldots \ldots 64$

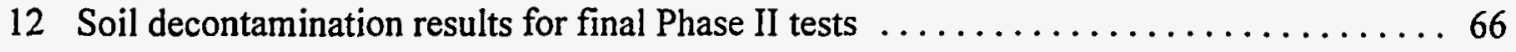

13 Uranium concentration in soil from leaching and rinsing steps $\ldots \ldots \ldots \ldots \ldots \ldots 67$ 


\section{ACRONYMS}

$\begin{array}{ll}\text { ANOVA } & \text { Analysis of variance } \\ \text { CBD } & \text { Sodium citrate-sodium bicarbonate-sodium dithionite } \\ \text { CERCLA } & \text { Comprehensive Environmental Response, Compensation, and Liability Act } \\ \text { CRU } & \text { CERCLA/RCRA Unit } \\ \text { DOE } & \text { Department of Energy } \\ \text { EM } & \text { Environmental Management } \\ \text { FEMP } & \text { Fernald Environmental Management Project } \\ \text { FERMCO } & \text { Fernald Environmental Restoration and Management Corporation } \\ \text { FFCA } & \text { Federal Facilities Compliance Agreement } \\ \text { FMPC } & \text { Feed Materials Production Center } \\ \mathrm{H}_{\mathrm{A}} & \text { Alternative hypothesis } \\ \mathrm{H}_{\mathrm{O}} & \text { Null hypothesis } \\ \text { ID } & \text { Integrated Demonstration } \\ \text { IT } & \text { International Technology Corporation } \\ \text { ORNL } & \text { Oak Ridge National Laboratory } \\ \text { OTD } & \text { Office of Technology Development } \\ \text { pCi } & \text { Picocuries } \\ \text { ppm } & \text { Parts per million by weight, on a dry basis unless otherwise indicated (mg/kg) } \\ \text { QA } & \text { Quality Assurance } \\ \text { RCRA } & \text { Resource Conservation and Recovery Act } \\ \text { RI/FS } & \text { Remedial investigation/feasibility study } \\ \text { SARA } & \text { Superfund Amendments and Reauthorization Act } \\ \text { SEM } & \text { Standard error of the mean } \\ \text { SNK } & \text { Student-Newman-Keuls statistical test } \\ \text { USID } & \text { Uranium in Soils Integrated Demonstration } \\ \alpha & (1-\alpha)=\text { confidence level for the t-test } \\ \beta & \text { (1 - } \beta \text { ) = power of the t-test } \\ \end{array}$




\section{ID Project Contacts}

R. Chernikoff, ORNL

(513) 738-6886

W. D. DeMarco, FERMCO

(513) 648-6106

K. R. Nuhfer, FERMCO

(513) 648-6556

L. L. Stebbins, FERMCO

(513) 738-9023

Fernald Test Unit Operations

C. Clinefelter, FERMCO (Co-op)

W. D. DeMarco, FERMCO

(513) 648-6106

M. J. Geyer, FERMCO

(513) 648-6111

J. Goines, FERMCO (Co-op)

M. Hofacre, FERMCO (Co-op)

K. L. Pylka, FERMCO

(513) 648-6133

M. W. Salisbury, FERMCO

(513) 648-6138

W. Schmidt, FERMCO (Co-op)

J. H. Wilson, ORNL

(615) $576-4413$

S. Wolfe, FERMCO (Co-op)

Fernald Test Unit Sampling

M. A. Arnett, FERMCO

(513) 738-9381

W. A. Neyer, FERMCO

(513) 738-9381

R. Nowlin, FERMCO

(513) 738-9381

\section{CRU5 Project Contacts}

D. M. Gerrick, FERMCO

(513) 738-6180

M. A. Krstich, FERMCO

(513) 648-6231

\section{ORNL Support}

M. P. Elless, ORNL

(615) $576-8192$

C. W. Francis, ORNL

(615) 574-7257

M. E. Timpson, ORNL

(615) 576-8192 


\section{EXECUTIVE SUMMARY}

To help meet the Department of Energy (DOE) cleanup goals of the nuclear waste sites such as the Fernald Environmental Management Project (FEMP) in Ohio, one program initiated by the Office of Technology Development (OTD) of DOE was the Integrated Demonstration (ID) of technologies program. The ID program focuses on improving/validating technologies by demonstrating effectiveness, cost savings, risk reduction potential, site applicability, and regulatory and public acceptance. Once such technologies have been demonstrated to embody the above criteria, efforts are then made for the technologies to be transferred for implementation throughout the DOE and the private sector.

One of the major problems facing the DOE Environmental Restoration Program is the remediation of uranium-contaminated soils. In response to this problem, OTD initiated the Uranium in Soils Integrated Demonstration (USID) program to evaluate and compare the versatility, efficiency, and economics of various technologies for the characterization and remediation of uranium-contaminated soils. The FEMP was selected as the host site for the USID program based on its past operating history and known environmental problems. In support of the USID program, soil leaching was to be evaluated at the pilot scale as a viable technology for remediation of contaminated soils at FEMP.

As part of the remedial investigation/feasibility study (RI/FS) for the Fernald facility, treatability studies directed at leaching uranium from several soil samples from the Fernald site were conducted by the International Technology Corporation (IT). Also, as part of the remedial technology selection process of the RI/FS, the Fernald Environmental Restoration and Management Corporation (FERMCO - the site manager for FEMP) CERCLA*/RCRA ${ }^{\dagger}$ Unit 5 constructed and installed a pilot-scale test unit for soil decontamination at Fernald (CRU5 - the technical strategy adopted by the CERCLA program divides the site into distinct operable units, the management team for each unit being known as a CRU). FERMCO CRU5 performed batch leaching studies using the test unit with the support of IT as the final phase of the RI/FS.

Under the USID program, the Oak Ridge National Laboratory (ORNL) has also carried out bench-scale studies on the leaching of uranium from soils. These studies have included tests with various leachants and pretreatment/leachant combinations. The results of the ORNL studies are summarized in the Phase II test plan.' After completion of the CRU5 work, modifications were made to the Fernald test unit and Phase II leaching studies were then conducted. The experimental design of these pilot-scale tests was based on the ORNL bench-scale results. Operations were performed by FERMCO and ORNL personnel.

The Phase II studies were an outgrowth of the integration of the pilot-scale work of CRU5 and the USID in 1991. The integration of the two programs' operations was organized into three phases. These are as follows:

PHASE I This is the FERMCO CRU5 portion of the soil decontamination studies on the Fernald test unit, cited above.

PHASE II This phase was conducted by the USID group with the support of ORNL, CRU5, and the FERMCO treatability group. This report describes the results of the PHASE II CRU5/USID batch soil leaching treatability studies. Data from this phase may be made available for CRU5 to use in the RI/FS.

\footnotetext{
* Comprehensive Environmental Response, Compensation, and Liability Act.
}

+ Resource Conservation and Recovery Act. 
PHASE III This phase was also to have been conducted by the USID group, with the same supporting organizations as Phase II. Plans were that the tests will be leaching studies with the Fernald test unit configuration modified to run in a continuous soil processing mode. This phase was canceled.

The ultimate goal of this project was to develop data on the efficiency and operability of the soil decontamination process that can be used for the design of a full-scale system. The purpose of the Phase II tests on the Fernald test unit was to assess the performance of selected leaching media and engineering process design for removal of uranium from soils in a pilot-scale unit. For the goal to be accomplished, there were several specific project objectives to be satisfied.

- The soil leaching process should produce a clean soil that has an uranium concentration level equal to or less than $52 \mathrm{ppm}$, the initial technology screening level adopted by the USID.

- The soil leaching process should decontaminate the soil without seriously degrading the soil's physicochemical characteristics (that might require its management or disposal as a waste) or generating a secondary waste form that is difficult to manage and/or dispose.

- Soil leaching tests, previously performed on the bench scale, should be demonstrated at the pilot scale. These results will be useful for full-scale application of the technology.

- The results of the CRU5/USID Phases II and III are to be shared with CRU5 and incorporated in the CRU5 RI, as applicable.

The Fernald test unit was operated in a batch mode to demonstrate the removal of uranium from two contaminated soils. These soils had been taken from near the waste incinerator and near the plant 1 storage pad. The soils had been stored as unmodified soils and blended soils. The blended soils, which had been sifted and then processed in a concrete mixer to obtain homogeneity, were used for the final four tests of Phase II. For use in the rest of the Phase II tests, the unmodified soils were screened and then processed through a ribbon blender.

In the Phase II operations of the Fernald test unit, a drum of soil was processed in each test. The standard processing sequence involved (1) removal of coarse material from the soil in a trommel and a vibrating screen, (2) centrifuging the soil slurry to produce a nominal $20-\mu \mathrm{m}$ size cut, (3) treating the coarse soil fraction in an attrition scrubber, and (4) recombining the two soil fractions and leaching with chemicals in a stirred reactor. This was followed by liquid/solid separation by centrifuging the reactor slurry and then rinsing the centrifuge wet cake to remove residual spent leaching solution from the treated soil.

The experimental design in the Phase II Test Plan consisted of 24 tests. Tests 0 through 19 were to be run and the test data analyzed before proceeding with the remaining tests. From the results of the analyses of the pilot-scale data for these first 20 tests and data from concurrent benchscale tests, "optimum" operating conditions were to be selected for the final four tests.

In Tests 0 through 19, leaching tests were to be run with up to four different leaching agents on each of the two Fernald soils. These leachants, which were used in previous bench-scale studies, were sodium carbonate/sodium bicarbonate (with potassium permanganate in the incinerator soil tests), sodium citrate/sodium bicarbonate/sodium dithionite (CBD), citric acid, and sulfuric acid. Because of modifications required to the Fernald test unit, the two CBD tests were not run. Also, the two sulfuric acid tests were not run because it was determined that adequate data had been 
generated in the Phase I tests. In addition to studying the effect of type of leachant on uranium removal, the experimental design included replicate tests to measure experimental variances and tests to determine the effects of leaching temperature and attrition scrubbing on uranium removal.

The analysis of the data generated in the Phase II tests included material balance calculations for solids and uranium using the analytical and process data. To check for consistency and to better characterize potential losses, three different material balances were made for each test; two were intermediate material balances (around certain sections of the pilot plant) and the third was an overall material balance taken around the entire pilot plant. The kinetics of the leaching reaction was examined by determining the percent of uranium leached from the soil as a function of time in the reactor. Statistical analyses were made to compare the uranium decontamination levels achieved in the tests with the technology screening level and to determine the effects of leachant type, attrition scrubbing, and reaction temperature on uranium leaching efficiency.

Based on the results of the analyses of the experimental data, the conclusions from the USID Phase II studies on the Fernald test unit are as follow:

- The preliminary decontamination target level of $52 \mathrm{ppm}$ uranium was not achieved with either the incinerator area or the storage pad soil.

- In the replicated tests in the experimental design, the average uranium levels in the treated soil that were achieved with carbonate as leachant were 132 and $123 \mathrm{ppm}$ for the storage pad soil and the incinerator area soil, respectively. In the final tests run under "optimum" operating conditions, uranium levels less than $100 \mathrm{ppm}$ were attained. However, because of the lower uranium concentrations in the feed soils, no conclusion can be drawn about an effect of operating conditions.

- The average percent uranium decontamination was $92 \%$ for the storage pad soil and $83 \%$ for the incinerator area soil.

- Attrition scrubbing had no significant effect on decontamination efficiency.

- Increased reaction temperature significantly increased uranium decontamination for the incinerator area soil. No effect of temperature was observed for the storage pad soil.

- The rates of uranium leaching with carbonate and with citric acid are reasonably fast; within $30-60 \mathrm{~min}$, the uranium removal is $90 \%$ or more of that reached at the end of the $120-\mathrm{min}$ reaction period.

- Citric acid was apparently not as effective as sodium carbonate/sodium bicarbonate for leaching the incinerator area soil. However, the comparison was confounded by a significantly higher uranium concentration in the feed soil that was used in the citric acid test. Thus, no conclusion is made concerning the effect of leaching agent in the incinerator soil tests. For the storage pad soil, there was no significant difference between the two leaching agents. 
Based on the results from the USID Phase II tests. recommendations for the design and operation of a soil leaching process for uranium decontamination are as follow:

- Perform bench-scale studies to establish whether or not successive leaching steps improve overall leaching efficiency.

- Exclude attrition scrubbing from the soil leaching process, as this unit operation has no significant beneficial effect on leaching efficiency.

- Operate the leaching reactor(s) at $40^{\circ} \mathrm{C}$.

- Specify a residence time of at least $1 \mathrm{hr}$ in the design of a soil leaching process.

Although the preliminary decontamination target level of $52 \mathrm{ppm}$ uranium was not achieved in the pilot plant tests, a significant portion of uranium was removed from the soils. The uranium remaining in the soil likely exists in a more refractory form. Because of the lower uranium concentrations and the apparent decreased mobility of the uranium, the soil leaching process may well produce a treated soil capable of meeting levels developed from risk-based analyses. 


\section{INTRODUCTION}

\subsection{DOCUMENT PURPOSE}

The purpose of this document is to describe the results of the soil decontamination demonstration conducted at the Fernald Environmental Management Project (FEMP) site by the Fernald Environmental Restoration and Management Corporation (FERMCO) and the Oak Ridge National Laboratory (ORNL). This demonstration, which began in November 1993 and ended in October 1994, involved the removal of uranium from contaminated soil sampled from two FEMP sites. The demonstration was conducted so as to meet the requirements of the Fernald Site Integrated Demonstration program, as well as all environmental, safety, and health requirements of the site.

\subsection{INTEGRATED DEMONSTRATION PROJECT DESCRIPTION}

To help meet the Department of Energy (DOE) cleanup goals for nuclear waste sites such as the FEMP, the Director of Environmental Restoration and Waste Management initiated the Office of Technology Development (OTD). One program formed by OTD was the Integrated Demonstration (ID) program. The ID program focuses on improving/validating technologies by demonstrating effectiveness, cost savings, risk reduction potential, site applicability, and regulatory and public acceptance.

The FEMP was selected to host an ID program. The FEMP, previously known as the Feed Materials Production Center (FMPC), is a contractor-operated federal facility for the remediation of a site which produced high purity uranium metal for the DOE. As such, this ID program, known as the Uranium in Soil Integrated Demonstration (USID) program, will address the issues from 
"cradle to grave" surrounding the characterization and remediation of uranium-contaminated soils. specifically soils with a high clay/silt content. Reduction of contaminated soil quantity, through the coupling of real time analysis and precise excavation, along with decontamination techniques applicable to high clay/silt soils are the major technology areas. Secondary waste reduction, cost optimization, risk reduction, and user applicability are other important elements in this USID.

Soil leaching is one of the technologies identified as a viable option for remediation of contaminated soils at Fernald. ${ }^{2}$ As part of a remedial investigation/feasibility study (RI/FS) for the Fernald facility, lab-scale treatability studies directed at leaching uranium from several soil samples from the Fernald site were conducted by the International Technology Corporation (IT). ${ }^{3}$ Also, as part of the remedial technology selection process of the RI/FS, FERMCO, the FEMP facility contractor, constructed a pilot-scale test unit for soil decontamination. This facility included several engineering unit operations such as size separation, particle attrition, reaction, filtration, and centrifugation, along with various pumps and storage and holding tanks. The FERMCO CRU5 installed the test unit at Fernald, and FERMCO with the support of IT carried out pilot-scale leaching studies on Fernald soils using leaching agents selected from the treatability studies.

In support of the USID, ORNL has also been involved in studies on the leaching of uranium from soils. ${ }^{4.5}$ Based on the results of these studies, leaching agents were identified for testing on the Fernald test unit. Modifications were made to the Fernald test unit, and Phase II leaching studies were then conducted. The experimental design of these pilot-scale tests was based on the ORNL bench-scale results. Operations were performed by FERMCO and ORNL personnel.

The Phase II studies were an outgrowth of the integration of the pilot-scale work of CRU5 and the USID in 1991. The pilot-scale work of CRU5 and the USID was integrated in 1991. The integrated operations of the two programs was organized into three phases: 
PHASE I This is the FERMCO CRU5 portion of the soil decontamination studies, detailed above. This phase included the Fernald test unit initial constructions and start-up.

PHASE II This phase was conducted by the USID group with the support of ORNL, CRU5, and the FERMCO treatability group. As in Phase I, batch leaching tests were to be performed on the Fernald test unit. Process modifications were made for Phase II operation. The existing Fernald test unit equipment remained the same; routing and the sequence of use of the equipment comprised the process modifications. This report details the results of PHASE II CRU5/USID batch soil leaching studies on the Fernald test unit. Data from this phase may be made available for CRU5 to use in the RI/FS.

PHASE III This phase was to be conducted by the USID group, with the same supporting organizations as in Phase II. Plans were that the tests will be leaching studies with the Fernald test unit modified to run in a continuous soil processing mode. This phase was canceled.

\subsection{HOST SITE DESCRIPTION AND NEED FOR URANIUM REMEDIATION}

A detailed description of the FEMP is given in the Phase II work plan.' The Federal Facilities Compliance Agreement (FFCA) that was entered into and the RI/FS which is in progress pursuant to the Comprehensive Environmental Response, Compensation, and Liability Act (CERCLA), as amended by the Superfund Amendments and Reauthorization Act (SARA), are also discussed. The technical strategy adopted by the CERCLA program divides the site into five distinct operable units.

The components of the operable units are as follows:

Operable Unit 1 - Waste Pits 1-6, Clearwell, and Burn Pit Operable Unit 2 - Other Waste Units (fly ash pile and Solid waste landfill) Operable Unit 3 - Production Area Operable Unit 4 - Silos 1, 2, 3, and 4 Operable Unit 5 - Environmental Media

Uranium is the principal soil contaminant of concern at the FEMP, and an acceptable concentration level for uranium in soils has not been established. Consequently, soil decontamination technologies were to be evaluated with respect to a level of $52 \mathrm{ppm}$, the initial technology screening level adopted by the USID. 
Uranium has deposited over the years on the soil from various sources. The stacks in the production area, dust blown from the disposal pits in the Waste Storage Area, and the incinerator in the sewage plant were sources of airborne uranium. Also, soil contamination has resulted from leaks and spills during processing activities in the production areas and from the spreading of contamination by vehicles. The majority of soils containing uranium exceeding $52 \mathrm{ppm}$ are located in the top $0.45 \mathrm{~m}$ of surficial material. ${ }^{6}$

One of the major concerns at FEMP relating to uranium contamination in soil is the potential for uranium to be leached from the soil into the Great Miami aquifer immediately below the FEMP site. The potential for such a phenomenon to occur is a real one because of the uranium forms in soil and the soil characteristics. Characterization data have shown that a large fraction (probably $>90 \%$ ) of the uranium in soil exists as the U(VI) or uranyl form. Over the years of plant operation, it appears that a considerable amount of carbonate-based material (namely, limestone containing calcite and dolomite minerals) has been added to the surface soils. Consequently, the pH of soils within the plant are relatively high ( $\mathrm{pH}$ values on the order of 7.2 to 8.4 ) compared with native soils adjacent to the plant ( $\mathrm{pH}$ values ranging from 5.4 to 6.3 ). These carbonate soils tend to serve as in situ leachants for uranium. For example, dissolution of carbonate minerals yields the $\mathrm{CO}_{3}{ }^{2-}$ anion that form the di- and tri-carbonate anionic complexes with uranyl, such as

$$
\left[\mathrm{UO}_{2}\left(\mathrm{CO}_{3}\right)_{2}\right]^{2-}
$$

and

$$
\left[\mathrm{UO}_{2}\left(\mathrm{CO}_{3}\right)_{3}\right]^{4-}
$$

Both of these uranyl-carbonate complexes are highly mobile in soils, creating a potential plume of uranium-contaminated water that could reach the Great Miami aquifer. Thus, it is critical that the carbonate-soluble fraction of uranium be removed from these soils to protect against uranium contamination of drinking water in the Great Miami aquifer. 


\section{PROJECT OBJECTIVE AND STRATEGY}

The purpose of the tests on the Fernald test unit was to assess the performance of selected soil leaching technologies for removal of uranium using FEMP soils. The ultimate goal of this project was to develop data on the efficiency and operability of the soil decontamination process that can be used for the design of a full-scale system. For this goal to be accomplished, there were several specific project objectives to be satisfied.

- The soil leaching process should produce a soil that has a uranium concentration level equal to or less than an acceptable contamination level. Soil decontamination will be evaluated with respect to (1) a preliminary technology screening level of $52 \mathrm{mg} \mathrm{U} / \mathrm{kg}$ of soil or (2) revised target levels based on risk assessment data.

- The soil leaching process should also represent an "earth friendly" approach to the treatment of soil. That is, the process should decontaminate the soil without seriously degrading the soil's physical/chemical characteristics or generating waste forms that are difficult to manage and/or dispose.

- The results of bench-scale soil leaching tests should be further demonstrated at the pilot scale. These results will be useful for full-scale application of the technology.

- The results of the CRU5/USID Phases II and III are to be shared with CRU5 and incorporated in the CRU5 RI as time and funding constraints permit.

The Phase II tests on the Fernald test unit were conducted based on the results of soil characterization studies ${ }^{5,6}$ and experimental leaching studies. ${ }^{4,5}$ In the latter studies, leaching agents such as sodium carbonate and citric acid were used to leach uranium from various soil and sediment samples. The objective of these leaching studies was to determine the effectiveness of these treatments in reducing uranium concentrations to acceptable regulatory levels without seriously degrading the physical/chemical characteristics of the soil. The process configuration used for the Phase II tests was based on the following considerations: 
- There is no experimental evidence that physical treatment alone, such as treatment with an attrition scrubber and fractionation by particle size, will remove uranium from a particular fraction of Fernald soils (e.g. uranium concentrations in sand, silt, and clay fractions of the storage pad soil and the incinerator site soil at Fernald were all $>52 \mathrm{mg} / \mathrm{kg}$, the proposed screening levels for applicable decontamination technologies $\left.{ }^{4}\right)$. Consequently, any successful soil decontamination process will likely depend on a chemical leaching process.

- By using an attrition scrubber to treat the entire soil, high leaching efficiencies were obtained at relatively short residence times in bench-scale studies. The bench-scale studies involved (1) a one-step test in which attritioning and leaching were done simultaneously and (2) a two-step test in which attritioning and leaching were done in sequence.

- In bench-scale studies, the highest uranium removal efficiencies were obtained in a two-step procedure involving scrubbing of a water/soil slurry at a $0.8 / 1$ weight ratio for $15 \mathrm{~min}$, followed by addition of a leaching agent and water to give a $2 / 1$ water-to-soil weight ratio and leaching for $15 \mathrm{~min}$. These results indicated that attrition scrubbing at high solids loadings and leaching at a higher liquid/solids ratio was an effective procedure for uranium removal.

- Multiple rinsings of the leached soil are needed to minimize the amount of spent (i.e., containing dissolved uranium) leaching solution retained by the soil (this procedure is commonly practiced in the uranium milling industry ${ }^{7}$ ).

In the process configuration developed for Phase II operation, tests were run in which either the entire soil or a coarse soil fraction was pretreated in an attrition scrubber and then subjected to leaching in a stirred tank. This was followed by liquid/solid separation by centrifugation and then rinsing to remove the spent leaching solution from the treated soil.

The Fernald test unit was operated in a batch mode in Phase II. Phase III plans included soil leaching in a continuous mode. 


\section{TREATABחLITY SOL DESCRIPTION}

Two FEMP soils were selected for this demonstration. The soils were collected from the Sewage Treatment Plant/Waste Incinerator area and the Plant 1 Pad area. The following describes the two soils and the method of preparation for their use in the pilot-scale tests.

\subsection{SEWAGE TREATMENT PLANT/WASTE INCINERATOR AREA (INCINERATOR SOL)}

The Sewage Treatment Plant, associated facilities, and the abandoned solid waste incinerator are located on the eastern property line of the FEMP reservation. The incinerator is located in the northwest corner of the Sewage Treatment Area. This incinerator was operated from November 1954 through December 1979. The incinerator was used to burn contaminated and uncontaminated combustible trash during its period of operation.

Surface radiological measurements and limited soil samples collected in the vicinity of these facilities indicated the presence of localized elevated concentrations of radionuclides. ${ }^{6}$ As a result of the RI/FS sampling activities, the concentration of ${ }^{238} \mathrm{U}$ in surface soils was found to range from 1.8 to $25,670 \mathrm{pCi} / \mathrm{g}$. In addition to surface soil samples, there was a limited number of core samples taken in this area as part of the RI/FS. The results indicated that uranium contamination is limited to the upper reaches of the soil column-only one sample exceeded $100 \mathrm{pCi} / \mathrm{g}$, which was taken from a depth of $0.45-0.91 \mathrm{~m}$. FEMP RCRA determination procedures have established that the USID incinerator area soils are non-RCRA. 


\subsection{PLANT 1 PAD (STORAGE PAD SOIL)}

During the production years at the FEMP, the Plant 1 Pad was used to temporarily store various residues from the production plants, raw ore, and material from other DOE sites. After Plants $2 / 3$ and 8 were shut down, the pad was used as a permanent storage area for the residues. The Plant 1 Pad did not have a containment barrier until the late 1980s. Numerous releases of material from deteriorated drums and accidental spills occurred throughout operational history of the pad. The lack of containment allowed released material to wash off the pad during rainstorms and routine water spraying of the pad, thereby contaminating the soil on the perimeter of the pad.

The Plant 1 Pad soil has been determined to be a low-level radioactive waste. FEMP RCRA determination procedures have established that the USID Plant 1 Pad soil is neither a RCRA-listed waste nor a RCRA characteristic waste.

\subsection{SOIL PREPARATION}

Soils were removed from the Waste Incinerator and the Plant 1 Pad areas. Two lots of blended soil were prepared, one lot from each of the areas. After removal from a particular area, the soil was sifted using a 3/4-in. screen to remove gravel fragments and unwanted debris. The sifted soil was then processed in a $5 \mathrm{yd}^{3}$ concrete mixer to obtain homogeneity. The two lots of blended soil were stored in drums as containerized material, along with metal boxes of unmodified (i.e., not sifted or blended) soils and residues from the blending process.

The soils used in most of the Phase II demonstration tests were taken from the unmodified soils in the metal boxes. Again, two lots of blended soil were prepared, one lot from each of the areas. After removing the metal boxes from storage, drums of each soil were prepared by screening the soil 
through a 3/4-in. screen. The screened soil was processed through a ribbon blender to obtain homogeneity and then drummed. The soils blended in this manner were used for all Phase II tests. with the exception of Tests $20,21,22$, and 25 . The soils that had been previously blended in the concrete mixer were used in the four final tests.

In preparing the lots of soil with the ribbon blender, each lot was actually blended in two batches. For the incinerator soil, eight drums were filled from the first batch of blended soil, and nine drums from the second batch. For the storage pad soil, six drums were filled from the first batch and the rest of the drums from the second batch. For each soil, the uranium concentrations in the drums were analyzed to determine if any statistically significant differences between drums existed. This is discussed later.

The soils that had been blended in the concrete mixer (in 1991) were used for Tests 20,21, and 22 as a demonstration of the best processing method developed in the previous Fernald test unit tests. These soils will be reference soils that will be tested by all USID investigators of soil decontamination technologies. A soil from the storage pad area that contained grass and roots was used for Test 25 . 


\section{FERNALD PILOT-SCALE TEST UNIT}

\subsection{BACKGROUND}

As part of the RI/FS for the Fernald facility, lab-scale treatability studies directed at leaching uranium from several FEMP soil samples were conducted by IT. Also, as part of the remedial technology selection process of the RI/FS, the FERMCO CRU5 constructed and installed a

pilot-scale test unit for soil decontamination at Fernald. FERMCO CRU5 performed batch leaching studies using the test unit with the support of IT as the final phase of the RI/FS. These studies were completed in 1993.

After completion of the CRU5 work, process modifications were made to the Fernald test unit for the Phase II studies. The same equipment was used; however, routing and the sequence of use of the equipment were modified. The Phase II uranium leaching tests with Fernald soils were then conducted by FERMCO and ORNL personnel.

\subsection{TEST UNIT DESCRIPTION}

Figure 1 shows the process flow diagram for the Fernald test unit as modified for Phase II. The process configuration illustrated was used for all replicated tests, as described in Sect. 5. This process configuration was based on the results of bench-scale studies and a conceptual design for a commercial-scale soil leaching process. In other tests, modifications were made to the process flow scheme to study the effects of process variables. Modifications were also made during the Phase II testing primarily to improve operations. These modifications are discussed later. During batch operation of the Fernald test unit, the same piece of equipment could be used in different steps. 


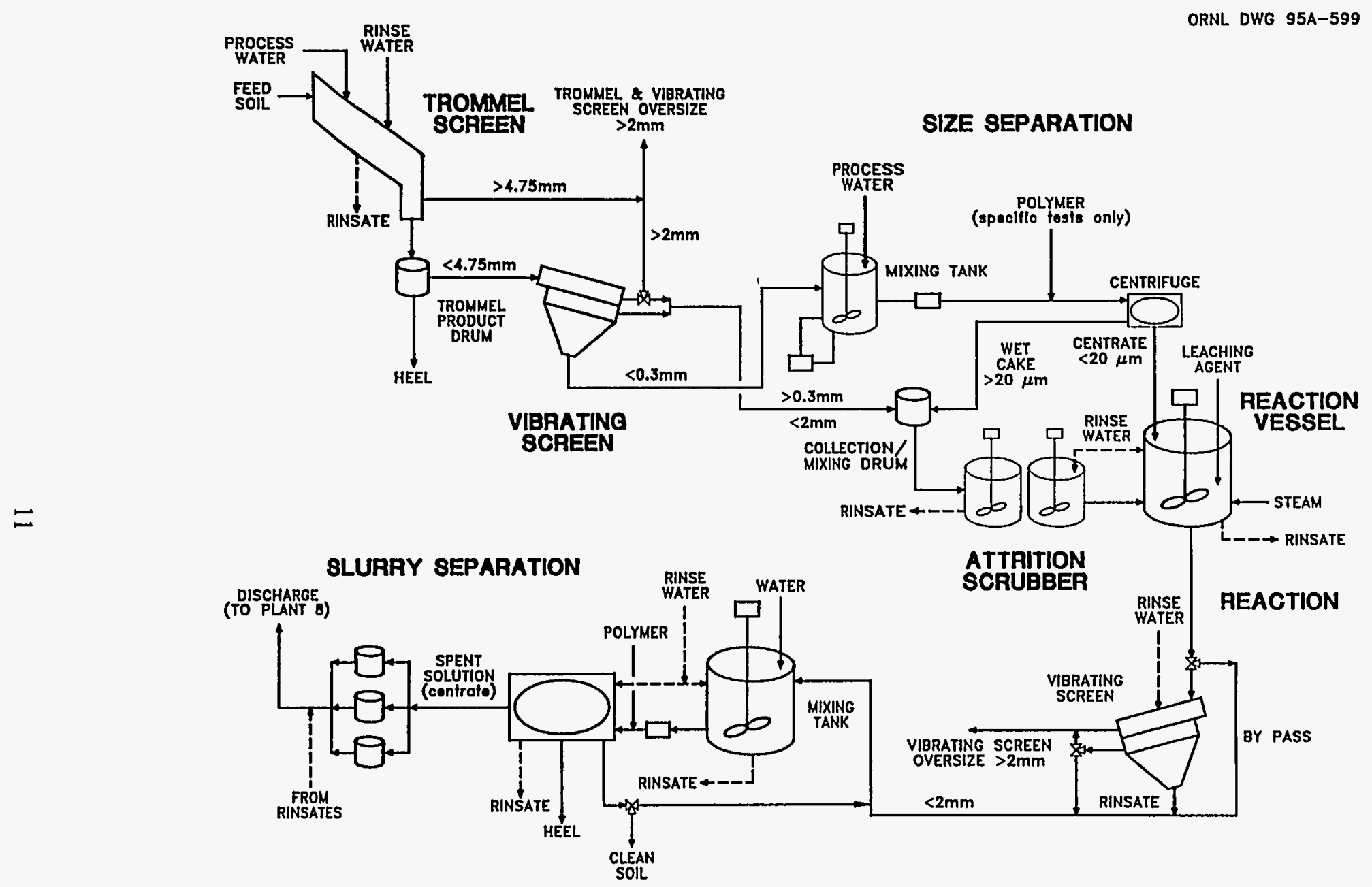

Fig. 1. Process flow diagram of soil leaching test unit used for Phase II 
For example, whereas the Fernald test unit equipment included only one centrifuge and one vibrating screen, Fig. 1 shows that each of these two pieces of equipment was used in more than one process step. This is of particular significance in the case of the centrifuge, as discussed later. The operation of the Fernald test unit in the standard configuration of Fig. 1 is outlined below.

In the batch operation of the Fernald test unit, $\sim 350 \mathrm{lb}$ from a feed soil drum was processed in each experimental test. The first step was to manually transfer the feed soil from the drum to a conveyor. The soil was continuously fed into a trommel screen to remove $>4.75-\mathrm{mm}$ material. This large size material was made up primarily of small rocks or pebbles. The slurry from the trommel, which consisted of $<4.75-\mathrm{mm}$ material and the water that was injected at high pressure (1000 psig) into the trommel, was collected in a surge drum that was equipped with a mixer.

The slurry produced in the trommel operation was continuously pumped from the surge drum to a vibrating screen deck, which contained a $2-\mathrm{mm}$ screen and a $0.3-\mathrm{mm}$ screen. The material in the $0.3-$ to $4.75-\mathrm{mm}$ size range was removed in the screen deck and collected for use later in the process. The material on the $0.3-\mathrm{mm}$ screen was removed along with the material on the $2-\mathrm{mm}$ screen to avoid processing particles greater than 2-mm through the centrifuge. Because the 2-mm screen was a Harpscreen ${ }^{\circledR}$ which had wires running in only one direction rather than two, some of the $>2-\mathrm{mm}$ material passed through to the $0.3-\mathrm{mm}$ screen. The slurry, which now contained $<0.3-\mathrm{mm}$ material, drained from the vibrating screen deck into a mixing tank.

Water was added to the slurry in the mixing tank to adjust the slurry volume to $\sim 350$ gal ( $10 \mathrm{wt} \%$ solids). The slurry in the mixing tank was then processed through the continuous centrifuge. The centrifuge was operated at conditions determined in Phase I to produce a nominal $20-\mu \mathrm{m}-$ size cut. The centrifuge wet cake, which consisted of the coarse soil fraction ( $20 \mu \mathrm{m}$ to $0.3 \mathrm{~mm}$ ), was combined with the $0.3-$ to $4.75-\mathrm{mm}$ material that had been collected from the screen deck. The centrate was collected in a surge tank and then transferred to the leaching reactor. The 
centrifuge heel (material collected when the centrifuge was stopped. as described later) was also added to the leaching reactor.

For most tests, the wet solids from the centrifuge operation were treated in an attrition scrubber for a residence time of $15 \mathrm{~min}$. Attrition scrubbers process high solids content slurries; scrubbing, polishing, and disintegration of the solid particles result from grain-to-grain contact. The particle contact occurs as the slurry is pumped within the scrubber by two impellers mounted on a common shaft. The impellers, which have opposite pitches, are rotated in a direction to produce upward pumping by the bottom impeller and downward pumping by the top impeller. After attrition scrubbing, the treated solids were added to the centrate and the centrifuge heel in the leaching reactor. The leaching agent was added directly to the stirred reactor in powder or granular form. The soil was then leached in the reactor for $2 \mathrm{hr}$. At the beginning of and during the leaching step, samples of the slurry were taken so that the uranium leaching efficiency could be determined as a function of time.

Upon completion of the leaching step, the reactor slurry was pumped through the vibrating screen deck (which had been thoroughly rinsed after processing the feed soil), to remove any 0.3 - to 4.75-mm material, and into the centrifuge feed tank. The slurry was then processed through the centrifuge to separate the treated solids from the leaching solution. The centrifuge was operated at the same conditions as before, except that a polymer solution was continuously injected into the centrifuge feed to maximize solids recovery.

The solids recovered from centrifuging the treated slurry were subjected to a rinse cycle to remove residual leaching solution. The rinse cycle involved returning the centrifuge solids to the mixing tank, adding process water to adjust the slurry volume to 350 gal, and feeding the slurry, with polymer injection, to the centrifuge. As the last processing step, the recovered solids were subjected to a second identical rinse cycle to produce a final treated soil. 


\subsection{CENTRIFUGE OPERATION}

ecause of a potential for cross-contamination, as discussed below, the centrifuge operation, in particular the production of the centrifuge heel, is described here. To help visualize the operation, Fig. 2 shows a schematic of the centrifuge. The centrifuge heel was residual material that discharged through the wet cake outlet port upon shutdown of the centrifuge. This material, referred to as a liquid pool, was held on the centrifuge wall by centrifugal force while the centrifuge was running (the depth of the liquid pool was determined by adjustable liquid overflow weirs). When the centrifuge stopped, the material dropped to the bottom of the centrifuge and overflowed through the wet cake and the centrate outlet ports, with the majority of the material passing through the wet cake port (before the centrifuge was stopped, the wet cake collection drum was replaced by the centrifuge heel collection drum).

The centrifuge heel from the first centrifuge operation (prior to the reactor) was combined with the centrate; it did not appear as a separate stream in the material balance calculations. The centrifuge heel that was collected as a by-product stream was a composite from the last three centrifuge operations in each test. Polymer was injected into the centrifuge feed during these operations to maximize solids recovery. The effectiveness of the polymer was evident from the rapid liquid/solid separation observed in the centrifuge feed samples that were taken immediately before the centrifuge. Thus, when the centrifuge feed was shut off and the discharge of wet cake and centrate from the centrifuge had ceased, the liquid pool held on the centrifuge wall, and consequently, the centrifuge heel would be expected to have a low solids content, perhaps comparable with the centrate that had been produced. However, during the Phase II tests, the solids recovered in the centrifuge heel represented a significant fraction of the feed solids. 

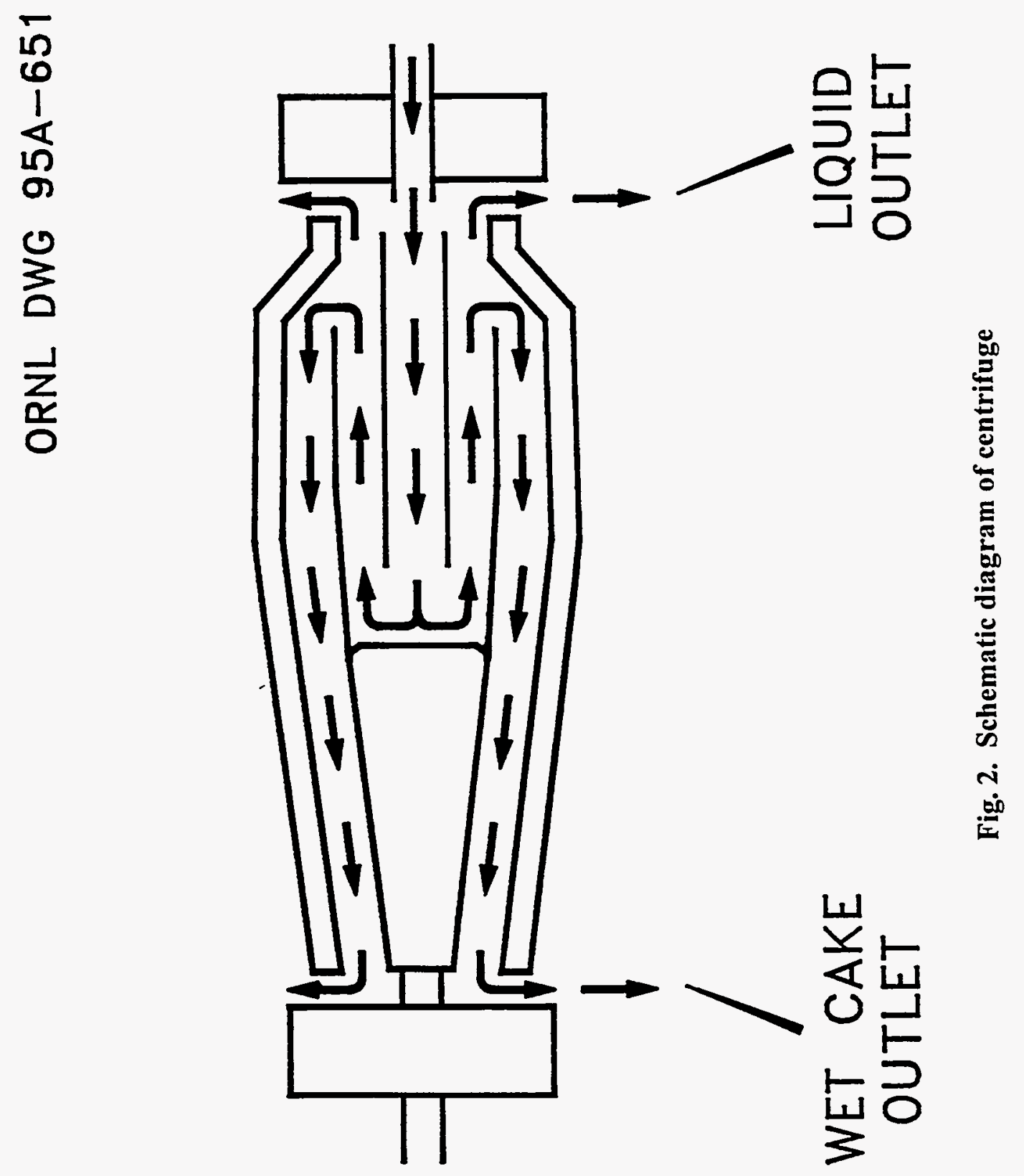
In addition to the liquid pool, the operation of the centrifuge forms a layer of solids between the scroll and the inner centrifuge wall. Once formed, this layer is thought to be permanent while the centrifuge is running. ${ }^{8}$ However, the unexpected amount of solids in the centrifuge heel suggests that some of this layer is being removed when the centrifuge is stopped. Once centrifugal force is lost, the heel is discharged from the centrifuge within a few seconds. Some of the solids layer could be washed off the wall by the sudden rush of liquid and collected as part of the centrifuge heel.

The use of the centrifuge to process both the feed soil and the treated soil was mentioned previously. To minimize the possible contamination of the treated soil by residual feed soil in the centrifuge, the collection of a centrifuge purge began in Test 18. This purge, which was collected during the centrifuge operation immediately following the leaching reactor operation, began in Test 18. The rationale for using this purge evolved during examination of the solids material balance problem in the initial Phase II tests.

In examining the material balance problem, the effect of solids holdup in the centrifuge was considered. Based on visual observation and experience with manual transfer operations, the centrifuge wet cake produced with polymer addition, as in the case of the treated soil slurry, was more viscous than that without polymer. Thus, variations in the thickness of the solids layer on the centrifuge wall seemed feasible. Due to a lower drag force from the less viscous wet solid, the soil layer on the centrifuge wall could be expected to be thicker when processing the feed soil slurry than when processing the treated soil slurry (except in Tests 14 and 16 in which polymer was added to the feed soil slurry). Consequently, the solids inventory in the centrifuge could increase when processing the feed soil slurry and then decrease when the treated soil was subsequently processed. This cycle would be repeated with each test.

Changes in the thickness of the soil layer on the centrifuge wall conceivably could affect the solids material balance. However, calculations indicated that the effect would not be significant. 
A more serious problem, though, appeared to be the potential of contamination of the treated soil by the feed soil. According to the scenario just described, some of the soil layer produced from the feed slurry would be removed by and mixed with the more viscous treated-soil wet cake. The effect could be significant; for example, $1 \mathrm{lb}$ of feed soil containing $0.2 \%$ (2000 ppm) uranium would add $0.002 \%(20 \mathrm{ppm})$ uranium to $100 \mathrm{lb}$ of treated soil. Several options were considered for reducing this cross-contamination potential. The method selected involved the collection of the first $60 \mathrm{lb}$ of wet cake produced by centrifuging the leaching reactor slurry. 


\section{SUMMARY OF EXPERIMENTAL AND SAMPLING PLANS}

\subsection{EXPERIMENTAL DESIGN}

The experimental design for the Phase II pilot-scale studies included 24 tests. According to the experimental plan, 20 tests were to be run and the test data analyzed before proceeding with the remaining four tests. Tests 0 through 19 are outlined in Table 1 . From the results of the analyses of the pilot-scale data for these first 20 tests and data from concurrent bench-scale tests, "optimum" operating conditions were to be selected for the final four tests. Sections 7 and 8 report the results of Tests 0 through 19, while Tests 20,21,22, and 25 are discussed in Sect. 9.

In Tests 0 through 19, leaching tests were to be run with up to four different leaching agents on each of the two Fernald soils. These leachants, which were used in previous bench-scale studies, were sodium carbonate/sodium bicarbonate, sodium citrate/sodium bicarbonate/sodium dithionite (CBD), citric acid, and sulfuric acid. The leaching solution molarities used in the Phase II tests were selected based on ORNL bench-scale results. In the carbonate runs with the incinerator soil, potassium permanganate was added to oxidize uranium (IV) to uranium (VI). Bench-scale tests showed this to be effective with the incinerator soil but not with the storage pad soil.

There were some exceptions to the original experimental design of Table 1. Because of modifications that would have been required to treat gas generated by the reaction of sodium dithionite, the $\mathrm{CBD}$ tests were eliminated. Also, the sulfuric acid tests, which were to depend on the results obtained in Phase I pilot-scale testing, were not run. It was determined that the Phase I results were adequate.

Nine tests (Tests $2,3,4,5,6,7,8,15$, and 19) in Table 1 were run at the standard set of operating conditions outlined in Sect. 4. As indicated in Table 1, replicates were run on each of the 
Table 1. Summary of conditions for Phase II batch tests

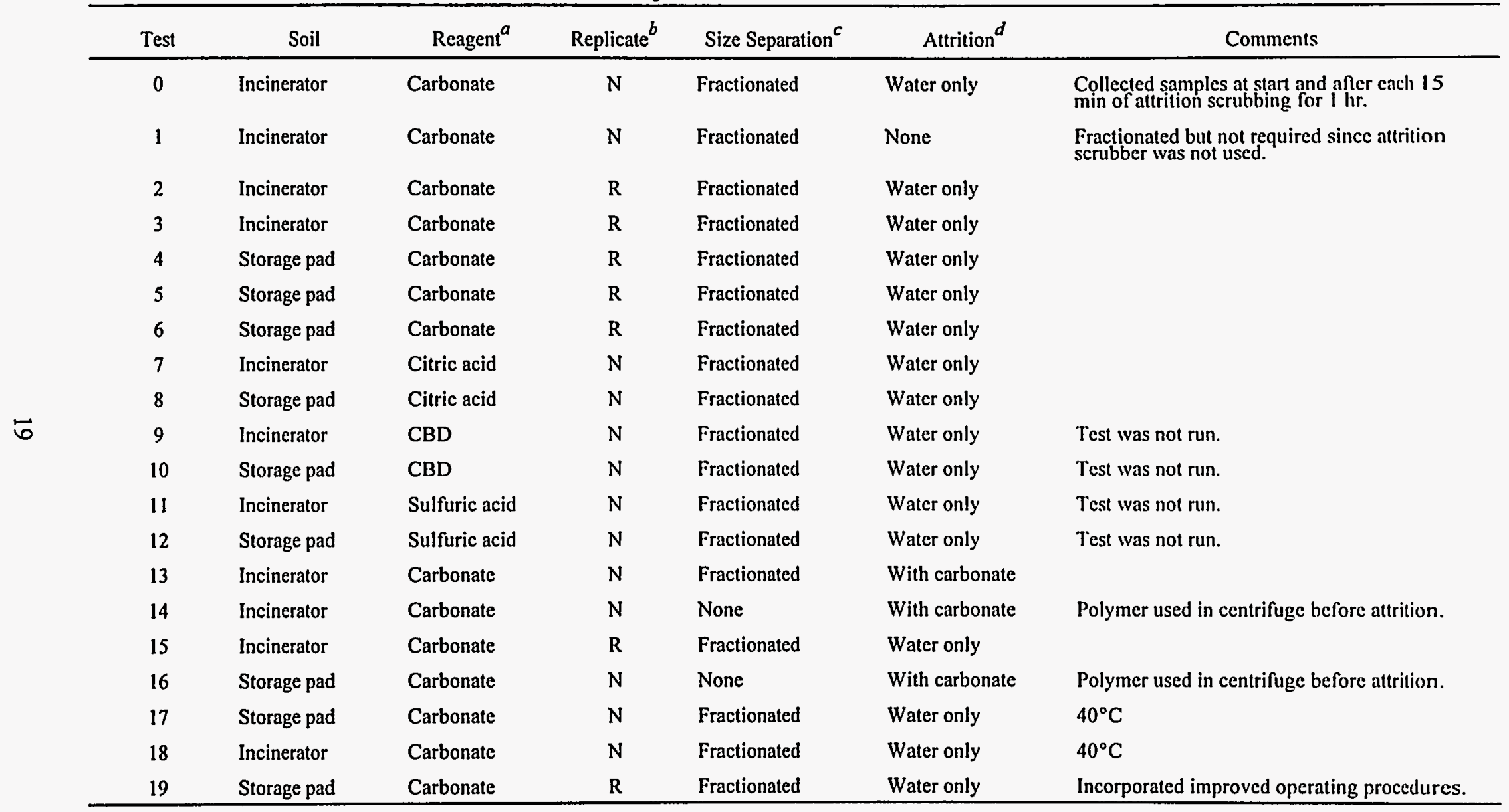

a Sodium carbonate/sodium bicarbonate at $0.25 \mathrm{M}$ total carbonate $\left(0.02 \mathrm{~g} \mathrm{KMnO}_{4} / \mathrm{g}\right.$ soil in incinerator tests); citric acid at $0.2 \mathrm{M}$.

${ }^{b} \mathrm{~N}=$ test not replicated; $\mathrm{R}=$ replicate test.

$c$ Fractionated-soil separated into two size fractions with centrifuge before attrition scrubbing.

$d$ Attrition scrubbing with water only or with carbonate added; None - no attrition scrubbing. 
Fernald soils using carbonate as the leachant. For each soil. the results from the replicate runs were used to calculate statistical parameters to be used for the comparison of the decontamination levels with the technology screening level. The parameters were also used to determine if attrition scrubbing or reaction temperature significantly affected decontamination level.

Test 0 was intended to be an initial run to check out the system operation. However, this test was not conducted until later because the drums of incinerator soil were not available at the start of operations. Test 0 operations followed the standard procedure, with the exception that the attrition scrubber residence time was $1 \mathrm{hr}$. During the attrition scrubber operation, samples were collected at the start and after each $15-$ min period. These samples were shipped to ORNL to determine the effect of attrition scrubbing on particle-size distribution and carbonate leaching efficiency.

The following six tests were included to determine the effects of temperature and the attrition scrubber on leaching efficiency. All six runs were made with sodium carbonate. The conditions for these runs are described below:

Test 1. Leaching reactor only: The attrition scrubber was bypassed in this test. Although not required, the slurry from the trommel was centrifuged and the centrate and the wet cake were transferred directly to the leaching reactor. When this test was initiated, intentions were to use the attrition scrubber. However, after the first centrifuge operation had been completed, it was learned that the new attrition scrubber was scheduled for installation. The decision was made to bypass the attrition scrubber in this test so that the new scrubber could be used in the remaining tests.

Test 13 Attrition scrubbing of a coarse soil fraction in the presence of sodium carbonate: The standard operating conditions were used for this test, with the exception that sodium carbonate was added to the attrition scrubber feed.

Tests $14 \& 16$ Attrition scrubbing of the total soil in the presence of sodium carbonate: The procedure for these tests was the same as that for Test 13, with the exception that flocculant was injected into the centrifuge feed (during the centrifuge operation before the attrition scrubber) to maximize the recovery of solids.

Tests $17 \& 18$ Leaching at elevated temperature: The standard operating conditions were used for these tests, with the exception that the leaching reactor was operated at $40^{\circ} \mathrm{C}$. 
As discussed previously, in addition to these modifications of the standard procedure to determine effects of process variables, other modifications were made while carrying out Tests 0 through 19 to improve operations. These modifications are discussed in Sect. 7. The "optimum" operating conditions for the final four tests are described in Sect. 9.

\subsection{SAMPLING AND ANALYSIS PLAN AND PROCESS DATA ACQUISITION}

The Sampling and Analysis Plan developed for the Phase II batch experiments is included in the Phase II test plan.' Samples were taken of feed, intermediate, and product streams. In the case of the leaching reactor, samples were taken at several specified times during the 2-hr reaction period. The samples were submitted to the FEMP analytical laboratory for analyses such as $\mathrm{pH}$, uranium content, and weight percent solids. The sample points for each run are identified in Sect. 7.

In addition to the acquisition of analytical data, measurements were made of process parameters. These parameters consisted primarily of the weights and volumes of feed and product streams (such as feed soil, leaching chemicals, trommel oversize material, centrifuge wet cake, leaching reactor slurry, spent leaching solutions, etc.).

The analytical and process data were used to calculate material balances and uranium leaching efficiencies. Variances (equal to the standard deviation squared) were calculated using the analytical results from replicate samples. These variances were used to compare measured uranium concentrations in the treated soils with target uranium levels. The results from these data analysis activities are discussed in Sect. 8. 


\section{DATA ANALYSIS PROCEDURES}

\subsection{MATERIAL BALANCE AND REACTOR KINETICS CALCULATIONS}

Analytical and process data were used to calculate material balances for solids and uranium. To check for consistency and to better characterize potential losses, three different material balances were made for each of Tests 0 through 19. Two were intermediate material balances, the first taken between the feed point and the centrate and the wet cake from the first centrifuge operation and the second between the feed point and the leaching reactor. The third was an overall material balance taken around the entire test unit. The inlet stream for the balances was the total amount of soil that was emptied from the feed drum. The outlet streams for each of the three material balances are listed in Table 2. Rather than including the chemicals in the inlet stream, the total weight of chemicals used in the test was subtracted from the total weight of solids calculated in the outlet streams. Since percent solids in the various streams was determined by evaporation of a sample to dryness, both soil and soluble chemicals were included in the calculated weight of solid product.

In addition to the material balances, the analytical data were used to examine the kinetics of the leaching reaction by determining the fraction of uranium leached from the soil as a function of time in the reactor. Again, this was done for Tests 0 through 19. The fraction of uranium leached at each sampling time was determined by dividing the measured uranium concentration in the reactor liquid by the uranium concentration in the reactor liquid that would be attained if the total uranium in the soil were leached into the liquid, that is, $100 \%$ decontamination of the soil. The reactor liquid was the filtrate obtained by collecting and filtering a sample of the reactor slurry. The uranium concentration in the liquid that would result at $100 \%$ decontamination was calculated by dividing the measured uranium concentration in the reactor slurry (which was determined on a weight fraction basis) by the weight fraction of liquid in the reactor slurry. 
Table 2. Outlet streams for material balance calculations

\begin{tabular}{|c|c|c|}
\hline Centrifuge balance & Reactor balance & Overall balance \\
\hline Feed soil samples & Feed soil samples & Feed soil samples \\
\hline Trommel oversize $e^{a}$ & Trommel oversize $^{a}$ & Trommel oversize $^{a}$ \\
\hline Trommel heel $^{a}$ & Trommel heel $^{a}$ & Trommel heel $^{a}$ \\
\hline $\begin{array}{l}\text { Centrate from centrifuge operation } \\
\text { after trommel } l^{h}\end{array}$ & $\begin{array}{l}\text { Attrition scrubber } \\
\text { samples }\end{array}$ & Attrition scrubber samples \\
\hline \multirow{7}{*}{$\begin{array}{l}\text { Wet cake from centrifuge operation } \\
\text { after trommel }\end{array}$} & Reactor slurry & Reactor samples \\
\hline & & Vibrating screen oversize $^{a}$ \\
\hline & & Centrifuge purge $^{a}$ \\
\hline & & $\begin{array}{l}\text { Centrates from final three centrifuge } \\
\text { operations }\end{array}$ \\
\hline & & $\begin{array}{l}\text { Solids samples from first two } \\
\text { centrifuge operations after reactor }\end{array}$ \\
\hline & & Centrifuge heel $l^{a, c}$ \\
\hline & & Treated soil \\
\hline
\end{tabular}

${ }^{a}$ See Sect. 7 for description of modifications made with each test.

${ }^{b}$ Includes the centrifuge heel from the centrifuge operation.

${ }^{c}$ From last three centrifuge operations.

The material balances and reactor kinetics calculations were programmed into ORACLE. ORACLE is the database program used to compile the results from the FERMCO analytical laboratory. In some tests, corrections were made to the material balance results by hand calculations. This was necessary when the operating procedure for a test was modified such that the equations did not strictly apply. In Test 16 , for example, the oversized material from the vibrating screen could not be mixed with the centrifuge solids (because of the physical characteristics of the solids as a result of polymer injection during centrifuging) before addition to the attrition scrubber. Consequently, the oversized material was weighed and analyzed separately.

\subsection{STATISTICAL ANALYSIS PROCEDURES}

The mean, or arithmetic average, and the standard deviation are customary statistical parameters calculated for sets of data. An informative statistic, but one that is not used in statistical 
comparisons, is the coefficient of variation. This parameter is defined as the ratio of the standard deviation to the mean of a set of replicate data. Since this ratio is a dimensionless number, it allows one to judge the relative precision of test methods regardless of the difference in units. The coefficient of variation is included in the calculation of descriptive statistics for various sets of data.

For the comparison of uranium decontamination levels with the preliminary technology screening level, the Student's t-test was used. The t-test was also used to determine if factors such as attrition scrubbing, type of leachant, or reactor temperature had any significant effect on decontamination level. This was done by comparing the results from the replicate tests with the result from each test in which a factor of interest was changed. For these comparisons, the mean and the standard error of the mean (SEM - equal to the standard deviation divided by the square root of the number of replicates) of the results from the replicate tests were determined for each soil. The SEM was then used to calculate confidence limits about the test mean in order to make the desired comparison. The confidence limits are determined as $\pm \mathrm{t}_{\alpha / 2} s / \sqrt{n}$, where $s / \sqrt{n}$ is the SEM, $n$ is the sample size, $(1-\alpha)$ is the confidence level, and $t_{\alpha / 2}$ is the value of the $t$ distribution at $n-1$ degrees of freedom leaving an area of $\alpha / 2$ to the right. ${ }^{9}$

The t-test comparisons were made using SigmaStat ${ }^{\mathrm{Tu}}$, a statistical software package. The procedure used in SigmaStat ${ }^{\mathrm{TM}}$ was the paired t-test. For such a comparison of many observations (the replicate tests) with a single value, the paired $t$-test procedure is equivalent to the $t$-test described above. If statistical comparisons showed that a particular factor had no significant effect, the results from the test or tests involving changes in that factor were pooled with the results from the replicate tests. Such a pooling of results when a factor has been shown to have no effect is an acceptable statistical technique. ${ }^{10}$ The consequence of this pooling is to increase the sensitivity of the statistical comparison by reducing the confidence interval about the mean of the replicates. In this and in the other SigmaStat ${ }^{\mathrm{TM}}$ procedures described below, the $95 \%$ confidence level was used.

In the Phase II Fernald test unit study, not all tests were replicated due to time and cost considerations. Consequently, in analyzing the effects of factors such as temperature and attrition scrubbing, the results of the replicate tests were compared with the result from a single test, as described above. If a significant difference was detected and the power of the t-test was high, the conclusion was that there was a high probability that the result from the single test was truly 
different from the mean result of the replicate tests. However, since the single test was not replicated, it could not be concluded that the result from the single test belonged to a population that was significantly different from the result of the replicate tests; that is, it could not be concluded that the factor being studied actually had an effect. If supported by the results of other studies, though. one might reasonably infer that the factor being investigated in the single test was the cause of the deviation from the replicate tests. This is the approach taken in this report in examining the effects of factors such as temperature and attrition scrubbing.

In the t-test, $\alpha$ is the probability of rejecting the null hypothesis $\left(\mathrm{H}_{0}\right)$ (i.e., no difference exists) when it is true. Obviously, it is desirable that $\alpha$ be small. Another statistical parameter is $\beta$, the probability of rejecting the alternative hypothesis $\left(\mathrm{H}_{\mathrm{A}}\right)$ (i.e., a difference does exist) when it is true. SigmaStat ${ }^{\text {Tw }}$ calculates the quantity $(1-\beta)$, which is known as the power of the test. The power is the probability of rejecting $\mathrm{H}_{0}$ when it is false. If $\mathrm{H}_{0}$ is rejected in a t-test at a particular level of significance of $(1-\alpha)$, it is important to examine the power of the test. If $\mathrm{H}_{0}$ is to be rejected, it is desirable that the power of the test be high. That is, one would like to have a high probability of concluding that a difference exists when it actually does.

Since pre-blended soils were used for feed, drums prepared from each blend would be expected to be fairly homogeneous. To test this assumption, a statistical comparison was made between the analytical data on the feed drums for each type of soil. This comparison was also made using SigmaStat ${ }^{\mathrm{TM}}$. The comparison method involved a one-way analysis of variance (ANOVA). This is a parametric test that assumes that all the samples were drawn from normally distributed populations with the same standard deviations (variances). The null hypothesis is that there is no difference among the populations from which the samples were drawn.

If the one-way ANOVA detected a significant difference between populations (drums), the Student-Newman-Keuls (SNK) test was used in SigmaStat ${ }^{\mathrm{TM}}$ to determine which drums were different. The SNK test is an all pairwise comparison of every combination of group pairs. It is said to generally be the preferred test for all pairwise comparisons.

The statistical test used for the soil feed drums was a group comparison test. This test compares random samples from two or more different groups for differences in the mean values that cannot be attributed to random sampling variation. Statistical tests were also done to compare the percent 
recoveries calculated for each leaching test by the three different material balances described previously. Uranium decontamination levels calculated for each leaching test by two different methods were compared as well. These comparisons of recoveries and decontamination levels were done by repeated measures procedures. These procedures take into account variation among individuals, allowing attention on the effect of the treatments rather than the differences between individuals. A paired t-test is used to compare the effect of a single treatment on the same individuals. A one-way repeated-measures ANOVA is used to compare the effects of a single series of treatments or conditions. The repeated-measures procedures in SigmaStat ${ }^{\mathrm{TM}}$ were used for the statistical comparisons. 


\section{EXPERIMENTAL SUMMARY}

This section applies to Tests 0 through 19. The final four tests are discussed in Sect. 9.

\subsection{OPERATIONS SUMMARY}

Table 3 shows the order in which the Phase II Tests 0 through 19 were run, the dates the tests were run, and the identification number of the drum used in each test. The standard operating procedure for the Phase II tests was described previously. However, as mentioned, modifications to this procedure (other than those made to study the effects of process variables) were made on several occasions, as recorded in the operations logbook. These modifications are summarized as follows.

Test 16 In this test and in all subsequent tests (after 1/5/94), a trommel heel product was collected. This heel was the material remaining in the bottom of the trommel product drum after completion of the trommel and the first vibrating screen operations. The heel contained large size material (some even $>4.74 \mathrm{~mm}$ ) that was not suspended by the mixer in the trommel product drum. In previous tests, this material was pumped through the vibrating screen. This was done by using a water jet to mobilize the material while operating the transfer pump. Because of the downstream processing problems, the decision was made to collect the trommel heel as a by-product. Also, in this test and in subsequent tests up to Test 15 , the 2- to $4.75-\mathrm{mm}$ material from the first vibrating screen operation was combined with the trommel oversize $(>4.75 \mathrm{~mm})$.

Collecting the trommel heel and the 2- to $4.75-\mathrm{mm}$ material from the vibrating screen as by-products (which represented an average of $4 \%$ of the feed soil) removed the large size material that was causing downstream processing problems. By collecting these streams as by-products, it was possible to eliminate the vibrating screen operation after the leaching reactor from this test and from all subsequent tests.

Test 17 Prior to this test (before 1/10/94), the centrifuge heel that was produced by the last three centrifuge operations was collected but was not analyzed. In this test and in all subsequent tests, this centrifuge heel was weighed, sampled, and analyzed for solids and uranium contents. This procedure was initiated when problems with the solids material balance were identified. In Phase II, the centrifuge was usually shut down after each operation. This generated a greater quantity of heel than typically produced in Phase I tests. In Phase I, the procedure was to keep the centrifuge running during a test until all centrifuge processing steps had been completed. 
Table 3. Test summary

\begin{tabular}{rll}
\hline Test no. & Date of test & $\begin{array}{c}\text { Feed drum } \\
\text { no. }\end{array}$ \\
\hline 4 & $11 / 23 / 93-12 / 6 / 93$ & B1 \\
5 & $12 / 6 / 93-12 / 8 / 93$ & B2 \\
6 & $12 / 9 / 93-12 / 14 / 93$ & B3 \\
16 & $12 / 16 / 93-1 / 5 / 94$ & B4 \\
17 & $1 / 10 / 94-1 / 12 / 94$ & B8 \\
18 & $1 / 31 / 94-2 / 4 / 94$ & A1 \\
1 & $2 / 7 / 94-2 / 10 / 94$ & A2 \\
2 & $2 / 14 / 94-2 / 17 / 94$ & A4 \\
3 & $2 / 15 / 94-2 / 16 / 94$ & A3 \\
15 & $2 / 22 / 94-2 / 25 / 94$ & A5 \\
13 & $2 / 25 / 94-3 / 1 / 94$ & A6 \\
14 & $3 / 2 / 94-3 / 3 / 94$ & A7 \\
0 & $3 / 7 / 94-3 / 10 / 94$ & A8 \\
7 & $3 / 11 / 94-3 / 15 / 94$ & A10 \\
8 & $3 / 16 / 94-3 / 17 / 94$ & B9 \\
19 & $3 / 28 / 94-3 / 30 / 94$ & B7 \\
\hline
\end{tabular}

Test 18 In this test and in all subsequent tests (after 2/4/94), a centrifuge purge was taken. This consisted of the initial $60 \mathrm{lb}$ of wet cake produced during the first centrifuge operation after the leaching reactor. The purge, which was taken as a by-product, was weighed and sampled for uranium and solids analyses. The objective was to minimize contamination of the treated soil with feed soil. Such cross-contamination was a possible consequence of using the same piece of equipment to process both materials, as discussed previously.

Test 15 In this test and in all subsequent tests (after 2/25/94), the 2- to 4.75-mm material from the first vibrating screen operation was added to the trommel heel rather than to the trommel screen oversize. Since the trommel heel should be $<4.75 \mathrm{~mm}$, the two materials should have similar physical characteristics. This change was of little consequence because of the small amount of the $2-$ to $4.75-\mathrm{mm}$ material produced by the vibrating screen $(<0.5 \%$ of the feed soil).

The process flow sheets for all the Phase II tests are included in Appendix A. These flow sheets, which are presented in the order that the tests were run, contain the process modifications discussed 
above. Also shown on the flow sheets are the sample points for each test. The process sample points are described in Table A-1. Samples were taken at these specified locations during each test. Sample points 12 through 18 were for rinsate samples taken while cleaning equipment after each test. Sample points 19 through 28 were for any samples that, although not specified in the sampling plan, could be included in any test. Sample point 29 was for a duplicate sample to be analyzed onsite, and sample points 101 through 118 were for duplicates for off-site analyses.

\subsection{PROCESS DATA}

Appendix B summarizes the Phase II process data. The data sheets for each run tabulate the weights and volumes of feed and product streams, as well as intermediate streams and samples.

\subsection{ANALYTICAL DATA}

The analytical results for the Phase II tests are presented in Appendix C. As mentioned previously, the process flow sheets in Appendix A indicate the locations of the sample points. 


\section{RESULTS OF DATA ANALYSIS AND DISCUSSION}

This section applies to Tests 0 through 19 . Section 9 discusses the final four tests.

\subsection{EXPERIMENTAL VARIANCES}

Table 4 shows results from the statistical analyses of the results for uranium concentration in the feed soils. Figures 3 and 4 show the individual results of the feed soil uranium analyses for each of the storage pad soil and the incinerator area soil tests, respectively. Included in the figures are

- results from analyses done in December 1993 after the soils had been blended. Results identified as replicates refer to multiple samples that were taken of the feed soils during the pilot plant tests, each sample being analyzed only once. The results identified as repeat analyses refer to single samples that were analyzed more than once.

The SNK test was run on the feed soil data to determine if there were significant differences between the drums of soil used in the Phase II tests. As discussed previously, each of the feed soils was blended in two batches. All the tests with the incinerator soil, except for Test 7, were run with soil blended in the same batch. For these tests, as might be expected, the SNK test showed no significant differences in uranium content between the drums of incinerator soil. For the storage pad soil, the SNK test did detect significant differences between drums. Differences would not be surprising since four tests used soil blended in one batch, and three tests used soil blended in another batch. An unexpected finding was that the SNK test detected differences not only between drums from different batches, but also between drums from the same batch. Because of these differences, uranium material balances for the storage pad soil tests were calculated using the individual feed soil data rather than the average uranium concentration for all the feed drums. This was also done for 
Table 4. Statistical parameters for feed soils

\begin{tabular}{lcc}
\hline & \multicolumn{2}{c}{ Uranium in feed soil. ppm (S-1) } \\
\cline { 2 - 3 } \multicolumn{1}{c}{ Statistical parameter } & Storage pad soil ${ }^{a}$ & Incinerator soil $^{b}$ \\
\hline Average & 1722 & 717 \\
Standard deviation & 147 & 55 \\
Coefficient of variation, \% & 8.5 & 7.7 \\
Standard error of mean & 56 & 20 \\
$95 \%$ confidence limits & \pm 136 & \pm 46 \\
\hline${ }^{a}$ Includes all tests with storage pad soil. & \\
${ }^{b}$ Includes all tests with incinerator soil, except Test 7.
\end{tabular}

the incinerator soil tests, even though the SNK test indicated no significant differences in uranium content between the feed drums prepared from the same batch. Based on the magnitude of the standard deviation for the uranium content of the incinerator soil feed drums, the individual feed drum data appeared to be more appropriate for the material balances. Decontamination efficiency was also calculated using the individual feed drum data.

Table 5 shows the statistical parameters determined from analysis of the treated soil data from the replicate tests (Table 1) for each soil. Also included are parameters for a set of seven of the incinerator soil tests. The rationale for pooling the results of these seven incinerator soil tests is discussed later. The parameters in Table 5 were used for the comparison of decontamination levels between tests and with the preliminary technology screening level of $52 \mathrm{mg} \mathrm{U} / \mathrm{kg}$ of soil.

\subsection{MATERIAL BALANCES}

The results of the material balances for solids and uranium are summarized in Table 6 for the storage pad soil tests and in Table 7 for the incinerator soil tests. As discussed above, uranium material balances were calculated using the analytical data for the feed drum used in each test. The 


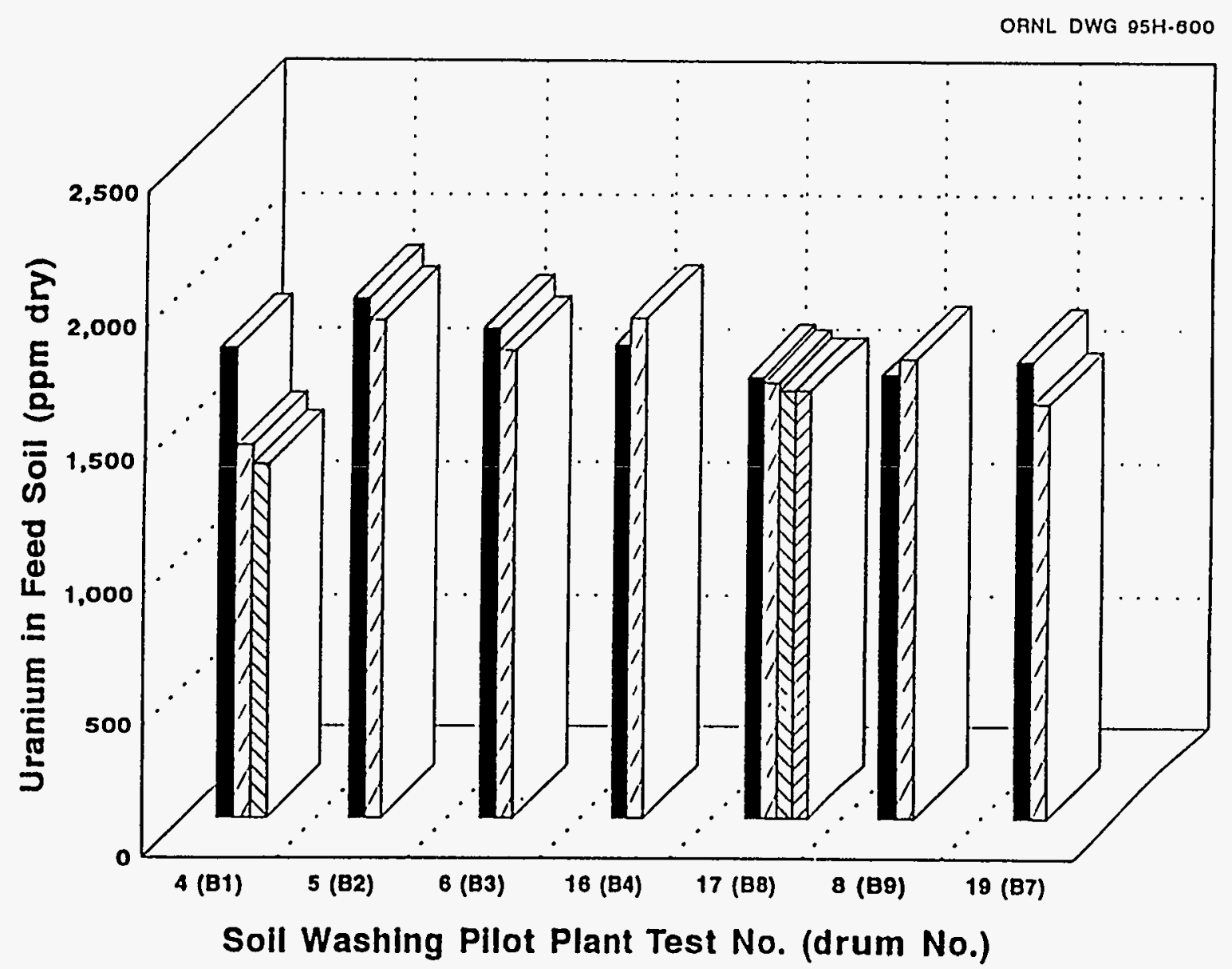

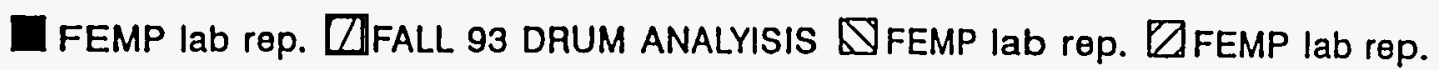

Fig. 3. Storage pad soils - analysis of feed soils 
ORNL DWG $95 \mathrm{H} \cdot 001$

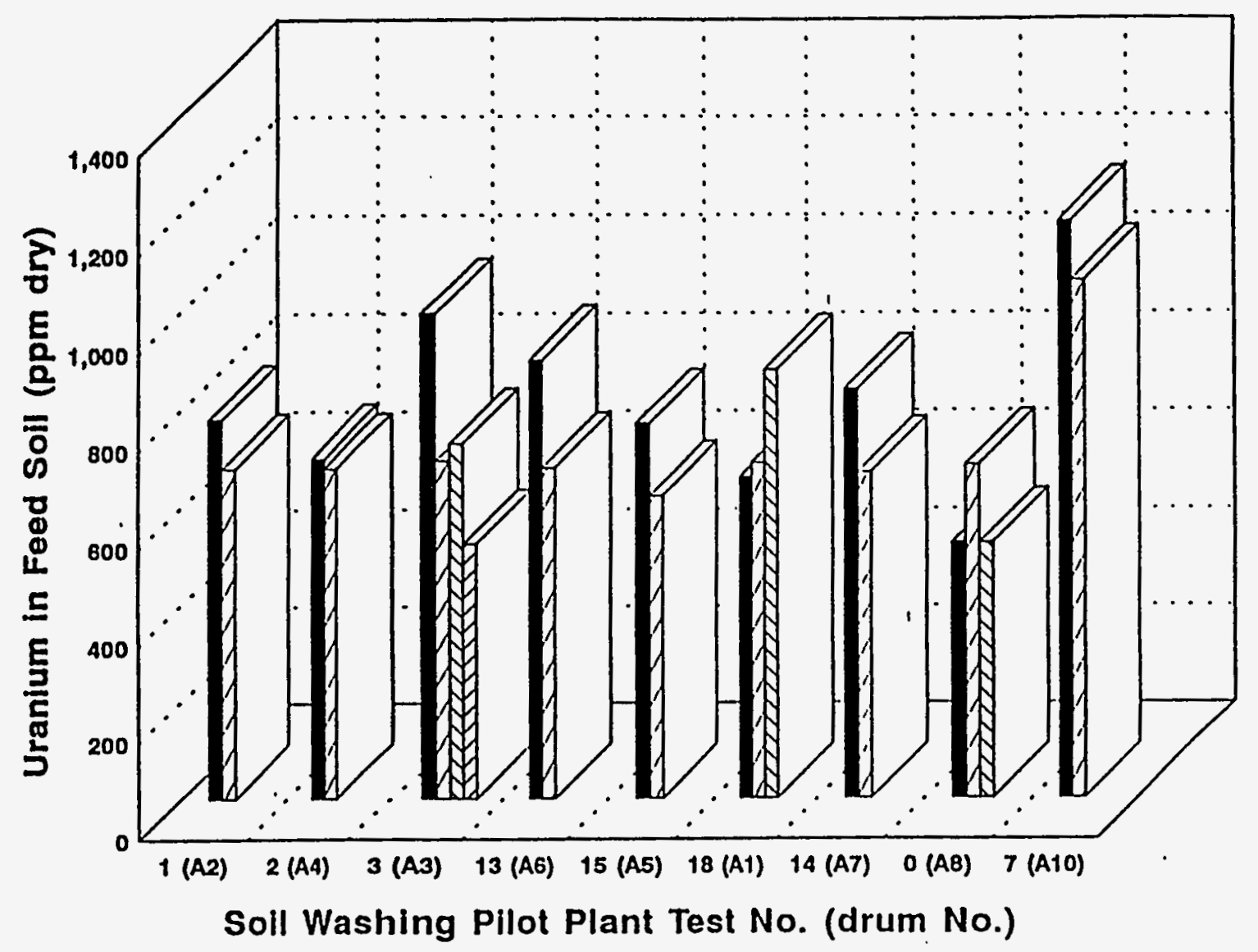

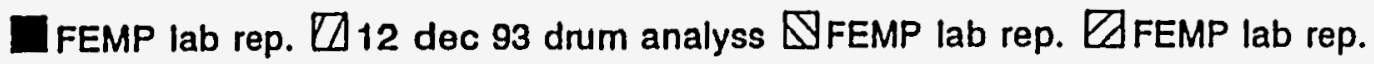

Fig. 4. Incinerator soils - analysis of feed soils 
Table 5. Statistical parameters for replicate tests

\begin{tabular}{lccc} 
& \multicolumn{3}{c}{ Uranium in treated soil, ppm (S-10) } \\
\cline { 2 - 4 } \multicolumn{1}{c}{ Statistical parameter } & Storage pad & \multicolumn{2}{c}{ Incinerator } \\
\cline { 2 - 4 } & 134 & 138 & $\begin{array}{c}\text { Tests } 0,1,2,3, \\
13,14, \text { \& } 15\end{array}$ \\
\hline Average & 33 & 27 & 129 \\
Standard deviation & 25 & 20 & 26 \\
Coefficient of variation, $\%$ & 17 & 16 & 20 \\
Standard error of mean & \pm 54 & \pm 69 & 10 \\
$95 \%$ confidence limits & & & \pm 24 \\
\hline
\end{tabular}

detailed material balance results are shown in Appendix D. These detailed balances list the amounts of solids and uranium in each stream.

The overall material balance results for solids from Tables 6 and 7 are portrayed in Figs. 5 and 6, respectively. In these figures, the solids are separated into three categories: product solids (treated soil), by-product solids, and solids loss. The by-product solids category represents all solids that were accounted for other than the product solids. This includes trommel oversize, trommel heel, vibrating screen oversize, centrifuge purge, centrates from last three centrifuge operations, centrifuge heel, and the samples (see Table 2, column 3). Figs. 7 and 8 show comparable information for uranium for the storage pad soil and the incinerator area soil, respectively.

\subsubsection{Storage Pad Soil}

As seen in Table 6 and Fig. 5, the overall material balances showed relatively low solids recoveries for the storage pad soil tests. For Tests 4, 5, 6, and 16, weight percent solids was not determined for the centrifuge heel, which contributed to the low recoveries. The recovery for Test 8 
Table 6. Solids and uranium material balances for storage pad soil tests

\begin{tabular}{|c|c|c|c|c|c|c|c|}
\hline & Test 4 & Test 5 & Test 6 & Test 8 & Test 16 & Test 17 & Test 19 \\
\hline Soil in $\left(1 b^{c}\right)$ & 394 & 299 & 299 & 322 & 366 & 308 & 309 \\
\hline \multicolumn{8}{|l|}{$\%$ Soil recovery ${ }^{b}$} \\
\hline Centrifuge balance & 83 & 84 & 92 & 91 & 82 & 87 & 86 \\
\hline Reactor balance & 68 & 74 & 78 & 77 & 56 & 88 & 71 \\
\hline Overall balance & 70 & 89 & 77 & 72 & 71 & 85 & 94 \\
\hline Uranium in ${ }^{c}(\mathrm{lb})$ & 0.584 & 0.574 & 0.542 & 0.551 & 0.673 & 0.506 & 0.510 \\
\hline \multicolumn{8}{|l|}{$\%$ Uranium recovered } \\
\hline Centrifuge balance ${ }^{c}$ & 55.2 & 61.8 & & 83.8 & 89.9 & 88.7 & 85 \\
\hline Reactor balance ${ }^{c}$ & 102.6 & 94.3 & 80.1 & 77.2 & 74.9 & 86.8 & 77.9 \\
\hline Overall balance $^{c}$ & 97.8 & 89.6 & 73.1 & 86.9 & 81.6 & 81.1 & 98.5 \\
\hline
\end{tabular}

"All weights are on a dry basis.

- See Table 2 for outlet streams used for each balance.

c Based on $\mathrm{U}$ concentration in feed drum for each test. 
Table 7. Solids and uranium material balances for incinerator soil tests

\begin{tabular}{|c|c|c|c|c|c|c|c|c|c|}
\hline & Test 0 & Test I & Test 2 & Test 3 & Test 7 & Test 13 & Test 14 & Test 15 & Test 18 \\
\hline Soil in $\left(1 b^{a}\right)$ & 307 & 283 & 283 & 281 & 276 & 275 & 285 & 293 & 298 \\
\hline \multicolumn{10}{|l|}{$\%$ Soil Recovery ${ }^{b}$} \\
\hline Centrifuge balance & 87 & 92 & 90 & 95 & 86 & 96 & 90 & 84 & 86 \\
\hline Reactor balance & 66 & 77 & 76 & 81 & 68 & 81 & 86 & 67 & 69 \\
\hline Overall balance & 80 & 103 & 89 & 89 & 72 & 90 & 93 & 92 & 86 \\
\hline Uranium in ${ }^{c}(\mathrm{lb})$ & 0.186 & 0.207 & 0.196 & 0.203 & 0.309 & 0.218 & 0.215 & 0.204 & 0.222 \\
\hline \multicolumn{10}{|l|}{$\%$ Uranium Recovered } \\
\hline Centrifuge balance ${ }^{c}$ & 106.9 & 95.9 & 90.1 & 101.1 & 100.2 & 93.5 & 88.6 & 89.9 & 85 \\
\hline Reactor balance $^{c}$ & 108.4 & 83.2 & 97 & 82.2 & 86.6 & 68.7 & 78.9 & 90.9 & 89.2 \\
\hline Overall balance ${ }^{c}$ & 107.9 & 93.7 & 94.8 & 90.4 & 97.3 & 84.1 & 87.8 & 98.8 & 83.7 \\
\hline
\end{tabular}

${ }^{a}$ All weights are on a dry basis.

${ }^{\circ}$ See Table 2 for outlet streams used in each material balance method.

${ }^{c}$ Based on uranium concentration in feed drum for each test. 
ORNL DWG 95H-602

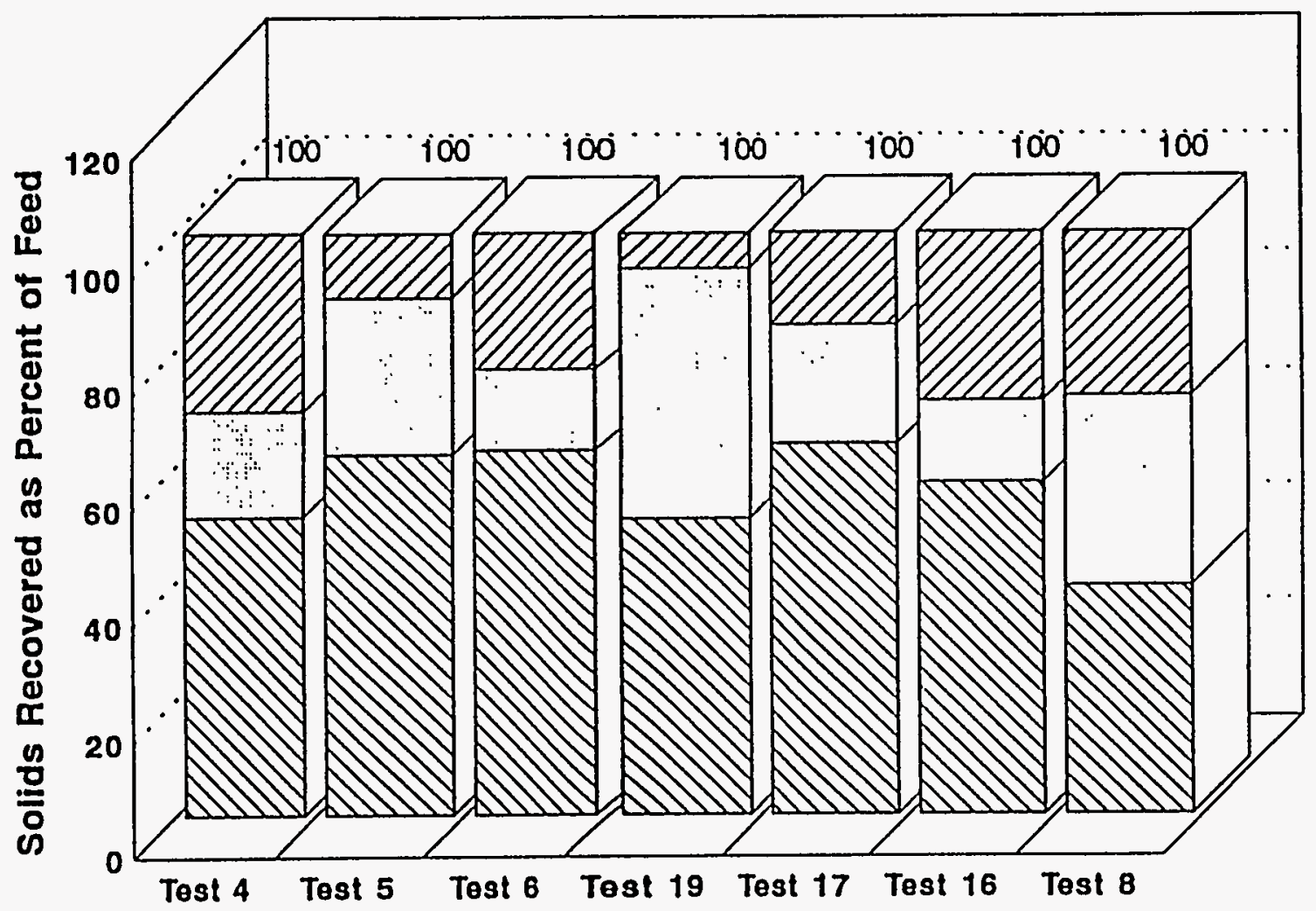

QProduct Soll $\square$ Byproduct Solids $\oslash$ Solids Loss

- Sollds Recovered In Byproduct Streams

Fig. 5. Solids balance for storage pad soils 
ORNL DWG 95H.603

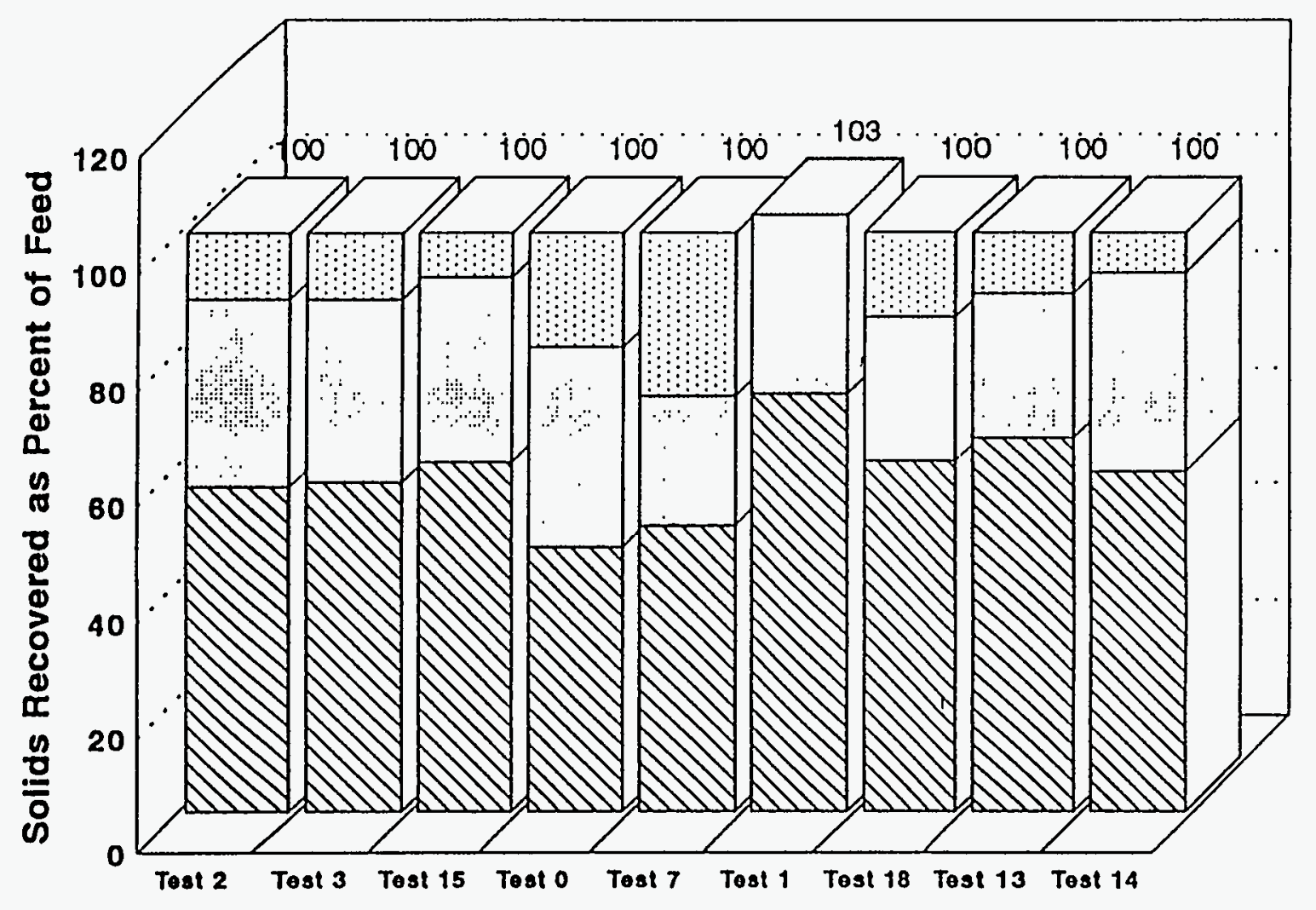

$\triangle$ Product Soil $\square$ BByproduct Solids $\square$ Solids Loss

* Solids Recovered in Byproduct Streams

Fig. 6. Solids balance for incinerator soils 
ORNL DWG 95H.804

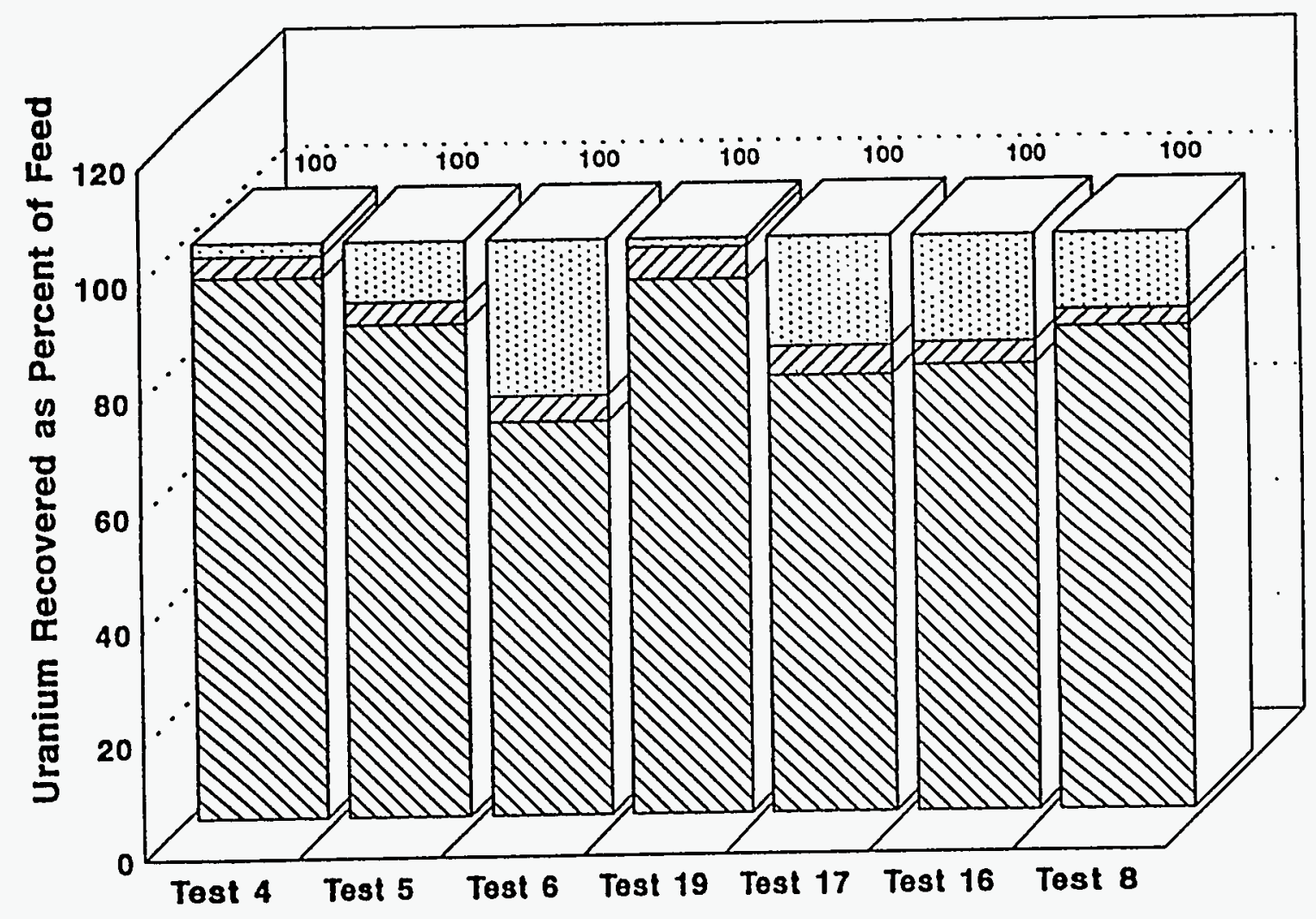

Q*Other Uranium $Q$ Uuranium in Product $\square$ Uranium Loss

- Uranlum Recovered In Byproduct Streams

Fig. 7. Uranium balance for storage pad soils 


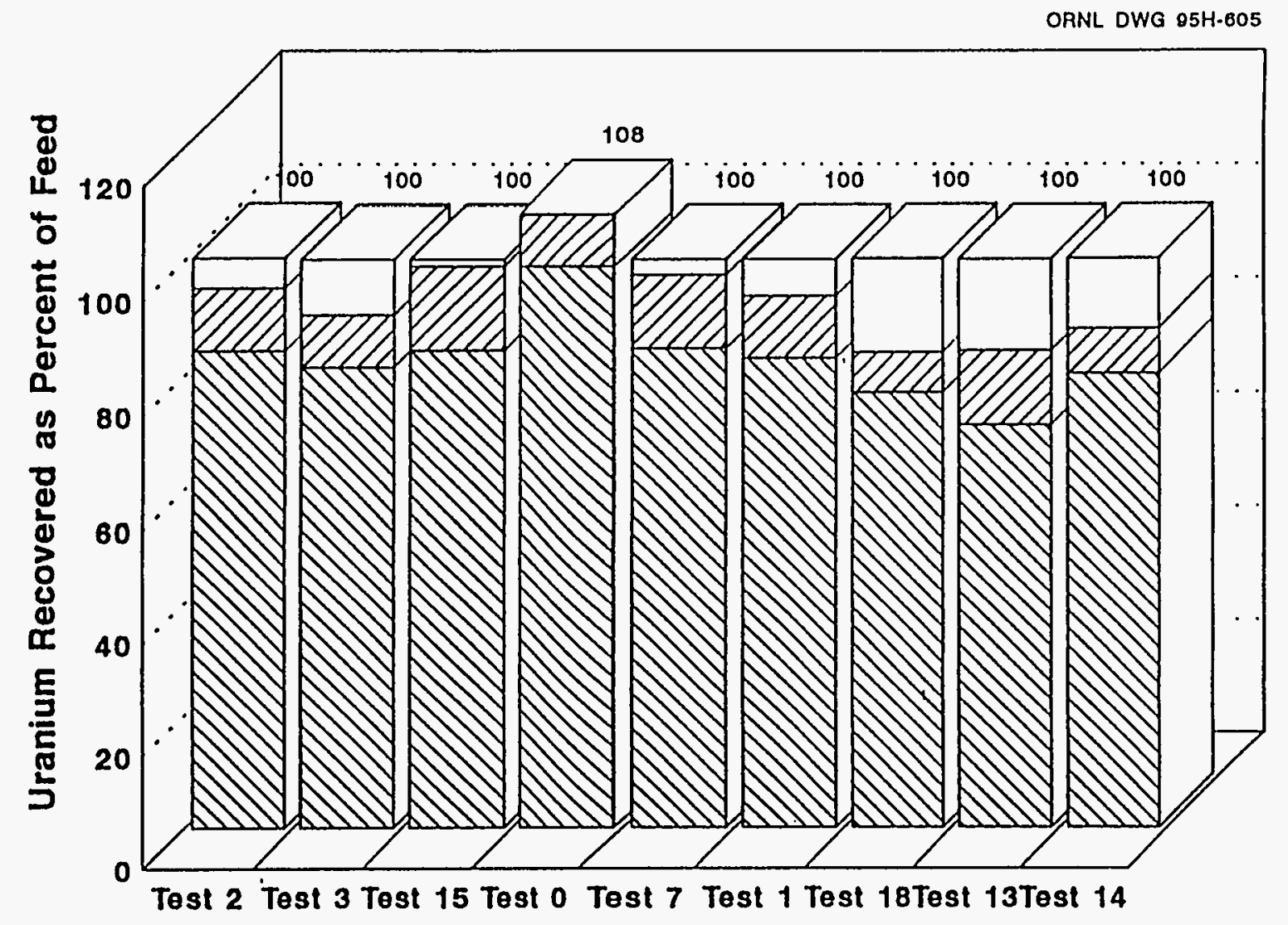

$\Xi *$ Other Uranium $\square$ Uranium in Product $\square$ Uranium Loss

- Uranium Recovered in Byproduct Streams

Fig. 8. Uranium balance for incinerator soils 
was low, as was that for Test 7 with the incinerator soil. Citric acid was the leachant in both of these tests. A possible explanation for the low recoveries with citric acid could be the dissolution of calcite and dolomite minerals. In secondary waste treatment studies, significant amounts of calcium and magnesium citrate were found to precipitate over time from citric acid solutions produced by leaching." Precipitation likely occurred in the Fernald test unit samples that were submitted for weight percent solids analysis. It is conceivable that the aliquots taken from the samples to be analyzed for weight percent solids were not representative due to the difficulty of resuspending the precipitate. This would result in a low value from the analysis of weight percent solids (determined by evaporation to dryness) in the centrate sample and, consequently, a low solids recovery in the material balance. An undetermined amount of solids was lost in Test 16 as a result of operational problems. The solids recovery was acceptable in Test 19. The reason for the low solids recovery in Test 17, which should have been comparable with that in Test 19, is not known.

For Tests 4, 5, 6, and 16, overall uranium recoveries, as presented in Table 6 and Fig. 7, also were reduced as a result of not measuring the uranium content of the centrifuge heel. However, as seen from the detailed balances in Appendix $D$ for the other tests, the uranium recoveries were reduced by only a few percent. In Test 6 and especially in Test 17, the analytical results for uranium in the centrate (Sample Point $11 \mathrm{~A}$ ) are lower than those for uranium in the reactor liquid. As may be seen from Fig. 1, both samples should have approximately the same uranium concentration. Since most of the uranium is recovered in this centrate stream, substitution of the uranium concentration in the reactor liquid for that in the centrate significantly improves the uranium material balance. The uranium recovery for Test 19 was acceptable.

For the three different material balances, the uranium and solids recoveries for the centrifuge material balance should be the highest and the overall material balance recoveries the lowest. This is due primarily to an expected increase in rinsing losses as the soil was processed through the 
Fernald test unit. An analysis of the solids recovery results in Table 6 by the one-way repeated-measures ANOVA and the SNK tests showed that the centrifuge material balance recoveries were significantly greater than those of the reactor vessel material balance. No significant differences were detected between the overall and the centrifuge material balances or between the overall and the reactor vessel material balances. For the uranium recovery results in Table 6 , the statistical tests did not detect any significant differences between any of the three material balances. One might conclude, then, that the statistical tests do not show the expected trends. However, the calculated recoveries are confounded as a result of not having measured the material in the centrifuge heel in several tests. Also, during Tests 4 and 5, problems were experienced in establishing the procedure for generating the samples from the centrifuge centrate and the reactor slurry. This likely affected the calculated recoveries for the intermediate material balances for these two tests. Because of these complications, no conclusions are made about the comparisons of the uranium and the solids recoveries between the different material balances for the storage pad soil tests.

\subsubsection{Incinerator Soil}

Table 7 and Fig. 6 show that in most cases the overall material balances for the incinerator soil tests gave good solids recoveries. A possible cause of the low recovery for Test 7 with citric acid was discussed above. The reason for the low solids recovery in Test 0 is not known.

For most of the incinerator soil tests, the overall uranium recoveries were satisfactory, as seen in Table 7 and in Fig. 8. The reason for the low recovery in Test 18 is unknown.

As was done for the storage pad soil tests, the solids and uranium recovery results in Table 7 were analyzed by the one-way repeated-measures ANOVA and the SNK statistical tests. For the 
solids, both the overall and the centrifuge material balance recoveries were significantly greater than those of the reactor vessel material balance. There was no significant difference between the recoveries of the overall and the centrifuge material balances. No significant differences were detected between the uranium recoveries for any of the three material balances.

\subsubsection{Slurry Measurement Problems}

Whereas it was inconclusive for the storage pad soil, the statistical analyses of the incinerator soil tests did not show the expected variation of recoveries with the different material balances (see the explanation in Sect. 8.2.1). A possible reason for this could be problems with obtaining accurate measurements of solids and uranium in slurries. For the intermediate material balances, samples of the centrate from the first centrifuge operation and of the reactor slurry were required. Except for Tests 14 and 16 , this centrate contained the nominal $<20-\mu \mathrm{m}$ fraction of the feed soil. The reactor contained the feed soil, less any losses that occurred and samples that were taken up to that point. Thus, any problems with slurry measurements would be expected to be more likely for the reactor than for the centrate due to the higher solids content.

Inaccurate measurements could result from (1) nonrepresentative samples that are taken from the process for submission to the laboratory, (2) nonrepresentative aliquots that are taken from the laboratory samples for analysis, and (3) inaccuracies in the analytical methods that are utilized.

To examine possible problems with slurry measurements, the results for the reactor slurry samples taken at the beginning and at the end of the 2 -hr reaction period in Test 0 were compared (three replicate slurry samples were taken at each of the two times). Although uranium is being transferred from the solid to the liquid phase during the reaction period, the total uranium content, as well as the total solids content, of the slurry samples does not change with time. A t-test 
comparison showed no significant difference between the uranium contents of the slurry samples taken at the two different times. However, the solids content, as well as the density, of the slurry at the beginning of the reaction period was significantly lower than that at the end. In the other tests, the uranium content of the reactor slurry samples also appears to be the same at the two different sampling times. However, differences in solids content are again seen, especially in the tests with incinerator area soil.

The results of these comparisons indicate problems with slurry measurements. Also, the problems do not appear to be due to taking nonrepresentative samples from the reactor. If this were the case, differences in both uranium and solids contents would likely have been observed. Because of the intense mixing in the reactor, obtaining representative slurry samples should not be difficult. A possible problem is taking representative aliquots of the samples in the laboratory for solids and density analyses.

The slurry samples from the beginning of the reaction period were taken before the addition of chemicals to the reactor. Thus, differences in settling behavior, due to the effect of chemicals, could have contributed to the differences seen in the solids content of the slurry samples.

In addition to material balance calculations, the reactor slurry data for uranium and solids contents were used in the analysis of the reactor kinetics. If either the low uranium or solids recoveries calculated by the reactor material balance were due to problems with slurry measurements, the kinetics analysis would be affected. This is discussed later.

\subsection{REACTOR KINETICS}

The reactor kinetics data are presented in Figs. 9-12. In Figs. 9 and 10, the concentration of uranium in the reactor solution (i.e., the filtrate from the reactor slurry) is plotted as a function of 


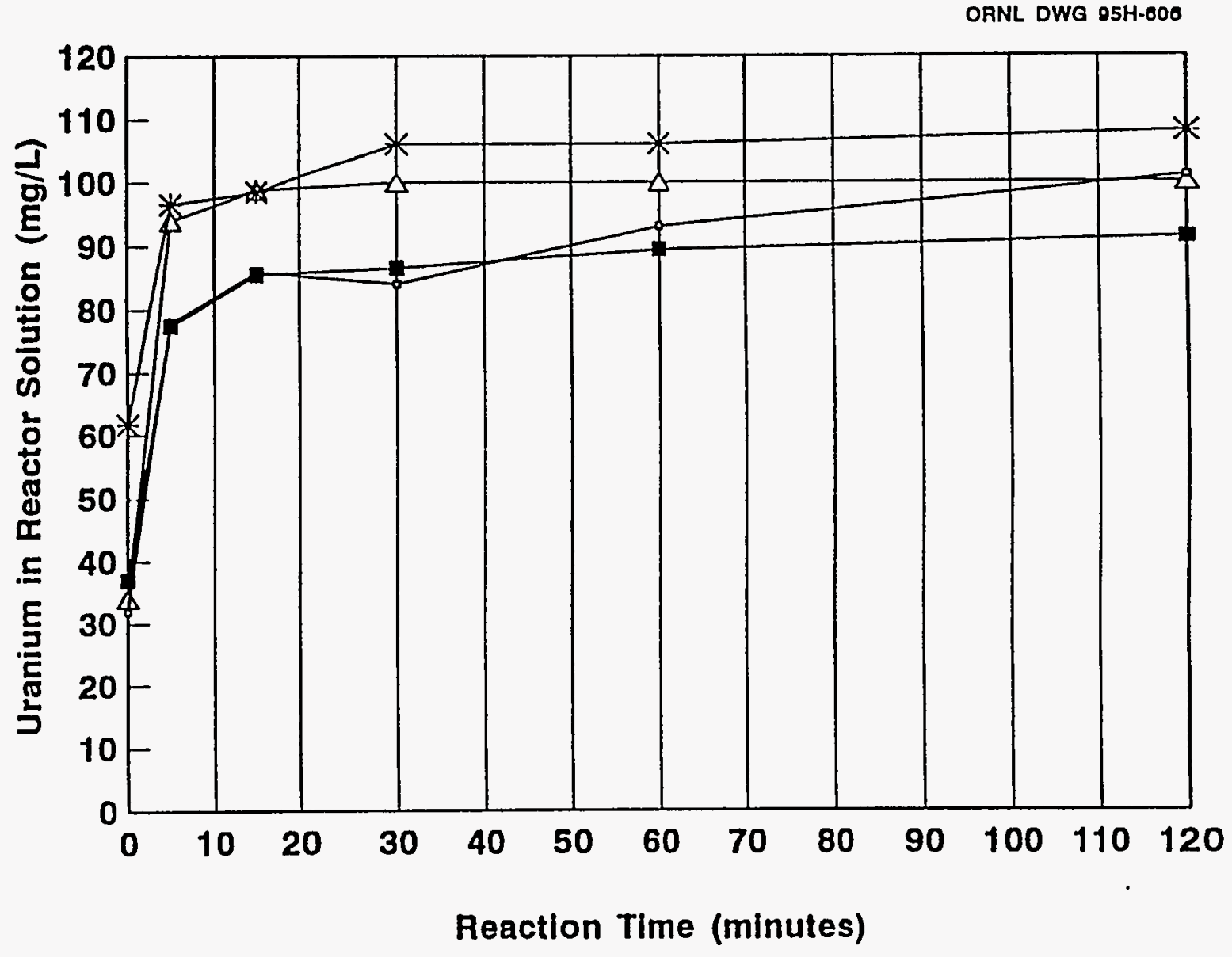

*Average tests $6 \& 19$ - ${ }^{-}$Test 8 * Test $16 \bowtie$ Test 17

Fig. 9. Storage pad soils - uranium concentration in reactor solution vs time 
OANL DWG 95H-607

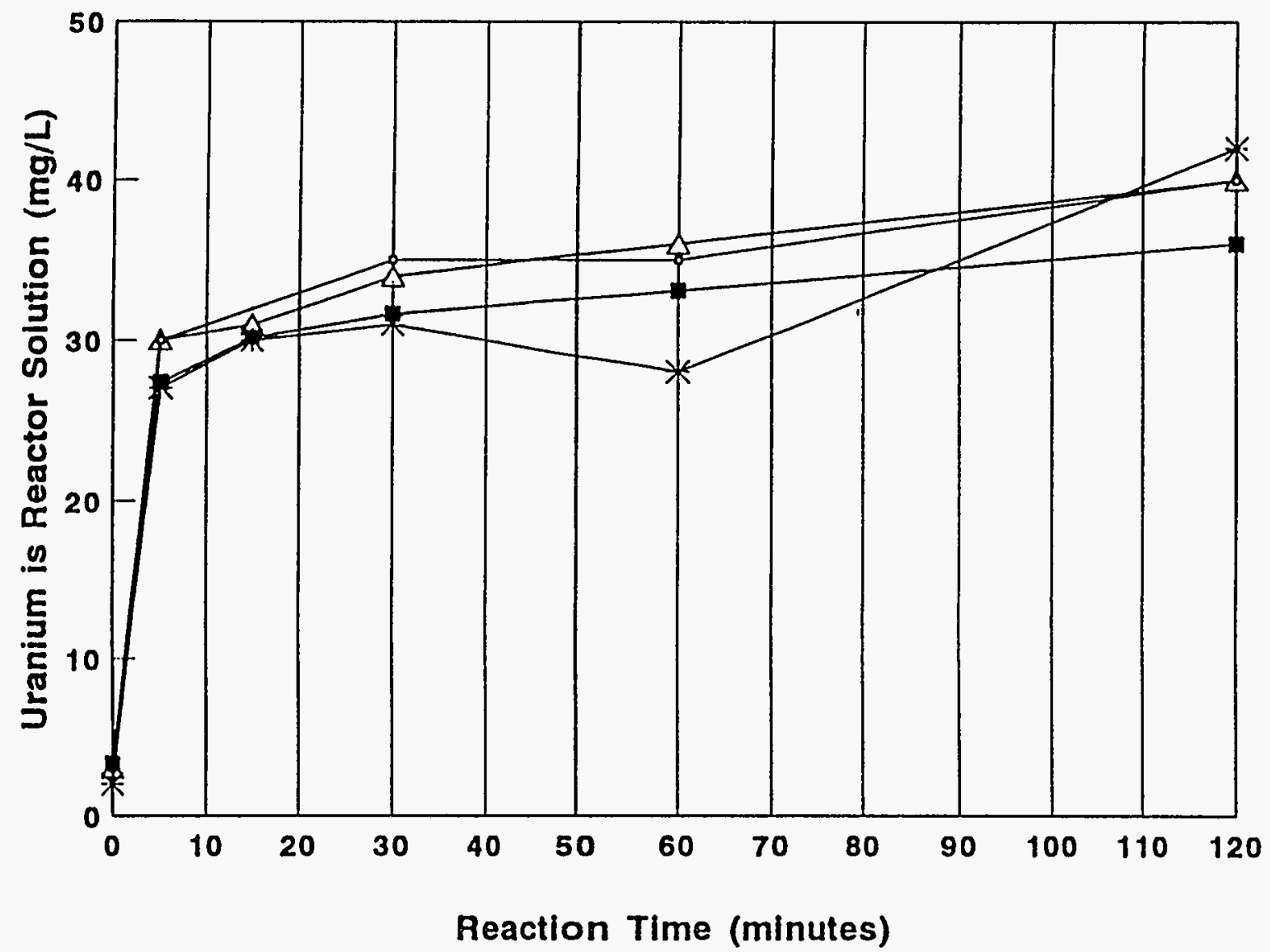

* Avg Tests 2, $3 \& 15$ - 15 Test 0 * Test $1 \unlhd$ Test 7

Fig. 10. Incinerator soils - uranium concentration in reactor solution vs time 


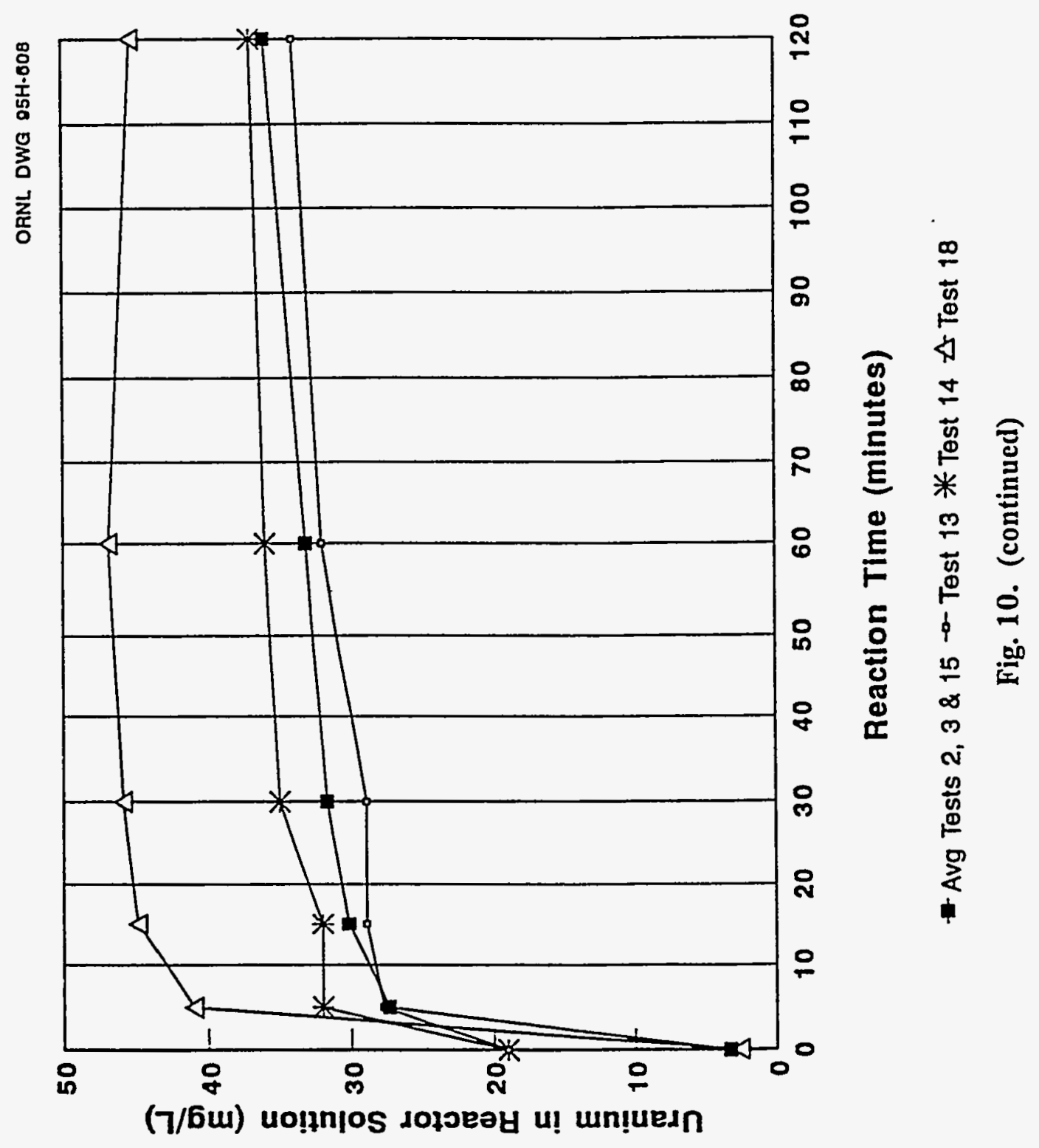




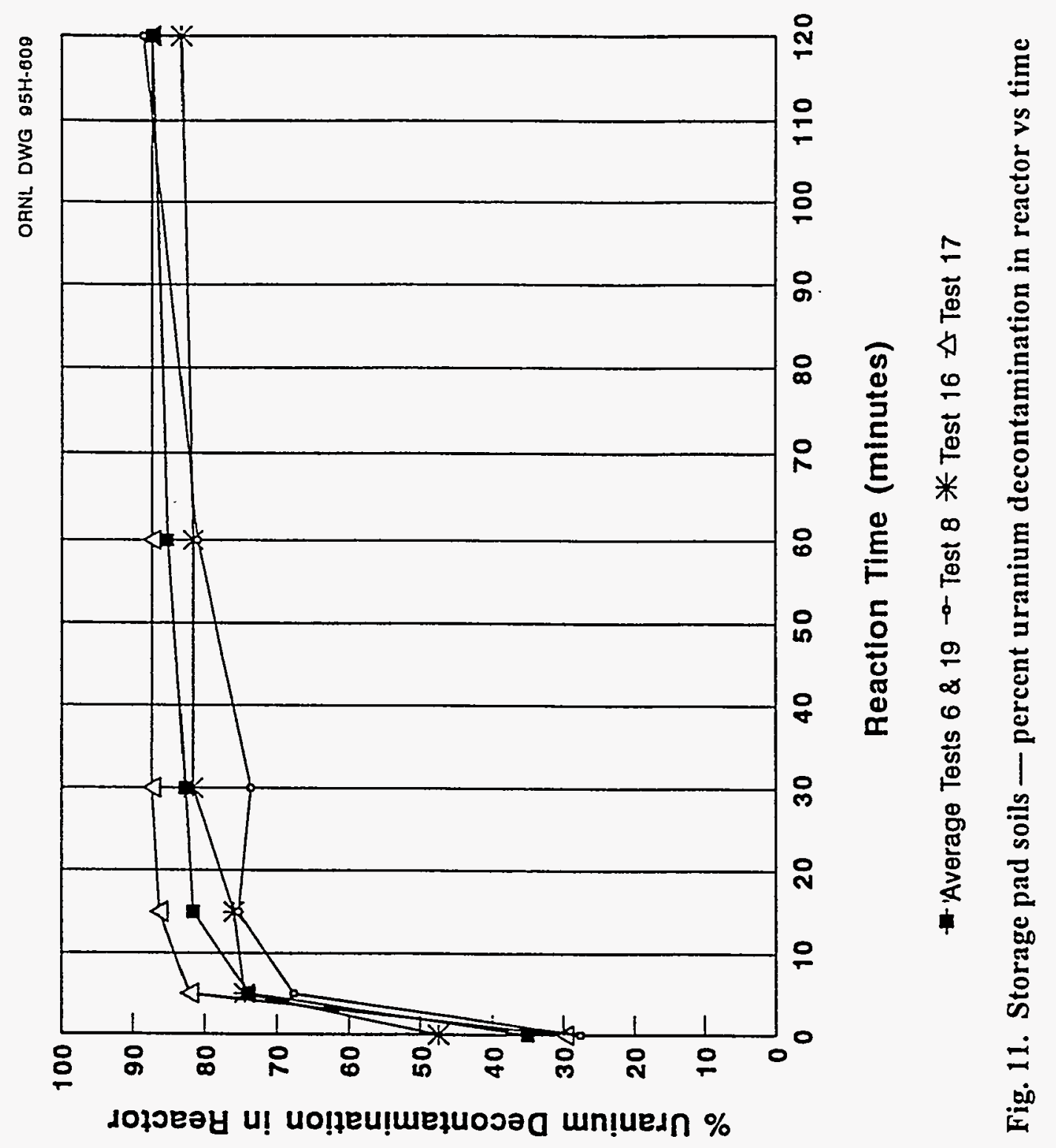


ORNL DWG 95H-610

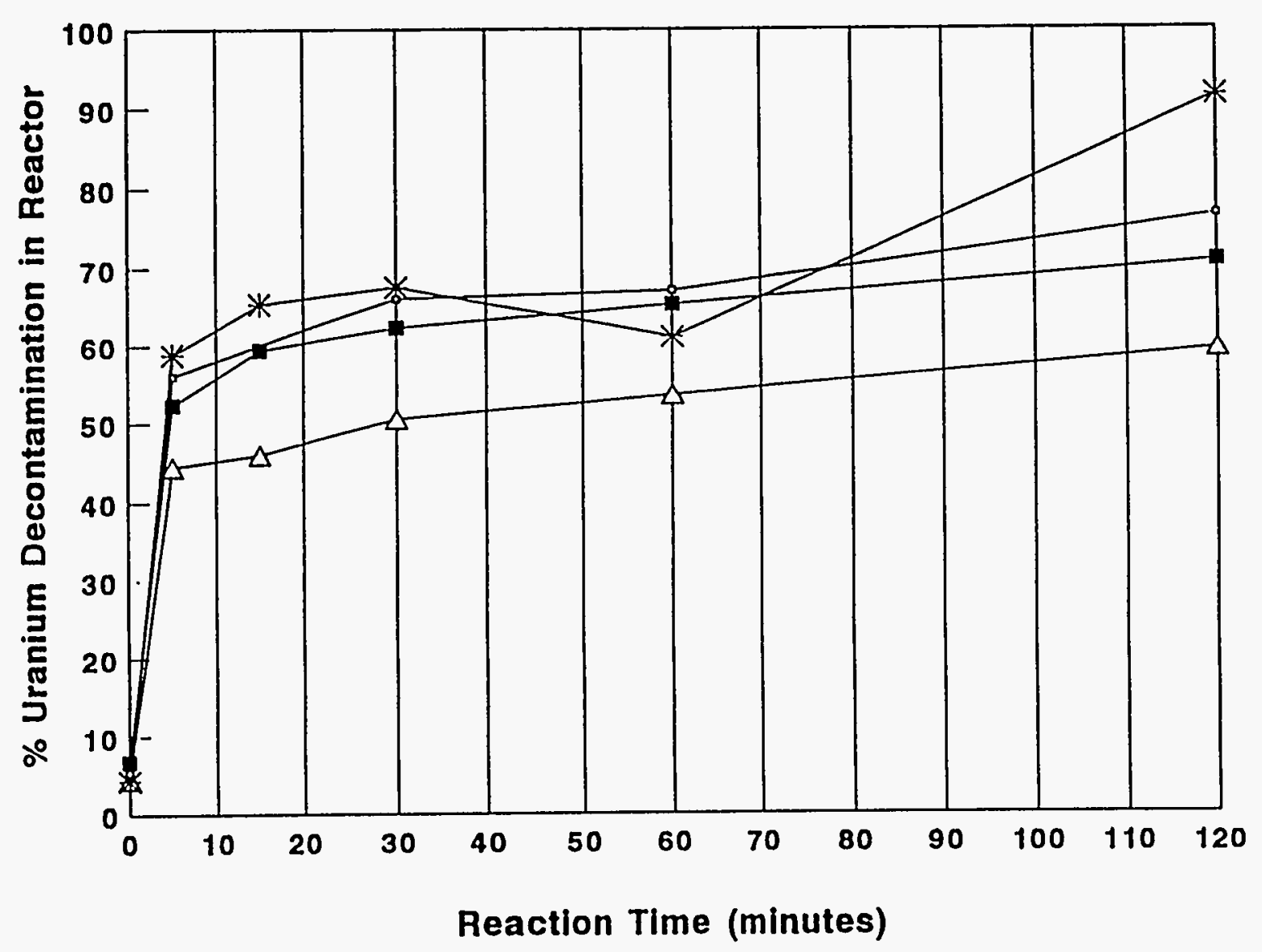

- Avg Tests 2, 3 \& 15 - $\rightarrow$ Test 0 米 Test $1 \triangle$ Test 7

Fig. 12. Incinerator soils - percent uranium decontamination in reactor vs time 


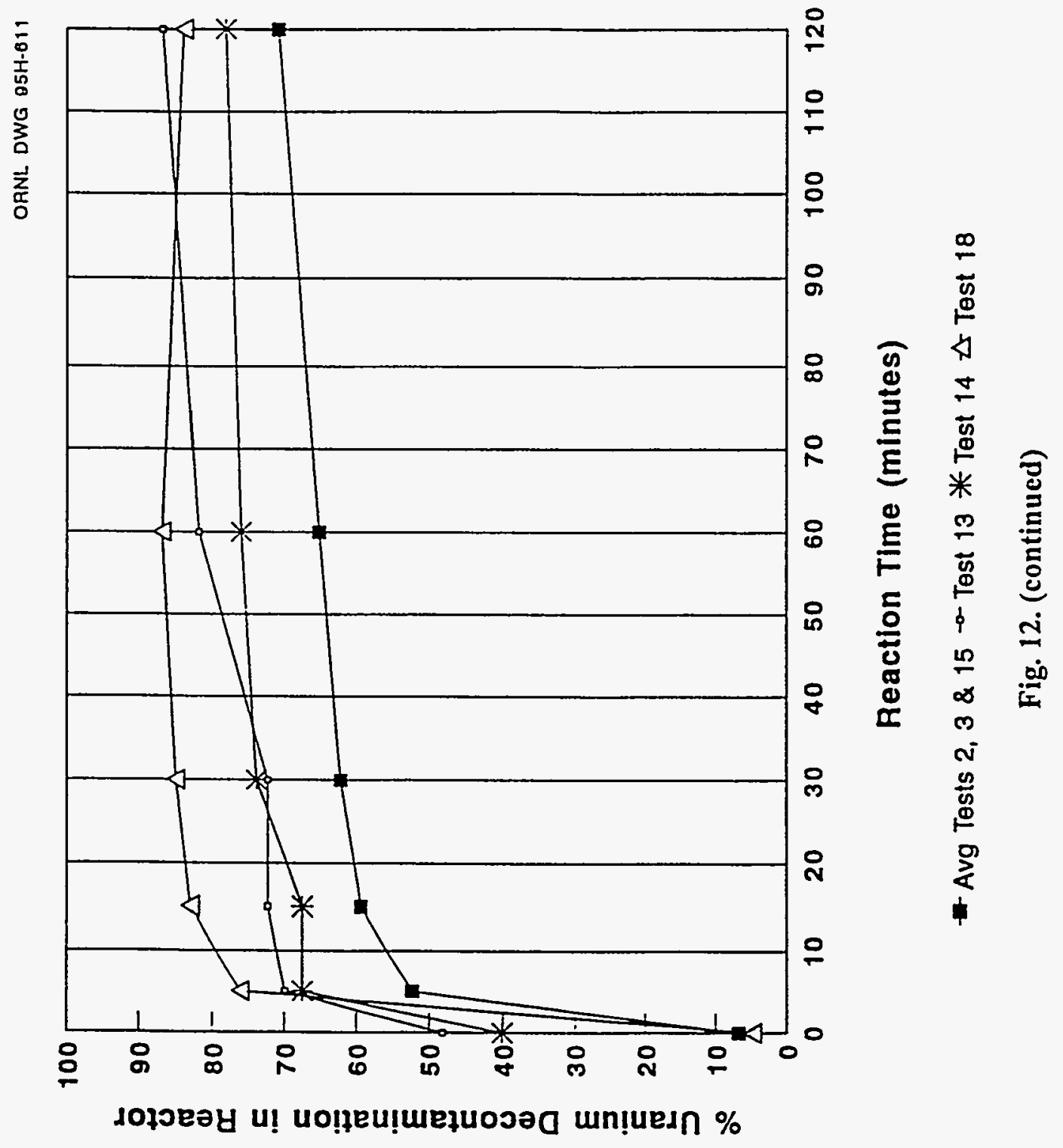


time. The percent decontamination (i.e., percent uranium leached from the soil) vs time is shown in Figs. 11 and 12. For each soil, the results from the replicate runs are compared with the results from each of the other tests.

\subsubsection{Storage Pad Soil}

In Figs. 9 and 11, a composite curve is shown for replicate Tests 6 and 19. The data from Tests 4 and 5, the other two of the four replicate tests for this soil, are not included. During these first two tests of Phase II, problems were experienced in establishing the procedure for filtering the reactor slurry. The anomalous data for Tests 4 and 5 likely resulted from these problems. Comparison of the curve of the replicate tests with those of the other tests does not indicate any effect of attrition scrubbing, type of leachant, or reaction temperature. For all the storage pad soil tests, the kinetic data show that the leaching reaction is essentially complete within 30 to $60 \mathrm{~min}$.

\subsubsection{Incinerator Soil}

In Figs. 10 and 12, a composite curve is shown for replicate Tests 2, 3, and 15. Comparison with the curves of the other tests does not indicate any effect of attrition scrubbing or type of leachant on leaching rate. As seen in Fig. 12, the percent decontamination curve for Test 7 did lie below the curve for the replicate tests. Because of the uncertainties in the measurements of uranium concentration in the reactor slurry, the difference between the curves was not great enough to indicate an effect. A confounding factor, though, is the high concentration of uranium in the feed soil in Test 7 (1120 ppm as compared with an average of $717 \mathrm{ppm}$ for the other incinerator tests). As discussed earlier, the Test 7 feed soil was prepared in a different batch from the other incinerator feed soils. 
Test 18 indicates that a higher reactor temperature increases leaching rate (Figs. 10 and 12). At the $40^{\circ} \mathrm{C}$ operating temperature, both the concentration and the percent decontamination curves have greater initial slopes and significantly higher final values than do the curves for the other tests.

The percent decontamination curve for Test 13 is seen to lie noticeably above that of the replicate tests. However, the Test 13 curve is suspect because of uncertainty about the analytical results for uranium concentration in the reactor slurry (which is used to calculate percent decontamination, as described previously). One of the analytical results was obviously in error (a factor of 10 too low), and the other was significantly lower than those for the other tests.

As with the storage pad soil, the kinetic data show that the leaching reaction is essentially complete within 30 to $60 \mathrm{~min}$.

\subsubsection{Effect of Slurry Measurement Problems}

If the low recoveries from the reactor material balance were due to slurry measurement problems, a likely consequence of the problems would be that the measured uranium and solids concentrations in the reactor slurry were too low. However, the comparisons of the measurements on reactor slurry samples taken at different times in Test 0 indicated that there were no significant problems with uranium determination but that solids content and density results were low. The effect on the kinetics analysis would be to increase the calculated value of percent decontamination somewhat (see Sect. 6 for a description of this calculation).

The uranium concentration in the liquid portion of the reactor slurry was another parameter used in the calculation of the percent decontamination in the reactor. This was determined by filtering a reactor slurry sample and submitting the filtrate for analysis. Comparison of the measured uranium concentrations in these filtrate samples with those in samples of the centrate (produced by 
centrifuging the reactor slurry) indicates problems with the filtration procedure.

The uranium concentration of the centrate should be less than that of the filtrate from the reactor slurry because of dilution during the centrifuge operation. At the end of the transfer of the reactor slurry to the centrifuge feed tank, the reactor was rinsed with water. Also, at the end of the centrifuge operation, the feed tank was rinsed. The water from both rinses was added to the centrate that was collected. Considering the volume of the rinse water and the fact that a portion of the centrate, before dilution by the feed tank rinse water, is collected with the centrifuge wet cake, the uranium concentration in the centrate should be about $90 \%$ or less of that in the reactor slurry filtrate. However, the test results do not exhibit such differences. In several cases, the centrate uranium concentration was actually higher than that of the reactor slurry filtrate.

A possible explanation for this anomalous behavior is that during the filtration of the reactor slurry samples, some of the uranium in solution is adsorbed by the filter paper. The measured concentration of uranium in the filtrate would then be lower than the actual concentration in the reactor solution. The obvious effect on the kinetics analysis would be to calculate low values for percent decontamination. This adsorption effect was also apparent in bench-scale studies. ${ }^{12}$

When the results of using centrifugation and filtration for separating leaching solution from solids were compared in these studies, the solutions generated by filtration contained less uranium. Again, an explanation is the adsorption of the soluble uranium species on the filter paper.

The percent decontamination values from the kinetic analysis were compared with those calculated from the measurements of uranium in the treated soil. This is discussed later. 


\subsection{SOIL DECONTAMINATION}

Tables 8 and 9 list the soil decontamination results for the storage pad soil tests and the incinerator soil tests, respectively. Percent decontamination is calculated using the uranium concentration in each feed drum and the uranium concentration in the treated soil. Figures 13 and 14 show the treated soil uranium concentrations corresponding to Tables 8 and 9 , respectively. In these figures, all the analytical results for each test are presented. As discussed previously for the feed soils, included are results for replicate samples and repeat analyses. The data in Tables 8 and 9 for the feed and the treated soils are averages of these replicate and repeat analyses.

\subsubsection{Storage Pad Soil}

As indicated by Table 8 and Fig. 13, except for Test 19, there appeared to be no significant differences between the treated soil uranium concentrations in the tests that were run with the storage pad soil. As a first approximation, all the treated soil uranium concentrations, except for Test 19, lay within two standard deviations from the average. While Test 19, which was a replicate of Tests 4,5 , and 6, appeared to be an outlier, statistical tests by the Dixon and the Grubbs methods ${ }^{13}$ could not reject the Test 19 result at a $95 \%$ confidence level. Using the paired t-test described previously, no significant differences were found between the results of the replicate tests and the results of each of the other three tests. This was the case even when Test 19 was excluded from the comparison (making the detection of a difference more likely). This agrees with the kinetic data presented above, which showed no effects of attrition scrubbing (Test 16), type of leachant (Test 8), or reaction temperature (Test 17). This is also consistent with the results of the ORNL bench-scale studies. Finally, the storage pad treated soils had significantly higher concentrations of uranium than 
Table 8. Soil decontamination results for storage pad soil tests

\begin{tabular}{|c|c|c|c|}
\hline Test & $\begin{array}{c}\mathrm{U} \text { in feed } \\
\text { (ppm) }\end{array}$ & $\begin{array}{c}\mathrm{U} \text { in product } \\
\text { (ppm) }\end{array}$ & $\begin{array}{c}\text { Decontamination }^{a} \\
(\%)\end{array}$ \\
\hline Test 4 & 1484 & 108 & 92.7 \\
\hline Test 5 & 1920 & 116 & 94 \\
\hline Test 6 & 1810 & 129 & 92.8 \\
\hline Test 8 & 1710 & 125 & 92.7 \\
\hline Test 16 & 1840 & 125 & 93.2 \\
\hline Test 17 & 1640 & 130 & 92.1 \\
\hline Test 19 & 1650 & 182 & 89 \\
\hline Average & 1722 & $131^{b}$ & 92.4 \\
\hline Standard deviation & 147 & 24 & 1.6 \\
\hline Coefficient of variation, $\%$ & 8.5 & 18 & 1.7 \\
\hline
\end{tabular}

$a_{0} \%$ decontamination $=100(1-(U$ in product $) /(U$ in feed $)$.

Average of carbonate tests $=132 \mathrm{ppm}$. 
Table 9. Soil decontamination results for incinerator soil tests

\begin{tabular}{lrrr}
\hline Test & $\begin{array}{c}\text { U in feed } \\
(\mathrm{ppm})\end{array}$ & $\begin{array}{c}\text { U in product } \\
(\mathrm{ppm})\end{array}$ & $\begin{array}{c}\text { Decontamination } \\
(\%)\end{array}$ \\
\hline Test 0 & 606 & 120 & 80.2 \\
Test 1 & 730 & 110 & 84.9 \\
Test 2 & 690 & 130 & 81.2 \\
Test 3 & 723 & 116 & 84 \\
Test 7 & 1120 & 290 & 74 \\
Test 13 & 791 & 159 & 79.9 \\
Test 14 & 756 & 99 & 86.9 \\
Test 15 & 697 & 168 & 75.9 \\
Test 18 & 743 & 85 & 88.6 \\
Average & 761 & 142 & 81.7 \\
Standard deviation & 144 & 62 & 4.9 \\
Coefficient of variation, \% & 19 & 43 & 5.9 \\
\hline
\end{tabular}

${ }_{b}^{a}$ Percent decontamination $=100[1-(\mathrm{U}$ in product $) /(\mathrm{U}$ in feed $)]$.

${ }^{b}$ Average of carbonate tests $=123$ ppm. 
ORNL DWG O5H.612

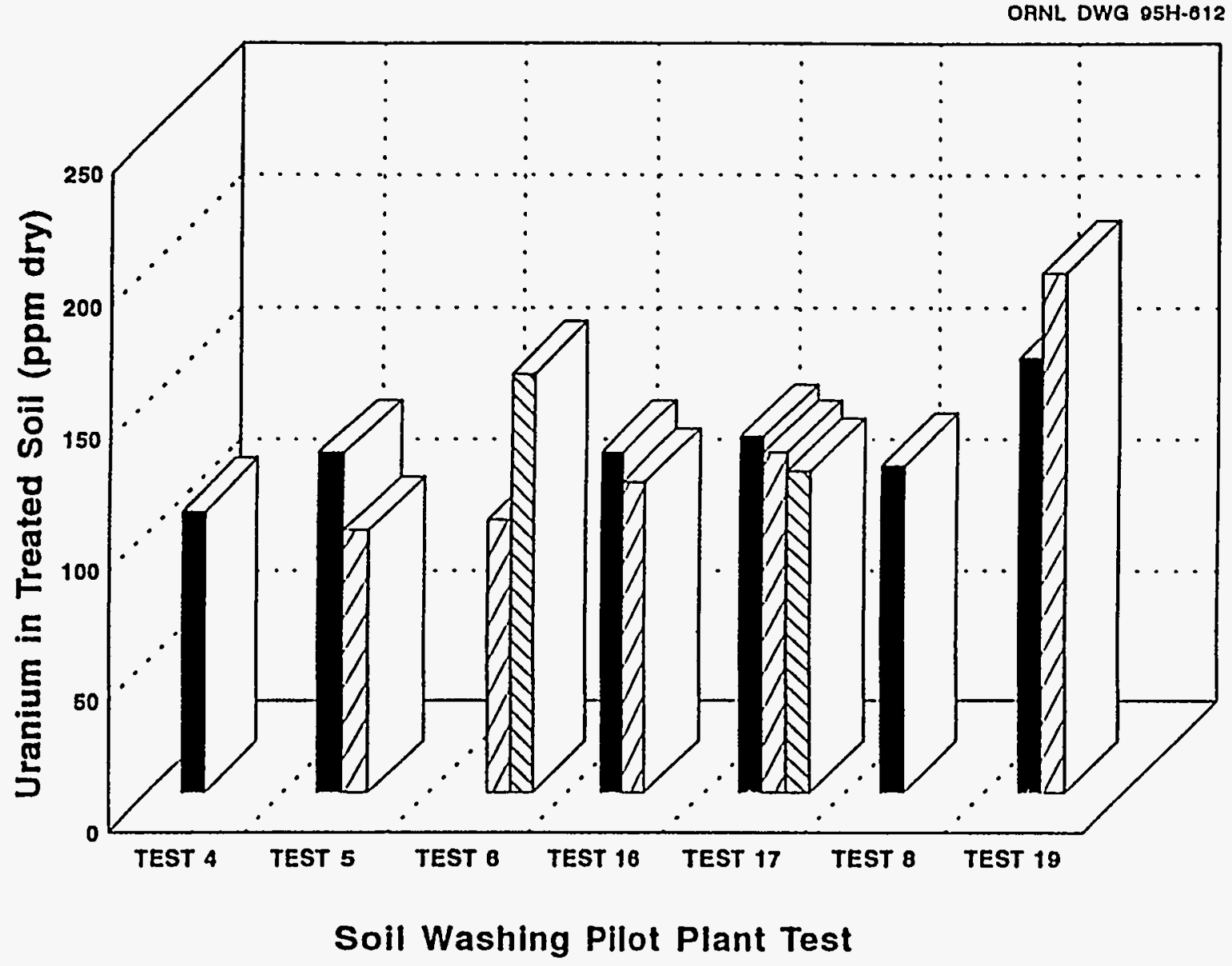

GEMP-Rep. 1 पFEMP-Rep. 2 QfFEMP-Rep. 3

Fig. 13. Storage pad soil tests - uranium concentration in treated soil 
ORNL DWG 95H.613

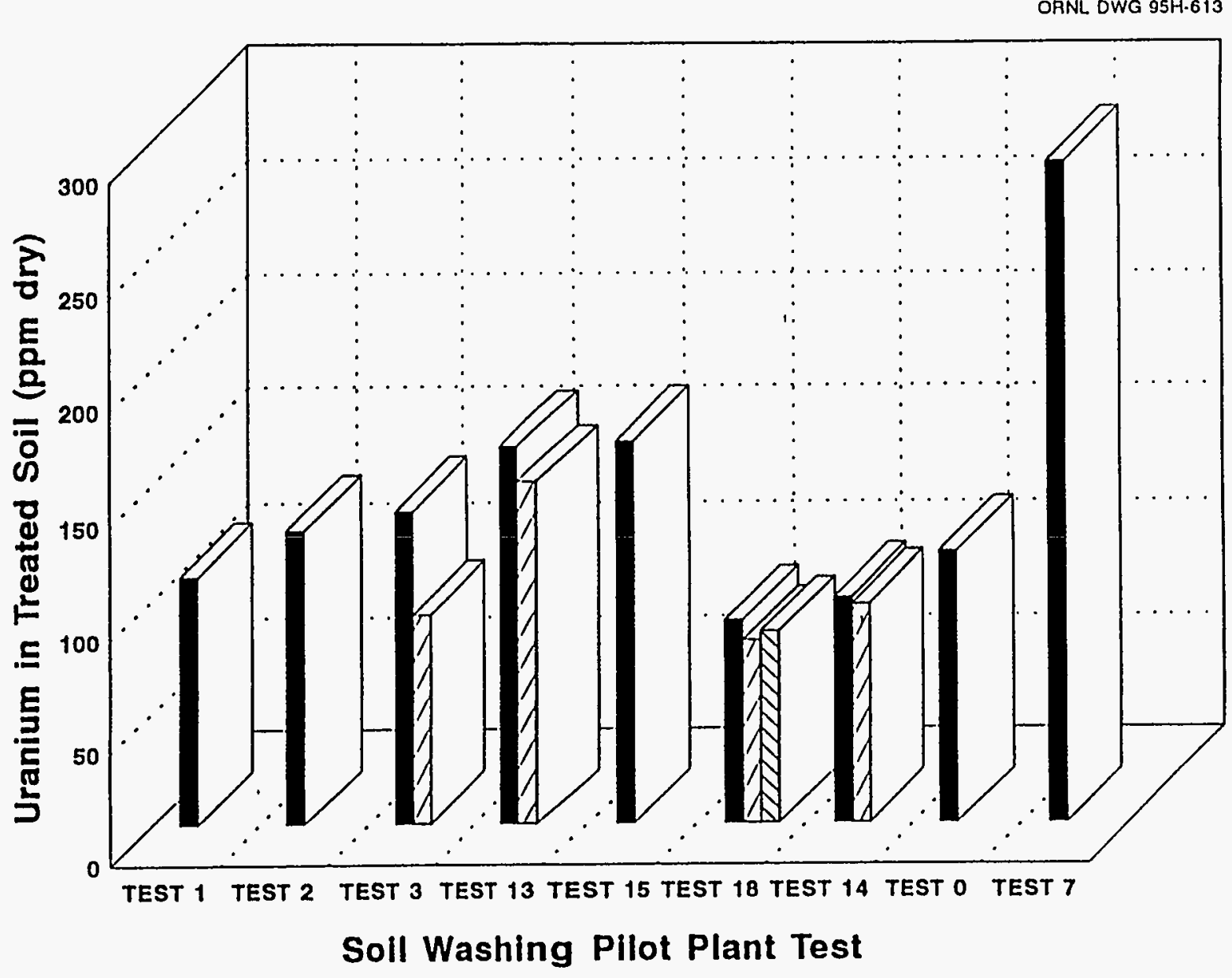

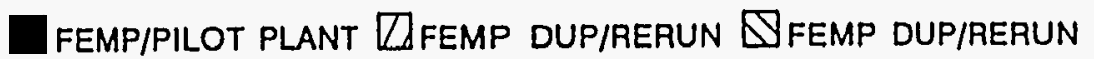

Fig. 14. Incinerator soil tests - uranium concentration in treated soil 
the preliminary decontamination target of $52 \mathrm{ppm}$ uranium, based on a the t-test comparison of the target level with the replicate test results (including Test 19) at a 95\% confidence level. The power of the t-test was 0.88 , indicating a high probability that the difference was true.

Statistical analysis showed no significant relationship between percent decontamination and the uranium feed concentration for the storage pad soil. The average percent decontamination was $92 \%$. Based on a paired t-test comparison, the percent decontamination values in Table 8 were significantly higher than those determined in the kinetic analysis [calculated as measured uranium concentration in the filtrate phase divided by the uranium concentration in the filtrate assuming $100 \%$ decontamination (Sect. 6)]. This is consistent with the speculation that low decontamination values in the kinetics analysis may have resulted from uranium adsorption on filtration paper.

\subsubsection{Incinerator Soil}

For the incinerator soil, Table 9 and Fig. 14 indicate that the type of leaching agent had a significant effect on the treated soil uranium concentration. Except for Test 7 , in which citric acid was the leachant, all the treated soil uranium concentrations lay within two standard deviations from the average. The average for the carbonate tests was $123 \mathrm{ppm}$, as compared with an average of $142 \mathrm{ppm}$ for all tests. Again using the paired t-test to compare with the results of the replicate tests (Tests 2,3, and 15), the treated soil uranium concentration from the citric acid test was significantly higher than those from the carbonate tests. However, as discussed above, a confounding factor is the high concentration of uranium in the feed soil in Test 7. Because of this, no conclusion is made about the effect of type of leaching agent on uranium decontamination.

The t-test did not detect any significant effect of attrition scrubbing (Tests $0,1,13, \& 14$ ) or reactor temperature (Test 18). As discussed previously, soil samples were taken in Test 0 at attrition scrubbing times of $0,15,30,45$, and $60 \mathrm{~min}$. Bench-scale tests with these samples confirmed the absence of a beneficial effect of attrition scrubbing on treated soil uranium concentration. ${ }^{14}$ Consequently, pooling the results of Tests $0,1,2,3,13,14$, and 15 is valid since attrition scrubbing had no effect. A subsequent paired t-test using the pooled results did show that increased reactor temperature significantly lowered the treated soil uranium concentration. The power of the t-test 
was 0.96 , indicating a high probability that the difference was true. The effect of reactor temperature is consistent with results of ORNL bench-scale leaching studies. As discussed above, the kinetic data also indicated a significant effect of temperature on leaching.

As was found for the storage pad soil, the t-test at a $95 \%$ confidence level showed that the treated incinerator soils from the replicate tests had significantly higher concentrations of uranium than the preliminary decontamination target of $52 \mathrm{ppm}$. The power of the t-test was essentially equal to 1 , indicating a very high probability that the difference was true.

Statistical analysis showed no significant relationship between percent decontamination and the uranium feed concentration. The average percent decontamination was $83 \%$. Based on a paired t-test comparison, the percent decontamination values in Table 9 were significantly higher than those calculated in the kinetic analysis. Again, this is consistent with the idea that low decontamination values in the kinetics analysis resulted from slurry filtration problems, namely, uranium adsorption on the paper filter. 


\section{RESULTS OF TESTS CARRIED OUT AT "OPTIMUM" CONDITIONS}

\subsection{BASIS FOR EXPERIMENTAL CONDITIONS}

As discussed in the Phase II test plan, the final tests of Phase II were to be carried out at "optimum" conditions. These conditions were to be based on the results of the Phase II tests listed in Table 1 , as well as previous and concurrent bench-scale tests at ORNL. Also, the feed soils were to be incinerator and storage pad soils, each of which had been prepared by blending in a concrete mixer, as described in Sect. 3.3, and a soil that contained grass and roots. In collecting the soils that were ultimately blended, the procedure involved removing several inches of the topsoil layer before collecting the actual soil samples. In collecting the latter soil from the Plant I Pad area, the topsoil layer, which contained grass and roots, was included as part of the soil sample.

Based on the results presented in Sect. 8 and on ORNL bench-scale results, the conditions for the final Phase II soil leaching tests were chosen as described in the following:

- Attrition scrubbing was eliminated as a process step. Fernald test unit and bench-scale tests showed no beneficial effect of attrition scrubbing on uranium removal efficiency. In fact, the ORNL bench-scale tests on the samples produced in the Fernald test unit attrition scrubber showed a detrimental effect on efficiency. A possible cause of this was the increase in surface area due to the generation of small soil particles. The additional surface area could provide more adsorption sites for solubilized uranium species, thereby decreasing the experimental leaching efficiency (which was determined by analysis of the solubilized uranium in the leaching solution).

- By eliminating attrition scrubbing, the centrifuge was used to process only treated soil. As discussed in Sect. 8, the centrifuge was used to process both feed soils and treated soils in the previous tests. Consequently, contamination of the treated soil by residual feed soil in the centrifuge was a potential problem. This was not the case in the final tests.

- In each test, the soil underwent three $1-h r$ leaching reactions followed by two rinsing steps. The soil slurry was centrifuged after each leaching reaction, and fresh lixiviant was added when another leaching reaction followed. When a rinsing step followed, the centrifuged solids were repulped with process water with no addition of chemicals. In bench-scale tests at ORNL, soil samples were subjected to five successive leaching steps, with fresh lixiviant used in each step. The results indicated that a certain amount of uranium was leached from the soil in each leaching step, the amount leached decreasing with each step.

- Potassium permanganate was used as an oxidant in the leaching reaction. ORNL bench-scale tests showed this to be beneficial in leaching uranium from incinerator area soil.

- The leaching reactor was to be operated at $40^{\circ} \mathrm{C}$. From the results discussed in Sect. 8 and from ORNL bench-scale tests, increased temperature has a beneficial effect on leaching rate and uranium leaching efficiency for incinerator area soil. 


\subsection{EXPERIMENTAL SUMMARY}

Table 10 shows the order in which the final Phase II tests were run, the dates the tests were run, the type of soil feed, and the number of the drum used in each test.

Table 10. Summary of final phase II tests

\begin{tabular}{|c|c|c|c|}
\hline Test no. & Date of test & Soil & Feed drum number \\
\hline 20 & $9 / 28 / 94-10 / 3 / 94$ & Incinerator area & $\begin{array}{l}\text { No. } 27 \\
\text { W050-766 } \\
\text { P011-A360 }\end{array}$ \\
\hline 25 & $10 / 3 / 94-10 / 5 / 94$ & $\begin{array}{l}\text { Storage pad } \\
\text { (grass and roots) }\end{array}$ & $\begin{array}{l}\text { No. } 1 \\
\text { W062-176 } \\
\text { P011-0389 }\end{array}$ \\
\hline 21 & $10 / 11 / 94-10 / 13 / 94$ & Storage pad & $\begin{array}{l}\text { No. } 22 \\
\text { W050-176 } \\
\text { P011-A360 }\end{array}$ \\
\hline 22 & $10 / 18 / 94-10 / 20 / 94$ & Incinerator area & $\begin{array}{l}\text { No. } 19 \\
\text { W050-766 } \\
\text { P01 1-A360 }\end{array}$ \\
\hline
\end{tabular}

At the start of the tests, the steam to Plant 8 had been shut off for repairs. Consequently, the first three tests were run with the reactor at ambient temperature. In Test 22 , the fourth and final test, the reactor was heated with steam for the first leaching reaction, with the next two leaching reactions carried out at ambient temperature.

In the four tests, $\mathrm{KMnO}_{4}$ was added only to the first leaching reaction. In Test 20 , the first test that was run, the reactor slurry was observed to be purple at the end of the first reaction step. In the previous Phase II tests, the reactor slurry changed from purple to brown within about $5 \mathrm{~min}$ after addition of $\mathrm{KMnO}_{4}$, indicating that the $\mathrm{KMnO}_{4}$ had been consumed in oxidizing reactions (the feed soils may have contained more organic material than those for the final tests). Since excess $\mathrm{KMnO}_{4}$ was present during the entire time of the first reaction period of Test 20 , the decision was made to use $\mathrm{KMnO}_{4}$ in only the first reaction step of each of the final four tests. As just three final tests had been originally planned, the quantity of $\mathrm{KMnO}_{4}$ on hand was not sufficient for the 12 reaction steps of the four tests that were actually run. In retrospect, a better approach would have been to use $\mathrm{KMnO}_{4}$ in the first two reaction steps of each of the final four tests. In later discussions with an 
USID consultant, ${ }^{15}$ the oxidation of uranium (IV) to uranium (VI) was identified as a relatively slow reaction. With $\mathrm{KMnO}_{4}$ present in the second leaching step, the additional reaction time may have been beneficial.

In Tests 20, 21, and 25, two 55-gal drums of slurry were collected from the reactor at the end of the first reaction period. Plans are to use these samples in future filtration tests.

In Test 25, the oversized material discharged from the trommel had a considerable amount of clay mixed with the rocks. The oversized material was recycled through the trommel after the feed soil had been processed.

Also in Test 25, problems were encountered with blinding of both screens in the vibrating screen deck. Blinding of the 10 mesh screen was caused primarily by grass. This material (approximately $500 \mathrm{~g}$ ) was collected and sampled separately, rather than combined with the trommel heel as was the usual procedure.

\subsection{DISCUSSION OF RESULTS}

The process data for the final four Phase II soil leaching tests are summarized in Appendix B. The analytical results for these tests are presented in Appendix C. This information was used to determine material balances for soil and uranium and decontamination efficiencies. The results are discussed in the following.

\subsubsection{Material Balances}

The material balance results for solids and uranium are summarized in Table 11. The detailed material balance results are presented in Appendix D. For the tests in which two 55-gallon drums of slurry were collected from the reactor, the quantity of solids removed was calculated based on the solids content of the slurry as determined from the net amount of soil fed to the reactor. The analytical results for slurry density and solids content of the slurry were not used since, as discussed in Section 8.2.3, problems with measurement of these parameters were evident. 
Table 11. Solids and uranium material balances for final Phase II tests

\begin{tabular}{lcccc}
\hline & \multicolumn{4}{c}{ Quantity of soil or uranium (lb) } \\
\cline { 2 - 5 } & Test 20 & Test 21 & Test 22 & Test 25 \\
\hline Feed soil & 340.4 & 293.2 & 332 & 282.5 \\
Product soil & 205.2 & 165.6 & 255.8 & 144.2 \\
Soil in other streams & 138.1 & 123.4 & 62.8 & 124.5 \\
Percent soil recovery & 100.9 & 98.6 & 96 & 95.1 \\
Uranium in feed & 0.1900 & 0.1507 & 0.1855 & 0.2495 \\
Uranium in product & 0.0179 & 0.0083 & 0.0171 & 0.0164 \\
Uranium in other streams & 0.1671 & 0.1250 & 0.1445 & 0.4205 \\
Percent uranium recovery & 97.4 & 88.5 & 87.1 & 175 \\
\hline
\end{tabular}

The material balances for soil for these four runs were very good, the average soil recovery being $97.7 \%$. The fraction of the feed soil recovered in the product soil in Tests 20,21 , and 25 was relatively low because of the 55 -gal drum samples of reactor slurry that were taken. The product soil accounted for an average of $56 \%$ of the soil that was recovered, as compared with $77 \%$ for Test 22.

The uranium recoveries for Tests 20,21 , and 22 were acceptable. In Test 25 , however, the uranium recovery was almost $200 \%$. This is considerably greater than would be expected due to experimental variances. The high recovery could be caused by errors in the data. If this were the case, the measured uranium concentrations in the feed soil and in the centrate would be the prime suspects (since these represent the major inlet and outlet uranium streams). However, the variance of the uranium concentrations of the three samples of the feed soil that were taken was acceptable (the coefficient of variation being equal to $9 \%$ ). Also, the uranium concentrations of the centrates agreed well with those of the filtrates from the reactor slurry samples (recall that the centrates were produced from centrifuging the reactor slurries). Thus, the high uranium recovery in Test 25 does not appear to be attributed to errors in the data. 
The uranium concentration of the grass collected on the 10 mesh screen in Test 25 was $21,900 \mathrm{ppm}$. If about $10 \mathrm{lb}$ of this grass had passed through the vibrating screens along with the soil, the high uranium recovery in this test could be explained. This assumes that the samples of the feed soil that were taken did not contain a representative amount of grass. This could have resulted if the grass and soil in the feed drum were not mixed together well.

\subsubsection{Soil Decontamination}

The soil decontamination results for the final four Phase II tests are shown in Table 12. Except for Test 25 , the uranium concentrations of the product soil were significantly less (by the paired t-test) than the averages of the corresponding replicate tests in Sect. 8 (i.e., Tests 20 and 22 compared with the incinerator soil tests and Tests 21 and 25 with the storage pad soil tests). It would appear that use of the "optimum" operating conditions resulted in a less contaminated soil product. However, the feed uranium concentrations in Table 12 were significantly lower than those of the replicate tests. Thus, if percent decontamination was unrelated to feed concentration, the observed lower uranium levels in the treated soil would be expected. Tests with feed soils similar to those used in the replicate tests would be desirable to confirm the effect of the "optimum" operating conditions. The results of Test 25 are believed to be confounded by the presence of highly contaminated grass in the feed soil.

Since the tests in Table 12 were not replicated, the results cannot be statistically compared with the target cleanup level of $52 \mathrm{ppm}$ uranium. If, however, Tests 20 and 22 can be considered to be replicates (the use of steam in the reactor in Test 22 being the main difference between the two tests), a uranium level less than $52 \mathrm{ppm}$ in the treated soil was apparently not achieved for the incinerator soil. 
Table 12. Soil decontamination results for final Phase II tests

\begin{tabular}{lccc}
\hline Test & $\begin{array}{c}\text { U in feed } \\
(\mathrm{ppm})\end{array}$ & $\begin{array}{c}\text { U in product } \\
(\mathrm{ppm})\end{array}$ & $\begin{array}{c}\text { Decontamination } \\
(\%)\end{array}$ \\
\hline Test 20 & $558^{b}$ & 87 & 84 \\
Test 21 & 514 & 50 & 90 \\
Test 22 & $558^{b}$ & 67 & 88 \\
Test 25 & 883 & 114 & 87 \\
$a_{0} \%$ decontamination $=100(1-(\mathrm{U}$ in product $) /(\mathrm{U}$ in feed). \\
Average of Tests 20 and 22.
\end{tabular}

To determine if additional leaching steps increased decontamination efficiency, samples of the centrifuge solids were taken after each leaching step, as well as after each rinsing step. Table 13 shows the uranium contents of the solids in these samples. Since the samples consisted of both soil and residual leaching solution, the analytical results were corrected by subtracting the uranium contained in the solution. Thus, the data in Table 13 represent the actual uranium concentrations of the solids.

In general, the decreases in uranium concentration shown in Table 13 indicate that the overall leaching efficiency is increasing with each leaching step. However, a significant decrease in the uranium content of the solids also occurs with the first rinsing step. Since dilution with rinse water dropped the carbonate concentration by more that a factor of 10 and residence time in the rinsing tank was relatively short, little, if any, additional reaction would be expected during rinsing. A possible cause of the observed behavior is the desorption of soluble uranium species from the soil particles. That is, the uranium concentrations in Table 13 include not only unreacted uranium, but also reacted uranium adsorbed on the soil particles in equilibrium with that in the leaching solution. In this case, the equilibrium relationship between the dissolved and adsorbed uranium species would have to be known in order to determine the effect of each leaching step on leaching efficiency. Alternatively, a portion of the solids from each leaching step could have been rinsed to remove adsorbed uranium species before sampling for uranium analysis. Before inclusion in the design of a commercial soil leaching process, experiments should be done to determine if there is a real effect of successive leaching steps on leaching efficiency. If no effect exists, the process would obviously be simplified by specification of only one leaching step. 
Table 13. Uranium concentration in soil from leaching and rinsing steps

\begin{tabular}{lrccc}
\hline & \multicolumn{4}{c}{ Uranium concentration in solids (ppm dry) } \\
\cline { 2 - 5 } \multicolumn{1}{c}{ Process step } & Test 20 & Test 21 & Test 22 & Test 25 \\
\hline 1st leaching & no sample & 98 & 122 & 331 \\
2nd leaching & 137 & 69 & 111 & 143 \\
3rd leaching & 119 & 74 & 75 & 148 \\
1st rinse & 89 & 55 & 69 & 114 \\
2nd rinse & 87 & 50 & 67 & 114 \\
\hline
\end{tabular}

\subsubsection{Decontamination of Trommel Oversize}

In the Phase II tests discussed in Sect. 8, the trommel oversized material, which consisted of clay and small rocks, typically contained significant amounts of uranium. The uranium likely was associated with the clay. To determine if this oversized material could be decontaminated, plans were to study the recycle of the material through the trommel during the final four Phase II tests. Of these tests, only Test 25 produced trommel oversize material with an appreciable clay fraction. After the feed soil had been processed through the trommel in this test, the oversize material was recycled. The resultant uranium content was $77 \mathrm{ppm}$, indicating removal of the clay did accomplish decontamination. Unfortunately, this cannot be confirmed because the oversize material was not sampled before being recycled. If desired, a short test could be run on the trommel using as feed the oversize material that was archived from previous runs. 


\section{CONCLUSIONS}

The conclusions from the USID Phase II Fernald test unit studies are as follow:

- No significant effects of attrition scrubbing were observed.

- Increased reaction temperature significantly increased uranium decontamination for the incinerator area soil. No effect was observed for the storage pad soil.

- The rates of uranium leaching with carbonate and with citric acid are reasonably fast; within $30-60 \mathrm{~min}$, the uranium removal is $90 \%$ or more of that reached at the end of the $120-\mathrm{min}$ reaction period.

- Citric acid was apparently not as effective as sodium carbonate/sodium bicarbonate for leaching the incinerator area soil. However, the comparison was confounded by a significantly higher uranium concentration in the feed soil that was used in the citric acid test. Thus, no conclusion is made concerning the effect of leaching agent in the incinerator soil tests. For the storage pad soil, there was no significant difference between the two leaching agents.

- The preliminary decontamination target level of $52 \mathrm{ppm}$ uranium was not achieved with either the incinerator area or the storage pad soil.

- In the replicated tests in the experimental design, the average uranium levels in the treated soil that were achieved with carbonate as leachant were 132 and $123 \mathrm{ppm}$ for the storage pad soil and the incinerator area soil, respectively.

- In the final tests run under "optimum" operating conditions, uranium levels less than $100 \mathrm{ppm}$ were attained. However, because of the lower uranium concentrations in the feed soils, no conclusion can be drawn about an effect of operating conditions.

- The average percent uranium decontamination was $92 \%$ for the storage pad soil and $83 \%$ for the incinerator area soil. 


\section{RECOMMENDATIONS}

Based on the results from the USID Phase II Fernald test unit studies, recommendations for the development, design, and operation of a soil leaching process for uranium decontamination are as follow:

- Perform bench-scale studies to establish whether or not successive leaching steps improve overall leaching efficiency.

- Exclude attrition scrubbing from the soil leaching process, as this unit operation has no beneficial effect on leaching efficiency.

- Specify a residence time of at least $1 \mathrm{hr}$ in the design of a soil leaching process.

- Operate the leaching reactor(s) at $40^{\circ} \mathrm{C}$.

Although the preliminary decontamination target level of $52 \mathrm{ppm}$ uranium was not achieved in the pilot plant tests, a significant portion of uranium was removed from the soils. The uranium remaining in the soil likely exists in a more refractory form. Because of the lower uranium concentrations and the apparent decreased mobility of the uranium, the soil leaching process may well produce a treated soil capable of meeting levels developed from risk-based analyses. 


\section{REFERENCES}

1. Uranium Solids Integrated Demonstration: Phase II Test Plan, Fernald CRU5/USID Soil Decontamination Pilot Plant (Carbonate/Citrate Leaching), ORNL/TM-12673 October 1, 1993, ORNL/TM-12673, prepared for the U.S. Department of Energy, Office of Technology Development, Fernald Site Office, by the Oak Ridge National Laboratory, Oak Ridge, Tennessee (in preparation).

2. Treatability Study Work Plan for Operable Unit 5 Soil Washing, Fernald Environmental Management Project, Fernald, Ohio, Remedial Investigation and Feasibility Study, March 1992, U.S. Department of Energy, Fernald Office.

3. C. W. Francis, A. J. Mattus, L. L. Farr, M. P. Elless, and S. Y. Lee, Selective Leaching of Uranium Contaminated Soils: Progress Report 1, ORNL/TM-12177, February 1993.

4. C. W. Francis, A. J. Mattus, M. P. Elless, and M. E. Timpson, "Carbonate- and Citrate-Based Selective Leaching of Uranium from Uranium-Contaminated Soils," Part 1 of Removal of Uranium from Uranium-Contaminated Soils, Phase 1: Bench-Scale Testing, ORNL-6762, 1993.

5. S. Y. Lee, and J. D. Marsh, Jr., Characterization of Uranium Contaminated Soil from DOE Fernald Environmental Management Project Site: Results of Phase I Characterization, ORNL/TM-11980, 1992.

6. R. C. Merritt, The Extractive Metallurgy of Uranium, Colorado School of Mines Research Institute of Mines, Library of Congress Catalog Card No. 71-157076, 1971.

7. J. H. Wilson, personal communication with M. J. Geyer, FERMCO, MS-81-3, 25 Merchant St., Executive Center 3, Springdale, Ohio 45246.

8. R. E. Walpole and R. H. Myers, Probability and Statistics for Engineers and Scientists, 2 ed., Macmillan Publishing Co., Inc., New York, 1978, p. 100.

9. J. H. Wilson, personal communication with Jeff Bock, Quality Division, Martin Marietta Energy Systems, P.O. Box 2003, Oak Ridge, Tennessee 37831-7383, April 1994.

10. J. H. Wilson, personal communication with M. R. Ally, Chemical Technology Division, Martin Marietta Energy Systems, P.O. Box 2008, Oak Ridge, Tennessee 37831-6044, April 1994.

11. J. H. Wilson, personal communication with C. W. Francis, Environmental Sciences Division, Martin Marietta Energy Systems, P.O. Box 2008, Oak Ridge, Tennessee 3783 1-63 1 7, July 1994.

12. C. Lipson and N. J. Sheth, Statistical Design and Analysis of Engineering Experiments, McGraw-Hill Book Company, New York, 1993, p. 91.

13. J. H. Wilson, personal communication with C. W. Francis, Environmental Sciences Division, Martin Marietta Energy Systems, P.O. Box 2008, Oak Ridge, Tennessee, 37831-6317, September 1994.

14. J. H. Wilson, personal communication with Wayne Henderson, Brown \& Root U.S.A., Inc., P.O. Box 3, Houston, Texas, 77001-0003, Dec. 1, 1994. 
APPENDIX A

PROCESS FLOW SHEETS 


\section{APPENDLX A}

\section{PROCESS FLOW SHEETS}

The process flow sheets for all of the Phase II tests are included in Appendix A. These flow sheets, which are presented in the order that the tests were run, illustrate the process configuration

of each test. Also shown on the flow sheets are the sample points for each test. The process sample points are described in Table A-1. Samples were taken at these specified locations during each test. Sample points 12 through 18 were for rinsate samples taken when cleaning equipment after each test. Sample points 19 through 28 were for any samples that, although not specified in the sampling plan, could be included in any test. Sample point 29 was for a duplicate sample to be analyzed onsite, and sample points 101 through 118 were for duplicates for off-site analyses. 
.

, 
Table A-1. Description of process sample points for phase II tests

\begin{tabular}{|c|c|c|}
\hline $\begin{array}{l}\text { Sample } \\
\text { point no. }\end{array}$ & Description & Comments \\
\hline 1 & Feed soil & $a$ \\
\hline 31 & Feed soil & Sample to CRUS \\
\hline 51 & Feed soil & Sample to ORNL \\
\hline 2 & Trommel screen oversize & \\
\hline 32 & Trommel screen oversize & Sample to CRUS \\
\hline 81 & Trommel screen heel & \\
\hline 3 & Not used & \\
\hline 4 & Not used & \\
\hline 5 & Centrifuge centrate & From centrifuge operation after trommel \\
\hline 6 & Centrifuge wet cake & From centrifuge operation after trommel \\
\hline 7 & Attrition scrubber effluent & Samples to ORNL in Test 0 \\
\hline$\underline{8}$ & Reactor & \\
\hline $8 Y L$ & Filtrate & Filtrate at time zero \\
\hline $8 Y S$ & Slurry & Slurry at time zero \\
\hline 85 & Filtrate & Filtrate at time $5 \mathrm{~min}$ \\
\hline 815 & Filtrate & Filtrate at time $15 \mathrm{~min}$ \\
\hline 830 & Filtrate & Filtrate at time $30 \mathrm{~min}$ \\
\hline $860 \mathrm{~L}$ & Filtrate & Filtrate at time $60 \mathrm{~min}$ \\
\hline $860 S$ & Slurry & Slurry at time $60 \mathrm{~min}$ \\
\hline 8ZL & Filtrate & Filtrate at time $120 \mathrm{~min}$ \\
\hline $8 Z S$ & Slurry & Slurry at time $120 \mathrm{~min}$ \\
\hline $818 \mathrm{~L}$ & Filtrate & Filtrate at time $180 \mathrm{~min}$ \\
\hline $818 \mathrm{~S}$ & Slurry & Slurry at time $180 \mathrm{~min}$ \\
\hline 9 & Vibrating screen oversize & From vibrating screen operation after reaction \\
\hline \multirow[t]{2}{*}{39} & Vibrating screen oversize & From vibrating screen operation after reaction \\
\hline & & Sample to CRU5 \\
\hline 60 & Centrifuge wet cake & $\begin{array}{l}\text { From centrifuge operation after first of three reactions (final four } \\
\text { tests only) }\end{array}$ \\
\hline 70 & Centrifuge wet cake & $\begin{array}{l}\text { From centrifuge operation after second of three reactions (final four } \\
\text { tests only) }\end{array}$ \\
\hline 80 & Centrifuge Wet Cake & From centrifuge operation after final reaction and before rinse cycles \\
\hline 90 & Centrifuge wet cake & From centrifuge operation in first rinse cycle \\
\hline \multirow[t]{2}{*}{10} & Centrifuge Wet Cake & From centrifuge operation in second rinse cycle \\
\hline & & Treated soil product \\
\hline \multirow[t]{3}{*}{40} & Centrifuge wet cake & From centrifuge operation in second rinse cycle \\
\hline & & Treated soil product \\
\hline & & Sample to CRUS \\
\hline \multirow[t]{3}{*}{50} & Centrifuge wet cake & From centrifuge operation in second rinse cycle \\
\hline & & Treated soil product. \\
\hline & & Sample to ORNL \\
\hline $11 \mathrm{~A}$ & Centrifuge centrate & From first centrifuge opcration after reaction \\
\hline IIB & Centrifuge centrate & From second centrifuge operation after reaction \\
\hline $11 \mathrm{C}$ & Centrifuge centrate & From third centrifuge operation after reaction \\
\hline IID & Centrifuge centrate & From fourth centrifuge operation after reaction \\
\hline ME & Centrifuge centrate & From fifth centrifuge operation after reaction \\
\hline 82 & Centrifuge heel & $\begin{array}{l}\text { Composite from centrifuge operations during reaction and rinsing } \\
\text { operations }\end{array}$ \\
\hline
\end{tabular}

aUnless otherwise noted, sample was sent to the FERMCO analytical laboratory for analysis. 


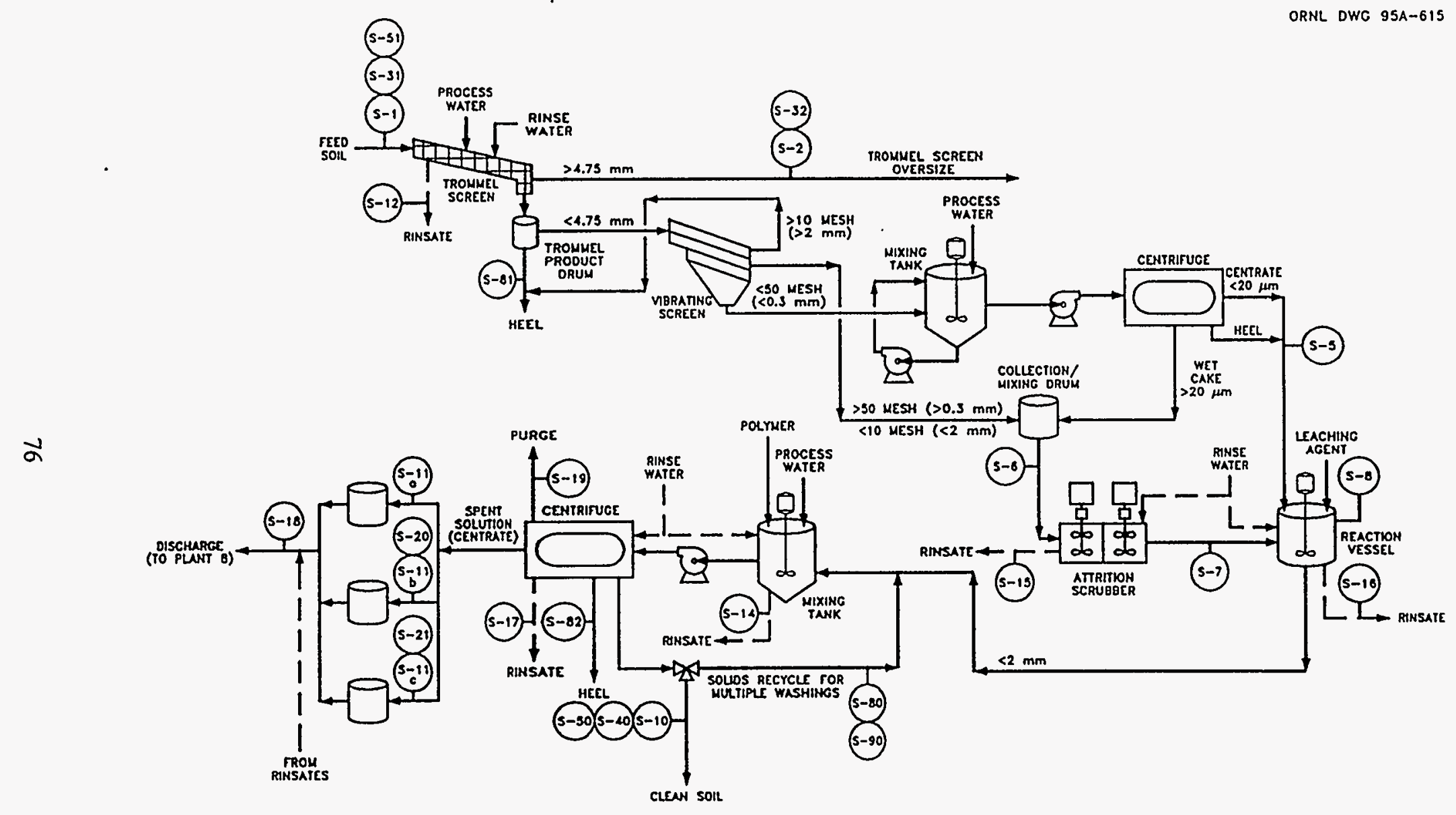

PHASE 2 SOIL WASHING SAMPLE POINTS - TEST 0 


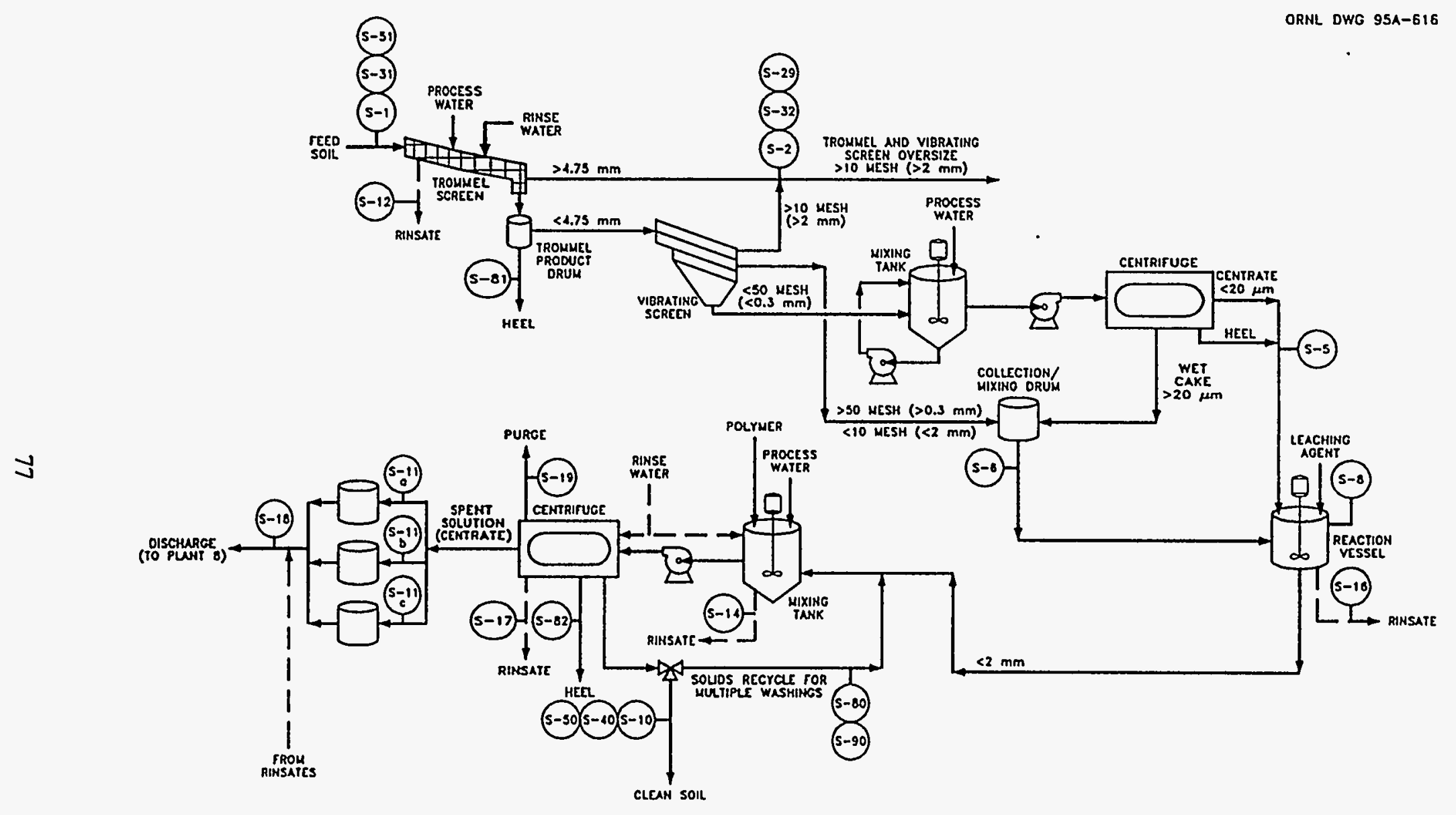

PHASE 2 SOIL WASHING SAMPLE POINTS - TEST 1 


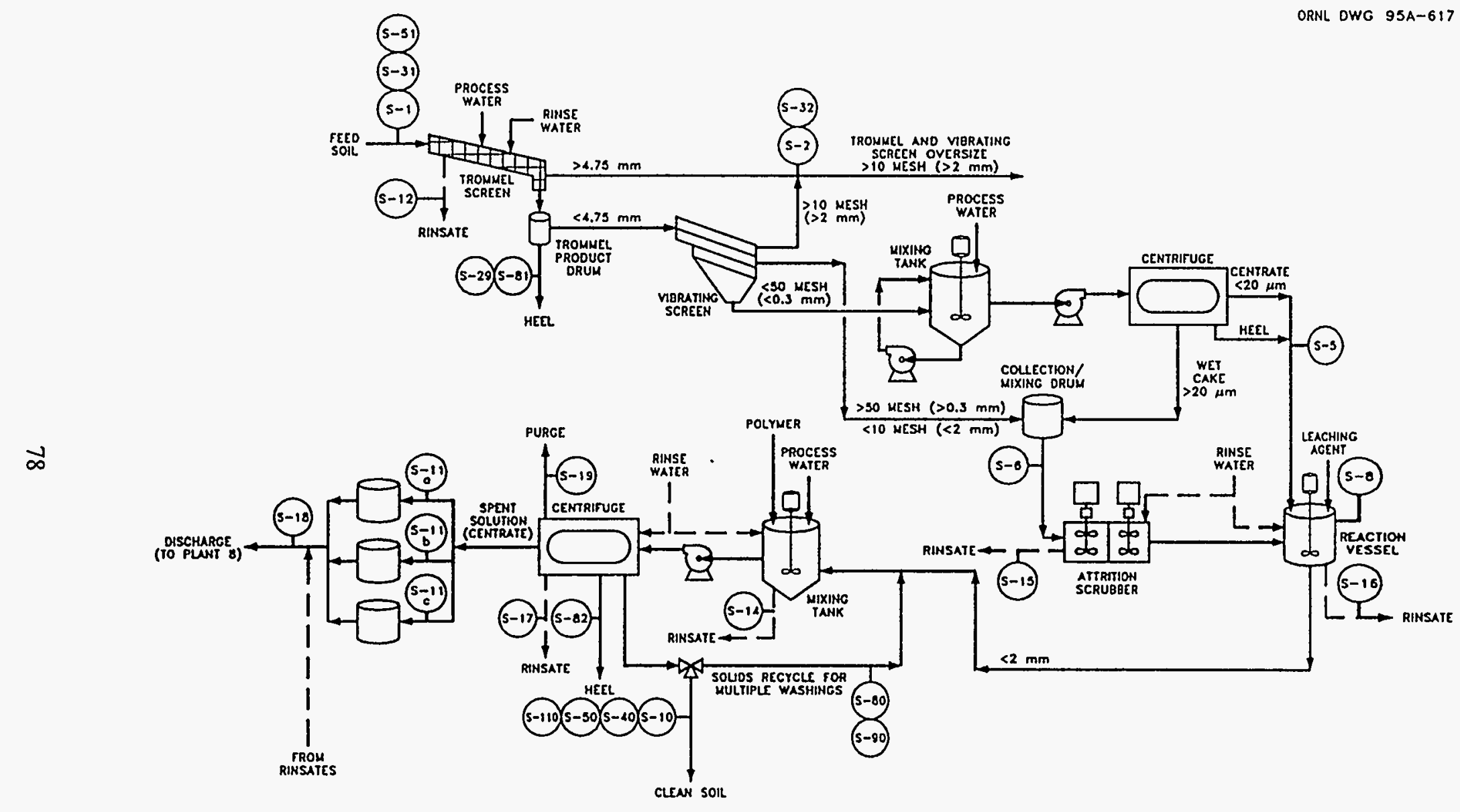

PHASE 2 SOIL WASHING SAMPLE POINTS - TEST 2 


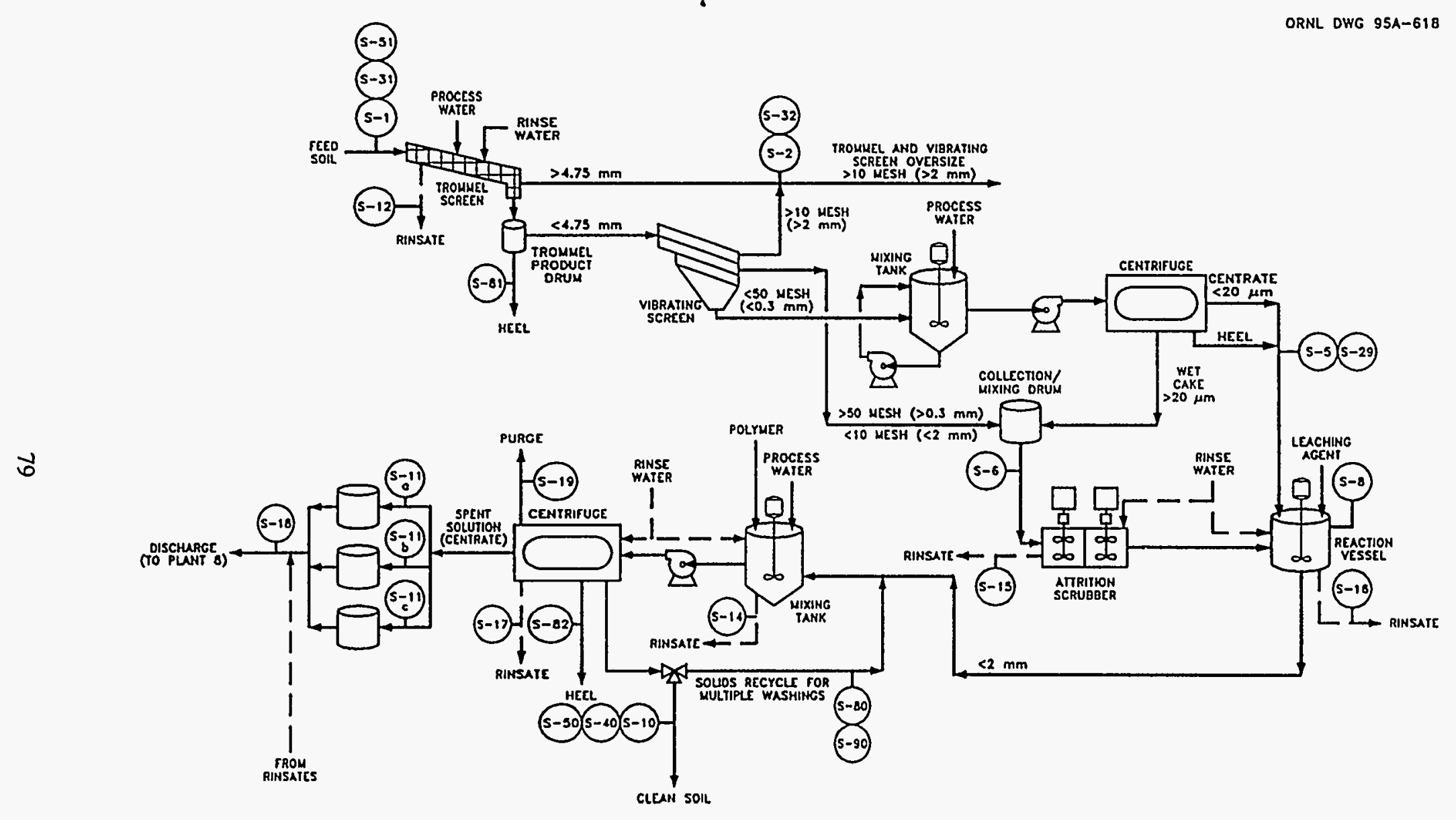

PHASE 2 SOIL WASHING SAMPLE POINTS - TEST 3 


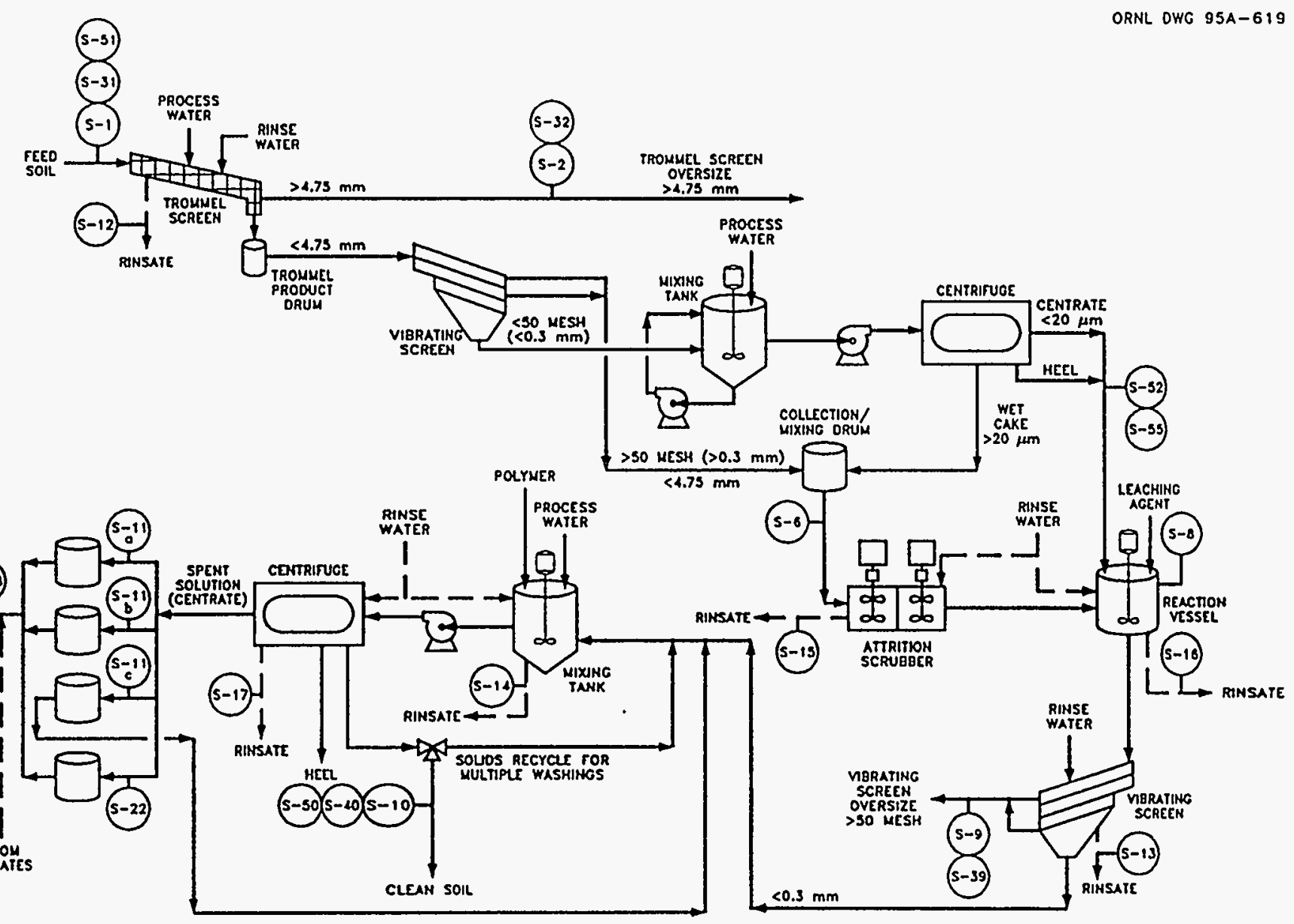

PHASE 2 SOIL WASHING SAMPLE POINTS - TEST 4 


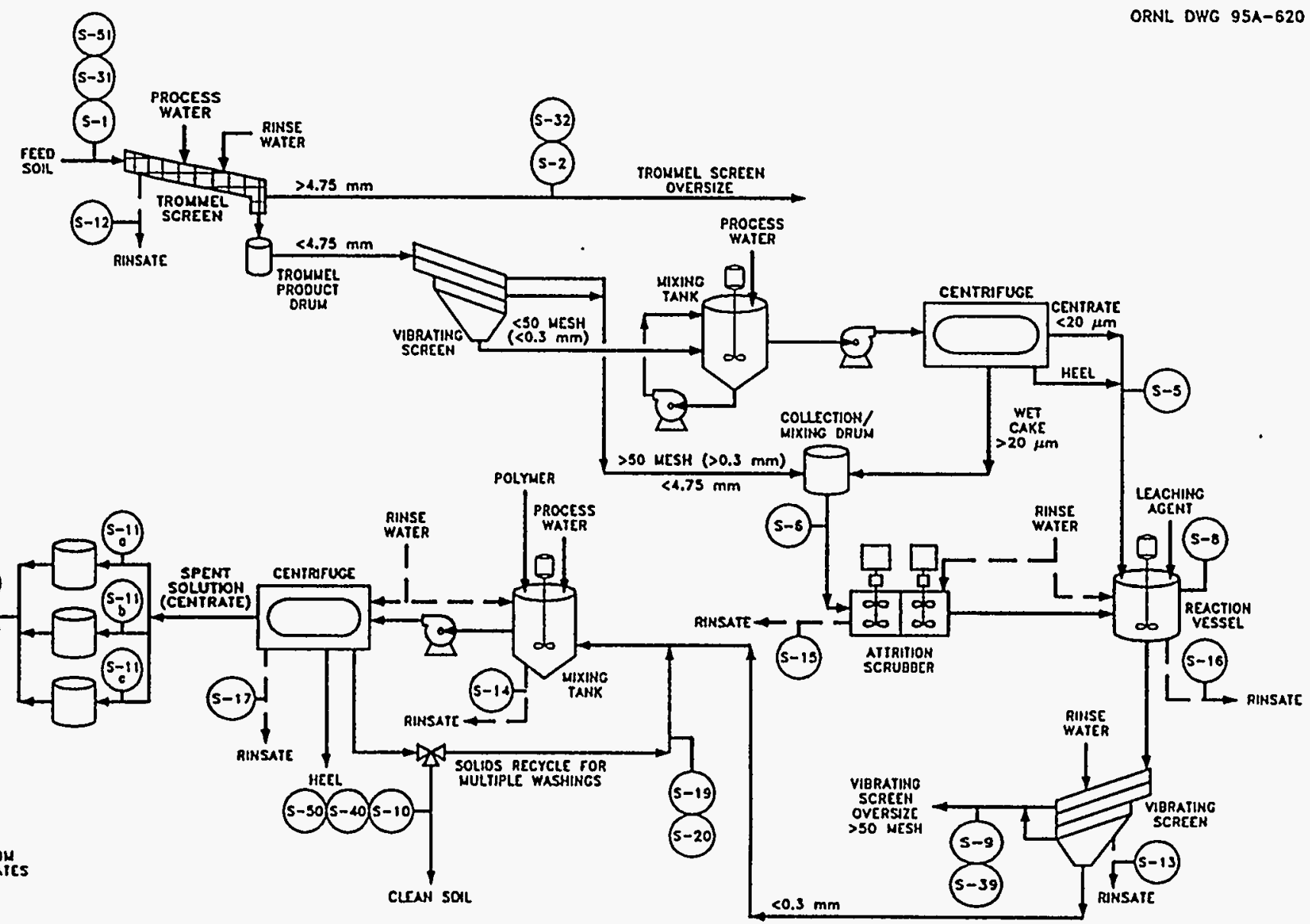

PHASE 2 SOIL WASHING SAMPLE POINTS - TEST 5 


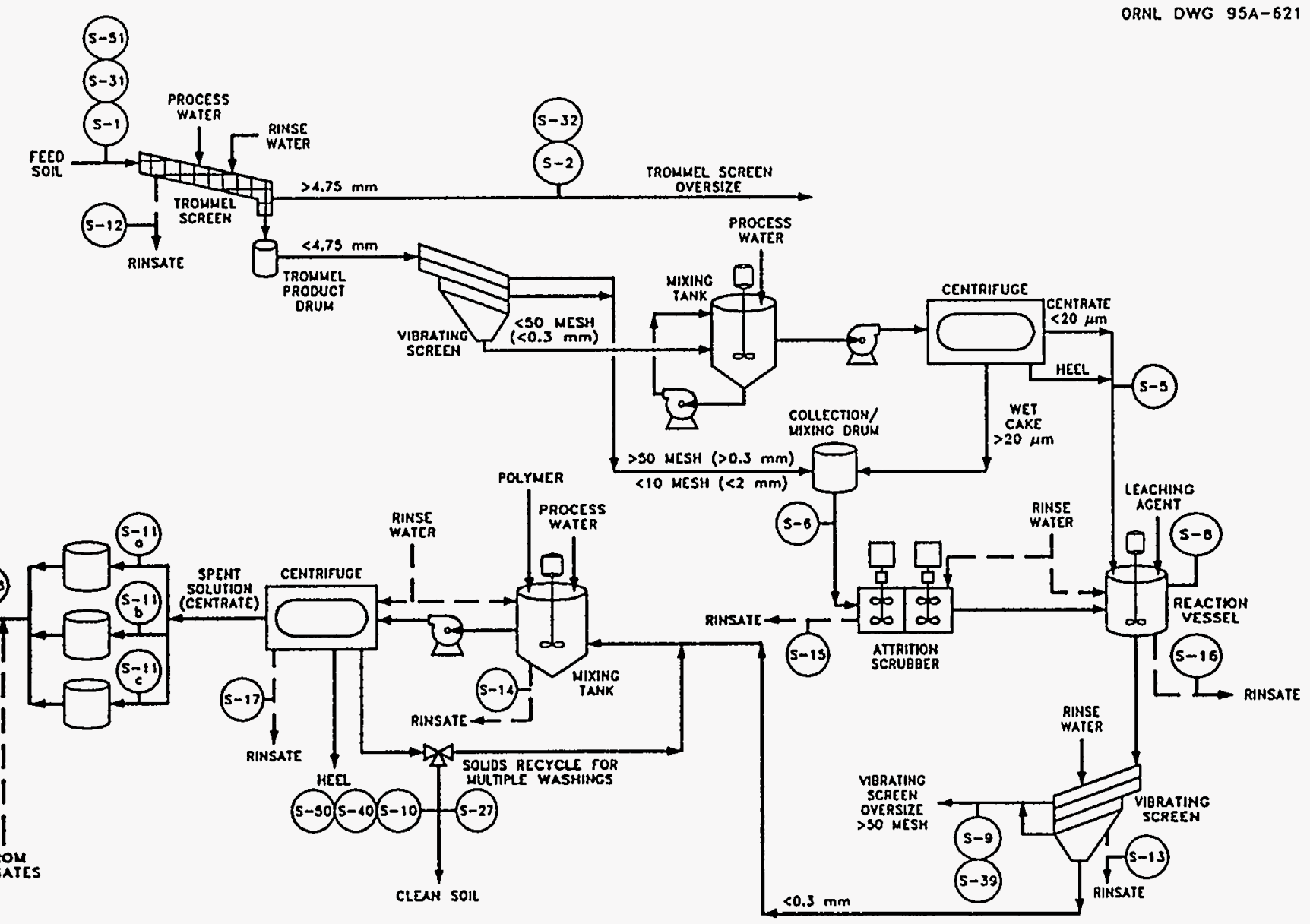

PHASE 2 SOIL WASHING SAMPLE POINTS - TEST 6 


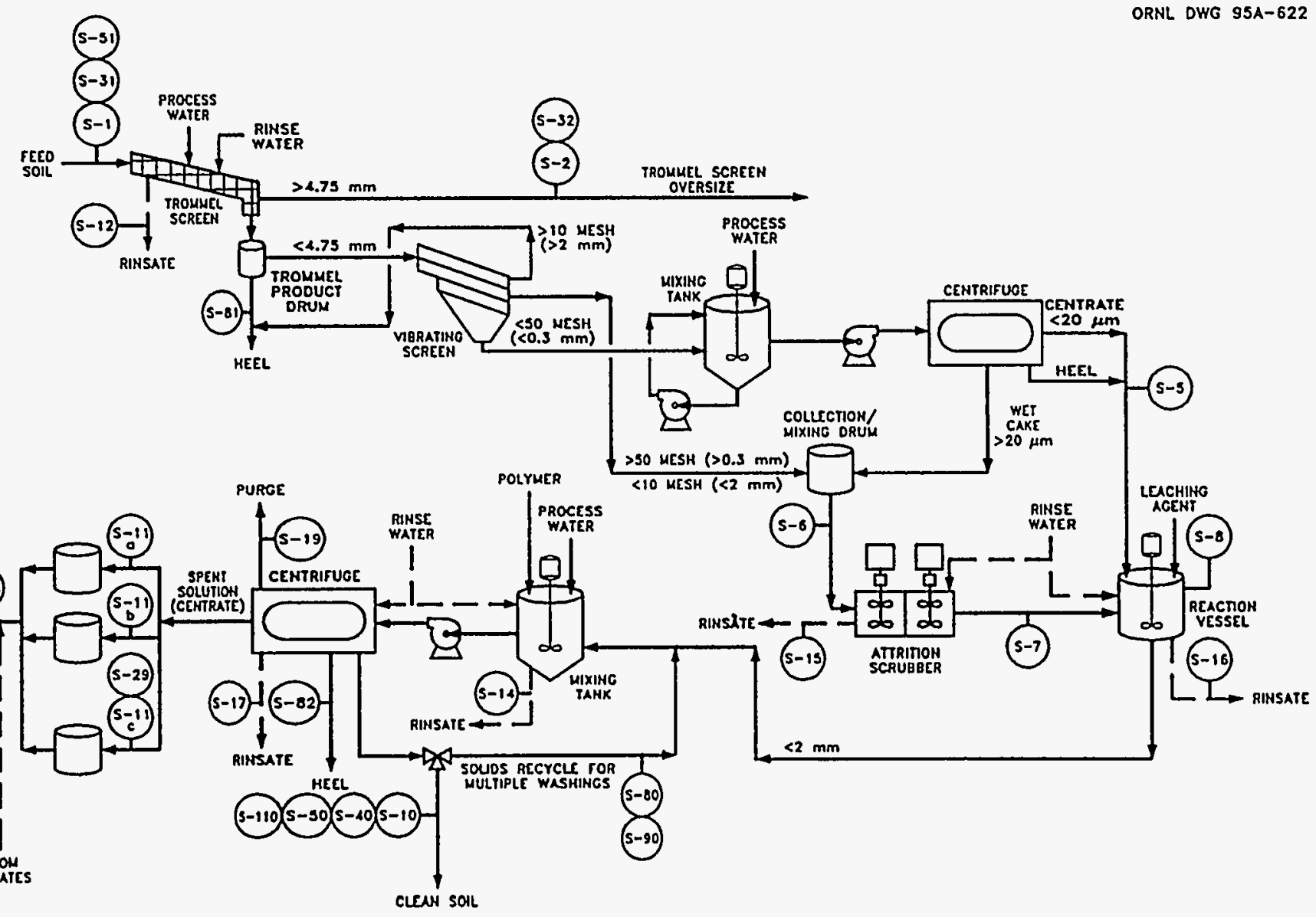

PHASE 2 SOIL WASHING SAMPLE POINTS - TEST 7 


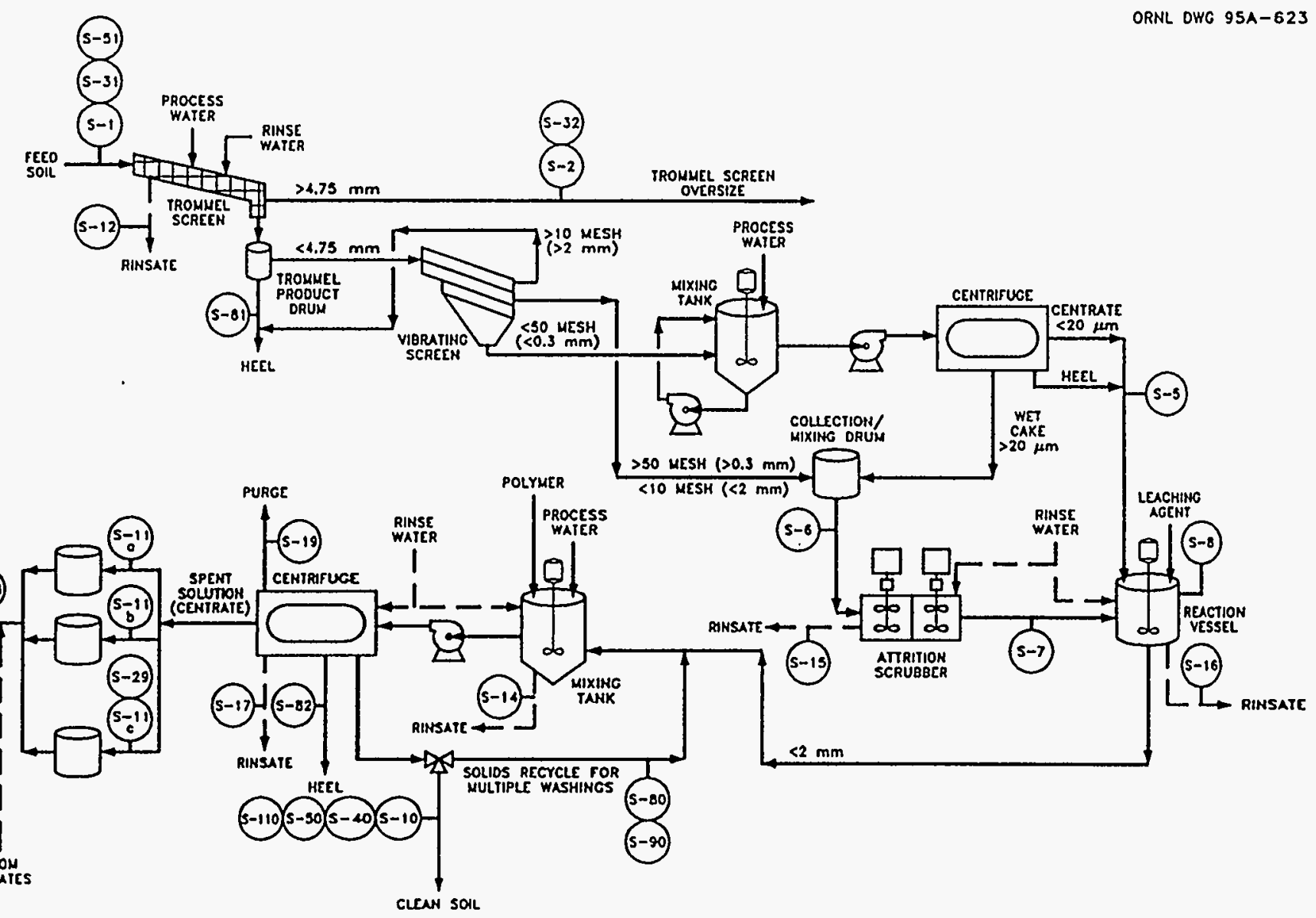

PHASE 2 SOIL WASHING SAMPLE POINTS - TEST 8 


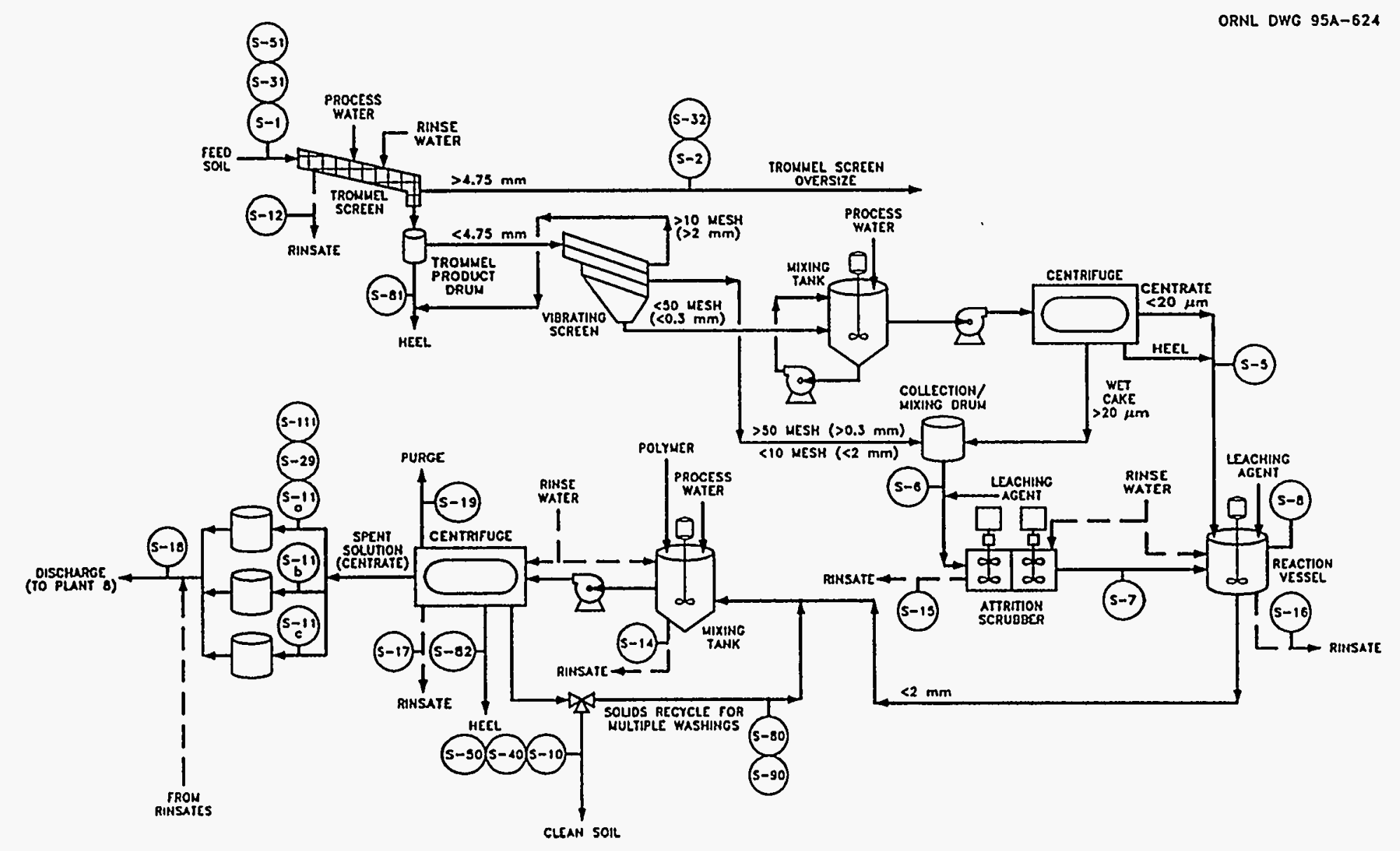

PHASE 2 SOIL WASHING SAMPLE POINTS - TEST 13 


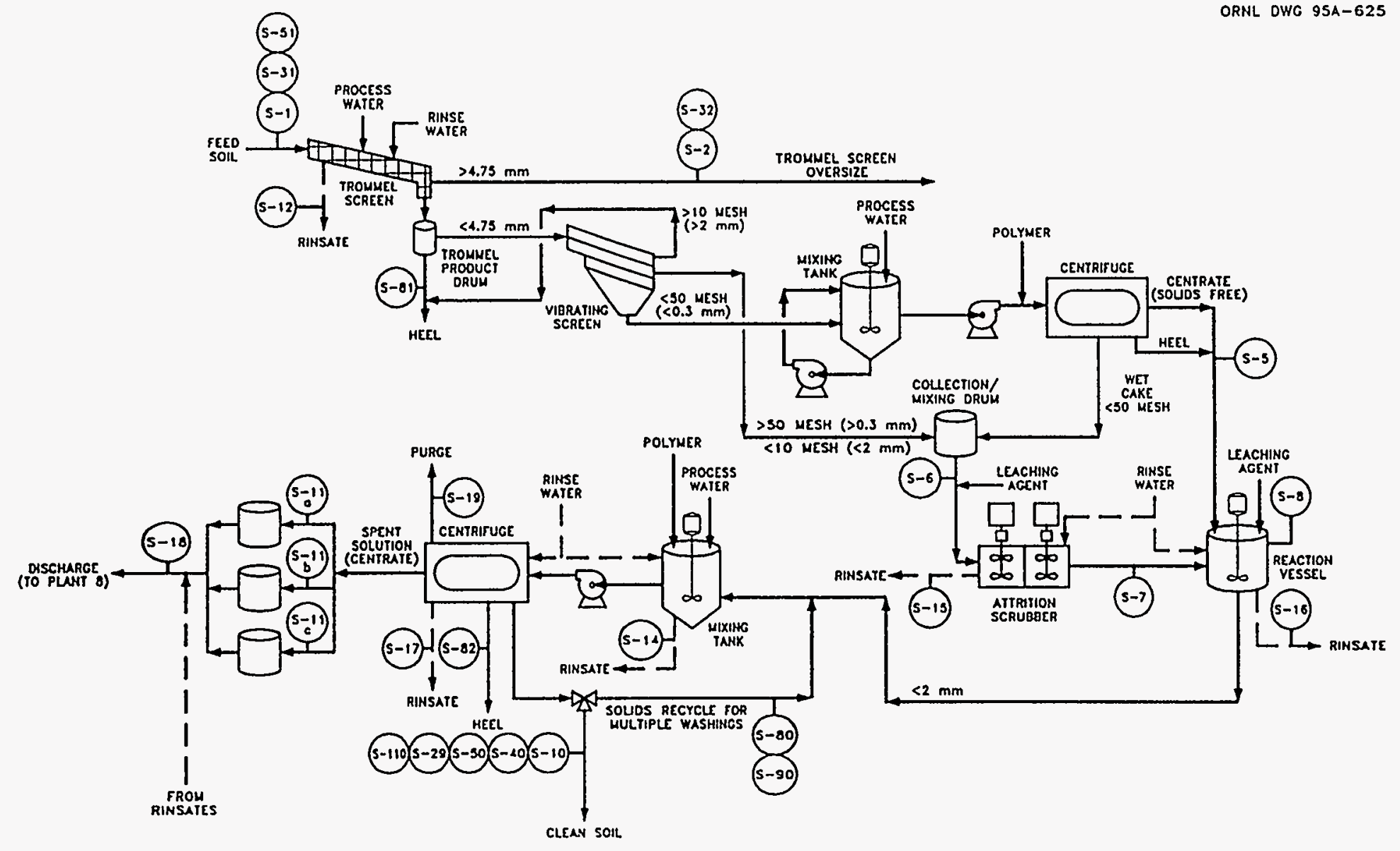

ORNL DWG 95A-625

$\stackrel{\infty}{\circ}$

PHASE 2 SOIL WASHING SAMPLE POINTS - TEST 14 


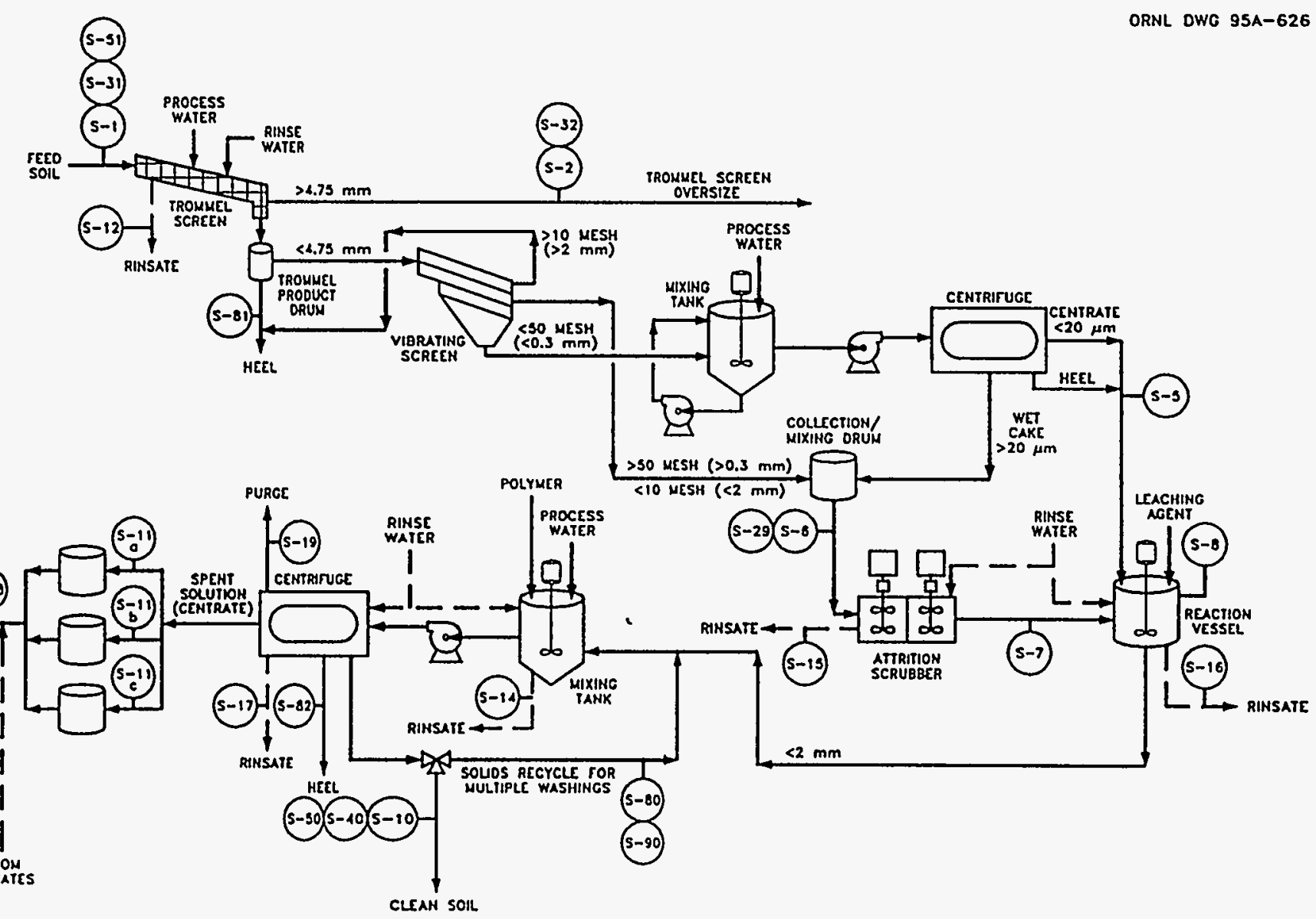

PHASE 2 SOIL WASHING SAMPLE POINTS - TEST 15 


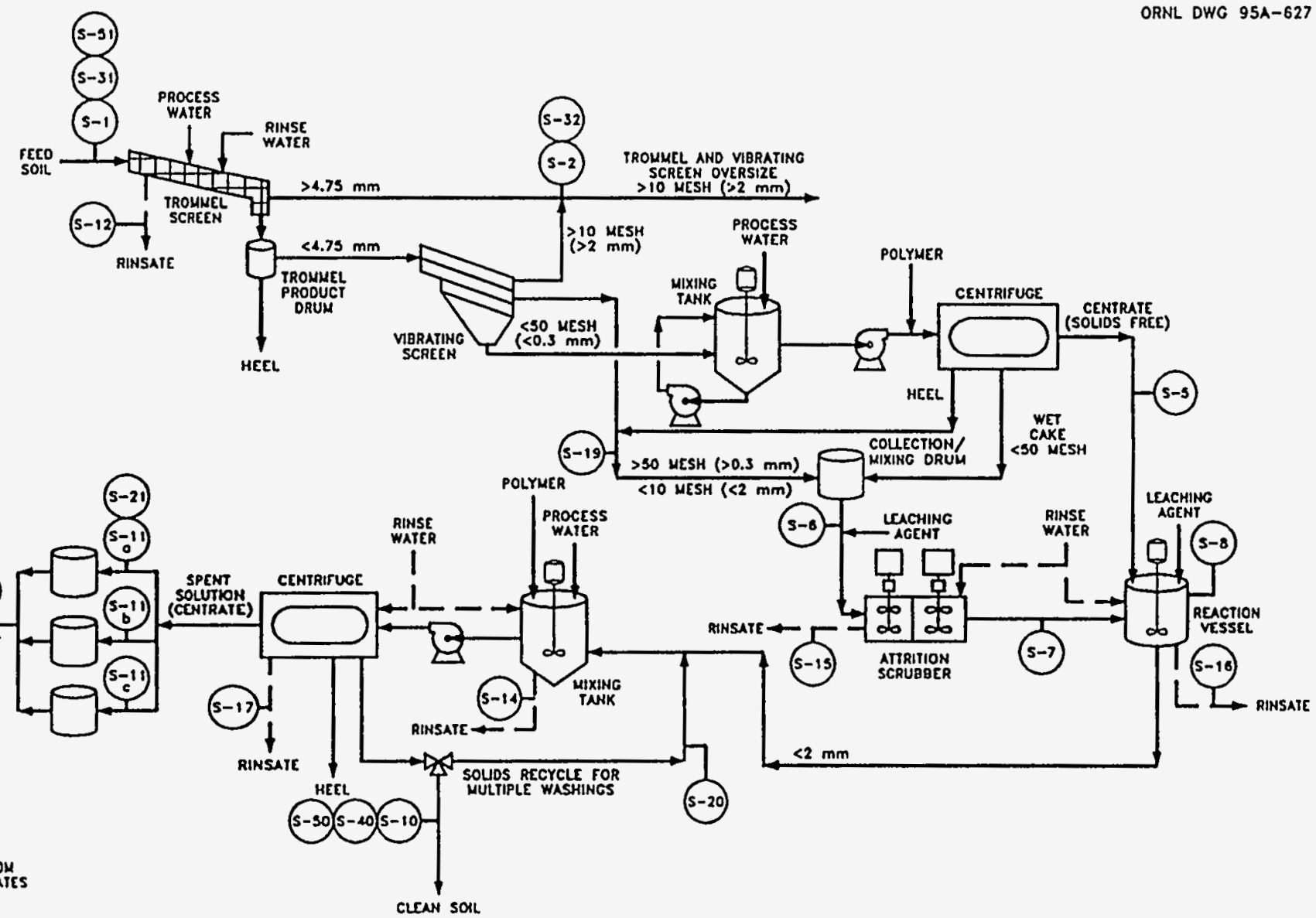

PHASE 2 SOIL WASHING SAMPLE POINTS - TEST 16 


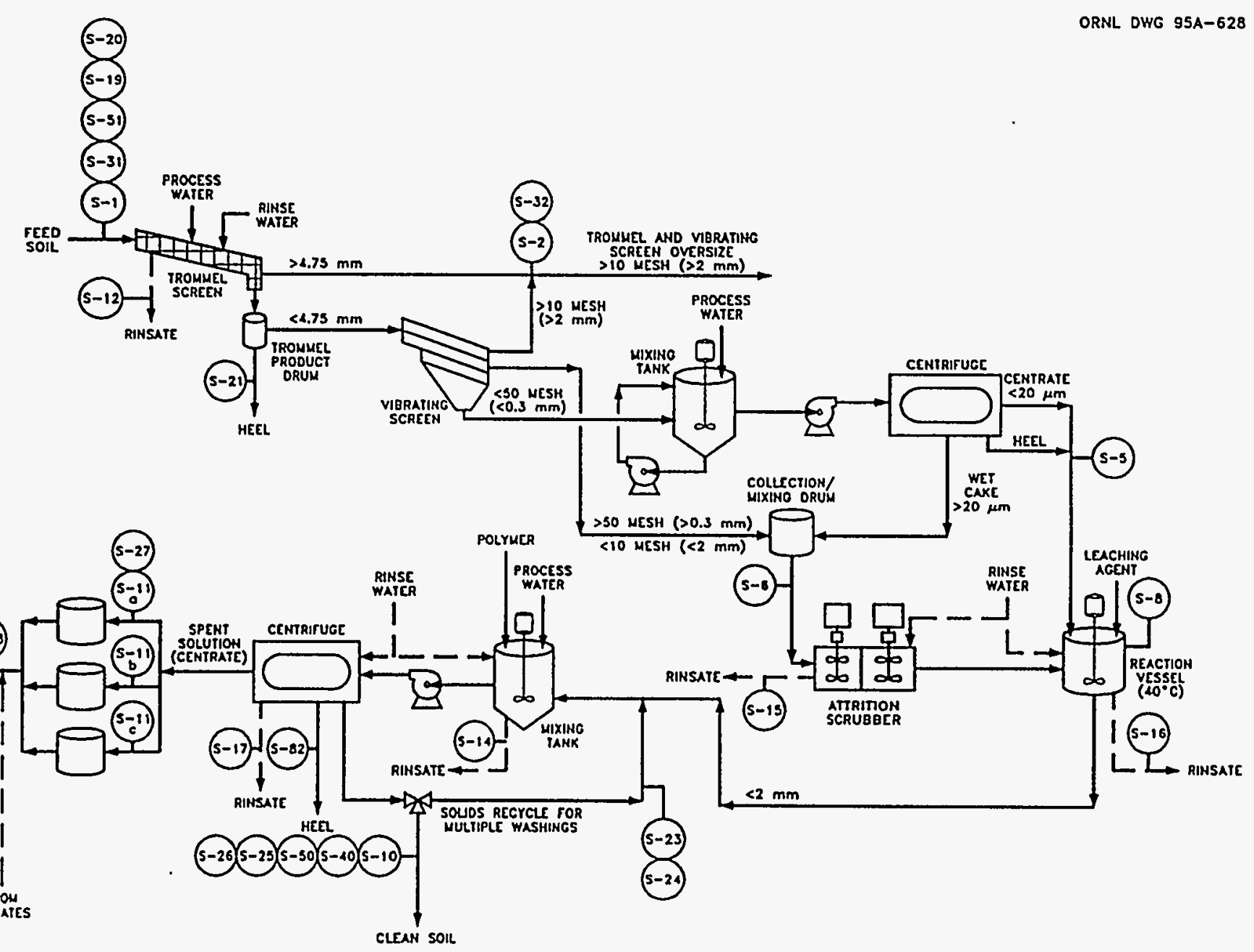

PHASE 2 SOIL WASHING SAMPLE POINTS - TEST 17 


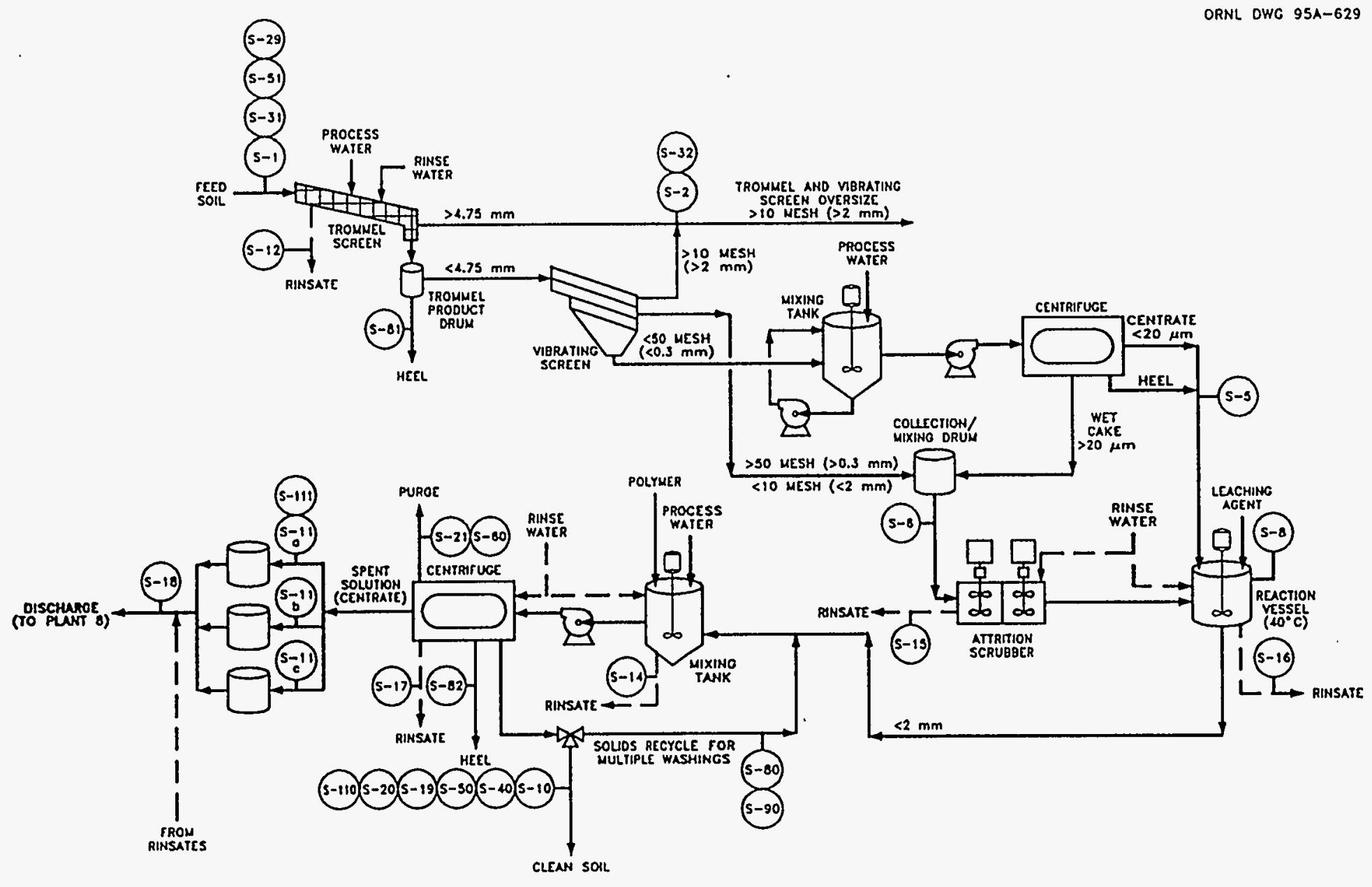

PHASE 2 SOIL WASHING SAMPLE POINTS - TEST 18 


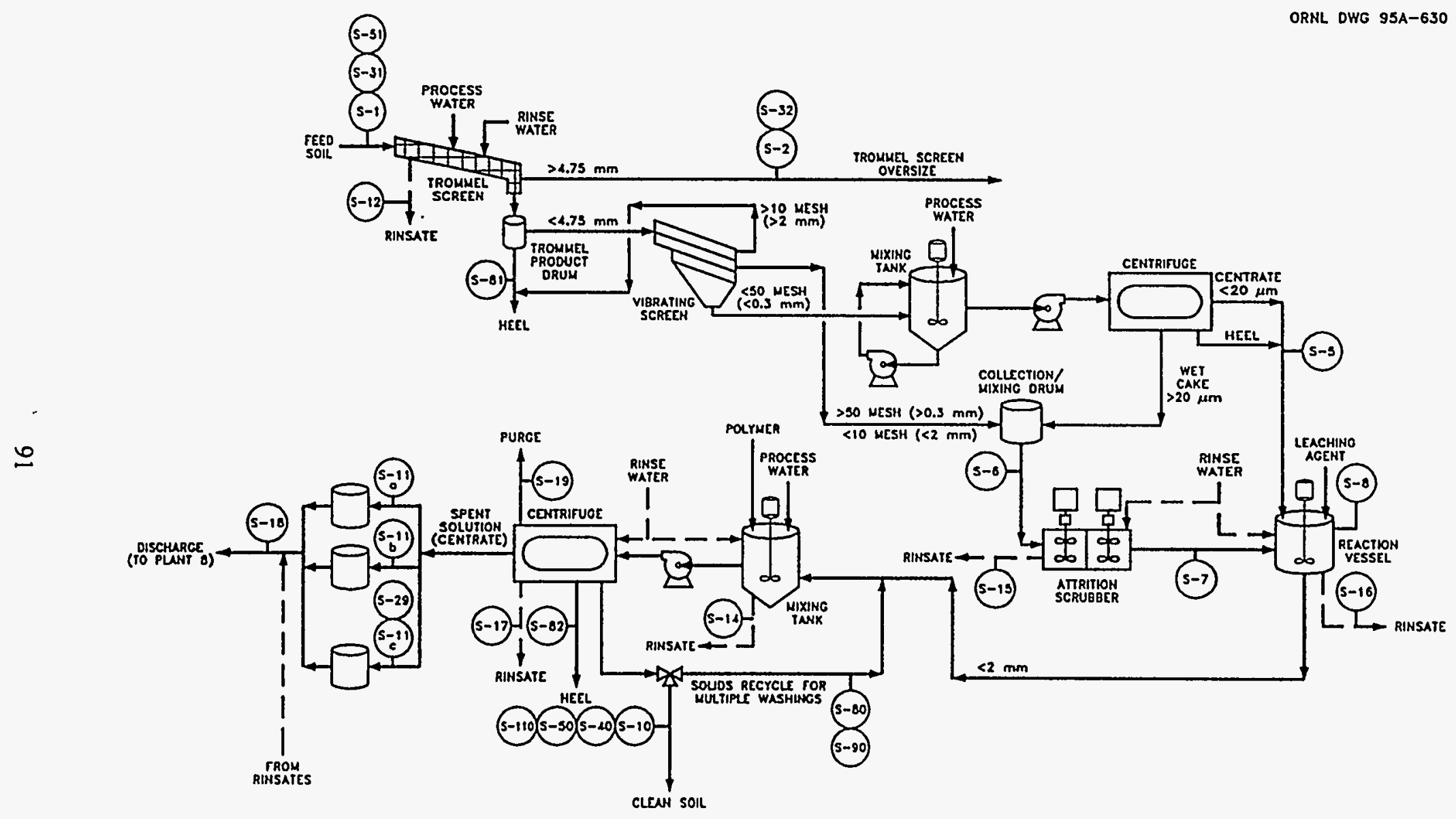

PHASE 2 SOIL WASHING SAMPLE POINTS - TEST 19 

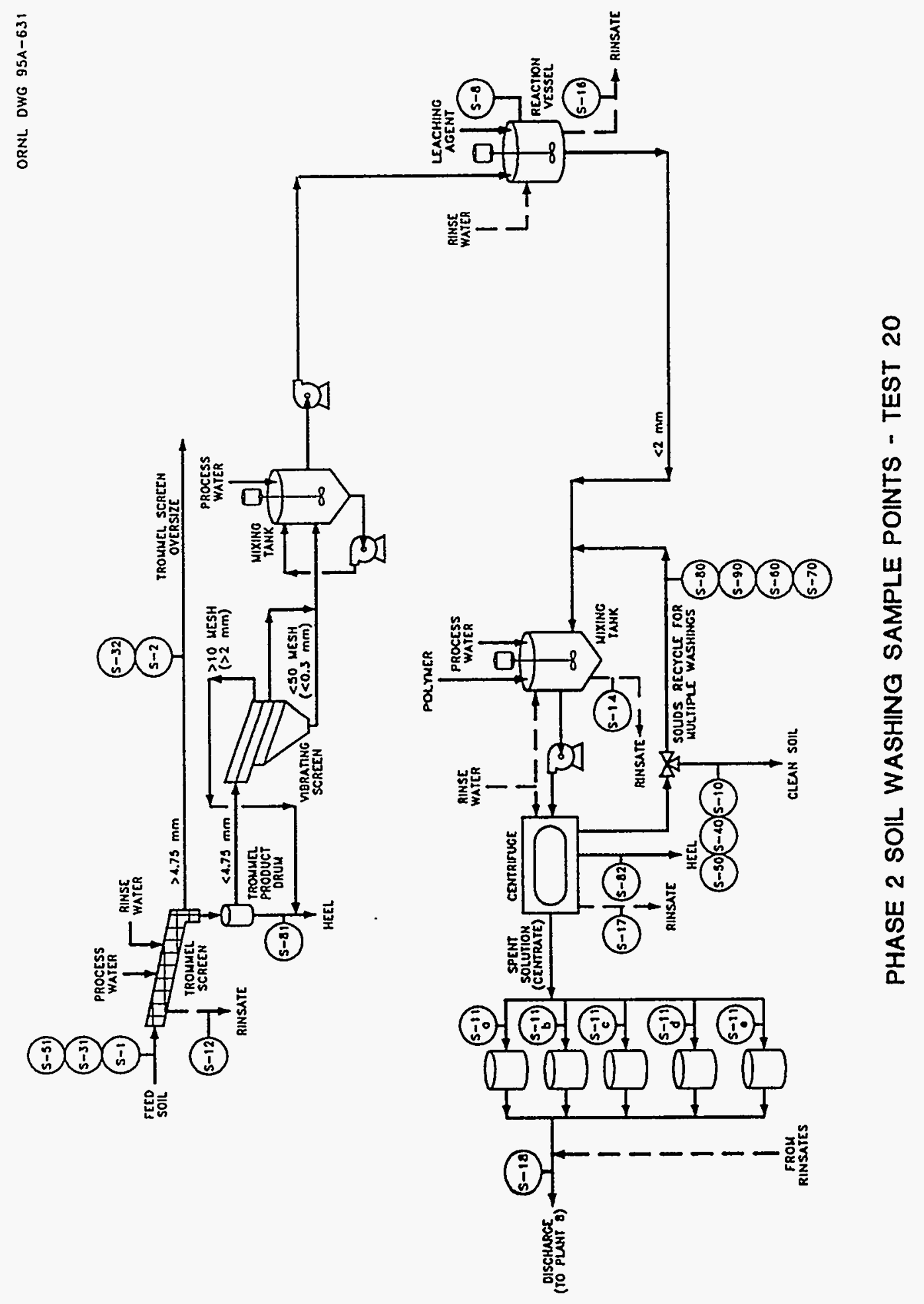


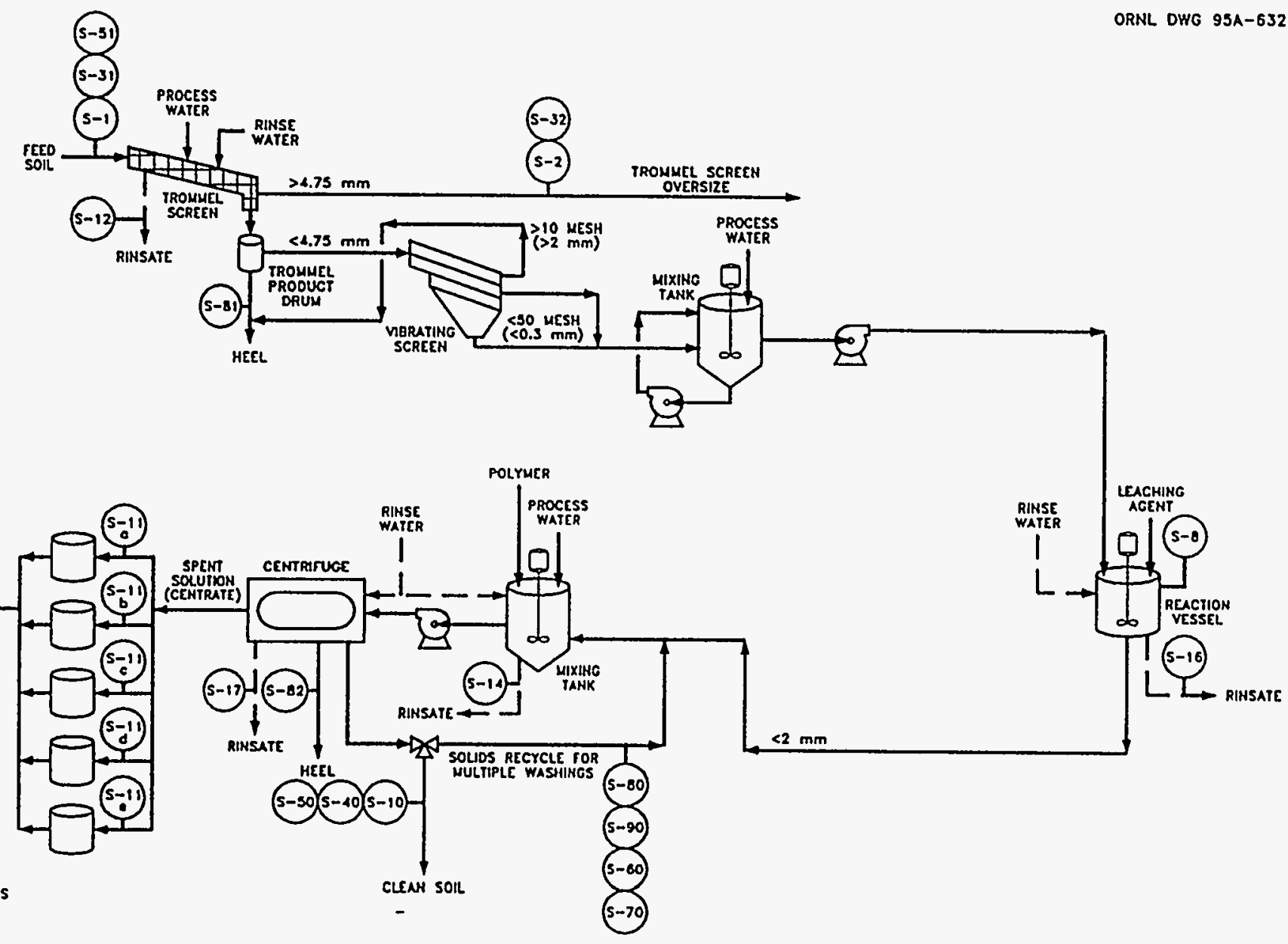

PHASE 2 SOIL WASHING SAMPLE POINTS - TEST 21 


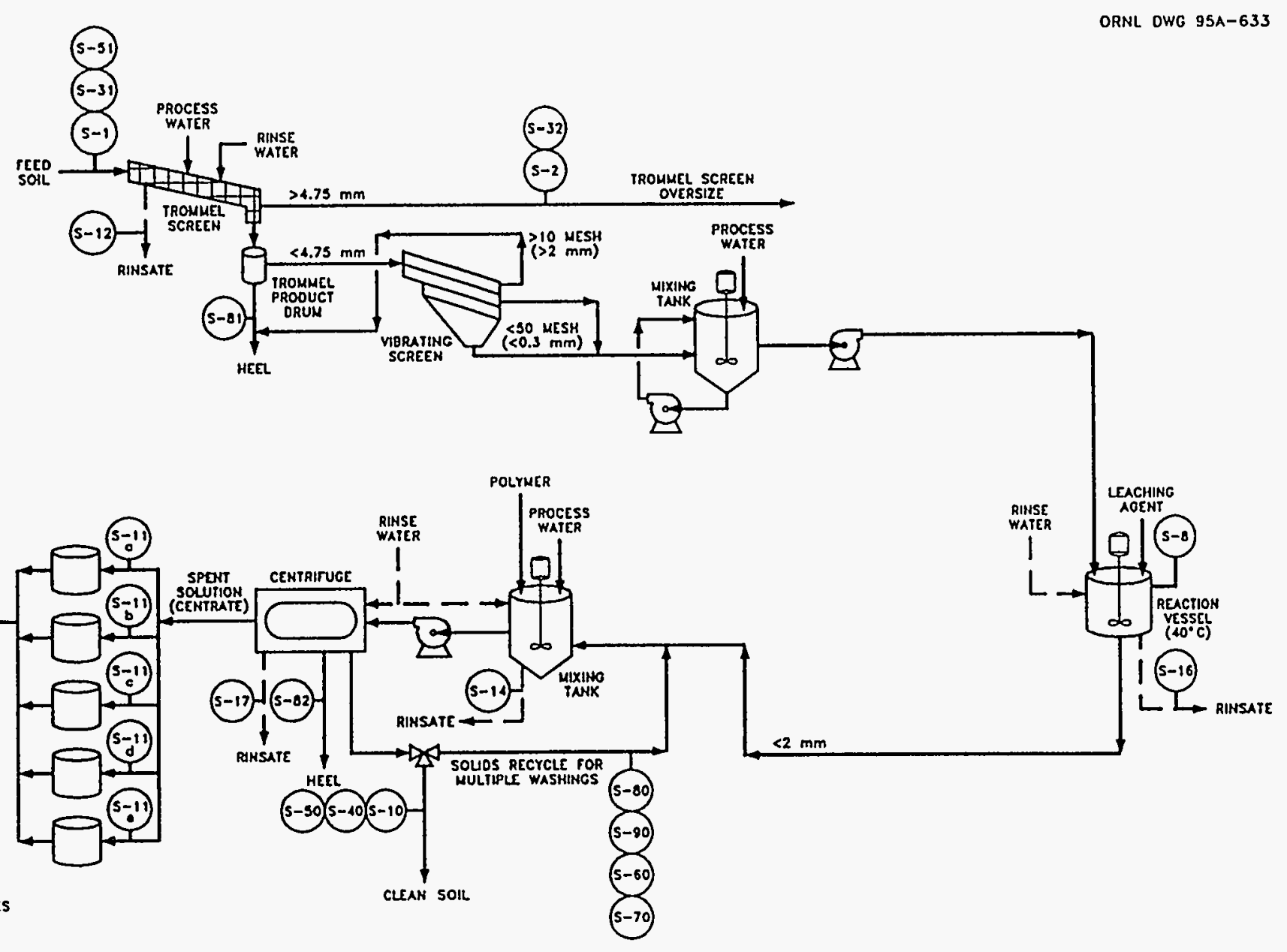

PHASE 2 SOIL WASHING SAMPLE POINTS - TEST 22 


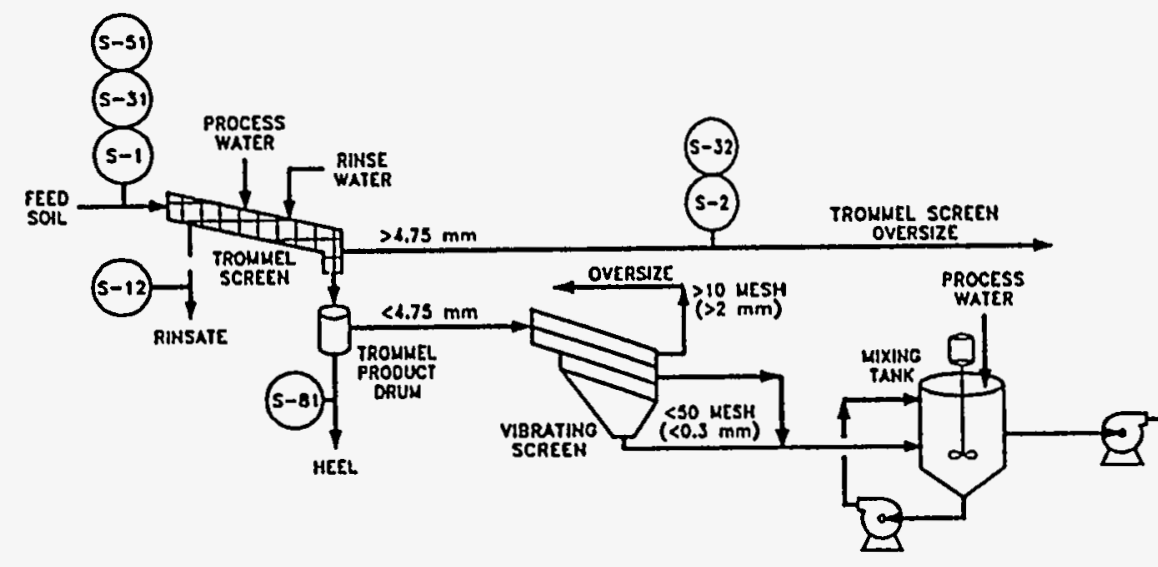

ORNL DWG 95A-634

象

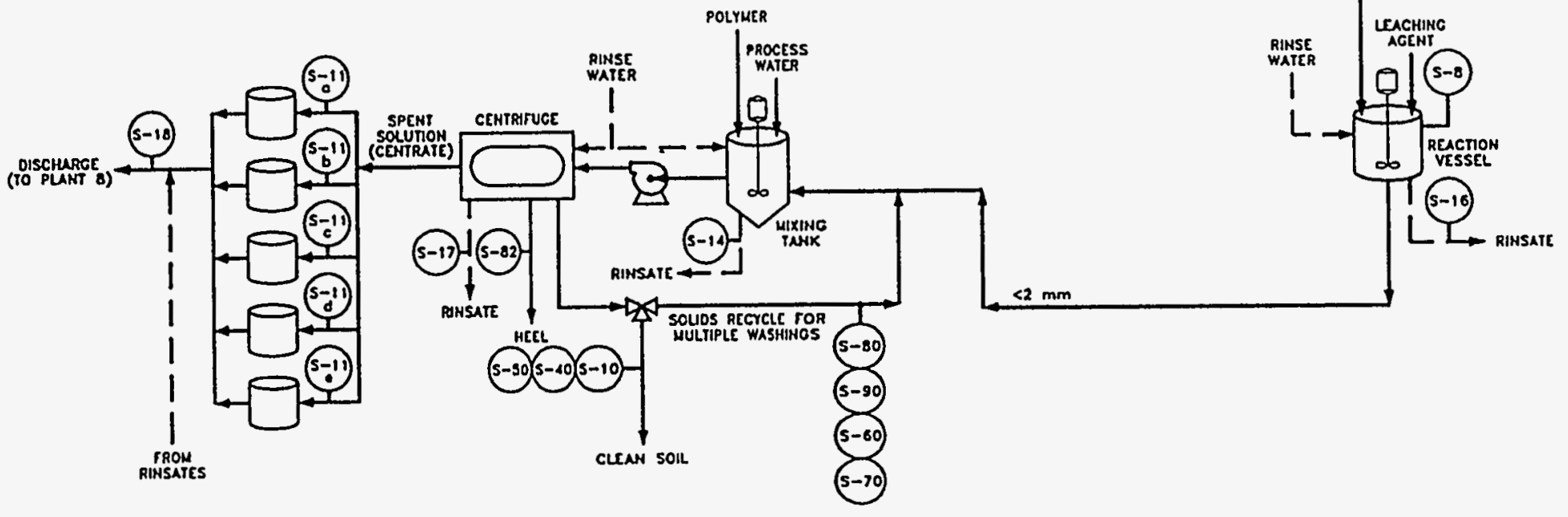

PHASE 2 SOIL WASHING SAMPLE POINTS - TEST 25 
APPENDIX B

PROCESS FLOW SHEETS 



\section{APPENDIX B}

\section{PROCESS DATA}

Appendix B summarizes the process data taken during the Phase II tests. Data sheets for each test are presented that tabulate the weights and volumes of feed and product streams, as well as intermediate streams and samples. The data sheets are arranged in the order in which the tests were run. 
Test No.

\section{PHASE II SOIL WASHING PILOT PLANT / PROCESS DATA}

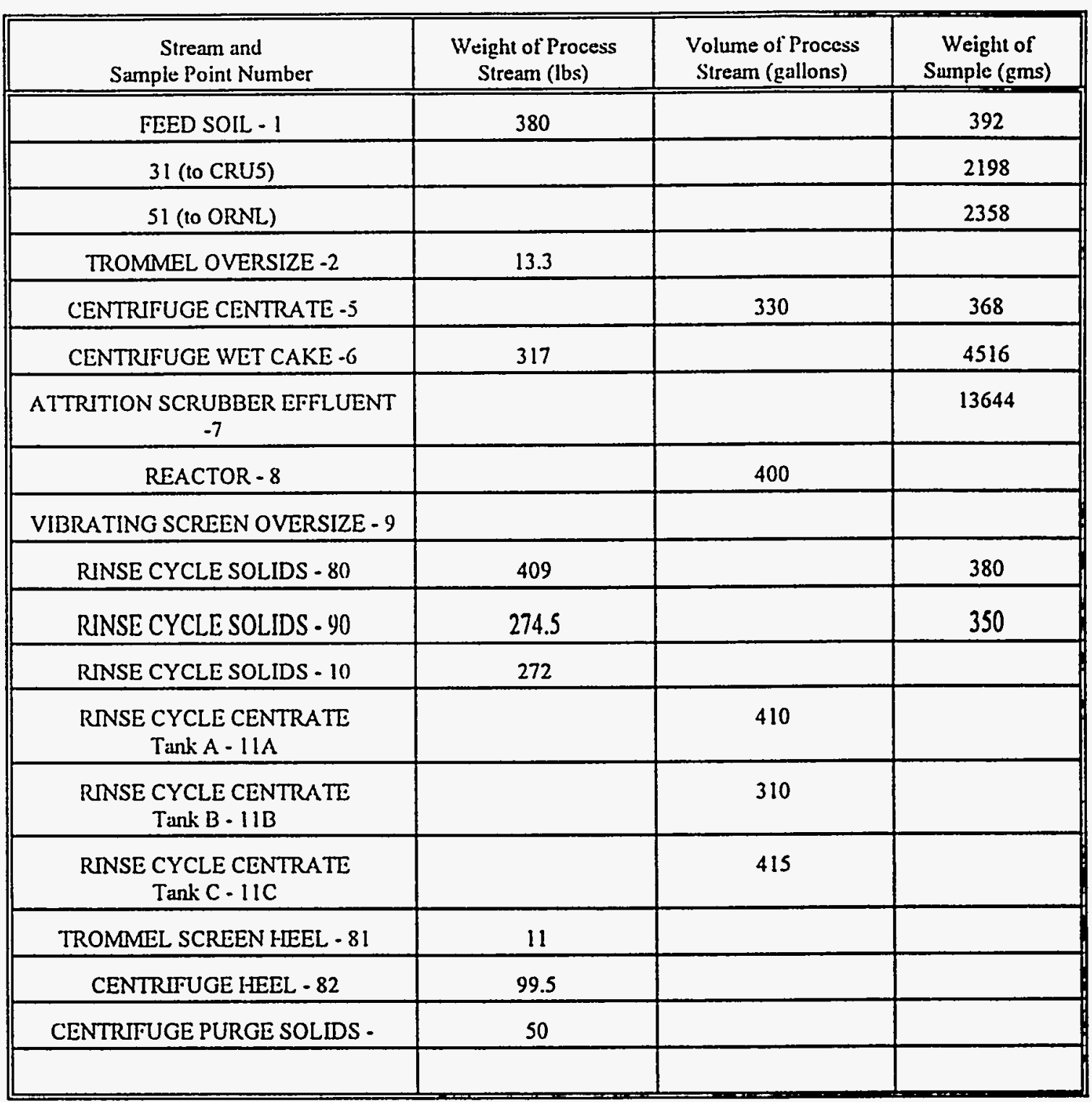


Test No. 0

PHASE II SOIL WASHING PILOT PLANT / PROCESS DATA

\begin{tabular}{|c|c|c|}
\hline Sample Number & Description & $\begin{array}{c}\text { Sample Weight } \\
\text { (gms) }\end{array}$ \\
\hline \hline 19 & Centrifuge Purge & 384 \\
\hline 20 & Centrate for Argonne (S-1 IB) & \\
\hline 21 & Centrate for Argonne (S-11C) & \\
\hline 22 & & \\
\hline 23 & & \\
\hline 24 & & \\
\hline 25 & & \\
\hline 26 & & \\
\hline 27 & & \\
\hline 28 & & \\
\hline 29 & & \\
\hline
\end{tabular}

\begin{tabular}{|c|c|c|c|c|c|c|}
\hline $\begin{array}{c}\text { Field Wt of Reactor } \\
\text { Samples (gms) }\end{array}$ & $\begin{array}{l}\text { Reaction } \\
\text { Time }=0\end{array}$ & $\begin{array}{c}5 \\
\text { minutes }\end{array}$ & $\begin{array}{c}15 \\
\text { minutes }\end{array}$ & $\begin{array}{c}30 \\
\text { minutes }\end{array}$ & $\begin{array}{c}60 \\
\text { minutes }\end{array}$ & $\begin{array}{c}120 \\
\text { minutes }\end{array}$ \\
\hline \multicolumn{7}{|l|}{ Test 0} \\
\hline Tests $1-19$ & 2690 & 1152 & & 1032 & 980 & 2072 \\
\hline
\end{tabular}


Test No._.1

PHASE II SOIL WASHING PILOT PLANT / PROCESS DATA

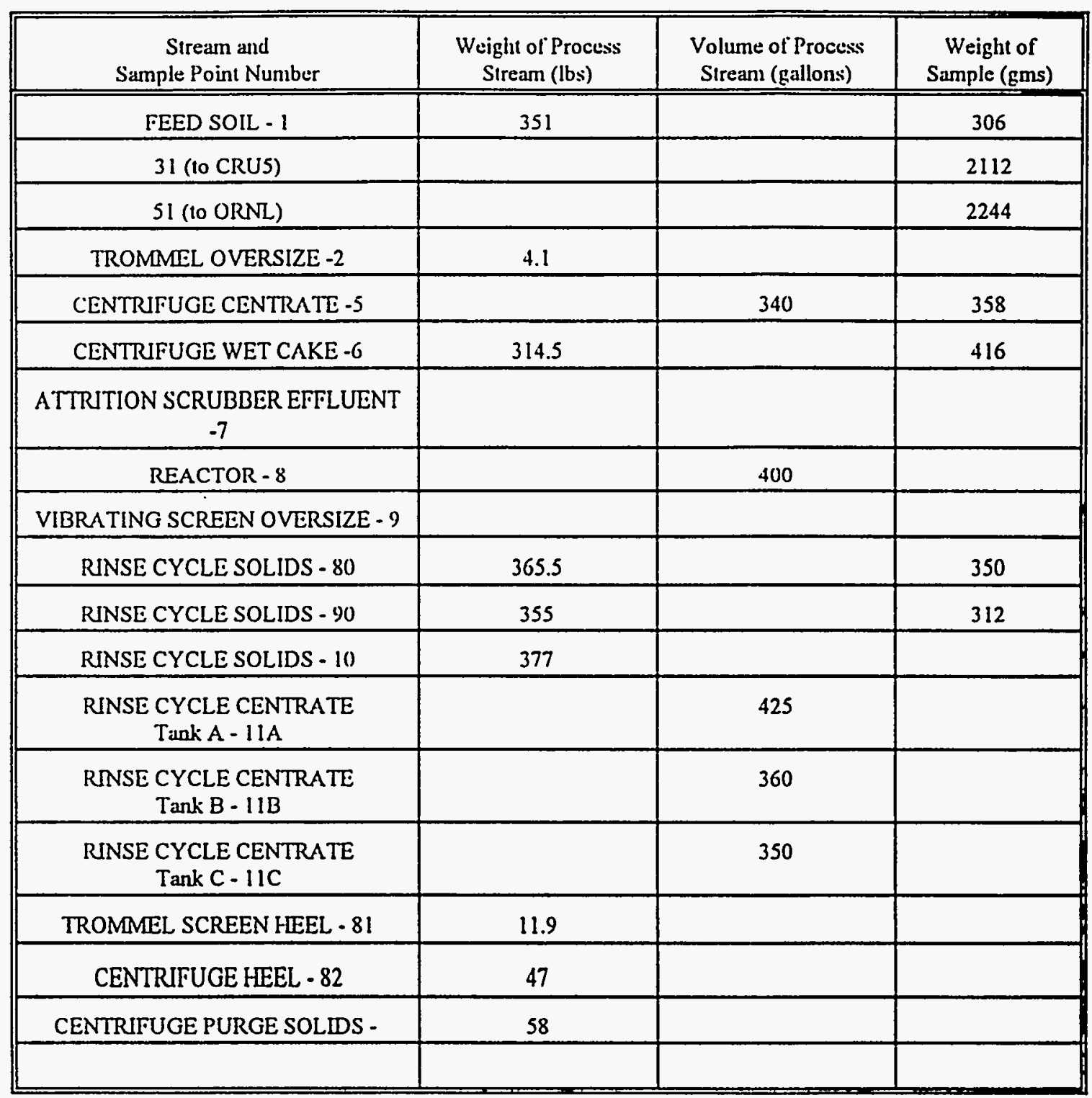


Test No.

PHASE II SOIL WASHING PILOT PLANT / PROCESS DATA

\begin{tabular}{||c|c|c||}
\hline Sample Number & Description & $\begin{array}{c}\text { Sample Weight } \\
\text { (gms) }\end{array}$ \\
\hline 19 & Centrifuge Purge Solids & \\
\hline 20 & & \\
\hline 21 & & \\
\hline 22 & & \\
\hline 23 & & \\
\hline 24 & & \\
\hline 25 & & \\
\hline 26 & Reactor Slurry (8ZS) & \\
\hline 27 & & \\
\hline 28 & & \\
\hline 29 & & \\
\hline 108 & & \\
\hline
\end{tabular}

\begin{tabular}{|c|c|c|c|c|c|c|}
\hline $\begin{array}{l}\text { Ficld Wt of Reactor } \\
\text { Samples (gms) }\end{array}$ & $\begin{array}{l}\text { Reaction } \\
\text { Time }=0\end{array}$ & $\begin{array}{c}5 \\
\text { minutes }\end{array}$ & $\begin{array}{l}15 \\
\text { minutes }\end{array}$ & $\begin{array}{c}30 \\
\text { minutes }\end{array}$ & $\begin{array}{c}60 \\
\text { minutes }\end{array}$ & $\begin{array}{l}120 \\
\text { minutes }\end{array}$ \\
\hline \multicolumn{7}{|l|}{ Test 0} \\
\hline Tests 1-19 & 1780 & 628 & 632 & 524 & 604 & 470 \\
\hline
\end{tabular}


Test No. 2

PHASE II SOIL WASHING PILOT PLANT / PROCESS DATA

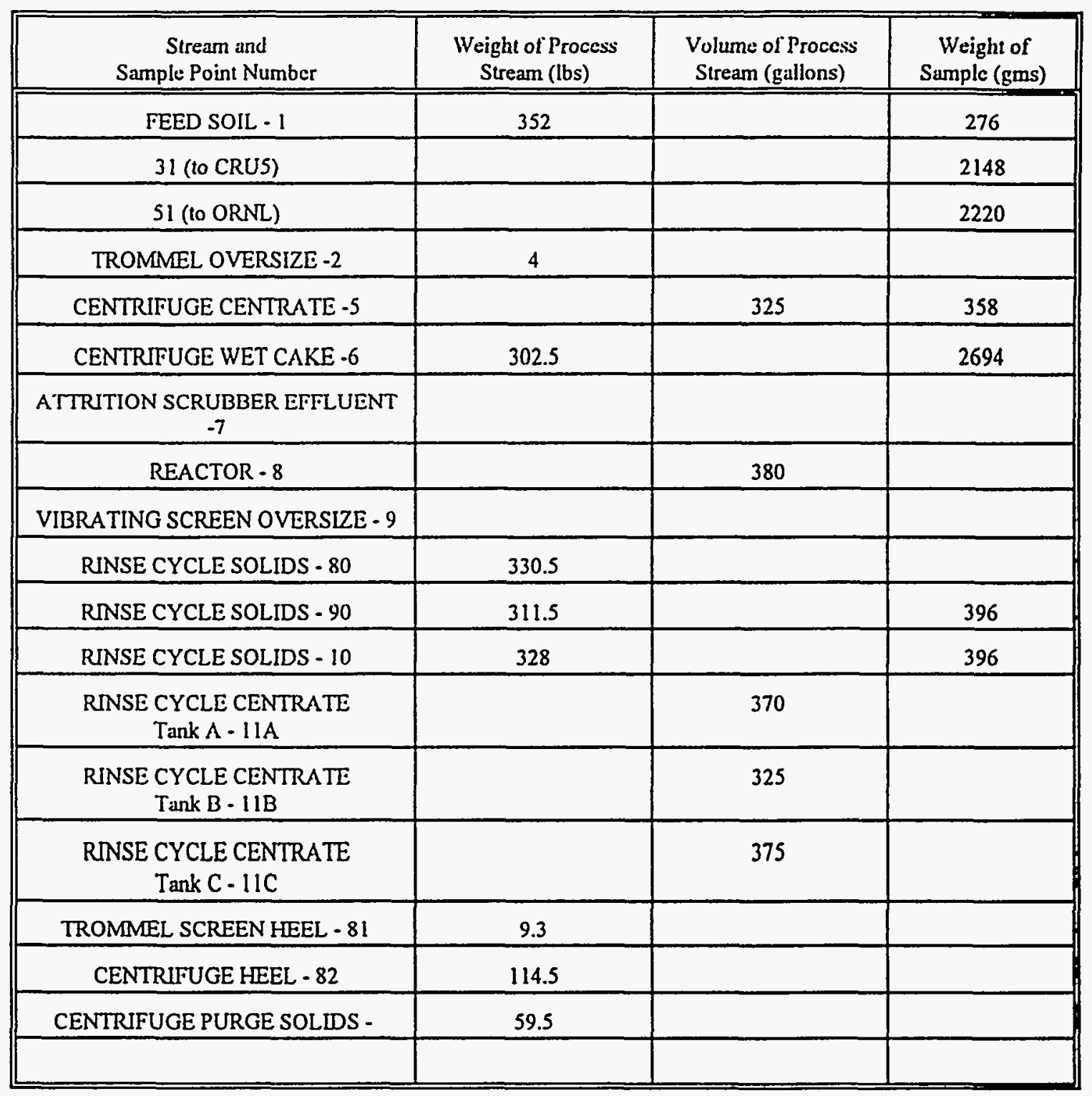


Test No._ 2

PHASE II SOIL WASHING PILOT PLANT / PROCESS DATA

\begin{tabular}{||c|c|c|}
\hline Sample Number & Description & $\begin{array}{c}\text { Sample Weight } \\
\text { (gms) }\end{array}$ \\
\hline 19 & Centriluge Purge & 364 \\
\hline 20 & & \\
\hline 21 & & \\
\hline 22 & & \\
\hline 23 & & \\
\hline 24 & & \\
\hline 25 & & \\
\hline 26 & & \\
\hline 27 & & 384 \\
\hline 28 & Trommel Heel Replicale & \\
\hline 29 & Treated Soil Replicate (S-10) & \\
\hline 110 & & \\
\hline
\end{tabular}

\begin{tabular}{|c|c|c|c|c|c|c|}
\hline $\begin{array}{l}\text { Field Wt of Reactor } \\
\text { Samples (gms) }\end{array}$ & $\begin{array}{l}\text { Reaction } \\
\text { Time }=0\end{array}$ & $\begin{array}{c}5 \\
\text { minutes }\end{array}$ & $\begin{array}{c}15 \\
\text { minutes }\end{array}$ & $\begin{array}{c}30 \\
\text { minutes }\end{array}$ & $\begin{array}{c}60 \\
\text { minutes }\end{array}$ & $\begin{array}{c}120 \\
\text { minutes }\end{array}$ \\
\hline \multicolumn{7}{|l|}{ Test 0} \\
\hline Tests $1-19$ & 948 & 534 & 608 & 558 & 627 & 780 \\
\hline
\end{tabular}


Test No. 3

PHASE II SOIL WASHING PILOT PLANT / PROCESS DATA

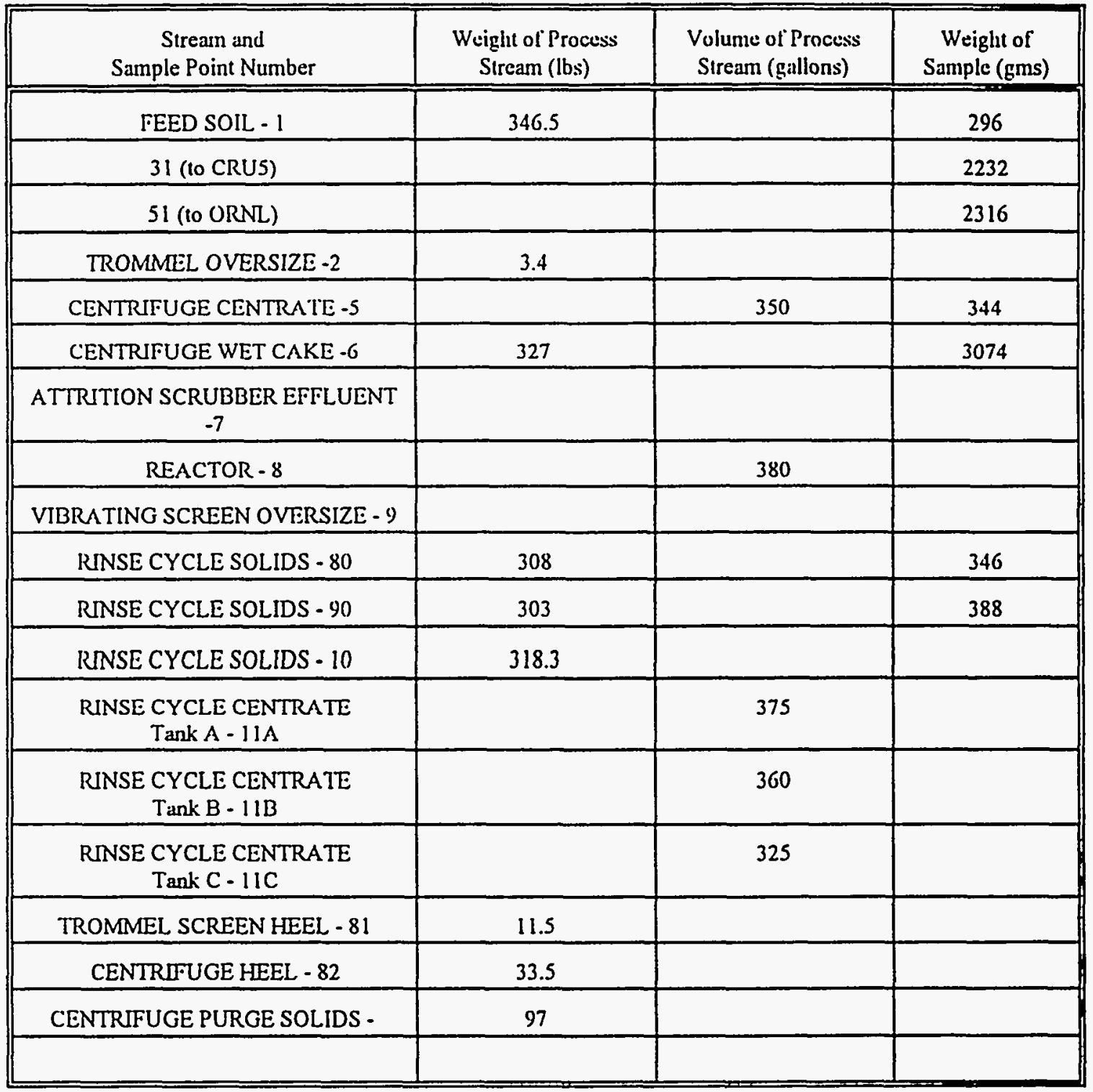


Test No. 3

\section{PHASE II SOIL WASHING PILOT PLANT / PROCESS DATA}

\begin{tabular}{||c|c|c|}
\hline Sample Nunber & Description & $\begin{array}{c}\text { Sample Weight } \\
\text { (gms) }\end{array}$ \\
\hline \hline 19 & Centrituge Purge & 388 \\
\hline 20 & & \\
\hline 21 & & \\
\hline 22 & & \\
\hline 23 & & \\
\hline 24 & & \\
\hline 25 & & \\
\hline 26 & & \\
\hline 27 & Centriluge Centratc Replicalc (S-5) & \\
\hline 28 & & \\
\hline 29 & & \\
\hline & & \\
\hline
\end{tabular}

\begin{tabular}{||c|c|c|c|c|c|c||}
\hline $\begin{array}{c}\text { Field Wt of Reactor } \\
\text { Samples (gms) }\end{array}$ & $\begin{array}{c}\text { Reaction } \\
\text { Time }=0\end{array}$ & $\begin{array}{c}5 \\
\text { minules }\end{array}$ & $\begin{array}{c}15 \\
\text { minutes }\end{array}$ & $\begin{array}{c}30 \\
\text { minutes }\end{array}$ & $\begin{array}{c}60 \\
\text { minutes }\end{array}$ & $\begin{array}{c}120 \\
\text { minutes }\end{array}$ \\
\hline \hline & & & & & & \\
\cline { 2 - 8 } & & & & & & \\
\hline
\end{tabular}


Test No. 4

PHASE II SOIL WASHING PILOT PLANT / PROCESS DATA

\begin{tabular}{|c|c|c|c|}
\hline $\begin{array}{c}\text { Stream and } \\
\text { Sample Point Number }\end{array}$ & $\begin{array}{l}\text { Weight of Process } \\
\text { Stream (lbs) }\end{array}$ & $\begin{array}{l}\text { Volume of Process } \\
\text { Stream (gallons) }\end{array}$ & $\begin{array}{c}\text { Weight of } \\
\text { Sample (gms) }\end{array}$ \\
\hline FEED SOIL - 1 & 460 & & 302 \\
\hline 31 (to CRU5) & & & 2210 \\
\hline 51 (to ORNL) & & & 2248 \\
\hline TROMMIEL OVERSIZE -2 & 13.6 & & \\
\hline CENTRIFUGE CENTRATE -5 & & 375 & 5000 \\
\hline CENTRIFUGE WET CAKE - 6 & 372.5 & & 436 \\
\hline \multicolumn{4}{|l|}{$\begin{array}{c}\text { ATIRITION SCRUBBER EFFLUENT } \\
-7\end{array}$} \\
\hline REACTOR - 8 & & 420 & \\
\hline VIBRA TING SCREEN OVERSIZE - 9 & 5 & & \\
\hline RINSE CYCLE SOLIDS - 80 & & & 688 \\
\hline RINSE CYCLE SOLIDS - 90 & & & 688 \\
\hline RINSE CYCLE SOLIDS - 10 & 370 & & \\
\hline $\begin{array}{l}\text { RINSE CYCLE CENTRATE } \\
\text { Tank } A-11 A\end{array}$ & & 410 & \\
\hline $\begin{array}{c}\text { RINSE CYCLE CENTRATE } \\
\text { Tank B - } 11 \mathrm{~B}\end{array}$ & & 330 & \\
\hline $\begin{array}{l}\text { RINSE CYCLE CENTRATE } \\
\text { Tank C - } 11 \mathrm{C}\end{array}$ & & 325 & \\
\hline \multicolumn{4}{|l|}{ TROMMEL SCREEN HEEL - 81} \\
\hline \multicolumn{4}{|l|}{ CENTRIFUGE HEEL - 82} \\
\hline CENTRIFUGE PURGE SOLIDS - & & & \\
\hline
\end{tabular}


Test No. 4

PHASE II SOIL WASHING PILOT PLANT / PROCESS DATA

\begin{tabular}{|c|c|c|}
\hline Sample Number & Description & $\begin{array}{c}\text { Sample Weight } \\
\text { (gms) }\end{array}$ \\
\hline 19 & & \\
\hline 20 & & \\
\hline 21 & Centrifuge Centrate (S-11D) & \\
\hline 22 & $\cdot$ & \\
\hline 23 & & \\
\hline 24 & & \\
\hline 25 & & \\
\hline 26 & & \\
\hline 27 & & \\
\hline 28 & & \\
\hline 29 & & \\
\hline
\end{tabular}

\begin{tabular}{||c|c|c|c|c|c|c|}
\hline $\begin{array}{c}\text { Field Wt of Reactor } \\
\text { Samples (gms) }\end{array}$ & $\begin{array}{c}\text { Reaction } \\
\text { Time }=0\end{array}$ & $\begin{array}{c}5 \\
\text { minutes }\end{array}$ & $\begin{array}{c}15 \\
\text { minutes }\end{array}$ & $\begin{array}{c}30 \\
\text { minutes }\end{array}$ & $\begin{array}{c}60 \\
\text { minutes }\end{array}$ & $\begin{array}{c}120 \\
\text { minutes }\end{array}$ \\
\hline \hline & & & & & & \\
\cline { 2 - 7 } Test 0 & & & & & & \\
\cline { 2 - 8 } & & & & & & \\
\hline Tests 1-19 & 252 & 234 & & 364 & 822 & 1000 \\
\hline
\end{tabular}


Test No._ 5

PHASE II SOIL WASHING PILOT PLANT / PROCESS DATA

\begin{tabular}{|c|c|c|c|}
\hline $\begin{array}{c}\text { Stream and } \\
\text { Sample Point Number } \\
\end{array}$ & $\begin{array}{l}\text { Weight of Process } \\
\text { Stream (lbs) }\end{array}$ & $\begin{array}{c}\text { Volume of Process } \\
\text { Stream (gallons) } \\
\end{array}$ & $\begin{array}{l}\text { Weight of } \\
\text { Sample (gms) }\end{array}$ \\
\hline FEED SOIL - 1 & 351 & & 304 \\
\hline 31 (to CRUS) & & & 2470 \\
\hline 51 (to ORNL) & & & 2510 \\
\hline TROMMEL OVERSIZE -2 & 16.5 & & \\
\hline CENTRIFUGE CENTRATE - 5 & & 340 & 368 \\
\hline CENTRIFUGE WET CAKE -6 & 291.5 & & 420 \\
\hline \multicolumn{4}{|l|}{$\begin{array}{l}\text { ATTRITION SCRUBBER EFFLUENT } \\
-7 \\
\end{array}$} \\
\hline REACTOR - 8 & & 385 & \\
\hline VIBRATING SCREEN OVERSIZE - 9 & 2.5 & & \\
\hline \multicolumn{4}{|l|}{ RINSE CYCLE SOLIDS - 80} \\
\hline \multicolumn{4}{|l|}{ RINSE CYCLE SOLIDS - 90} \\
\hline RINSE CYCLE SOLIDS - 10 & 330.6 & & \\
\hline $\begin{array}{l}\text { RINSE CYCLE CENTRATE } \\
\text { Tank A - 11A }\end{array}$ & & 400 & \\
\hline $\begin{array}{l}\text { RINSE CYCLE CENTRATE } \\
\text { Tank B - I1B }\end{array}$ & & 350 & \\
\hline $\begin{array}{l}\text { RINSE CYCLE CENTRATE } \\
\text { Tank C - 11C }\end{array}$ & & 350 & \\
\hline \multicolumn{4}{|l|}{ TROMMEL SCREEN HEEL - 81} \\
\hline \multicolumn{4}{|l|}{ CENTRIFUGE HEEL - 82} \\
\hline \multicolumn{4}{|l|}{ CENTRIFUGE PURGE SOLIDS - } \\
\hline & & & \\
\hline
\end{tabular}


Test No. 5

PHASE II SOIL WASHING PILOT PLANT / PROCESS DATA

\begin{tabular}{|c|c|c|}
\hline Sample Number & Description & $\begin{array}{c}\text { Sample Weight } \\
\text { (gms) }\end{array}$ \\
\hline \hline 19 & Centrifuge Wet Cake (S-80) & 362 \\
\hline 20 & Centrifuge Wet Cake (S-90) & 410 \\
\hline 21 & & \\
\hline 22 & & \\
\hline 23 & & \\
\hline 24 & & \\
\hline 25 & & \\
\hline 26 & & \\
\hline 27 & & \\
\hline 28 & & \\
\hline 29 & & \\
\hline
\end{tabular}

\begin{tabular}{||c|c|c|c|c|c|c|}
\hline $\begin{array}{c}\text { Field Wt of Reactor } \\
\text { Samples (gms) }\end{array}$ & $\begin{array}{c}\text { Reaction } \\
\text { Time }=0\end{array}$ & $\begin{array}{c}5 \\
\text { minutes }\end{array}$ & $\begin{array}{c}15 \\
\text { minutes }\end{array}$ & $\begin{array}{c}30 \\
\text { minutes }\end{array}$ & $\begin{array}{c}60 \\
\text { minutes }\end{array}$ & $\begin{array}{c}120 \\
\text { minutes }\end{array}$ \\
\hline & & & & & & \\
\cline { 2 - 7 } Test 0 & & & & & & \\
\hline & & & & & & \\
\hline Tests 1-19 & 766 & 398 & 780 & 662 & 648 & 1830 \\
\hline
\end{tabular}


Test No.

PHASE II SOIL WASHING PILOT PLANT / PROCESS DATA

\begin{tabular}{|c|c|c|c|}
\hline $\begin{array}{c}\text { Stream and } \\
\text { Sample Point Number }\end{array}$ & $\begin{array}{l}\text { Weight of Process } \\
\text { Stream (lbs) }\end{array}$ & $\begin{array}{l}\text { Volume of Process } \\
\text { Stream (gallons) }\end{array}$ & $\begin{array}{c}\text { Weight of } \\
\text { Sample (gms) }\end{array}$ \\
\hline FEED SOIL - 1 & 349.5 & & 274 \\
\hline 31 (to CRU5) & & & 2354 \\
\hline 51 (to ORNL) & & & 2388 \\
\hline TROMMEL OVERSIZE -2 & 13.2 & & \\
\hline CENTRIFUGE CENTRATE -5 & & 370 & 382 \\
\hline CENTRIFUGE WET CAKE - 6 & 330.5 & & 424 \\
\hline \multicolumn{4}{|l|}{$\begin{array}{c}\text { ATTRITION SCRUBBER EFFLUENT } \\
-7\end{array}$} \\
\hline REACTOR - 8 & & 415 & \\
\hline VIBRATING SCREEN OVERSIZE - 9 & 4.5 & & \\
\hline \multicolumn{4}{|l|}{ RINSE CYCLE SOLIDS - 80} \\
\hline \multicolumn{4}{|l|}{ RINSE CYCLE SOLIDS - 90} \\
\hline RINSE CYCLE SOLIDS - 10 & 335 & & \\
\hline $\begin{array}{l}\text { RINSE CYCLE CENTRATE } \\
\text { Tank A - 11A }\end{array}$ & & 400 & \\
\hline $\begin{array}{l}\text { RINSE CYCLE CENTRATE } \\
\text { Tank B - } 11 \mathrm{~B}\end{array}$ & & 350 & \\
\hline $\begin{array}{l}\text { RINSE CYCLE CENTRATE } \\
\text { Tank C - 11C }\end{array}$ & & 375 & \\
\hline \multicolumn{4}{|l|}{ TROMMEL SCREEN HEEL - 81} \\
\hline \multicolumn{4}{|l|}{ CENTRIFUGE HEEL - 82} \\
\hline CENTRIFUGE PURGE SOLIDS - & & & \\
\hline & & & \\
\hline
\end{tabular}


Test No. 6

PHASE II SOIL WASHING PILOT PLANT / PROCESS DATA

\begin{tabular}{||c|c|c|}
\hline Sample Number & Description & $\begin{array}{c}\text { Sample Weight } \\
\text { (gms) }\end{array}$ \\
\hline 19 & & \\
\hline 20 & & \\
\hline 21 & & \\
\hline 22 & & \\
\hline 23 & & \\
\hline 24 & & \\
\hline 25 & Treated Soil (S-10) from 5 gal. bucket & \\
\hline 26 & $(3-29-94)$ & \\
\hline 27 & Free Water from Sample No. 27 & \\
\hline 28 & & \\
\hline 29 & & \\
\hline
\end{tabular}

\begin{tabular}{||c|c|c|c|c|c|c|}
\hline $\begin{array}{c}\text { Field Wt of Reactor } \\
\text { Samples (gms) }\end{array}$ & $\begin{array}{c}\text { Reaction } \\
\text { Time=0 }\end{array}$ & $\begin{array}{c}5 \\
\text { minutes }\end{array}$ & $\begin{array}{c}15 \\
\text { minutes }\end{array}$ & $\begin{array}{c}30 \\
\text { minutes }\end{array}$ & $\begin{array}{c}60 \\
\text { minutes }\end{array}$ & $\begin{array}{c}120 \\
\text { minutes }\end{array}$ \\
\hline \hline & & & & & & \\
\cline { 2 - 7 } Test 0 & & & & & & \\
\hline & & & & & & \\
\hline Tests 1-19 & 1166 & 780 & 766 & 702 & 746 & 1918 \\
\hline
\end{tabular}


Test No. 7

PHASE II SOIL WASHING PILOT PLANT / PROCESS DATA

\begin{tabular}{|c|c|c|c|}
\hline $\begin{array}{c}\text { Stream and } \\
\text { Sample Point Number }\end{array}$ & $\begin{array}{l}\text { Weight of Process } \\
\text { Stream (lbs) }\end{array}$ & $\begin{array}{l}\text { Volume of Process } \\
\text { Stream (gallons) }\end{array}$ & $\begin{array}{c}\text { Weight of } \\
\text { Sample (gms) }\end{array}$ \\
\hline FEED SOIL - 1 & 336 & & 312 \\
\hline 31 (to CRUS) & & & 2202 \\
\hline 51 (to ORNL) & & & 2366 \\
\hline TROMMEL OVERSIZE -2 & 4.5 & & \\
\hline CENTRIFUGE CENTRATE - 5 & & 340 & 370 \\
\hline CENTRIFUGE WET CAKE -6 & 317 & & 8140 \\
\hline \multicolumn{4}{|l|}{$\begin{array}{c}\text { ATTRITION SCRUBBER EFFLUENT } \\
-7\end{array}$} \\
\hline REACTOR - 8 & & 375 & \\
\hline \multicolumn{4}{|l|}{ VIBRATING SCREEN OVERSIZE - 9} \\
\hline RINSE CYCLE SOLIDS - 80 & 304 & & 402 \\
\hline RINSE CYCLE SOLIDS - 90 & 278 & & 366 \\
\hline RINSE CYCLE SOLDS - 10 & 265 & & \\
\hline $\begin{array}{l}\text { RINSE CYCLE CENTRATE } \\
\text { Tank A - 11A }\end{array}$ & & 425 & \\
\hline $\begin{array}{l}\text { RINSE CYCLE CENTRATE } \\
\text { Tank B - 11B }\end{array}$ & & 310 & \\
\hline $\begin{array}{l}\text { RINSE CYCLE CENTRATE } \\
\text { Tank C - 11C } \\
\end{array}$ & & 370 & \\
\hline TROMMEL SCREEN HEEL - 81 & 13 & & \\
\hline CENTRIFUGE HEEL - 82 & 96 & & \\
\hline CENTRIFUGE PURGE SOLIDS - & 58.5 & & \\
\hline
\end{tabular}


Test No.

PHASE II SOIL WASHING PILOT PLANT / PROCESS DATA

\begin{tabular}{||c|c|c||}
\hline Sample Number & Description & $\begin{array}{c}\text { Sample Weight } \\
\text { (gms) }\end{array}$ \\
\hline 19 & Centrifuge Purge & 414 \\
\hline 20 & & \\
\hline 21 & & \\
\hline 22 & & \\
\hline 23 & & \\
\hline 24 & & \\
\hline 25 & & \\
\hline 26 & & \\
\hline 27 & Treated Soil Replicate (S-10) & \\
\hline 28 & & \\
\hline 29 & & \\
\hline 110 & & \\
\hline
\end{tabular}

\begin{tabular}{||c|c|c|c|c|c|c|}
\hline \hline $\begin{array}{c}\text { Field Wt of Reactor } \\
\text { Samples (gms) }\end{array}$ & $\begin{array}{c}\text { Reaction } \\
\text { Time }=0\end{array}$ & $\begin{array}{c}5 \\
\text { minutes }\end{array}$ & $\begin{array}{c}15 \\
\text { minutes }\end{array}$ & $\begin{array}{c}30 \\
\text { minutes }\end{array}$ & $\begin{array}{c}60 \\
\text { minutes }\end{array}$ & $\begin{array}{c}120 \\
\text { minutes }\end{array}$ \\
\hline \hline \multirow{2}{*}{ Test 0 } & & & & & & \\
\cline { 2 - 7 } & & & & & & \\
\hline \hline Tests 1-19 & 1036 & 642 & 612 & 616 & 650 & 998 \\
\hline
\end{tabular}


Test No 8

PHASE II SOL WASHING PILOT PLANT / PROCESS DATA

\begin{tabular}{|c|c|c|c|}
\hline $\begin{array}{c}\text { Stream and } \\
\text { Sample Point Number }\end{array}$ & $\begin{array}{l}\text { Weight of Process } \\
\text { Stream (lbs) }\end{array}$ & $\begin{array}{l}\text { Volume of Process } \\
\text { Stream (gallons) }\end{array}$ & $\begin{array}{l}\text { Weight of } \\
\text { Sample (gms) }\end{array}$ \\
\hline FEED SOIL - 1 & 377 & & 292 \\
\hline 31 (to CRU5) & & & 2218 \\
\hline 51 (to ORNL) & & & 2324 \\
\hline TROMMEL OVERSIZE -2 & 29 & & \\
\hline CENTRIFUGE CENTRATE -5 & & 335 & 368 \\
\hline CENTRIFUGE WET CAKE -6 & 312 & & 3156 \\
\hline \multicolumn{4}{|l|}{$\begin{array}{l}\text { ATTRITION SCRUBBER EFFLUENT } \\
-7\end{array}$} \\
\hline REACTOR - 8 & & 380 & \\
\hline \multicolumn{4}{|l|}{ VIBRATING SCREEN OVERSIZE - 9} \\
\hline RINSE CYCLE SOLIDS - 80 & 312 & & 356 \\
\hline RINSE CYCLE SOLDS - 90 & 291 & & \\
\hline RINSE CYCLE SOLDS - 10 & 269 & & \\
\hline $\begin{array}{l}\text { RINSE CYCLE CENTRATE } \\
\text { Tank A - } 11 \mathrm{~A} \\
\end{array}$ & & 425 & \\
\hline $\begin{array}{l}\text { RINSE CYCLE CENTRATE } \\
\text { Tank B - I1B } \\
\end{array}$ & & 340 & \\
\hline $\begin{array}{l}\text { RINSE CYCLE CENTRATE } \\
\text { Tank C - I1C } \\
\end{array}$ & & 370 & \\
\hline TROMMEL SCREEN HEEL - 81 & 25 & & \\
\hline CENTRIFUGE HEEL - 82 & 108 & & \\
\hline CENTRIFUGE PURGE SOLIDS - & 56.5 & & \\
\hline
\end{tabular}


Test No.

PHASE II SOIL WASHING PILOT PLANT / PROCESS DATA

\begin{tabular}{||c|c|c|}
\hline Sample Number & Description & $\begin{array}{c}\text { Sample Weight } \\
\text { (gms) }\end{array}$ \\
\hline 19 & Centrifuge Purge & 354 \\
\hline 20 & & \\
\hline 21 & & \\
\hline 22 & & \\
\hline 23 & & \\
\hline 24 & & \\
\hline 25 & & \\
\hline 26 & & \\
\hline 27 & & \\
\hline 28 & & \\
\hline 29 & & \\
\hline 110 & & \\
\hline & & \\
\hline
\end{tabular}

\begin{tabular}{||c|c|c|c|c|c|c|}
\hline $\begin{array}{c}\text { Field Wt of Reactor } \\
\text { Samples (gms) }\end{array}$ & $\begin{array}{c}\text { Reaction } \\
\text { Time }=0\end{array}$ & $\begin{array}{c}5 \\
\text { minutes }\end{array}$ & $\begin{array}{c}15 \\
\text { minutes }\end{array}$ & $\begin{array}{c}30 \\
\text { minutes }\end{array}$ & $\begin{array}{c}60 \\
\text { minutes }\end{array}$ & $\begin{array}{c}120 \\
\text { minutes }\end{array}$ \\
\hline & & & & & & \\
\hline & & & & & & \\
\hline
\end{tabular}


Test No. 13

PHASE II SOIL WASHING PILOT PLANT / PROCESS DATA

\begin{tabular}{|c|c|c|c|}
\hline $\begin{array}{c}\text { Stream and } \\
\text { Sample Point Number }\end{array}$ & $\begin{array}{l}\text { Weight of Process } \\
\text { Stream (lbs) }\end{array}$ & $\begin{array}{l}\text { Volume of Process } \\
\text { Stream (gallons) }\end{array}$ & $\begin{array}{l}\text { Weight of } \\
\text { Sample (gms) }\end{array}$ \\
\hline FEED SOIL - 1 & 343 & & 262 \\
\hline 31 (to CRU5) & & & 1974 \\
\hline 51 (to ORNL) & & & 2018 \\
\hline TROMMEL OVERSIZE -2 & 3.8 & & \\
\hline CENTRIFUGE CENTRATE -5 & & 340 & \\
\hline CENTRIFUGE WET CAKE - 6 & 313 & & 3405 \\
\hline \multicolumn{4}{|l|}{$\begin{array}{c}\text { ATTRITION SCRUBBER EFFLUENT } \\
-7\end{array}$} \\
\hline REACTOR - 8 & & 385 & \\
\hline \multicolumn{4}{|l|}{ VIBRATING SCREEN OVERSIZE - 9} \\
\hline RINSE CYCLE SOLIDS - 80 & 355 & & 526 \\
\hline RINSE CYCLE SOLDS - 90 & 334.5 & & 454 \\
\hline RINSE CYCLE SOLIDS - 10 & 342 & & \\
\hline $\begin{array}{l}\text { RINSE CYCLE CENTRATE } \\
\text { Tank A - } 11 \mathrm{~A}\end{array}$ & & 365 & \\
\hline $\begin{array}{l}\text { RINSE CYCLE CENTRATE } \\
\text { Tank B - 11B }\end{array}$ & & 325 & \\
\hline $\begin{array}{l}\text { RINSE CYCLE CENTRATE } \\
\text { Tank C - 11C }\end{array}$ & & 360 & \\
\hline TROMMEL SCREEN HEEL - 81 & 14 & & \\
\hline CENTRIFUGE HEEL - 82 & 43.5 & & \\
\hline CENTRIFUGE PURGE SOLIDS - & 60 & & \\
\hline
\end{tabular}


Test No. 13

PHASE II SOIL WASHING PILOT PLANT / PROCESS DATA

\begin{tabular}{||c|c|c|}
\hline Sample Number & Description & $\begin{array}{c}\text { Sample Weight } \\
\text { (gms) }\end{array}$ \\
\hline 19 & Centrifuge Purge & 586 \\
\hline 20 & & \\
\hline 21 & & \\
\hline 22 & & \\
\hline 23 & & \\
\hline 24 & & \\
\hline 25 & & \\
\hline 26 & & \\
\hline 27 & Centrifuge Centrate Replicate (S-11A) & \\
\hline 28 & & \\
\hline 29 & & \\
\hline 111 & & \\
\hline & & \\
\hline
\end{tabular}

\begin{tabular}{|c|c|c|c|c|c|c|}
\hline $\begin{array}{l}\text { Field Wt of Reactor } \\
\text { Samples (gms) }\end{array}$ & $\begin{array}{l}\text { Reaction } \\
\text { Time }=0\end{array}$ & $\begin{array}{c}5 \\
\text { minutes }\end{array}$ & $\begin{array}{c}15 \\
\text { minutes }\end{array}$ & $\begin{array}{c}30 \\
\text { minutes }\end{array}$ & $\begin{array}{c}60 \\
\text { minutes }\end{array}$ & $\begin{array}{c}120 \\
\text { minutes }\end{array}$ \\
\hline \multicolumn{7}{|l|}{ Test 0} \\
\hline Tests $1-19$ & 1074 & 706 & 870 & 692 & 650 & 1048 \\
\hline
\end{tabular}


Test No. 14

PHASE II SOIL WASHING PILOT PLANT / PROCESS DATA

\begin{tabular}{|c|c|c|c|}
\hline $\begin{array}{c}\text { Stream and } \\
\text { Sample Point Number }\end{array}$ & $\begin{array}{l}\text { Weight of Process } \\
\text { Stream (lbs) }\end{array}$ & $\begin{array}{l}\text { Volume of Process } \\
\text { Stream (gallons) }\end{array}$ & $\begin{array}{c}\text { Weight of } \\
\text { Sample (gms) }\end{array}$ \\
\hline FEED SOIL - 1 & 350 & & 306 \\
\hline 31 (to CRU5) & & & 2236 \\
\hline 51 (to ORNL) & & & 2412 \\
\hline TROMMEL OVERSIZE - 2 & 5.5 & & \\
\hline CENTRIFUGE CENTRATE -5 & & 250 & \\
\hline CENTRIFUGE WET CAKE - 6 & 413 & & 6973 \\
\hline \multicolumn{4}{|l|}{$\begin{array}{l}\text { ATTRITION SCRUBBER EFFLUENT } \\
-7\end{array}$} \\
\hline REACTOR - 8 & & 375 & \\
\hline \multicolumn{4}{|l|}{ VIBRATTNG SCREEN OVERSIZE - 9} \\
\hline RINSE CYCLE SOLIDS - 80 & 322.5 & & 410 \\
\hline RINSE CYCLE SOLIDS - 90 & 315 & & 406 \\
\hline RINSE CYCLE SOLIDS - 10 & 329 & & \\
\hline $\begin{array}{l}\text { RINSE CYCLE CENTRATE } \\
\text { Tank A - 11A }\end{array}$ & & 400 & \\
\hline $\begin{array}{l}\text { RINSE CYCLE CENTRATE } \\
\text { Tank B - } 11 \mathrm{~B}\end{array}$ & & 375 & \\
\hline $\begin{array}{l}\text { RINSE CYCLE CENTRATE } \\
\text { Tank C - } 11 \mathrm{C}\end{array}$ & & 325 & \\
\hline TROMMEL SCREEN HEEL - 81 & 8 & & \\
\hline CENTRIFUGE HEEL - 82 & 74 & & \\
\hline CENTRIFUGE PURGE SOLIDS - & 59.5 & & \\
\hline
\end{tabular}


Test No. 14

PHASE II SOIL WASHING PILOTT PLANT / PROCESS DATA

\begin{tabular}{|c|c|c|}
\hline Sample Number & Description & $\begin{array}{c}\text { Sample Weight } \\
\text { (gms) }\end{array}$ \\
\hline 19 & Centrifuge Purge & 428 \\
\hline 20 & & \\
\hline 21 & & \\
\hline 22 & & \\
\hline 23 & & \\
\hline 24 & & \\
\hline 25 & & \\
\hline 26 & & \\
\hline 27 & Treated Soil Replicate (S-10) & \\
\hline 28 & & \\
\hline 29 & & \\
\hline 110 & & \\
\hline & & \\
\hline
\end{tabular}

\begin{tabular}{|c|c|c|c|c|c|c|}
\hline $\begin{array}{c}\text { Field Wt of Reactor } \\
\text { Samples (gms) }\end{array}$ & $\begin{array}{c}\text { Reaction } \\
\text { Time }=0\end{array}$ & $\begin{array}{c}5 \\
\text { minutes }\end{array}$ & $\begin{array}{c}15 \\
\text { minutes }\end{array}$ & $\begin{array}{c}30 \\
\text { minutes }\end{array}$ & $\begin{array}{c}60 \\
\text { minutes }\end{array}$ & $\begin{array}{c}120 \\
\text { minutes }\end{array}$ \\
\hline & & & & & & \\
\hline
\end{tabular}


Test No. 15

PHASE II SOIL WASHING PLOT PLANT / PROCESS DATA

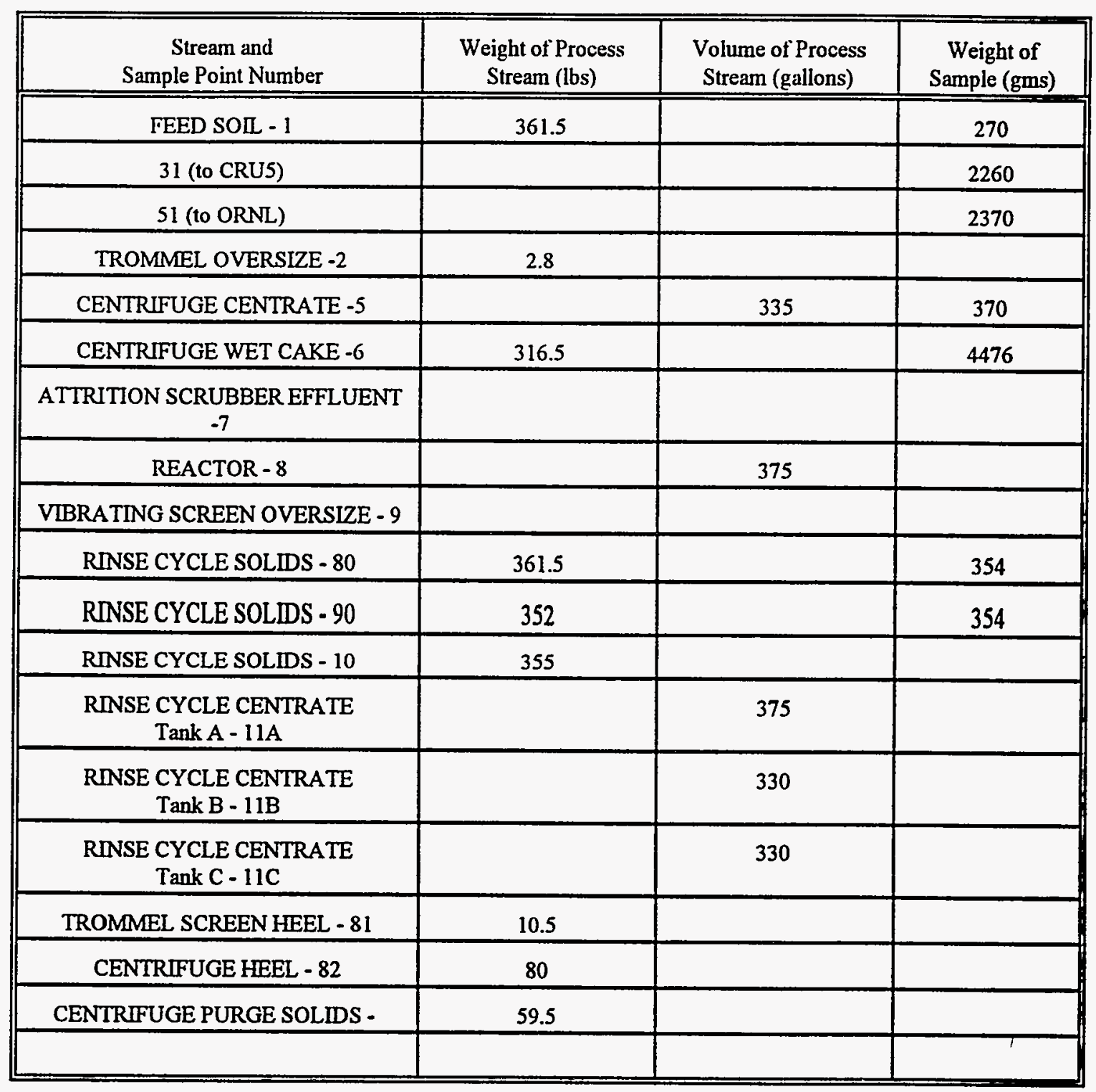


Test No. 15

PHASE II SOIL WASHING PILOT PLANT / PROCESS DATA

\begin{tabular}{|c|c|c|}
\hline Sample Number & Description & $\begin{array}{c}\text { Sample Weight } \\
\text { (gms) }\end{array}$ \\
\hline 19 & Centrifuge Purge & 336 \\
\hline 20 & Solids from Trench & \\
\hline 21 & & \\
\hline 22 & & \\
\hline 23 & & \\
\hline 24 & & \\
\hline 25 & & \\
\hline 26 & & \\
\hline 27 & & \\
\hline 28 & & \\
\hline 29 & & \\
\hline & & \\
\hline
\end{tabular}

\begin{tabular}{||c|c|c|c|c|c|c|}
\hline $\begin{array}{c}\text { Field Wt of Reactor } \\
\text { Samples (gms) }\end{array}$ & $\begin{array}{c}\text { Reaction } \\
\text { Time=0 }\end{array}$ & $\begin{array}{c}5 \\
\text { minutes }\end{array}$ & $\begin{array}{c}15 \\
\text { minutes }\end{array}$ & $\begin{array}{c}30 \\
\text { minutes }\end{array}$ & $\begin{array}{c}60 \\
\text { minutes }\end{array}$ & $\begin{array}{c}120 \\
\text { minutes }\end{array}$ \\
\hline \hline & & & & & & \\
\hline & & & & & & \\
\hline & & & & & & \\
\hline Test 0 & & & & & & \\
\hline
\end{tabular}


Test No. 16

PHASE II SOIL WASHING PILOT PLANT / PROCESS DATA

\begin{tabular}{|c|c|c|c|}
\hline $\begin{array}{c}\text { Stream and } \\
\text { Sample Point Number }\end{array}$ & $\begin{array}{l}\text { Weight of Process } \\
\text { Stream (lbs) }\end{array}$ & $\begin{array}{l}\text { Volume of Process } \\
\text { Stream (gallons) }\end{array}$ & $\begin{array}{c}\text { Weight of } \\
\text { Sample (gms) }\end{array}$ \\
\hline FEED SOIL - 1 & 429.5 & & 276 \\
\hline 31 (to CRUS) & & & 2246 \\
\hline 51 (to ORNL) & & & 2382 \\
\hline TROMMEL OVERSIZE - 2 & 19 & & \\
\hline CENTRIFUGE CENTRATE -5 & & 350 & 364 \\
\hline CENTRIFUGE WET CAKE -6 & 535.5 & & 19068 \\
\hline \multicolumn{4}{|l|}{$\begin{array}{c}\text { ATTRITION SCRUBBER EFFLUENT } \\
-7\end{array}$} \\
\hline REACTOR - 8 & & 385 & \\
\hline \multicolumn{4}{|l|}{ VIBRATING SCREEN OVERSIZE - 9} \\
\hline \multicolumn{4}{|l|}{ RINSE CYCLE SOLIDS - 80} \\
\hline \multicolumn{4}{|l|}{ RINSE CYCLE SOLDS - 90} \\
\hline RINSE CYCLE SOLDS - 10 & 419.5 & & \\
\hline $\begin{array}{l}\text { RINSE CYCLE CENTRATE } \\
\text { Tank A - } 11 \mathrm{~A} \\
\end{array}$ & & 400 & \\
\hline $\begin{array}{l}\text { RINSE CYCLE CENTRATE } \\
\text { Tank B - } 11 \mathrm{~B} \\
\end{array}$ & & 350 & \\
\hline $\begin{array}{l}\text { RNNSE CYCLE CENTRATE } \\
\text { Tank C - 11C }\end{array}$ & & 425 & \\
\hline \multicolumn{4}{|l|}{ TROMMEL SCREEN HEEL - 81} \\
\hline \multicolumn{4}{|l|}{ CENTRIFUGE HEEL - 82} \\
\hline \multicolumn{4}{|l|}{ CENTRIFUGE PURGE SOLIDS - } \\
\hline & & & \\
\hline
\end{tabular}


Test No._. 16

PHASE II SOIL WASHING PILOT PLANT / PROCESS DATA

\begin{tabular}{|c|c|c|}
\hline Sample Number & Description & $\begin{array}{c}\text { Sample Weight } \\
\text { (gms) }\end{array}$ \\
\hline \hline 19 & Centrifuge heel + Vibrating Screen Oversize & 348 \\
\hline 20 & Centrifuge Solids (S-80) & 280 \\
\hline 21 & 11A Filtrate & \\
\hline 22 & & \\
\hline 23 & & \\
\hline 24 & & \\
\hline 25 & & \\
\hline 26 & & \\
\hline 27 & & \\
\hline 28 & & \\
\hline 29 & & \\
\hline
\end{tabular}

\begin{tabular}{|c|c|c|c|c|c|c|}
\hline $\begin{array}{l}\text { Field Wt of Reactor } \\
\text { Samples (gms) }\end{array}$ & $\begin{array}{l}\text { Reaction } \\
\text { Time }=0\end{array}$ & $\begin{array}{c}5 \\
\text { minutes }\end{array}$ & $\begin{array}{c}15 \\
\text { minutes }\end{array}$ & $\begin{array}{c}30 \\
\text { minutes }\end{array}$ & $\begin{array}{c}60 \\
\text { minutes }\end{array}$ & $\begin{array}{c}120 \\
\text { minutes }\end{array}$ \\
\hline \multicolumn{7}{|l|}{ Test 0} \\
\hline Tests 1-19 & 1212 & 526 & 540 & 516 & 476 & 1774 \\
\hline
\end{tabular}


Test No. 17

PHASE II SOIL WASHING PILOT PLANT / PROCESS DATA

\begin{tabular}{|c|c|c|c|}
\hline $\begin{array}{l}\text { Stream and } \\
\text { Sample Point Number }\end{array}$ & $\begin{array}{l}\text { Weight of Process } \\
\text { Stream (lbs) }\end{array}$ & $\begin{array}{l}\text { Volume of Process } \\
\text { Stream (gallons) }\end{array}$ & $\begin{array}{c}\text { Weight of } \\
\text { Sample (gms) }\end{array}$ \\
\hline FEED SOIL - 1 & 361 & & 880 \\
\hline 31 (to CRU5) & & & 2378 \\
\hline 51 (to ORNL) & & & 2450 \\
\hline TROMMEL OVERSIZE -2 & 13.5 & & \\
\hline CENTRIFUGE CENTRATE -5 & & 378 & 440 \\
\hline CENTRIFUGE WET CAKE -6 & 280 & & 4767 \\
\hline \multicolumn{4}{|l|}{$\begin{array}{c}\text { ATTRITION SCRUBBER EFFLUENT } \\
-7\end{array}$} \\
\hline REACTOR - 8 & & 400 & \\
\hline \multicolumn{4}{|l|}{ VIBRATING SCREEN OVERSLZE - 9} \\
\hline \multicolumn{4}{|l|}{ RINSE CYCLE SOLIDS - 80} \\
\hline \multicolumn{4}{|l|}{ RINSE CYCLE SOLDS - 90} \\
\hline RINSE CYCLE SOLIDS - 10 & 411.5 & & \\
\hline $\begin{array}{c}\text { RNSE CYCLE CENTRATE } \\
\text { Tank A - 11A }\end{array}$ & & 420 & \\
\hline $\begin{array}{c}\text { RINSE CYCLE CENTRATE } \\
\text { Tank B - 11B }\end{array}$ & & 375 & \\
\hline $\begin{array}{l}\text { RINSE CYCLE CENTRATE } \\
\text { Tank C - } 11 \mathrm{C}\end{array}$ & & 350 & \\
\hline TROMMEL SCREEN HEEL - 81 & 33.5 & & \\
\hline CENTRIFUGE HEEL - 82 & 32 & & \\
\hline CENTRIFUGE PURGE SOLIDS - & & & \\
\hline
\end{tabular}


Test No. 17

PHASE II SOIL WASHING PILOT PLANT / PROCESS DATA

\begin{tabular}{|c|c|c|}
\hline Sample Number & Description & $\begin{array}{c}\text { Sample Weight } \\
\text { (gms) }\end{array}$ \\
\hline 19 & Feed Soil Replicate & 302 \\
\hline 20 & Feed Soil Replicate & 296 \\
\hline 21 & Trommel Screen Heel & 450 \\
\hline 22 & Reactor Slurry at time=0 (S8YS) & 222 \\
\hline 23 & Centrifuge Solids (S-80) & 306 \\
\hline 24 & Centrifuge Solids (S-90) & 306 \\
\hline 25 & Treated Soil Replicate (S-10) & 304 \\
\hline 26 & Treated Soil Replicate (S-10) & \\
\hline 27 & Centrate S-1 lA Replicate & \\
\hline 28 & & \\
\hline 29 & & \\
\hline
\end{tabular}

\begin{tabular}{||c|c|c|c|c|c|c||}
\hline $\begin{array}{c}\text { Field Wt of Reactor } \\
\text { Samples (gms) }\end{array}$ & $\begin{array}{c}\text { Reaction } \\
\text { Time=0 }\end{array}$ & $\begin{array}{c}5 \\
\text { minutes }\end{array}$ & $\begin{array}{c}15 \\
\text { minutes }\end{array}$ & $\begin{array}{c}30 \\
\text { minutes }\end{array}$ & $\begin{array}{c}60 \\
\text { minutes }\end{array}$ & $\begin{array}{c}120 \\
\text { minutes }\end{array}$ \\
\hline \hline & & & & & & \\
\cline { 2 - 7 } Test 0 & & & & & & \\
\cline { 2 - 8 } & & & & & & \\
\hline \hline Tests 1-19 & 1126 & 528 & 566 & 1092 & 792 & 1036 \\
\hline
\end{tabular}


Test No. 18

PHASE II SOIL WASHING PILOT PLANT / PROCESS DATA

\begin{tabular}{|c|c|c|c|}
\hline $\begin{array}{c}\text { Stream and } \\
\text { Sample Point Number }\end{array}$ & $\begin{array}{l}\text { Weight of Process } \\
\text { Stream (lbs) }\end{array}$ & $\begin{array}{l}\text { Volume of Process } \\
\text { Stream (gallons) }\end{array}$ & $\begin{array}{c}\text { Weight of } \\
\text { Sample (gms) }\end{array}$ \\
\hline FEED SOIL - 1 & 370 & & 272 \\
\hline 31 (to CRU5) & & & 2116 \\
\hline 51 (to ORNL) & & & 2186 \\
\hline TROMMEL OVERSIZE -2 & 5.5 & & \\
\hline CENTRIFUGE CENTRATE -5 & & 350 & 440 \\
\hline CENTRIFUGE WET CAKE -6 & 315 & & 6099 \\
\hline \multicolumn{4}{|l|}{$\begin{array}{l}\text { ATTRITION SCRUBBER EFFLUENT } \\
-7\end{array}$} \\
\hline REACTOR - 8 & & 375 & \\
\hline \multicolumn{4}{|l|}{ VIBRATING SCREEN OVERSIZE - 9} \\
\hline RINSE CYCLE SOLDS - 80 & 330 & & \\
\hline RINSE CYCLE SOLIDS - 90 & 340.5 & & 350 \\
\hline RINSE CYCLE SOLIDS - 10 & 358.5 & & 368 \\
\hline $\begin{array}{l}\text { RINSE CYCLE CENTRATE } \\
\text { Tank A - 11A } \\
\end{array}$ & & 380 & \\
\hline $\begin{array}{l}\text { RINSE CYCLE CENTRATE } \\
\text { Tank B - 11B } \\
\end{array}$ & & 375 & \\
\hline $\begin{array}{l}\text { RINSE CYCLE CENTRATE } \\
\text { Tank C - 11C } \\
\end{array}$ & & 375 & \\
\hline TROMMEL SCREEN HEEL - 81 & 18 & & \\
\hline CENTRIFUGE HEEL - 82 & 48 & & \\
\hline CENIRIFUGE PURGE SOLIDS - & 60 & & \\
\hline
\end{tabular}


Test No. 18

PHASE II SOIL WASHING PILOT PLANT / PROCESS DATA

\begin{tabular}{|c|c|c|}
\hline Sample Number & Description & $\begin{array}{c}\text { Sample Weight } \\
\text { (gms) }\end{array}$ \\
\hline 19 & Treated Soil Replicate (S-10) & 314 \\
\hline 20 & Treated Soil Replicate (S-10) & 342 \\
\hline 21 & Centrifuge Purge (after rinsing) & 233 \\
\hline 22 & Centrate from rinsing Centrifuge Purge & \\
\hline 23 & & \\
\hline 24 & & \\
\hline 25 & & \\
\hline 26 & & \\
\hline 27 & Treated Soil Replicate (S-10) & \\
\hline 28 & & \\
\hline 29 & Fentrifuge Centrate Replicate (S-11A) & \\
\hline 108 & & \\
\hline 110 & & \\
\hline 111 & & \\
\hline
\end{tabular}

\begin{tabular}{||c|c|c|c|c|c|c|}
\hline $\begin{array}{c}\text { Field Wt of Reactor } \\
\text { Samples (gms) }\end{array}$ & $\begin{array}{c}\text { Reaction } \\
\text { Time }=0\end{array}$ & $\begin{array}{c}5 \\
\text { minutes }\end{array}$ & $\begin{array}{c}15 \\
\text { minutes }\end{array}$ & $\begin{array}{c}30 \\
\text { minutes }\end{array}$ & $\begin{array}{c}60 \\
\text { minutes }\end{array}$ & $\begin{array}{c}120 \\
\text { minutes }\end{array}$ \\
\hline & & & & & & \\
\cline { 2 - 7 } Test 0 & & & & & & \\
\hline & & & & & & \\
\hline Tests 1-19 & 912 & 506 & 604 & 532 & 516 & 1056 \\
\hline
\end{tabular}


Test No. 19

PHASE II SOIL WASHING PILOT PLANT / PROCESS DATA

\begin{tabular}{|c|c|c|c|}
\hline $\begin{array}{c}\text { Stream and } \\
\text { Sample Point Number }\end{array}$ & $\begin{array}{c}\text { Weight of Process } \\
\text { Stream (lbs) }\end{array}$ & $\begin{array}{c}\text { Volume of Process } \\
\text { Stream (gallons) } \\
\end{array}$ & $\begin{array}{c}\text { Weight of } \\
\text { Sample (gms) }\end{array}$ \\
\hline FEED SOIL - 1 & 356 & & 306 \\
\hline 31 (to CRU5) & & & 2296 \\
\hline 51 (to ORNL) & & & 2644 \\
\hline TROMMEL OVERSIZE -2 & 12.8 & & \\
\hline CENTRIFUGE CENTRATE - 5 & & 360 & \\
\hline CENTRIFUGE WET CAKE - 6 & 304 & & 3829 \\
\hline \multicolumn{4}{|l|}{$\begin{array}{l}\text { ATTRITION SCRUBBER EFFLUENT } \\
-7\end{array}$} \\
\hline REACTOR - 8 & & 410 & \\
\hline \multicolumn{4}{|l|}{ VIBRATING SCREEN OVERSIZE - 9} \\
\hline RINSE CYCLE SOLIDS - 80 & 305.5 & & 406 \\
\hline RINSE CYCLE SOLIDS - 90 & 317.5 & & 388 \\
\hline RINSE CYCLE SOLIDS - 10 & 333 & & \\
\hline $\begin{array}{l}\text { RINSE CYCLE CENTRATE } \\
\text { Tank A - 11A } \\
\end{array}$ & & 425 & \\
\hline $\begin{array}{l}\text { RINSE CYCLE CENTRATE } \\
\text { Tank B - 11B } \\
\end{array}$ & & 340 & \\
\hline $\begin{array}{l}\text { RINSE CYCLE CENTRATE } \\
\text { Tank C - 11C } \\
\end{array}$ & & 350 & \\
\hline TROMMEL SCREEN HEEL - 81 & 19.5 & & \\
\hline CENTRIFUGE HEEL - 82 & 74.5 & & \\
\hline CENTRIFUGE PURGE SOLIDS - & 59 & & \\
\hline
\end{tabular}


Test No. 19

PHASE II SOIL WASHING PILOT PLANT / PROCESS DATA

\begin{tabular}{||c|c|c|}
\hline Sample Number & Description & $\begin{array}{c}\text { Sample Weight } \\
\text { (gms) }\end{array}$ \\
\hline \hline 19 & Centrifuge Purge & \\
\hline 20 & & \\
\hline 21 & & \\
\hline 22 & & \\
\hline 23 & & \\
\hline 24 & & \\
\hline 25 & & \\
\hline 26 & & \\
\hline 27 & & \\
\hline 28 & & \\
\hline 29 & Centrifuge Centrate Replicate (S-11C) & \\
\hline 110 & Treated Soil Replicate (S-10) & \\
\hline & & \\
\hline
\end{tabular}

\begin{tabular}{||c|c|c|c|c|c|c|}
\hline $\begin{array}{c}\text { Field Wt of Reactor } \\
\text { Samples (gms) }\end{array}$ & $\begin{array}{c}\text { Reaction } \\
\text { Time=0 }\end{array}$ & $\begin{array}{c}5 \\
\text { minutes }\end{array}$ & $\begin{array}{c}15 \\
\text { minutes }\end{array}$ & $\begin{array}{c}30 \\
\text { minutes }\end{array}$ & $\begin{array}{c}60 \\
\text { minutes }\end{array}$ & $\begin{array}{c}120 \\
\text { minutes }\end{array}$ \\
\hline \hline & & & & & & \\
\cline { 2 - 7 } Test 0 & & & & & & \\
\hline \hline Tests l-19 & 924 & 600 & 600 & 600 & 600 & 1000 \\
\hline
\end{tabular}


Test No. 20 .

PHASE II SOIL WASHING PILOT PLANT / PROCESS DATA

\begin{tabular}{|c|c|c|c|c|}
\hline \multicolumn{2}{|c|}{$\begin{array}{c}\text { Stream and } \\
\text { Sample Point Number }\end{array}$} & $\begin{array}{c}\text { Weight of Process } \\
\text { Stream (lbs) }\end{array}$ & $\begin{array}{c}\text { Volume of Process } \\
\text { Stream (gallons) }\end{array}$ & $\begin{array}{l}\text { Weight of } \\
\text { Sample (lbs) }\end{array}$ \\
\hline \multicolumn{2}{|c|}{ Feed Soil - 1} & 377 & & 2.3 \\
\hline \multicolumn{2}{|c|}{31 (to CRU5) } & & & 5.6 \\
\hline \multicolumn{2}{|c|}{51 (to ORNL) } & & & 5.4 \\
\hline \multicolumn{2}{|c|}{ Trommel Oversize -2 } & 11.5 & & 2.9 \\
\hline \multicolumn{2}{|c|}{ Reaction 1 - 8} & & 350 & 2.55 gal. drums \\
\hline \multicolumn{2}{|c|}{ Reaction 2 - 8} & & 250 & \\
\hline \multicolumn{2}{|c|}{ Reaction 3 - 8} & & 250 & \\
\hline \multicolumn{2}{|c|}{ Leached Solids $1-60$} & 342.5 & & \\
\hline \multicolumn{2}{|c|}{ Leached Solids 2 - 70} & 331.5 & & \\
\hline \multicolumn{2}{|c|}{ Leached Solids 3 - 80} & 326.5 & & \\
\hline \multicolumn{2}{|c|}{ Rinse Cycle Solids $1-90$} & 320 & & \\
\hline \multicolumn{2}{|c|}{ Rinse Cycle Solids 2 - 10} & 330.5 & & \\
\hline \multicolumn{2}{|c|}{ Centrifuge Centrate - 11A } & & 325 & \\
\hline \multicolumn{2}{|c|}{ Centrifuge Centrate - 11B } & & 275 & \\
\hline \multicolumn{2}{|c|}{ Centrifuge Centrate - $11 \mathrm{C}$} & & 325 & \\
\hline \multicolumn{2}{|c|}{ Centrifuge Centrate - 11D } & & 240 & \\
\hline \multicolumn{2}{|c|}{ Centrifuge Centrate - 11E } & & 270 & \\
\hline \multicolumn{2}{|c|}{ Trommel Screen Heel - 81} & 15.5 & & \\
\hline \multicolumn{2}{|c|}{ Centrifuge Heel - 82} & 24 & & \\
\hline \multirow[t]{3}{*}{ Chemicals } & Reaction 1 & 67.5 & & \\
\hline & Reaction 2 & 48 & & \\
\hline & Reaction 3 & 48 & & \\
\hline
\end{tabular}


Test No. 21

\section{PHASE II SOIL WASHING PLOT PLANT / PROCESS DATA}

\begin{tabular}{|c|c|c|c|c|}
\hline \multicolumn{2}{|c|}{$\begin{array}{c}\text { Stream and } \\
\text { Sample Point Number }\end{array}$} & $\begin{array}{c}\text { Weight of Process } \\
\text { Stream (lbs) }\end{array}$ & $\begin{array}{l}\text { Volume of Process } \\
\text { Stream (gallons) }\end{array}$ & $\begin{array}{c}\text { Weight of } \\
\text { Sample (lbs) }\end{array}$ \\
\hline \multicolumn{2}{|c|}{ Feed Soil - 1} & 328 & & 1.7 \\
\hline \multicolumn{2}{|c|}{31 (to CRU5) } & & & 3.9 \\
\hline \multicolumn{2}{|c|}{51 (to ORNL) } & & & 7.1 \\
\hline \multicolumn{2}{|c|}{ Trommel Oversize - 2} & & & 1.9 \\
\hline \multicolumn{2}{|c|}{ Reaction $1-8$} & & 350 & 2 - $55 \mathrm{gal}$. drums \\
\hline \multicolumn{2}{|c|}{ Reaction 2 - 8} & & 250 & \\
\hline \multicolumn{2}{|c|}{ Reaction 3 - 8} & & 250 & \\
\hline \multicolumn{2}{|c|}{ Leached Solids 1 - 60} & 280.5 & & \\
\hline \multicolumn{2}{|c|}{ Leached Solids $2-70$} & 284 & & \\
\hline \multicolumn{2}{|c|}{ Leached Solids 3 - 80} & 284 & & \\
\hline \multicolumn{2}{|c|}{ Rinse Cycle Solids 1 - 90} & 269.5 & & \\
\hline \multicolumn{2}{|c|}{ Rinse Cycle Solids 2 - 10} & 289.5 & & \\
\hline \multicolumn{2}{|c|}{ Centrifuge Centrate - 11A } & & 320 & \\
\hline \multicolumn{2}{|c|}{ Centrifuge Centrate - 11B } & & 310 & \\
\hline \multicolumn{2}{|c|}{ Centrifuge Centrate - 11C } & & 325 & \\
\hline \multicolumn{5}{|c|}{ Centrifuge Centrate - 11D } \\
\hline \multicolumn{2}{|c|}{ Centrifuge Centrate - 11E } & & 290 & \\
\hline \multicolumn{2}{|c|}{ Trommel Screen Heel - 81} & 25.5 & & \\
\hline \multicolumn{2}{|c|}{ Centrifuge Heel - 82} & 28.5 & & \\
\hline \multirow[t]{3}{*}{ Chemicals } & Reaction 1 & 67.5 & & \\
\hline & Reaction 2 & 48 & & \\
\hline & Reaction 3 & 48 & & \\
\hline
\end{tabular}


Test No. 22

PHASE II SOIL WASHING PILOT PLANT / PROCESS DATA.

\begin{tabular}{|c|c|c|c|c|}
\hline \multicolumn{2}{|c|}{$\begin{array}{c}\text { Stream and } \\
\text { Sample Point Number }\end{array}$} & $\begin{array}{l}\text { Weight of Process } \\
\text { Stream (lbs) }\end{array}$ & $\begin{array}{l}\text { Volume of Process } \\
\text { Stream (gallons) }\end{array}$ & $\begin{array}{c}\text { Weight of } \\
\text { Sample (lbs) }\end{array}$ \\
\hline \multicolumn{2}{|c|}{ Feed Soil - 1} & 372 & & $\approx 2$ \\
\hline \multicolumn{2}{|c|}{31 (to CRU5) } & & & \multirow[t]{2}{*}{$\approx 11$} \\
\hline \multicolumn{2}{|c|}{51 (to ORNL) } & & & \\
\hline \multicolumn{2}{|c|}{ Trommel Oversize -2} & 9.5 & & $\approx 3$ \\
\hline \multicolumn{2}{|c|}{ Reaction $1-8$} & & 350 & \\
\hline \multicolumn{2}{|c|}{ Reaction 2 - 8} & & 350 & \\
\hline \multicolumn{2}{|c|}{ Reaction 3 - 8} & & 350 & \\
\hline \multicolumn{2}{|c|}{ Leached Solids $1-60$} & 442 & & \\
\hline \multicolumn{2}{|c|}{ Leached Solids 2 - 70} & 411 & & \\
\hline \multicolumn{2}{|c|}{ Leached Solids 3 - 80} & 399 & & \\
\hline \multicolumn{2}{|c|}{ Rinse Cycle Solids 1 - 90} & 391 & & \\
\hline \multicolumn{2}{|c|}{ Rinse Cycle Solids $2-10$} & 433.5 & & \\
\hline \multicolumn{2}{|c|}{ Centrifuge Centrate - $11 \mathrm{~A}$} & & 405 & \\
\hline \multicolumn{2}{|c|}{ Centrifuge Centrate - 11B } & & 405 & \\
\hline \multicolumn{2}{|c|}{ Centrifuge Centrate - 11C } & & 375 & \\
\hline \multicolumn{2}{|c|}{ Centrifuge Centrate - 11D } & & 370 & \\
\hline \multicolumn{2}{|c|}{ Centrifuge Centrate - $11 \mathrm{E}$} & & 370 & \\
\hline \multicolumn{2}{|c|}{ Trommel Screen Heel - 81} & 24 & & \\
\hline \multicolumn{2}{|c|}{ Centrifuge Heel - 82} & 40 & & \\
\hline \multirow[t]{3}{*}{ Chemicals } & Reaction 1 & 67.5 & & \\
\hline & Reaction 2 & 62 & & \\
\hline & Reaction 3 & 62 & & \\
\hline
\end{tabular}


Test No. 25

PHASE II SOIL WASHING PILOT PLANT / PROCESS DATA

\begin{tabular}{|c|c|c|c|c|}
\hline \multicolumn{2}{|c|}{$\begin{array}{c}\text { Stream and } \\
\text { Sample Point Number }\end{array}$} & $\begin{array}{l}\text { Weight of Process } \\
\text { Stream (lbs) }\end{array}$ & $\begin{array}{l}\text { Volume of Process } \\
\text { Stream (gallons) }\end{array}$ & $\begin{array}{l}\text { Weight of } \\
\text { Sample (lbs) }\end{array}$ \\
\hline \multicolumn{2}{|c|}{ Feed Soil - 1} & 327 & & $\approx 2$ \\
\hline \multicolumn{2}{|c|}{31 (to CRUS) } & & & \multirow[t]{2}{*}{$\approx 11$} \\
\hline \multicolumn{2}{|c|}{51 (to ORNL) } & & & \\
\hline \multicolumn{2}{|c|}{ Trommel Oversize -2} & 15.5 & & $\approx 3$ \\
\hline \multicolumn{2}{|c|}{ Reaction $1-8$} & & 350 & 2 - 55 gal. drums \\
\hline \multicolumn{2}{|c|}{ Reaction 2-8 } & & 250 & \\
\hline \multicolumn{2}{|c|}{ Reaction $3-8$} & & 250 & \\
\hline \multicolumn{2}{|c|}{ Leached Solids 1 - 60} & 286.5 & & \\
\hline \multicolumn{2}{|c|}{ Leached Solids $2-70$} & 269.5 & & \\
\hline \multicolumn{2}{|c|}{ Leached Solids 3 - 80} & 270.5 & & \\
\hline \multicolumn{2}{|c|}{ Rinse Cycle Solids 1 - 90} & 269.5 & & \\
\hline \multicolumn{2}{|c|}{ Rinse Cycle Solids $2-10$} & 267.5 & & \\
\hline \multicolumn{2}{|c|}{ Centrifuge Centrate - 11A } & & 325 & \\
\hline \multicolumn{2}{|c|}{ Centrifuge Centrate - 11B } & & 275 & \\
\hline \multicolumn{2}{|c|}{ Centrifuge Centrate - 11C } & & 350 & \\
\hline \multicolumn{2}{|c|}{ Centrifuge Centrate - 11D } & & 275 & \\
\hline \multicolumn{2}{|c|}{ Centrifuge Centrate - 11E } & & 300 & \\
\hline \multicolumn{2}{|c|}{ Trommel Screen Heel - 81} & 24.5 & & \\
\hline \multicolumn{2}{|c|}{ Centrifuge Heel - 82} & 20 to 30 & & \\
\hline \multirow[t]{3}{*}{ Chemicals } & Reaction 1 & 67.5 & & \\
\hline & Reaction 2 & 48 & & \\
\hline & Reaction 3 & 48 & & \\
\hline
\end{tabular}


APPENDIX C

ANALYTICAL RESULTS 


\section{APPENDIX C}

\section{ANALYTICAL RESULTS}

All of the analytical results from the Phase II tests are included in Appendix C. For each result, the test number and the sample number are shown as part of the User Sample Identification Number. For example, T4S830 refers to the reactor filtrate sample taken at a reaction time of $30 \mathrm{~min}$ in Test 4 (refer to Appendix A for a description of the sample points). 
RELEASE MULGER : 1000001428

PROLECT HAKE : 50.05.03 93-614 CRUS \$NO TREAT-PHASE II

\begin{tabular}{|c|c|c|c|c|c|c|c|c|}
\hline LAB & SAMPLE ID USER SAKPLE ID & SAMPLE POINT & SUFFIX COAPONENT & RESULI & UMITS & 느 & $\begin{array}{l}\text { DATE } \\
\text { SAMPLED }\end{array}$ & $\begin{array}{l}\text { DATE TAST } \\
\text { PEREonyED }\end{array}$ \\
\hline INORENUTCS-EPH & $20002574893-616-1000145$ & $59-1$ & solios & 85.6 & we $x$ & & $23-140 \mathrm{~V}-93$ & 3 OS-DEC- 93 \\
\hline IKOREANIES-EPH & $20002576893-616-7000765$ & $5 P-1$ & URentiva & 1520 & pesp & & $23-$ nov-93 & 3 17-DEC-93 \\
\hline IMORGNICS-EPN & $20002574893-616-1000 T 65$ & $S P-1$ & URAKIUM & 1670 & Ppon od & & $23-$ Hov- 93 & $301-\mathrm{MuR}-96$ \\
\hline inoreanies-EPM & $20002575773-616-1003-16$ & SP-2 & SOLIDS & 91.6 & ue $\mathbf{x}$ & & $23-10 v-93$ & $310-$ FEB- 96 \\
\hline SHORENUJCS-EPY & $20002575793-616-1003-74$ & $s p-2$ & URAHILA & 1500 & Pom & & $23-120 V-93$ & 315-DEC-93 \\
\hline IHOReNHICS-EPM & $20002575893-616-T 6512$ & $s p \cdot 12$ & $\mathbf{P H}$ & 8.41 & pH un & & 23-wov-g3 & $07-08 c-93$ \\
\hline JHORCAMICS-EPM & $20002575893-614-14512$ & SP-12 & URANTUY & 1.6 & $\cos$ & & $23-$ NoV-93 & $07-D E C-93$ \\
\hline IMOREAHICS-EPY & $20002575993-616-1006-74$ & $5 p-6$ & sol 108 & 64.7 & we $x$ & & 26-10v-93 & 30-8EB-96 \\
\hline IMOReAUtCS-EPW & $20002575993-616-1006-76$ & $5 P-6$ & uneniun & 780 & ppon & & $26-\operatorname{mov}-93$ & 3 15-DEC-93 \\
\hline
\end{tabular}

Your selection cricerio Wens Release Mnber: $x$ Fren Received Dates $x$

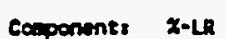
Display Text? N
Subaieston ID: $\%$ Project Manal $50.05 .08 \times 9 \%-616 x$ 
RELEASE MUKaER : 1000001648

PROSECT WAKE : 50.05.08 93-614 CRUS $1 / 0$ TREAT-PHASE II

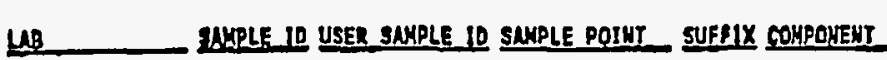

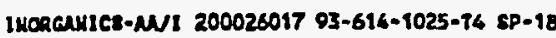
thORENHICs-MNI 200026017 93-614-1025-16 sp-18 IMORGANICS-M/1 200026017 $93-614-1025-T 6$ SP-18 IHorcunics-M/I 200026017 93-614-1025-76 sp-18 Inonautcs-MVI 200026017 93-616-1025-74 sp-18 Inoreunics-MVI 200026017 93-616-1025-76 Sp-18 IMOAGANICS-MNI 200026017 93-616-1025-16 SP-1B

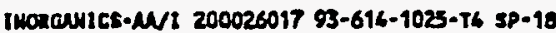
Inonourtes-M/1 200026017 93-616-1025-T6 SP-18 Imorantcs-MVI 200026017 93-616-1025-74 5P-18 IMORenuICs-MN/ 200026017 93-616-1025-T6 5p-18 Inorgantes-EDH 200026239 93-614-1011-74 SP-RB ILOREANICS-EPH 200026240 93-614-1012-T6 SP-FB IMOREANICS-EPM 200026261 93-616-1023-T4 SP-13 Inarenial-EPH 200026246 93-616-1025-T4 sp-18 IMONaUUTCS-EPM 200026244 93-616-5025-T4 SP-1E IHOREAMICS-EPW 200026245 93-616-1021-T6 SP-17 IHCRENICS-EPN 200026246 93-614-1022-T4 SP-15 IHoreuster-EPH 200026267 93-614-1024-T4 sp-16

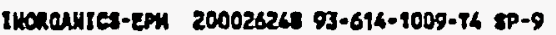
IHorentce-eph 200026218 93-616-1009-T6 sp-9 Ivanautcs-EPK 200026269 93-616-1014-Th sp-10-1 tworauics-eph 200026249 93-616-1016-T6 SP-10-1 IMOnQuitce-EPH 200026250 \$5-616-1015-T6 sp-10-2 inonaurcs-29H 200026250 93-616-1015-T6 SP-10-2 IHongurics-EPW 200026251 93-616-1017-76 sp-10-3 IHORGAHICS-EPH 200026251 93-616-1017-76 SP-10-3 ILONGUHCA-EPX 200026251 93-616-1017-16 9p-10-3

\begin{tabular}{|c|c|c|c|c|}
\hline Axtikony & 60.0 & $u g / 6$ & 0 & 02-DEC-93 07-DEC-93 = \\
\hline arsente & 10.0 & $\mathbf{u g} / \mathrm{L}$ & $\mathbf{u}$ & 02-0E6-93 05-JAN-96 D \\
\hline BERYLLLLU & 5.0 & $\omega / L$ & $\mathbf{U}$ & $02-D E S-93$ 07-0EC-93 B \\
\hline CADKIUA & 5.0 & Ug $/ L$ & $\mathbf{u}$ & 02-DEC-93 07-DEC-93 * \\
\hline CHRONIL:A & 10.0 & ugll & $\mathbf{u}$ & 02-0EC-93 07-046-93 \\
\hline COPPER & 25.0 & $\mathbf{u g} / \mathbf{6}$ & $\mathbf{u}$ & 02-085-93 07-085-93 \\
\hline LEAD & 6.0 & us/ $/ 6$ & $\mathbf{U}$ & $02-056-9328-0 E 6=93$ \\
\hline MICXEL & 60.0 & ug/l & $\mathbf{U}$ & 02-DEC-93 07-DEC-93 D \\
\hline SELENIUH & 5.0 & $\mathrm{ug} / \mathrm{l}$ & $u$ & $02-0 E 5-93$ 05- $1 \mathrm{AL}-94$ \\
\hline THALGIUN & 10.0 & $49 / 6$ & $\mathbf{v}$ & $02-016-9306-114 k-96=$ \\
\hline zrne & 637.0 & ug/l & & $02-056-93$ 07-0Ec-933 a \\
\hline URANILY & 0.2 & $\mathbf{n e / l}$ & & 03-DEC-93 09-DEC-93 \\
\hline URAiu & 0.9 & $m / 2$ & $\mathbf{u}$ & $01-0 E C-93$ 09-0EC-93 E \\
\hline Luktur & 1.0 & $m / 6$ & & 02-DEC-93 09-DEC-93 D \\
\hline PH & 7.73 & DH Un & & $02-0 E C-93 \quad 07-025-93$ \\
\hline URAHILA & 2.3 & $\infty / L$ & & 02-DEC-93 07-DEC-93 = \\
\hline IResice & 0.2 & $m / 2$ & & DZ-DEC-93 09-DEC-93 E \\
\hline LReTtU & 0.5 & $\infty / L$ & & O2-DEC-93 09-0EC-93 \\
\hline URAMTUA & 1.0 & $\mathbf{m} / 6$ & & $02-0 E C-93$ 0s-016-93 \\
\hline colios & 82.7 & wt $x$ & & $01-D E C-93$ 09-DEC-93 \\
\hline vantor & 210 & pom & & $01-D E C-9316-0 E C-93$ \\
\hline $\operatorname{soc} 105$ & 52.6 & ut $x$ & & $02-0 E C-9300-D E C-93=$ \\
\hline unerilus & 190 & par & & $02-0 E C-9316-D E C-93$ ह \\
\hline soutos & 57.2 & we $x$ & & O2-DEC-93 09-0EC-93 = \\
\hline URAMILA & 100 & ppq & & $02-D E C-9314-0 E 5-93=$ \\
\hline solios & 56.8 & we $x$ & & $02-0 E c-9309-056-93=$ \\
\hline ECANIUN & 59 & Ppm & & $02-0 E C-9316-0 E C-93$ C \\
\hline undius & 120 & ppond & & 02-DEC-93 07-puR-96 D \\
\hline
\end{tabular}

\section{Your selection Criturie Has: \\ nolease lumbers $\%$}

Fron Rucelved Dotes $x$

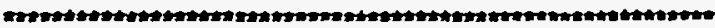

Componente: $x-L$

sutomistion 10: $x$

Proleet Hane: 50.05.005xy-616x

DATE DATT taST SAYPLED PERLORKED ASL

BESULI UNITS LL SAYYPLED PERLORKED ASL


$\begin{array}{llll}\text { FEB- 3-95 FRI 15:51 FERMCO ANALYTICAL } & \text { FAX NO. } 5137386667 & \text { P. O4 }\end{array}$

DATE 02-FEL-95

SUMGURY REPORT

PACE 3

TIKE 11:52:33

RELERSE MLABER : 1000001686

PRONECT WULE \& 50.05.08 93-614 CRUS I/D TREAT-PHASE II

LAB SAMPLE IO USER SNMPLEID QMMPLE POINT SUFEIX COMPONEHT

IMOUECNICE-EPM 200026595 93-614-1038-75 5-871 INGRGANTCS-8PH 20002689S 93-614-1038-TS S-82L INoraurics-IPM 200026898 93-614-1039-75 5-9 INORGNHICS-EPH 200026898 93-674-1039-75 5-9 IKONEANICS-EPW 200026899 93-614-1041-75 9-19 IKDECANICS-EPM 200026899 93-616-1061-T5 S-19 1MONCWHICS-EPH 200026900 93-614-1045-15 5-20 IHOAGAUICS-EPA 200026900 93-614-1045-75 s-20 IWONEAMICS-EPM 200026901 93-616-1062-15 \$-11a INERCuICS-EPH 200026901 93-616-1042-75 s-11A IHORCUHICS-EPH 200026902 93-616-75s114 5-111 INorGuICS-EPH 200026904 93-616-1063-74 8-22 INONCUNICS-EPM 200026906 93-614-1063-16 5-22 IHORGUVIC8-EPH 200026937 93-614-1038-15 s-8rs

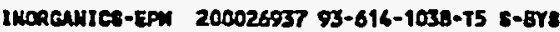

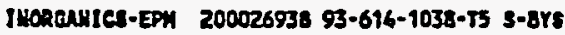
IHORGulcs-EPW 200026939 93-616-1036-75 5-8YL Imorcurtcs-EPW 200026939 93-616-1038-75 s-8YL IHCRCAUTC8-EPW 200026960 93-616-1038-75 5-85 Imoreurtes-epW 200026960 93-616-1038-75 s-8s JWoreanics-EPH 200026961 93-616-1036-TS s-815 IHORGANLCS-EPH 200026841 93-616-1038-75 5-815 IWOACUHICS-EPW 200026942 93-614-1038-15 S-830 IMoreunics-5PY 200026962 93-614-1038-T5 8-830 IICneawics-EPW 200026963 93-614-1038-75 5-860 IMORCANICS-EPH 200026943 03-616-1038-75 5-850 IHOREUICS-EPM 200026946 93-616-1038-15 8-825 ImoneAKIC5-EPM 200026945 93-616-1038-75 3-825 IHORCuNIC3-EPM 200026946 93-616-1038-15 8-825 IMORGAUICS-EPX 200026950 93-616-1064-T5 18 IMoreuniCs-EPM 200026950 93-616-1046-75 18 IMonaluice-MVi 200026951 93-616-1046-75 18 Iloncaxics-MVI 200026951 93-616-1046-75 18 I Horcuntcs-ANI 200026551 93-614-1046-t5 18 thoreantcs-MNt 200026951 93-616-1046-75 18 IHonGuricz-AM/1 200026951 93-614-1064-T5 is INoreuniCt-NVI 200026951 93-616-1046-75 18 IMDOCUNICs-MNI 200026951 93-614-1064-T5 18 IHoncenict-NI 200026951 93-614-1046-75 18 Iroreanics-MVI 200026951 93-614-1064-75 18

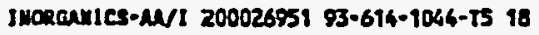
iwoneamics-MNi 200026951 93-614-1046-75 18

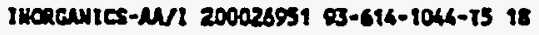
IMoncuntCS-EPW 200027666 93-616-1064-76 518 1HOREUMIC3-EPW 200027666 93-616-1066-76 518 IMOnGuHICs-MVI 200027667 93-614-1064-86 518 Imoreavics-M1 200027667 93-616-1064-76 S18
PH URANIUA SOLIDS URenisu souldes urenium SOLIDS UReNIUM PH ureniur SOLIOS urenius URANIU⿴⿱冂一⿰丨丨八 sotios

URovitur DEHSsTr AH Lrentur PH urensuar PH LRAMrux PH unauru PH บoevium urevisu oensitr SOLIDS PH URenIU⿴ ANTINOWY ARSEMIE MeRrLLIUU caprises enrowilu COPPER LED micres. SELENIUM silver THabliun zine PH LenNiun ANTIKOWY ARSEMIC

You selection Critaris wes:

Releasa Nubars 8

Prow Racalved Dates $\mathbf{x}$

Companene: $x-1$ h Diapley Text? 4

DATE DATE TAKK

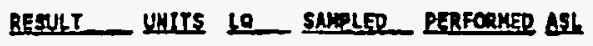

9.46 76.8 77.3

56.5 230 58.0 120$$
9.36
$$

116

9530

118

111

5.7

146

1.06

7.40

45.1

0.42

74.7

9.43

62.4

9.46

30

9.46

63.4

150

1.06

61895

9.67

17.5

60.0

100.0

16.1

11.5

259.5

1121

407.2

462.6

100

10.0

900

185?

9.55

13.0

60.0

100 ph Un

mg/L

we $x$

ppon d

we $X$

Pros d

ye $x$

pand

pH in

pan

$\cos / 6$

ppa

ag/

we $z$

pon

g/at.

oft th

noth

on Un

no/

pt un

og/L

ph un

ng/6

pit in

mos

pon

g/al

$\mathrm{ma/L}$

pH in

$\mathrm{mo/t}$

wo/l 4

ug/L U

ug/L

$49 / 6$

ug/

us/

$\mathrm{ug} / \mathrm{L}$

unt

4a/L U

$w / 6 \quad U$

$w / 4$

uoll

puts

a/l

$\mathbf{\omega} / \mathbf{L}$

ug/t U
07-0EC- 93 13-0EC- 93 D 07-DEC-93 16-DRC-03 घ 07-0EC-93 13-0EC-93 07-0EC-95 16-DEC-93 07-DEE-93 13-DEC-93 D 07-DEC-93 16-DEC-93 3 OS-DEC-93 13-DEC-93 D 08-0ze-93 16.0Re-93 07-DEC-93 15-DEC-93 B 07-0EC-93 17-0EC-93 07-DEC-93 16-DEC- 93 0s-0EC-93 17-0工e-93 co-DEC-93 03-FEs-96 = 07-05C-93 13-0RC-93 07-OEC-93 17-016-93 07-DEC-93 17-DRe-93 a 07-0LC-93 16-0LC-93 07-0EC-93 17-DEC-9S 07-DEC-93 16-DEC-93 07-DEC-93 17-0EC-93 थ O7-DEC-93 15-DEC-93 07-0EC-93 17-0EC-93 C 07-DEC-93 16-DEC-93 D 07-0EC-9B 16-DEC-93 07-0EC-As 16-DLC-93 o7-bre-9s 17-axc-93 07-02C-93 17-DEC-93 07-DEC-93 17-0EC-93 07-DEC-93 16-DEC-93 ह 0A-DEC-93 13-DEC- 93 a C8-0EC-93 10-0EC-93 0 08-DEC-93 10-DEC-93 05-0EC-93 14-02C-93 D 08-DEC-93 10-DEC-93 B 08-DEC- 33 10-DIe- 0 0.-DLe-93 10-DEC-93 08-0EC-93 10-DEC-93 08-DEC- 93 10-DEC- 93 08-DEC-93 10-DEC-93 08-DEC-93 03-JAN-96 08-0EC-93 10-DEC-93 = 08-DEC-93 11-JNi-96 D D8-DEC- 93 10-DEC-93 ] D9-0EC-93 13-DIC-93 09-DEC-O3 10-DEC-9S 09-DEC-93 13-DEC-93 09-DEC-93 16-DEC-93 (1) 
$\begin{array}{llll}\text { FEB- 3-95 FRI } 15: 52 \text { FERMCO ANALYTICAL } & \text { FAX NO. } 5137386667 & \text { P. } 05\end{array}$

DATE O2-FEI-95

SWWHRY REPORT

PAEE 4

TIKE 11,52133

RELEASE MUMBER : 1000001686

PROJECT WUKE I 50.05.08 93-616 CRUS I/O TREAT-PHASE II

느

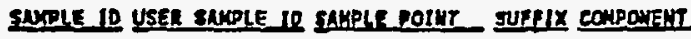

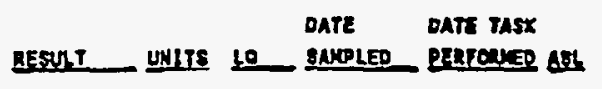

IKoreunica-NVI $20002766793-614-1086-16518$ JKorcuntct-NNI 200027667 93-614-1066-T6 518 thoncuitcs-MVI 200027667 93-614-1066-T6 \$18 Inoneautcs-MVI 200027667 93-616-1064-16 518 IHoRenulCs-M/l 200027667 93-616-1066-T6 818 IHORGUYIES-MVI 20002766793-616-1066-76 $\$ 18$ IKOAGAHICL-NI 200027667 93-614-9066-76 \$18 IHORCunIC8-MVI 200027667 93-614-1064-16 518

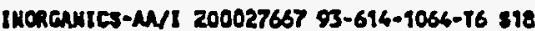
Inoredutcs-M/l 200027667 93-616-1066-96 818 1KOREAXICS-EPA 200027813 93-616-1026-75 8-118 IHORCEHICA-EPM 200027a13 93-614-1046-T5 S-118 IHonaukres-EPH 200027516 93-614-1048-75 s-11C IMorcunrCs-EPM 200027a14 93-616-1048-75 s-19C IMORCAMICS-EPH 200027815 93-614-1046-15 5-118 IHOU CUNICS- IPM 200027818 93-614-1048-75 s-11C IMORGAUICS-EPH 200027331 93-614-1049-T5 5-17 IKoncunics-IPH 200027034 93-614-1057-75 s-13 IHORGAMICS-EPM 200027835 93-616-1050-15 s-15 ZKoneANICS-Em 200027836 93-616-1051-TS 8-16 IHONENICS-EPM 200027337 93-616-1052-15 8-16 IHoncanics-EPW 200027340 93-614-1063-T6 8-12 troteunics-EPH 200027346 93-616-1047-75 3-10 Inonaunics-LPH 200027246 93-614-1047-15 s-10

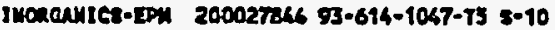
Inoreculics-zen 200027845 93-614-1035-T3 5-RB

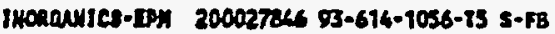
I Horeurics-EDA 200027447 93-616-1058-76 8-1 IHOHCuNICS-EPN 200027017 93-616-1058-16 5-1

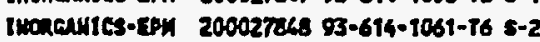

\begin{tabular}{|c|c|c|c|c|}
\hline $\begin{array}{l}\text { DERYLLIUH } \\
\text { CAOHILK }\end{array}$ & $\begin{array}{l}5.0 \\
5.0\end{array}$ & ug/L & $\begin{array}{l}u \\
u\end{array}$ & $\begin{array}{l}09 \text {-0Ec-93 13-0EC-93 } \\
09 \text {-DEc-93 13-bEc-93 }\end{array}$ \\
\hline $\begin{array}{l}\text { chonitu } \\
\text { Chrowion }\end{array}$ & 40,1 & 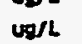 & & $\begin{array}{l}09-D E C-93 \\
13-0 R C-93\end{array}$ \\
\hline coprea & 239.6 & $u=/ L$ & & $09-\operatorname{Dec}-93 \quad 13-$ Dec- 93 \\
\hline LEND & 74.0 & $u g / L$ & & $09-0 E E-93 \quad 15-D E E-93$ \\
\hline HICXEL & 102.7 & $u g / 6$ & & $09-0 E C-93 \quad 13-0 E C-93$ \\
\hline SELEMIUM & 100 & ug/L & u & O9-DEC-93 03-SAN-96 \\
\hline SILVER & 10.0 & $u g / L$ & u & 09-DEC-93 $13-0 E C-93$ \\
\hline Treacesuen & 10.0 & $u g / L$ & v & 09-DEC-93 07- JlW-96 \\
\hline ZIXe & 372.7 & $U \mathrm{U} / \mathrm{h}$ & & $09-D E C-93 \quad 13-\infty E C-93$ \\
\hline PH & 9.37 & ph un & & $08-0 E C-93$ 16-OEC-93 \\
\hline LReNitum & 18 & pem & & 08-DEC-93 17-DRC-93 D \\
\hline PH & 9.66 & pH un & & O8-DEC-93 $96-D E C-93$ \\
\hline LReMILA & 3 & ppon & & D8-DEC-93 16-0EG-93 \\
\hline Sol.1Ds & 5815 & $\mathrm{ma} / \mathrm{L}$ & & C8-0EC-93 16-0EC-93 \\
\hline SOLIDS & 1630 & $m g / L$ & & $08-D E C-93 \quad 16-D E[-9]$ \\
\hline venimium & 0.2 & $\infty / L$ & & $08-D E C-93 \quad 16-D E C-93=$ \\
\hline чRен1L: & 0.6 & $=2 / 6$ & & 08-0EC-93 $16-8 E C-93$ \\
\hline vecurlut & 0.4 & $m / 2$ & & QS-DEC-93 17-DRe-93 \\
\hline veraniom & 0.7 & $m / 2$ & & $08-025-9316-8 c c-93$ \\
\hline Uramitun & 1.3 & $\omega / L$ & & 08-0<c-93 16-06c-93 = \\
\hline Lrawitas & 4.2 & $\mathrm{ma} / \mathrm{L}$ & & D9-DEe-93 16-DEE-93 \\
\hline 80110s & 56.2 & wt $x$ & & DQ-DEC-93 23-DEC-93 I \\
\hline veraitur & 130 & ppom d & & $08-0 E C-93$ 16-0EE-93 \\
\hline URENIUM & 101 & ppon o & & Q5-9EC-93 03. \\
\hline veenitur & 12.2 & $\mathbf{m a / L}$ & & $09-0 E C-93$ 16-AEC-93 \\
\hline urenitu & 0.1 & $\mathrm{me/t}$ & u & $09-056-93$ 16-8ec-93 \\
\hline solios & 85.6 & we $x$ & & $09-0<c-93$ 13-x<e-93 \\
\hline Gruilus & 1830 & $\operatorname{pond}$ & & DQ-DEC-93 16-DEC-93 $=$ \\
\hline Lenertur & 1470 & pond & & 09-8Ee-93 16-015-93 \\
\hline
\end{tabular}

Your selection Eritoris wass

Releave nubarl $z$

from Recalved onses $\$$

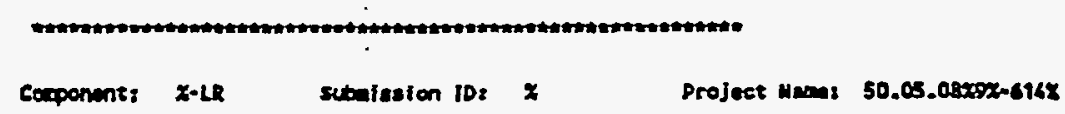

Dieplay Text? 
LA SUMPLE ID USER SAMPLE ID SAMPLE POIUT SUEFIX CONPOUENT

IMORCunics-EPM 200032397 96-616-1100-11 17 INORGANIES-EPA 200032393 96-616-1101-T1 13 tHOREANICS-EPX 200032399 94-616-1103-T1 15 INORCUNICS-EPM 200032400 96-614-1105-T1 16 INORGAHICs-EPX 200032601 96-614-1109-T1 16 INerauics-EPH 200032402 96-616-1110-T1 21 1Haxcuxics-EPH 200032402 96-616-1110-71 21 IMORCANICS-EPM 200032603 $96-616-1102-\$ 1111$ INORENAICS-EPW 200032403 96-616-1102-T1 118

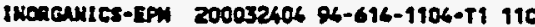
IKORCUNICB-EPM 200032606 96-616-1904-71 I1C IworGanics-EPM 200032403 96-616-1102-T1 118 IHoRGUHCS-EPA 200032408 94-616-1106-T1 T1C SHoraunICs-EPM 200032600 96-616-1106-T1 10 IHorganics-EPM 200032609 96-616-1106-11 10 INORGUHICS-EPA 200032409 96-616-1106-T1 10

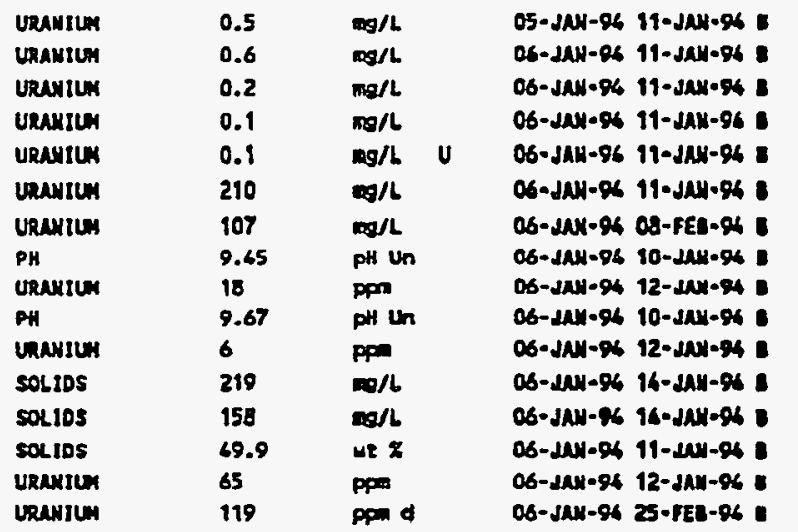

DATE DATE TASK

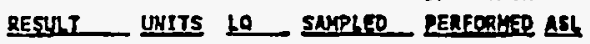

$0.1 \quad \mathrm{mg} / \mathrm{L}$

$210 \quad 0.6$

9.67 PH U

$210 \quad \mathrm{mos}$

69.9 ut $\%$

119 ppon of

\section{Your selection Criteris uass Relcase ulubers $x$} Frea Received Dutes $x$

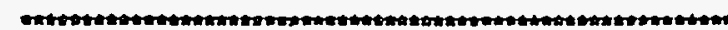

Componenss $x-L R$

Subatsuion IDS $x$

Project Mane: $50.05 .08 \times 9 x-614 x$

Dieplay Texts II 
TIKE 11:52.33

RELEASE MUKBER \& 1000001663

PROJECT WAME I 50.05.08 93-616 CRUS I/D TREAT-PHASE II

LAB SNAPLE DO USER SAMPLE ID SAMPLE DOINT SUFFIX CONPONENT

IHORGAHICE-EPY 200032785 94-614-1119-T1 18 IKORCANICS-EPX 200032785 96-616-1119-TI 1B IMORGAHICS-M/L 200032786 96-616-1119-TI 18

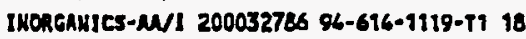
IHORGANICS-MVI 200032786 96-616-1119-11 18 IKongules-M/I 2000327es 94-616-1119-T1 18 I WoranICs-M/I 200032786 96-616-1119-TI 18 IHORCANICS-MNI 2000327es 94-614-1119-19 18 INoreurtes-M/l 200032786 94-614-1119-T1 28 IKCRCANICS-NNI 200032785 94-616-1119-71 18 Inotcunics-MVI 200032786 94-614-1119-T1 18 IHORGAWICS-NWI 2000327es 96-614-1119-11 18 IMORCNUJCS-MVI 200032786 96-614-1119-T1 18 IHoRaures-N/ 200032786 94-614-1119-71 18 IHORGUMICT-EPM 200032787 94-614-1119-T1 1 IMORGNICS-EPN 200032707 94-614-1111-T1 1 IMoreluses-EPM 200032767 94-616-1111-71 I IrodCUHICs-EPH 20003278s 94-674-1197-T1 19 INORGANIC2-EPM 20003278s 96-616-1117-I1 19 ImoReuHICs-EPM 200032789 94-616-1118-T1 20 1Horeulice-EPH 200032789 94-614-1118-T1 20 IHCRaurict-EPH 200032790 9h-614-1114-T1 2 IMorcauics-EPM 200032791 96-676-1115-71 12

\begin{tabular}{|c|c|c|c|c|c|}
\hline PH & 9.60 & ph Un & & $10-24 x-96$ & - 12-JAN-96 \\
\hline IRANILX & 32.7 & $\operatorname{mg} / \mathrm{L}$ & & $10-3 A N-96$ & $12-J A N-96$ \\
\hline AxtLONY & 60.0 & $\log / L$ & $\mathbf{u}$ & $10-J A H-9 S$ & - 13-JAN-96 \\
\hline ARSEMIC & 12.69 & Ug/L & & $10-J A K-96$ & 25-JNN-96 \\
\hline BERYLLIUH & 5.0 & ug/L & $u$ & 10-JAN-98 & $13-3101=94$ \\
\hline CADHILH & 5.0 & $\mathbf{u g / L}$ & $\mathbf{u}$ & $10-1 A N-94$ & $16-2016-96$ \\
\hline CHEOntU: & 47.2 & $v s / 6$ & & $10-J \mu N-96$ & 13-J21-96 \\
\hline COPPER & 429.5 & $u g / 6$ & & $10-5 \Delta \mu-94$ & $13-J N 1-96$ \\
\hline LEND & 112.0 & $v g / L$ & & $10-j 2 \mu-96$ & $26-146-96$ \\
\hline NICKEL & 107.7 & $u g / 6$ & & $10-5 \lambda M-96$ & $13-J A N-96$ \\
\hline SELEKIUH & 30.0 & ug/h & $\mathbf{u}$ & $10-J A 1-96$ & $25-J A N-96$ \\
\hline SILVER & 10.0 & $\operatorname{ug} n$ & $u$ & $10-J 14=96$ & $13-314-96$ \\
\hline THuLlith & 10.0 & ug/L & $\mathbf{u}$ & $10-J \mu N-94$ & $28-J A K-96$ \\
\hline zinc & 356.6 & $u g / L$ & & $10-2011-06$ & $13-12 x-94$ \\
\hline sol.10s & 85.6 & we $x$ & & $10-$ JAH-94 & $11-504-94$ \\
\hline unangur & 1670 & pin & & 20-21N-94 & $12-401-96$ \\
\hline URANsen & 1588 & ppond & & $10-2 N N-94$ & c5-kek-94 \\
\hline soltos & 85.3 & we $x$ & & $10-2 A N-94$ & $11-201-98$ \\
\hline uncistur & 1620 & $\mathbf{m a n}$ & & $10-2 \mathrm{N1}-\mathrm{gs}$ & $12-J \mu x-94$ \\
\hline 504105 & 85.6 & we $X$ & & $10-2 \mathrm{NN}-94$ & $11-J \Delta k-\infty 6$ \\
\hline unarion & 1620 & ppn & & $10-2101-96$ & 12-JAX-O6 \\
\hline URAKIUN & 950 & ppos & & $10-J A N-Q 6$ & 12-JAN-94 \\
\hline URantun & 1.6 & m/L & & $10-J A N-Q 6$ & $12-244-94$ \\
\hline
\end{tabular}

DATS DafE ThST RESULI U UHITS LO

in $10-34 \mathrm{~N}-96$ 12-J4N-96 mg/L 10-JAN-96 12-JAN-96 $10-\mathrm{JAH}-96$ 13-J)N-96 g/L $\quad 90-\mathrm{JAK}-96$ 25-JAN-96

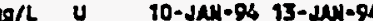

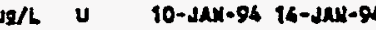

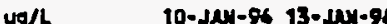
Ug/L $\quad$ 10-JAN-96 13-JAN-96

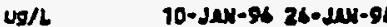
$\mathrm{ug} / \mathrm{L} \quad$ 10-JAN-96 13-JAN-96

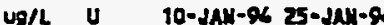

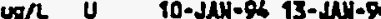

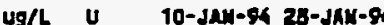
ug/L 10-72011-96 13-70N-96

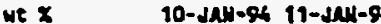

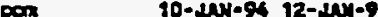

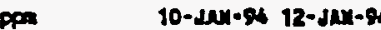
ut $x \quad 10-\mathrm{JNN}-9411-\mathrm{JaN}-96$ $10-J A N-96$ 12-2AN-96

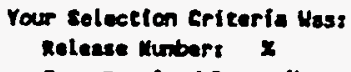

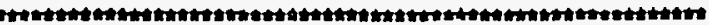

Componants X-LR

Display Text? sutuixsion 10: $x$

\section{$\mathbf{7}$}

Project Maros: 50.05.00252-616x 
$\begin{array}{llll}\text { FEB- 3-95 FRI } 15: 55 \text { FERMCO ANALYTICAL } & \text { FAX NO. } 5137386667 & \text { P. } 08\end{array}$

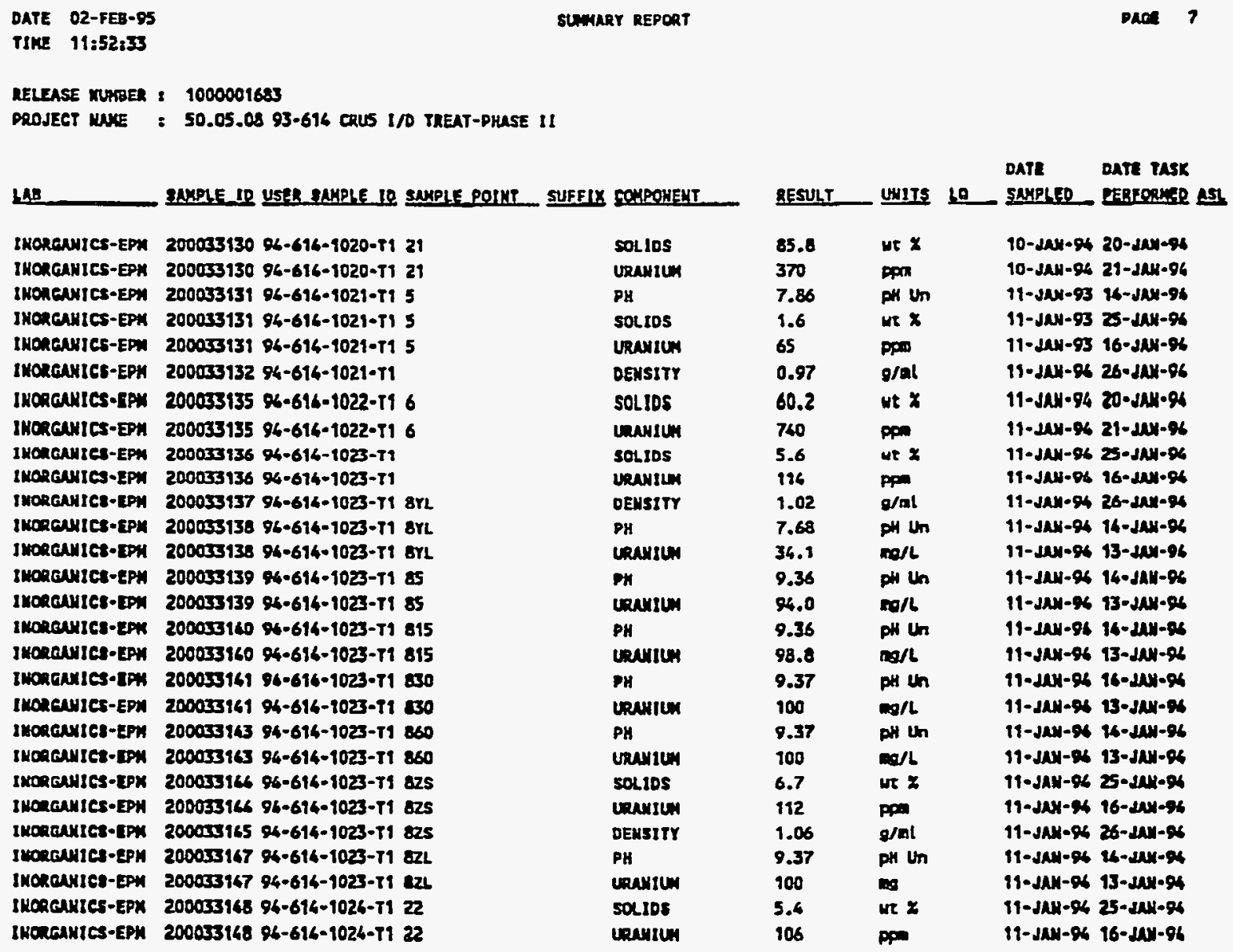

rour selection critenfle vas:

Release Mubars $x$

From Reeoived Dater $x$ cheresto

Compenenes $x-L R$

subaistion $108 x$

Project Mana: 50.05.00x9x-616x

Dieplay Texis 
RELEASE WUAER I 1000001607

PROSECT RHEE \& 50.05.08 93-616 CUUS I/D TREAT-PruSE II

$\mu B$

IMYPLE ID USER MAMPLE IO SAMPLE POIMT SUEFIX COMPOMEMT

IKORGAHICa-MM/1 200033308 94-614-1162-T1 is

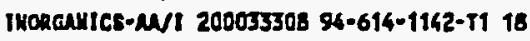
IKoncukics-N1 200033308 94-614-9142-T1 18

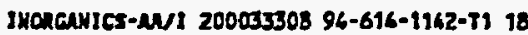
IMonoutce-MVI 200033508 94-614-1142-T1 18 JHoucuries-MVI 200033308 $24-614-1162-71$ 18

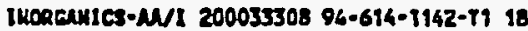
Imorounics-M/I 200053308 96-616-1142-T1 18

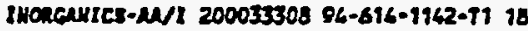

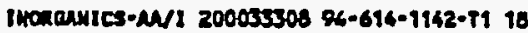
IHoreanics-MVI 200033308 96-616-1142-71 18 IHOWCWICs-NWI 200033308 96-616-1142-11 18 IHORGANICS-EPH 200053309 96-616-1142-11 10 IHoreuntcs-EPM 200033309 94-616-1142-71 18 IMONGCNICS-EPM 200033310 96-616-1136-11 11 IXoneuMtCS-EPM 200033310 94-614-1136-T1 11C Imoncante8-EPH 200033310 94-614-1136-71 I1C Imoneduics-EPH 200053311 96-616-1137-T1 13 IWOACUMICs-EPM 200033312 96-616-1127-11 11A IHoncuurcs-EPM 200033312 94-616-1127-11 114 IHoncayicr-EpH 200033312 96-616-1127-T1 114 IHONGWICS-EPW 200033313 96-614-1129-11 FB IHonewutcs-EPN 200033314 96-616-1163-11 27 Itoradutcs-Em 200033316 96-616-1143-11 27 thoucuntcs-IPm 200033316 96-616-1143-11 27

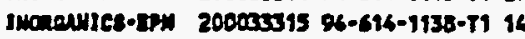

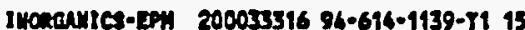
Inonanutca-IPH 200033317 96-616-1141-71 17 IMOnGAHICS-SPM 200033318 96-616-1160-11 16 IMONCANIES-EPM 200035319 Y4-616-1128-T1 118 I woresulcs-em 200035319 94-616-1128-T1 118 Inoncalles-E5M 200033319 96-616-8128-T1 111 INoreanics-EPA 200033520 84-616-1130-Y1 RE Imoncenitics-1PM 200033323 96-616-1125-71 23 IMONChIC5-ED 200033324 94-616-1131-71 10

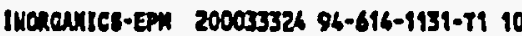
Imonculles-Em 200033326 94-616-9131-P1 10 IMORCUVICS-EPM 200033325 94-616-9126-T1 24

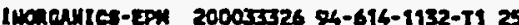
Imoncullics-ron 200033326 $96-616-1132-7125$

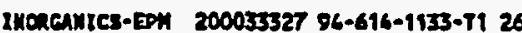
IMORGUICS-EPWI 200033327 \%6-616-1133-T1 26

\begin{tabular}{|c|c|c|c|c|}
\hline AMTIMONY & 60.0 & $w / L$ & $12-5 A N-96$ & $16-5(N)-96$ \\
\hline AREEWIC & 10.0 & $48 / 6$ & $92-J A N-84$ & 19-10N-86 \\
\hline gERYLLIUM & 5.0 & $48 / 6$ & $12-J A K-94$ & $16-2 N N \cdot 96$ \\
\hline CADMILM & 5.0 & $u g / 6$ & $12-21 N 1-94$ & $16-2 \mu N-96$ \\
\hline CHROHIUm & 35.8 & Ug/L & $12-\mathrm{J} A \mathrm{~N}-96$ & $16-5 N N-96$ \\
\hline COPPER & 280.3 & $w / L$ & $12-12 N-96$ & $16-20 \mu-96$ \\
\hline LEAD & 66.28 & cos & $12-\operatorname{seN}-860$ & $08-5 E \mid-96$ \\
\hline ntckel & 86.7 & $U 9 / 6$ & $12-5 k 14-24$ & $16-24111-96$ \\
\hline SELENIUY & 50.0 & $w=/ 6$ & $12-\operatorname{sen} 11-36=$ & $25-1211-96$ \\
\hline SILVER & 10.0 & Ug/L & $12-134-96$ & $16 ;-24 \mathrm{AN}-96$ \\
\hline THatlior & 50 & $\omega g / 6$ & $12-3 A N-963$ & $30-5 A N-96$ \\
\hline ZIKe & 274.7 & ug/L & $12-584-96$ & $16 \cdot J 1 N H-96$ \\
\hline PH & 9.36 & PH Un & $12-J A H-96$ & $x \in=14 \mu-96$ \\
\hline UREMtLA & 25.6 & $m / L$ & $12-\mathrm{dax}-94$ & $16-2121-94$ \\
\hline PH & 9.90 & pet un & $12-\mathrm{d} 2 \mathrm{~N}-96$ & $16-1201-96$ \\
\hline solios & 0.1 & we $z$ & $12-\operatorname{sen} x-96$ & $20-1201-96$ \\
\hline Lrewiun & 1.6 & $m s / L$ & 12-JAN-96 1 & $16-\sqrt{211}-96$ \\
\hline veantion & 1.6 & $m / L$ & $12-21 N-96$ & $16-21 \times 1+96$ \\
\hline PH & 0.39 & PH in & $12-3 \mu v-961$ & $16-2010-96$ \\
\hline SOLIDS & 1.6 & $w \tau x$ & $12-\mathrm{JN} / 262$ & $20-201-96$ \\
\hline cention & 85 & ppom & $12-24 x-96$ & $16-2126-96$ \\
\hline LRewium & 0.1 & $m / L$ & $12-\operatorname{sak}-\theta \mathrm{C}^{\prime}$ & $16-14 x-96$ \\
\hline PH & 9.38 & ph un & $13-J A N-961$ & $16-2 a k-94$ \\
\hline solios & 1.6 & we $x$ & $13-24 x-242$ & $20-2121-94$ \\
\hline LaNiun & 85.3 & $\infty / 6$ & $13-3 \mathrm{AK}-96$ & $16-2312-96$ \\
\hline verunitu & 0.2 & 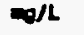 & $12-5 \mathrm{~N}-8 \mathrm{~S}, 1$ & $16-2046-96$ \\
\hline countun & 0.3 & $\infty$ & $12-24 k-561$ & $16-11 \times 1-96$ \\
\hline venion & 0.3 & $\mathbf{m a} / \mathbf{L}$ & $12-\operatorname{se} x-24$ & $16-2130-96$ \\
\hline Urenfur & 0.2 & $m / L$ & $13-\operatorname{sen}-96$ ? & $16-2 x N-96$ \\
\hline PH & 9.67 & DH Un & $12-3 \mu x-261$ & $16-204-96$ \\
\hline 50L105 & 0.3 & $w \tau x$ & $12-184-962$ & $20-1011-96$ \\
\hline veramzor & 10 & pp & $12-20 x-841$ & $16-214-96$ \\
\hline uarusur & 0.2 & $m / L$ & $12-\operatorname{saN}-86$ & $26-2 N-96$ \\
\hline couldos & 60.7 & ue $x$ & 12-JAN-94 2 & $20-5010-56$ \\
\hline saltos & 47.8 & wet $x$ & $12-542-942$ & $20-\operatorname{san}-96$ \\
\hline unevitury & 65 & ppn & $12-J 3 x-96$ & $\mu-J \mu \nu-\varphi$ \\
\hline Venstira & & pon o & $12-\mathrm{JAN}-8 \mathrm{SH}$ & \\
\hline EOLIDS & 53.7 & wt $x$ & $12-\operatorname{sen}-062$ & $20-14 x-86$ \\
\hline 80LIDS & 47.8 & we $x$ & $12-\operatorname{sen}-962$ & $20-\mathrm{SAM}-96$ \\
\hline Leavilur & 62 & pon & $12-\mathrm{JNA}-961$ & $16-22 x-96$ \\
\hline Sol.10s & 48.0 & we $x$ & $12-\operatorname{sen}-962$ & $20-25 x-96$ \\
\hline Lechinur & 59 & Ppon & $12-\mathrm{JAN}-94$ & $16-24 \times-94$ \\
\hline
\end{tabular}

Your selection criteria was: Relence unobars $x$ irom eccelved pates $x$

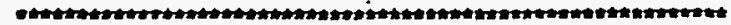


RELEASE MUKAER \& 1000001836

PROSECT KIME : 50.05.08 93-616 CRUS I/D TREAT-PHASE II

LAB SAMPLE TD USER SAKPLE ID SAMPLE DOINT SUFFIX COLPOHENT

INCReuHics-EPX 200037646 94-616-1959-71 s IHORCUIICS-EFX 200037645 94-616-1159-TI 5 IKORGAMICS-EPW 200037645 94-616-1159-T1 5 INOREUNICS-EPH 200037645 94-614-1159-71 5 INORCANIEA-EPM 200037646 94-614-1161-T1 ars IHORCANICS-EPY 200037667 96-616-1161-T1 825 IMCRedNics-EPM 200037648 96-616-1169-11 8YS IRORCAUICS-EPM 200057648 94-614-1161-T1 8Ys IMoreanies-EPH 200037650 94-616-1161-TI oYL IWCRGAnICE-EPX 200037650 96-614-116i-T1 8YL IHCRGuries-EPW 200037651 96-616-1161-T1 825 IMORCuNICS-EPM 200037651 96-614-1161-71 a25 IMOREunics-EPH 200037652 96-614-1161-T1 821 1worgantCE-EPM 200037652 94-614-1161-71 82L Inorecuries-EPM 200037652 94-616t1161-T1 82L INoreanies-EPX 200037653 96-616-1161-71 85 1WorenuICs-EPM 200037653 96-616-1161-11 85 INORGNITCS-EPM 200037654 96-616:1161-II 815

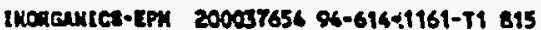
Inoneantcs-EPW 200037655 96-61681161-71 030 1NOREAUTC5-EPM 200037655 94-61641161-T9 B30 INCRECUICD-EPX 200037656 96-614<1161-T1 860 InOREenICs-EPN 200037656 96-61411161-T1 860 JKokQuires-EPH 200037657 96-61411164-71 11A IHORGANLCS-EPW 200037657 Ph-616-11964-71 11A Imorgentcs-EPA 200037657 96-61GA1166-T1 11A INORGAMICs-EPH 200037672 96-61641161-19 6 IworentCE-EPW 200037672 94-6iGi1161-i1 6 INORGuNIC5-EPW 200037697 94-614+1163-T1 80 IMonaulcs-IPW 200037697 96-61411163-T180

\begin{tabular}{|c|c|c|c|c|}
\hline $\begin{array}{l}\text { DEMSITY } \\
\text { PH }\end{array}$ & $\begin{array}{l}1.01 \\
7.04\end{array}$ & $\begin{array}{l}\text { g/mi } \\
\text { pht Un }\end{array}$ & $\begin{array}{l}03-F E B-96 \\
03-F E B-96\end{array}$ & $\begin{array}{l}16-\text { FEB-96 } \\
11-\text { FEU-9h }\end{array}$ \\
\hline SOLIOS & 0.9 & we $x$ & $03-F E B-96$ & $16-F E 0-96$ \\
\hline URANJUM & 20.0 & pos & $03-F E B-96$ & $11-1 E 2-96$ \\
\hline OEKSITY & 1.01 & gral & O3-FER-96 & $16-8 E R-96$ \\
\hline DEKSITY & 9.07 & $g / m b$ & OS-FEB-94 & 16-FEB-96 \\
\hline SOLIDS & 3.8 & we $x$ & $03-F E B-96$ & 16-FEL-96 \\
\hline UREMIUM & 32.1 & $\mathrm{mads}$ & 03-5ED-96 & 11 -FED-96 \\
\hline PH & 6.61 & py un & 03-FES-gh & 10-FEn-g4 \\
\hline venisiun & 2.6 & $m / L$ & C3-PEB-96 & 10-PEL-Q6 \\
\hline SOLIOS & 8.6 & we $x$ & 03-FEI-94 & 16-FEL-96 \\
\hline URentur & 55.81 & $\mathrm{mg} / \mathrm{L}$ & 03-FEB-94 & $11-F E=-96$ \\
\hline PH & 9.30 & PH Un & 03-FES-96 & 11-FEL-96 \\
\hline solids & 1.9 & we $x$ & 03-FET-94 & 16 -FEB-96 \\
\hline veranion & 65.2 & $\mathbf{m} / \mathrm{L}$ & 03-FEI-96 & 11-FEL-96 \\
\hline PH & 9.26 & phit Un & $03-5 E 5-96$ & $10-F 52-94$ \\
\hline URentum & 61.0 & $m / 2$ & $03-1 E 0-96$ & 20-res-of \\
\hline PH & 9.26 & ph un & 03-FE8-94 & 10-FEL-96 \\
\hline UReNiU: & 44.8 & $m g / h$ & D3-FE3-96 & $10-721-9$ \\
\hline PH & 9.25 & PH Un & $03-82 B-96$ & $10-P E D=94$ \\
\hline URAHIOA & 45.8 & $m / L$ & 03-FE8-94 & 10-FEB-96 \\
\hline PH & 9.26 & pH Un & $03-7 E B-96$ & 10-PED- 86 \\
\hline URenisuan & 46.8 & mo/L & O3-FER-96 & $10-$ F10-g6 \\
\hline PH & 9.32 & pan un & OS-PED-96 & $11-725-96$ \\
\hline saljos & 1.9 & we $x$ & $a b-F E z-g 6$ & $16-F E 2-96$ \\
\hline Crensiun & 46.0 & 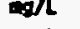 & 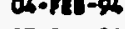 & 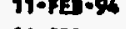 \\
\hline sotros & 66.3 & $u z x$ & $\omega 3-\sqrt{L}-96$ & $86-8 E 2-96$ \\
\hline unusizm & 350 & ppom & 03-FEE-96 & 12-FED-96 \\
\hline Soltos & 61.5 & we $x$ & $04-\operatorname{tEB}-96$ & $x-1, E]-\alpha$ \\
\hline Leentury & 75 & ppom & O4-FEZ-96 & 11-FE]-96 \\
\hline
\end{tabular}

04-FEQ-96 11-PEJ-96
oAte Date taSK SAMPLED PARYOQRED ASL

RESULT UNITS LO SO SAMPLED PERYOAMED ASL
Your selection Critoria vas:
Relesce muber: $x$ Prom Roenived oatez $X$

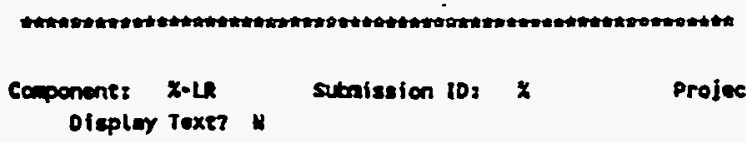


RELEASE MUMBER, 1000001875

PROJEGT YNNE : 50.05.08 93-616 CRUS 1/D TREAT-PHASE II

LA) SAMPLE ID USER SAMPLEID SAMPLE POIKT SUFFIX COKPONEHT

IKORCANICS-EPH 20003E677 96-616-1199-71 11A IHORGNHICS-EPH 200031677 04-616-1199-PI 11A INORCAHICS-ЕРИ 200038677 96-616-1199-91 11A WATER TREATKENT 200038678 94-616-1200-T1 118 IKCQCUNIES-EPH 200038678 94-614-1200-T1 118 1WORCAKTCS-EPM 200038678 94-614-1200-T1 118 JHOREAHICS-EPM 200038679 94-614-1201-T1 16 IHORGAutCs-EPM 20003E680 94-614-1206-T1 I1C IMORQUAICE-EPH 200038680 94-614-1204-71 11C JHORGAHICS-EPH 200038680 94-616-1206-71 11C UATER TREATKENT 200038681 94-614-1192-T1 5 iworeutLS-EPH 20003Ess1 9h-614-1192-T1 s IHorcautcs-EPH 200036681 94-614-1192-T1 5 INORCCUICS-EPA 200038682 96-616-1192-TI 5 IHORCuXICE-EPW 200038683 96-614-1194-T1 ors IHORCANIC8-SPW 200036683 96-616-1196-T1 Bys IHORCNuICs-EPH 20003e6s6 94-616-1194-T1 ors IKoncuutes-IPH 200038685 96-614-1199-11 on tMoreuntes-IPW 200038685 96-616-1199-T1 8YL IMONCulCs-EPM 200038686 96-694-1194-T1 85 THORGAYICS-EPH 200038686 96-616-1994-T1 85 thoucuics-EPH 200038687 96-616-1996-T1 815

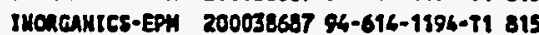
IMOnGasics-EPW 200038680 94-614-1196-T1 830 IMOReuHics-EPN 200038683 94.614-1194-T1 830 INORGANICt-LPW 200038689 96-614-1994-TI 260 IHoRenNICs-8PH 200038689 96-616-1194-71 860 IMONGUICS-EPA 200038689 94-616-1196-11 8S0 IHCRCuHICS-EPA 200038690 96-614-1199-11 825 IHCRGuHICs-IPN 200036591 96-616-1196-71 825 IKORCUIICS-EPH 20003Es91 94-614-1194-T1 B28 IKONGWICS-EPH 20003E692 94-616-1195-T1 82L IHORGNICS-EPM, 200038592 94-616-1195-71 822 IKORGAHICS-EPH 200038692 94-614-1995-71 821 IMORaUNies-EFH 200038692 96-616-1195-T1 8Z1 1Horeunics-EPY 200038s93 96-614-1210- 1113 IMGRounics-IPH 200038696 96-614-1209-71 14 IHORCAMIC5-EPM 200038695 94-616-1211-T1 17 IHCRGAUICs-EPW 20003a707 94-614-1203-71 18 JMORCWUICS-EPM 200036707 94-616-1203-71 18 IHORGuICS-M/1 200038703 94-616-1203-71 18 IKencuHIC5-M/1 20003a70s $94-616-1203-7118$ iconcunics-MVI 20003870s 94-616-1203-T1 18 IHoR QuHtCa-M/1 200038708 24-614-1203-71 is IKonGUiJCs-AMAl 200030708 94-614-1203-11 18 IKorquites-NW/ 20003870s 94-694-1203-T1 18 ILORCAUICF-NVI 200030708 94-614-1203-T1 is

\section{PH}

SOLIOS

URANILH

PH

SOLIOS

URAKIUH

UReNIUN

$\mathrm{PH}$

SOLIDS

URNIIUH

PH

SOLIÒs

Lreantim

DENSITY

so..105

URenicm

DExsITY

PH

vacrisur

PH

Leanius

PH

URAuiser

PH

LRANIU⿴⿱冂一⿰丨丨一𧘇卜

PH

veruitur

Uresisum

DEMSITY

SOLIDS

URAurum

PII

solios

usausun

urevitur

urensium

URovitur

UReiJum

PH

URAMILY

AReEMTC

EERTLILY

comstur

CHrowtum

COPPER

LEND

MICKEL

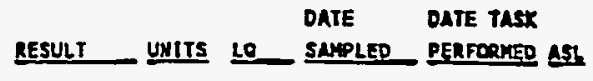

9.38 PK Un 10-FER-9R 12-FER-gh

2.0 we $x$

36 ppD

9.57 PH Un

0.3 we $x$

6 ppon

1 Pp U

9.51 pH un

0.2 we $x$

2 ppro

7.22 pH Un

1.3 We $X$

19 pen

$1.00 \quad \mathrm{~g} / \mathrm{mil}$

5.4 we $x$

62 pom

$1.02 \quad g / a l$

6.63 pH in

2

9.40

27

9.39

30

9.38

31

9.36

28

pap

phi un

ppos

plit in

pan

PA Un

PP

pHit in

pom

ogr

$1.05 \mathrm{~g} / \mathrm{ml}$

7.8 we $x$

49 Dom

9.36 pH in

1.9 we $x$

42 ppon

$42 \quad 00 / 1$

1 prom

1 prom

1 por $U$

9.56 PN in

9.56

10

27.2

5.0

5.0

35.8

136.0

86.4

\section{ppon}

wa/l

uall 4

$\omega / 6$

$\cos / 2$

vall

$58.1 \mathrm{ug} / \mathrm{L}$
10-FEJ - 16-FE8-96 10-FEB-SS 12-FER-96 90-PEQ-96 12-1ER-96 = 10-PEB-96 16-FE2-96 10-7ED-96 12-PES-96 10-1EE-96 12-Fft-gh 10-FE1-96 12-FEs-g6 10-FEB-96 16-FEB-SK 10-FEB-96 12-PEB-g6 09-FEB-96 12-FEB-S4 09-FEB-96 16-FES-96 09-FEB-96 12-FEB-96 09-1ED-96 16-1E8-96 09-FER-96 17-FEg-94 09-712-96 16-728-96 09-PET-06 16-PER-96 10-FER-OS 16-FER-g4 10-FEt-96 16-FEL-84 OS-FEg-P4 16-FEI-94 O9-FES-OS 16-FEB-96 CO-FEE-96 12-FEZ-96 09-FEB-96 16-853-84 O9- FED-96 16-PLE-96 CO-FEZ-Q6 16-FES-96 09-FEB-PS 16-FEL-96 OQ-PEE-S6 14-PEL- $\$$ O9-FEL-g6 09-FEI-94 16-FED-94 10-FEL-9S 17-FED-Q6 10-FEB-96 14-FED-96 O9-FE3-96 16-PED-Q6 O9-5EL-96 17-PES-96 09-FED-96 16-PEL-96 O9-FED-96 10-REB-g6 16-FEA-96 10-FES-9S 16-FEB-96 10-FED-9S 16-FEL-96 10-PEA-g6 12-FEB-96 10-FEI-96 12-FEE-96 10-FED-96 16-FEQ-96 10-FEW-S6 M-FEE-PS 10-FER-96 Ho-FES- 96 10-FEE-gS 16-TEL-96 10-FEA- 94 16-FED- 96 10-PER-96 10-MUK-96 D 10-PEL-96 14-FES-96
Your solection Griteria Uass

Releare numberi $z$

Fron Recoived Onte: $x$

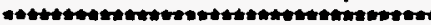

Components $X-1 R \quad$ subaisston $10: \quad x$
Project Mane: 50.05.03x9ke-614x 
$\begin{array}{llll}\text { FEB- 3-95 FRI 15:59 FERMCO ANALYTICAL. } & \text { FAX NO. } 5137386667 & \text { P. } 12\end{array}$

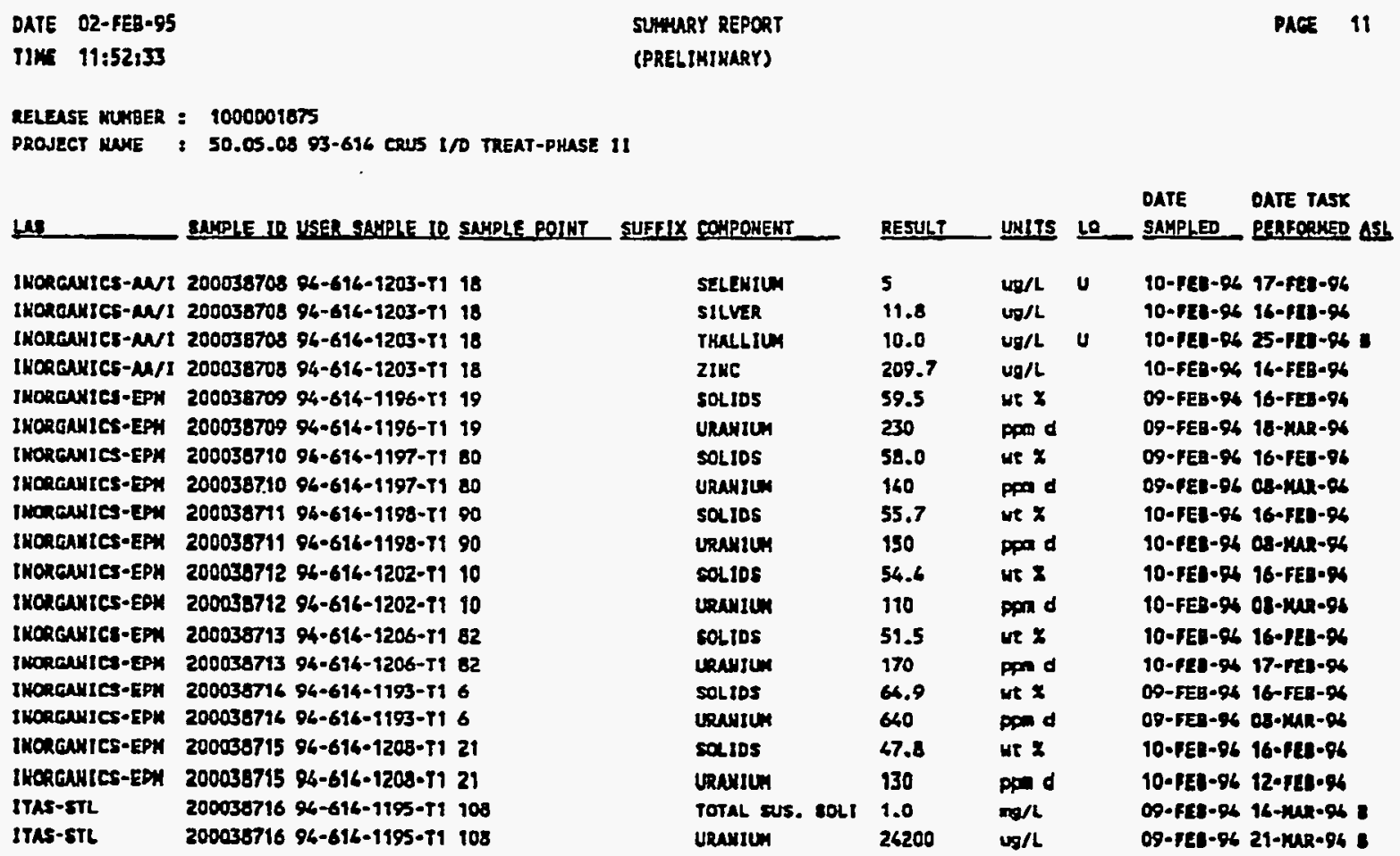

Your solection Critorie uess

Relesse number: $x$

Pron Recelved Dates $x$

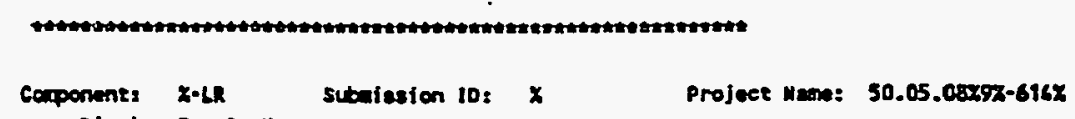

Dioplay Texe? 


\section{RESULT}

solios

IKORCWNICE-EPM 200039907 24-614-1266-73 19 IKORCAMICS-EPM 200039907 96-616-1246-13 19 SKORGAKICS-EPH 200039908 94-616-1269-73 80 thoneurics-EPH 200039908 94-614-1269-73 80 INONOANICl-EPH 200039908 96-614-1247-73 90 IHoresuics-EPH 200039909 94-614-12h7-7390 iwowauntes-5PH 200039910 94-614-1254-73 10 tMonGurCs-EPH 200039910 94-616-1254-T3 10 JWonchlules-IPW 200039910 96-614-1254-T3 10 INoncunics-IPM 200039911 96-614-1257-73 82 IKOACuHICE-LPH 200039911 96-616-1257-73 82 INORauxtcs-EH 200039912 96-616-1264-72 10 IKCAGANICS-EPW 200039912 94-614-1266-12 10 I WoreunICI-EPH 200039913 96-614-1268-T2 82 IMOACUICS-EPW 200039913 94-614-1268-12 62 INonCuHICs-IPH 200039914 94-614-1272-79 1 IMoneauICs-IPH 200039916 94-614-1272-79 I IHoRaulcs-IPH 200039915 94-616-1273-T9 2 IHoroulics-tiph 200039915 96-614-1273-T9 2 INORaAHICs-IPA 200039916 96-616-1274-79 3 IHORCuMICR-EPA 200039916 96-614-1274-79 3 IHOACANIC5-EPM 200039917 94-616-12T5-19 4 IHORCuHIES-EPW 200039917 96-614-1275-19 6 IHOLCWICS-EPH 200039918 94-616-1276-T9 5

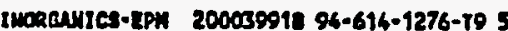

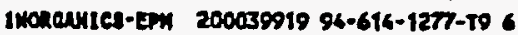
IHORCuHICs-EPW 200039919 94-616-1277-T9 6 IMORGANICS-EPM 200039920 96-614-1276-59 7 IHORGUICS-EPM 200039920 96-616-1270-T9 7 Imonculice-EFW 200039921 96-69-1279-79 8 IKORCANICA-EPN 200039921 94-616-1279-79 : Inoreunics-10x 200039922 94-616-1280-T9 9 InCreuntes-EPM 200039922 96-614-1280-T9 9 IHoncusics-IPH 200039923 96-614-1231-T9 10 Iroreuxtes-EPH 200039023 96-614-128t-T9 10 InorednJCs-Em 200039926 96-616-1282-T9 11 IHORANYICS-EPA 200039926 96-616-1282-19 11 JHoresurics-EPM 200039925 96-616-1255-T9 12 IMOACANICR-EPA 200039925 94-616-1283-T9 12 twonaures-EPH 200039926 94-616-1250-T3 11A IMorgentcs-8PH 200039926 96-616-1250-T3 11A

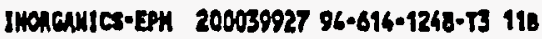
twoneurics-EPH 200039927 \%-616-1245-13 118 Imolaures-EPM 200039928 94-614-1252-T3 ks Inonevitcs-IPM 200039929 96-614-1253-T3 FB JWONQWUICS-EPM 200039931 94-616-1258-T3 11 IMorauxics-EPH 200039931 96-616-1258-T3 110

\section{Uenitur}

sor.10s

URANIU:

soulds

UReili:

SOLIDS

urentur

LRAMtin

SoLtos

venitu

socios

urentu

SOLIDS

tearity

SOL105

uruyiu

sol.108

crantur

SOLIDS

conalua

solios

veentus

soustos

venilum

socios

urevilu:

secides

veniva

socios

unewitu

coures

urensur

SOLIDS

ueveruer

SOLIDS

veritu

soctos

ventiun

socids

vedNitu

soutos

vaculiun

cerention

uravium

solios

veaviun

\section{5} 250 55.9 136

\section{2} 150 50.2

$$
138
$$$$
96
$$

45.6

250

48.5

130

40.5

226

99.7

86

99.6

43

9.6

9.6
55.1

110

55.1

130

52.7
520

127

55.4

169

53.4

172

99.9

162

100

100
140

100

100
133

53.4

160

1.7

37.5

0.3

0.3

4

0.1

0.1

0.2
DATE DATE TAST

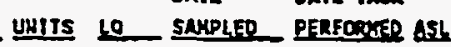

we $x$ pond us $x$ porad d we $\mathcal{X}$ ppa d we $x$ ppod ppond ut $x$ ppond ur $x$ pros d we $x$ ppon d we $x$ pow d ME $X$ $\cos d$ ue $x$ pond d ut $x$ pond we $x$ ppon d we $x$ pom d ue $\mathrm{X}$ ppe of ut $\mathrm{x}$

peand we $x$

ppon of

$x$

pand

we $x$

ond of

wt $x$

pos of

ue $x$

ppo

we $x$

mo

$\infty / 2 \quad U$

$m / 2$ U

4t ppo

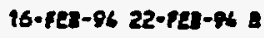

16-FED-96 26-8El-94 : 16-FEB-S6 22-FER-O6 \& 16-PER-96 27-PER-O6 a 16-PEL- 96 22-PE]-P6 : 16.1fL-96 25.1E1. 84 a 16-FLL-96 22-7z1-96 : 16-FER-96 27-FEL-96 : 16-PER-gh 13-erA-sh : 16-FER-94 22-FEI-96

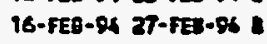
17-FEs-96 22-7ES-96 17-FES-96 26-FIs-96 : 17-FEA-94 22-FE3-96 : 17-FEB-96 os-rus-96 : 15-FEI-S4 22-FEM-P6 15-FEL-96 27-FEz-96 : 16-rEE-96 22-FET-96 : 16-FED-86 26-857-96 16-FET-96 22-FES-gh : 16-fE3-96 01-ruke-96 : 16-15i-ge 22-pel-gh : 16-FER-96 26-FER-96: 16-FEL-S6 22-FES-96: 16-8ED-96 26-1EQ-96 : 16-FES-S6 22-FED-96 : 16-FER-96 01- WuR-96. 16-FE2-84 22-FEA-95 I 16-rEe-g6 27-rEa-g6 : 16-FER-96 22-120-96 a 16-FER-96 27-rER-94 17-FEL-96 22-FET-96:

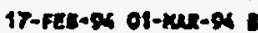
17-FEA-g6 22-rell-gh : 17-rEE-g6 26-Fen-96: 17-FEE-96 22-15R-96 = $17-568-9625+153-96$ 17-FEE-O6 22-FEt-96 : 17-res-96 26-rts-96 = 16-PEA-gs 22-IER-gh : 16-FEb-gh 02-1uR-gs I 16-FEB-g6 22-FE]-96 I 16-FEL-g6 01-MAR-S6 E 16-8E]-96 01 +7uk-96. 16-FEB-g6 01-rue-gh : 16-FER-OS 22-FEW-96 16-PEL-O6 OT-MAR-96.
Your selection criteria uast

Release Numbers $x$

fron Recalved oute: $x$

\author{
Component: $x$-LR Subatssion 10; $x$
} Oisplay Texe? $k$
151
Projest unte: $50.03 .08 \times 9 x-614 x$ 
RELEASE MUMSE : 1000001940

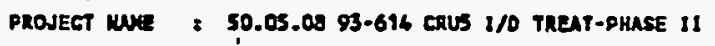

149

SMYPLE ID USER SAMPLE ID SAMPLE POTMT SUEFIX COHPOHENT

INORCuHICs-IPH 200039932 $94 \cdot 616 \cdot 1259-1316$ IHowarustes-194 200039933 96-614-1260-13 17 IMONCUICS-EPM 200039936 96-616-1261-13 13 INORGANICS-EPK 200039935 94-616-1262-73 14 IMORENICS-5FM 200039936 96-614-1263-T2 13 Imorenulcs-EPH 200039937 96-616-1266-72 10 I Horentes-EPN 200039949 96-616-1269-T2 118 Inonentcs-Em 200039969 96-616-1269-T2 110 IwoncukIC8-EPM 200039949 94-614-1269-T2 116 Imoreutics-EPN 200039950 96-616-1270-12 14 I wonenutcs-EPM 200039951 94-616-9271-T2 17 IMORGHICS-EPN 200039952 96-616-1251-13 18 IHORGAXICS-EPH 200039952 96-616-1251-T3 18 IMOReruIEs-MNI 200940001 96-616-1251-T3 18 IHozentes-MVI 200040001 96-616-1251-T3 18 Inoacukics-M/1 200060001 P6-616-1251-T3 18 JMoReAHICS-M/1 200040001 94-616-125t-73 18 Imorewies-N/ 200050001 96-616-1251-T3 is

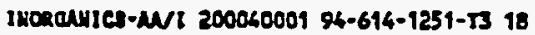
Inorexutes-M/I 200060001 94-614-1251-T3 is 1woreules-M/1 200040001 $94-616-1251-\mathrm{T3}_{3} 18$ IMonentICs-M/1 200040001 94-616-1251-T3 is Inoneanjes-MNI 200040001 96-616-1251-T3 18 IMORENICS-M/I 200040001 94-616-1251-T3 18 INokentes-Mrt 200040001 96-616-1251-73 18 ITAS-STL 200062033 94-616-1267-T2 110 ITas-sth 206042053 96-616-1267-72 110 mes sptetnoseo 200076060 94-616-1272 19 wass EPTetrosco 200076060 94-674-1272 is? uss spectnosco 200076060 06-616-1272 10 1 wes ePECTROS00 200076060 94-616-1272 t9 mes sptetRosco 200076061 94-614-1273 T9 2 wass spetnesco 200076061 94-614-1273 to 2 mus spetrosed 200076061 94-614-1273 T9 2 uss EPECT10500 200076061 96-616-1273 79 2 use spECTnOSD 200076082 96-616-1274 793 mass EPECTROSc0 20007c0s2 96-616-1274 T9 3 uss spetroseo 200076062 94-614-1276 to 3 muss sPECTLOsen 200076062 94-614-1274 79 3 mes epectrasen 200076063 96-616-1275 T9 4 wass spEetRosco 200076063 94-616-1275 794

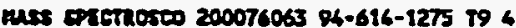
use epectiosed 200076003 \%-616-1275 t9 4 mse epetrosec 200076064 96-616-1276 T9 5 WS5 spzetinoseo 2000760s6 \%-614-9276 79 Muss specthoseo 200076064 96-614-1276 T9 5 MUSS SPECTROSCO 200076064 96-614-1276 t9 5 Your selection Griterlo Vasz release lubar: $\boldsymbol{x}$ Pron Racalved Deter $x$ Cenponent: $x-6 R$ Diepley Texte? $N$

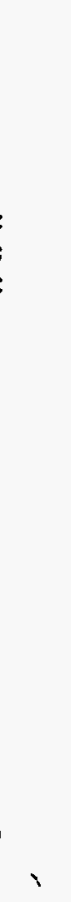

(1)

\begin{tabular}{|c|c|c|c|c|}
\hline URANIUS & 1 & pom & $\mathbf{U}$ & $17-5 E 8-9625-F E 8-96$ : \\
\hline URAHIUA & 1 & ppm & $\mathbf{U}$ & $17-F 20-96$ 25-120-96 \\
\hline URANIUH & 1 & $\operatorname{son}$ & $\mathbf{u}$ & $17-F E B-94$ 23-8E1-96 \\
\hline URakiLy & 1 & pan & $\mathbf{u}$ & $17-8 E B-96$ 26-FEI-96 \\
\hline URANIUY & 1 & ppan & $\mathbf{u}$ & 16-FED-O6 Z3-FIL-94 = \\
\hline URAMIU: & 74 & ppo: & & 17-FEB-94 2Q-FEB-D6 D \\
\hline PH & 8.10 & PH Un & & $17-5 E 8-9601-1212-960$ \\
\hline souros & 0.1 & we $x$ & & 17-FER-96 22-FED-96 = \\
\hline uReNIUN & 1 & Ppon & & 17-FEL-96 01-1MR-96 = \\
\hline unerites & 1 & $\mathbf{P m}$ & $\mathbf{u}$ & $17-858-9625-120-96=$ \\
\hline veraviun & 1 & $p \operatorname{pon}$ & $\mathbf{u}$ & 17-PED-96 03-14R-96 \\
\hline PH & 7.45 & DH Un & & 16-FER-96 27-PEe-96 \\
\hline URasicen & 3 & pos & & $16-F E B-9623-F E D-96=$ \\
\hline astrmory & 60.0 & $\operatorname{vg} / \mathrm{L}$ & $\mathbf{u}$ & $16-5 E 6-96$ 26-f2s-94 \\
\hline ARSENIC & 10.0 & $w / L$ & $\mathbf{u}$ & $16-12 E-96$ o1-2uk-96 \\
\hline DERYLLIUX & 5.0 & $40 / 6$ & $\mathbf{u}$ & 16-FEE-96 26-FES-96 : \\
\hline cabrion & 5.0 & $\omega g / 6$ & $\mathbf{u}$ & $16-92-9626-521-96$ \\
\hline chronitu & 16.6 & $\cos / 2$ & & 16 -FE-94 24-FEE-96 8 \\
\hline COPPER & 75.6 & $\omega 0 / L$ & & 16-FEg-94 26-FEB-96 \\
\hline LEND & 56.0 & $\cos / 2$ & & 16-FE]-96 09-MR-96 \\
\hline MIEKEL & 40.0 & $\cos / 6$ & $\mathbf{u}$ & $16-F E 8-96$ 25-FEB-96 \\
\hline SELENIU: & 50.0 & $40 / \mathrm{h}$ & $\mathbf{U}$ & $16-625-\alpha$ as-me-gs 0 \\
\hline SILVER & 11.5 & $\log / 2$ & & $16-P E S-96$ 26-PEA-MA B \\
\hline THALLIUA & 60.0 & $\omega / 2$ & $\mathbf{u}$ & 16-FED-96 12-muk-96 \\
\hline zInc & 20.0 & $\omega g / L$ & $\mathbf{u}$ & $16-F E 4-96$ 26-7EE-96 0 \\
\hline POTAL SUS. SOL1 & 47.88 & $m o / l$ & & 17-FER-96 \\
\hline uremitun & 17.7 & $\mathbf{u g} / \mathbf{a}$ & & $17-162-96$ 23-4he-96 \\
\hline cansiun 236 & $6.0 E+01$ & PCi/g & & 15-FEL-94 06-416-96 \\
\hline creniter 235 & $1.3 \mathrm{E} \bullet 00$ & PCi/s & & $15-7 E 8-9406-216-96$ \\
\hline UeAnIUY 236 & $1.2 x=01$ & $\operatorname{pet/a}$ & & $15-F E B-96$ 06- $246-96=$ \\
\hline unurun 238 & $2.95+01$ & pel/s & & $15-120-9406-246-960$ \\
\hline unarion 236 & $1.2 E+01$ & pcists & & $16-F E 0-04$ 07- $200-94$ \\
\hline venitu 235 & 6.EE-01 & pei/g & & 16-FED-96 of-4ve-96 E \\
\hline URNetuN 236 & $2.8 E-02$ & $\mathrm{DCl} / \mathrm{s}$ & $\mathbf{u}$ & 16-fEB-96 07-A10-96 B \\
\hline vamiun 238 & $1.4 E+01$ & pells & & $16-P E S-96$ 07-N16-96 $=$ \\
\hline unurua 236 & & $\mathrm{pct} / \mathrm{e}$ & & 16-PED-O \\
\hline tantux 235 & & pl/e & & 16 -FED- 96 \\
\hline UnANRU 236 & & pei/s & & $16-5[t]-96$ \\
\hline URAKIU 238 & & $D<1 / 9$ & & $16-$ FED-96 \\
\hline unnrus 236 & $3.5 E+01$ & $\mathrm{pel} / \mathrm{a}$ & & 16-FED-96 OS-4156-96 D \\
\hline unauiun 235 & $1.5 E \bullet 00$ & DCI/D & & 16-PED-ES OS-ANS-96 I \\
\hline Lentun 236 & $6.21 \cdot 01$ & pci/e & & 16-1ED-O6 05-A140-96 D \\
\hline contun 238 & $3 . \pi+01$ & pcl/s & & $16-F E-\$ 6$ os-146-86 \\
\hline unawtun 236 & $3.62+01$ & $\mathbf{p c I} / \mathbf{a}$ & & 16-FED-Q6 O6- L16-96 E \\
\hline veruitu 235 & $1.8 E+10$ & pci/s & & $16-120-9606-1100+85$ \\
\hline URAMIUA 236 & 5.6E-01 & $\mathrm{pel} / \mathrm{g}$ & & $16-527-96$ O6-A15-94 \\
\hline uranzun 238 & $4.3 E+01$ & DEi/g & & $16-F E E-96$ 06-1146-96 $=$ \\
\hline
\end{tabular}

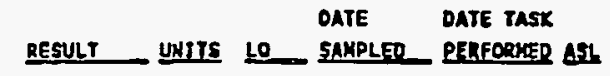


RELEASE MUKBEE \& 1000001960

PROJECT WHEE \& 50.05.08 93-614 CRUS I/O TREAT-PHASE II

y

MASE SPECTROSCO 200076065 96-616-1277 T9 6 MUSS SPECTROSCO 200076065 94-626-1277 796 KASS SPECTROSCO 200076065 94-614-1277 796 MASS EPECTHOSCO 200076065 94-616-1277 T9 6 WhSE SPECTROSCO 200076066 94-614-1278 T9 7 MASS SPEETROSCO 200076066 96-614-1278 T9 7 MASS SPECTKOSCO $20007606696-614-1278$ i9 ? MASS SPECTROSCO 200076066 96-616-1276 T9 ? MASS SPECTROSCO 200076057 94-616-1279 T9 8 MASS IPECTROSCO 200076067 94-614-1279 T9 a muse epECTROSc0 $20007605794-614-1270$ t9 8 muss spLetnoseo 200076067 94-674-1279 19 : Muss EPECTROSCO 200076068 96-614-1280 79 9 MASS sPECTROSCO 200076083 96-616-1280 iq MASS SPECTROSCO 20007606s 96-616-1280 t9 mus spECTROSCO 200076068 96-616-1280 i9 9 MLSS EPECTROSCO 200076069 94-616-1281 T9 10 MASE EPECTROSCO 200076069 94-614-1281 T9 10 MAss spretnosco 200076069 94-614-12si t9 10 muss apEcthosco 2000760s9 96-614-128t T9 10 mASs SDECTROSCD 200076070 96-616-1282 T9 11 MUSS SPECTROSE0 200076070 96-614-1282 T9 11 mass spectroseco 200076070 94-616-1282 ig 11 MASE SPECTROSCD 200076070 96-616-1282 T9 I1 ruse epzetroseo 200076071 200076071 12 Mess EPETROsc0 200076071 200076071 12 MAsx SPECTROSCO $200076071200076071 \quad 12$ MASS SPECTROSCO 200076071200076071 URe⿻112 235 URANILM 236 URNILA 238 บRaviun 236 LReNitus 235 UReNIIUA 236 Uеexilum 238 UReviun 236 Lrenitur 235 URentem 236 URevilun 238 URentix 234 UReNIL4 235 LReakiun 236 URANicun 238 URanjon 236 URNIIUA 235 Lrentin 236 Leention 238 URevilus 236 URANIIUn 235 URDNIIIM 236 LRentin 238 UReN14 236 verintix 235 urvisium 236 urevilion 230
DATE DATE TAST RESULT UNITS LO SANPLED PERFORNEP ASL

$6.4 E+01$ pCi/g 16-PE8-96 09-114a-96 = 1.0E+CO PCi/g 16-7EL-96 08-NUG-96 : 6.7E-01 PCI/g 16-FEL-OS OS-NUG-96 E 6.2E+01 pCi/g 16-5ER-96 08- $116-96=$ 4.2E+01 PCI/g 16-FES-94 26-OCT-96 2.2E+00 PCi/g 16-FEg-96 26-0CT-96 6.9E-01 PCI/g 16-FEB-94 26-0CT-96 5.4E+01 PCi/g 16-PEQ-06 26-0CT-96 \& 5.6E+01 pCi/g 16-PEB-96 07-Alle-94 \& $2.6 E+00$ PCI/S 16-FEB-gh 07-AlGG-SA 5.7E-01 PCI/g 16-FEP-94 07-AUE-9S 5.7E+01 PCI/g 16-FEG-96 07-ANG-96 : $5.6 E+01$ PCi/g 17-FEH-96 05-Nis-96 E 2.5E+00 PCi/a 17-PEB-96 OS-NiE-96 a

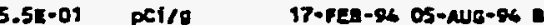
5.6E+01 PCi/g 17-PEB-96 O5-AUG-96 B 9.7E+00 PCI/g U 17-FEL-96 05-AUG-96 :

2.1E +00 PCI/O 17-FEB-94 O5-Nic-9S

9.1E-02 DCi/g U 17-FEH-96 OS-AUC-SS

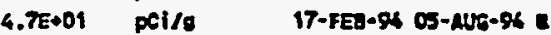

9.0E+01 PCI/G 17-PEA-96 19-007-96

$1.9 E+\infty 0$ DCi/g 17-FEB-96 99-0CT-96

1.1E+00 PC1/S 17-FEQ-96 19-0ET-96:

$6.4 E+01$ PC1/E 17-FEI-96 19-0CT-S6 I

$6.2 E+01$ pCi/g 17-FEL-96 OC-Nuc-9s a

$2.25+00$ PCI/S 17-FET-94 OH-NUG-SS

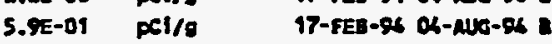

6.TE+01 DCI/G 17-FEB-96 OS-AU6-96 E
Your solection criterin thes Release Nubars $x$ from Received Dates $x$
-

Component: X-LR subatienton to: $x$

Display Taxt? $n$
153 
RELEASE MUNEER : 1000002055

PROJECT WNE I 50.05.08 93-614 CRUS I/D TREAT-PHASE II

Le? SAYPLE ID USER SAYOLE IO SUMPLE POINT SUFFIX COYPOUEAT

INORGAUICS-EPH 200042890 96-616-1331-19 5 IHOREANIES-EPW 200062800 06-616-1331-11 5 IKORGANIC8-EPN 200042890 96-616-1331-T1 5 IHORGANICS-EPK 200042891 96-614-1331-71 s INOREAHICS-EPH 200062892 96-616-1332-T1 ors INORCANICA-EPM 200042892 96-616-1332-71 oYs IHCREAHTCS-EPH 200042893 96-616-1332-71 BYL INORGMICS-EPX 200042893 94-614-1332-T9 BYL ILORGANICS-EPA 200062896 94-614-1333-T1 13 JNORGAHSCS-EPK 200042895 94-614-1349-11 FB IMORENICS-EPI 200042896 $\%$-614-1336-71 111 IพOREAHTS-EPA 200042898 94-614-1336-P1 11A IHORGAICS-EPN 200062896 94-614-1336-71 114 IXCRGANICS-EDN 200062897 96-616-1360-T1 111 INERENHCS-EPY 200062897 96-614-1340-71 11 INORCANICS-EPH 200042897 96-616-1340-71 11 IKCReuxtc1-EPH 200042898 96-616-1332-TI 821

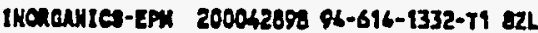
thorahucs-EPH 200042898 96-616-1332-T1 oz1 IHopeurtcs-EPH 200042899 94-616-1361-71 111 IHoranics-ISPH 200042899 $94-616-1361-T 1$ 11L IKORCANICS-EPX 200052899 96-614-1341-11 11L INOREAUICS-EPN 200042900 94-616-1372-TI 11A IHOReuvics-EPH 200042900 96-616-1372-T1 11A Iwonenulcs-5PH 200042900 96-616-1372-Y1 11A IHOagautcs-EPH 200042909 94-616-1375-T1 110 INOREN1CS-EPA 200042901 94-614-1375-71 11 IMCRGANICS-EPY 200042901 96-616-1375-T1 118

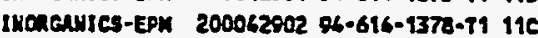
Iwotcente1-EPH 200042902 96-616-1376-T1 11c IMORaurcs-EPH 200042902 94-616-1378-T1 11C THorgurics-EPM 200042903 94-616-1332-T1 ars Imorenutcs-EPM 200042904 94-614-1332-71 825 twoncuylcs-EPN 200042905 94-616-1363-71 ors Imanewres-EPH 200042906 96-616-1369-71 825 IMonaures-EPH 200042907 \$-616-1332-T1 875 Iwoneunics-EPM 200062907 94-616-1332-T1 825 INoneurtes-EPH 200062909 96-616-1369-t1 azs Imonautes-EPY 200042909 96-616-1369-71 828 Inorakies-IPH 200042910 $94-616-1361-$ T1 5 Inoreurtcs-EFu 200062910 94-616-1361-T1 5 Inonaulcs-EPH 200052911 96-616-1363-T1 ors Inonguics-EPH 200042911 96-614-1363-T1 ors Imoranics-ean 200042912 96-616-1332-T1 o5 Inoneurcs-ePM 200062912 94-614-1332-T1 \&S IHOREWICS-EFK 200062013 96-616-1332-T1 815 Imonautes-TPH 200062913 96-616-1332-T1 815

DEnstTr

ex.105

irantur

solios

verautin

colids

URNiUn

sosids

URATIL

PH

uensulu

PH

URerits
DATE DATE TASK

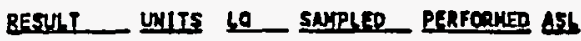

7.30 pH in 28-5Es-94 16-14k-96 1.5 ut $X$ 28-FEB-96 09-1210-96 26 PF 28-FEB-96 16-14h-o6 1.00 20-8ER-96 13-MUR-94 5.8 we $x \quad 28-8 t 1-94$ og-nuk-94 39 PF 28-FEL-95 $18-$ - MU 9.35 pH in 28-FEs-96 12-nuk-96 19 pan 28-FEL-96 13-M12-96 0.6 ppo 23-f2s-96 13-nutess 0.1 as/6 u 01-kuR-96 13-ruk-gh 9.19 ph un 28-518-96 16-2un-96 1.8 we $x$ 2g-pec-os 09-ver-gs 37 pow 28-FEL-96 16-whes6 9.25 PH un 28-FEB-94 16-14R-96 0.3 we $x$ 28-FES-96 09-1211-96 Pom 28-FER-96 16-M1 -96 9.20 pit in 28-FE-96 16-yllog 1.6 wr $x$ 28-7Es-96 09-pul-96 34 28-7Es-96 $16-\mathrm{mL}-96$

8.67 ph in $01-\mathrm{mh}-96$ 16-me-96 0.2 we $x$ 2 pqa 9.26 PH Un 1.8 ue $x$ 38 pom 9.18 pH Un 0.3 ise 2 ppor 0.05 of un 0.1 ye $\mathrm{x}$ 1

01-mR-94 09-whe-96 01-mak-96 16-MR-96 03-mak-96 16-mar-94 03-14h-96 09-1012-96 o3-mar-96 16-man-96 = 03-mak-96 16-Mk-96 o3-nur-9s os-knk-9h 1 o3-mak-86 16-mik-96 a o3-12he-96 16-2he-96 03-142-96 09-me-96 03-14R-96 16-212-96 a 28-FEB-g4 13-Mh-96 28-FEs-96 13-kin-96 = 02-mur-96 13-14R-94 e 02-14k-94 13-nuR-96 23-FE:-96 09-114k-96 28-FER-96 17-MuR-96 02-114R-96 09-114-9s a cz-ruR-96 22-ruk-gs 02-14h-96 00-k4R-96 = 02-kn-96 26-me-96 = 02-rent-os 09-nur-es 02-puR-94 07-APN-96 = 2Q-FEJ-96 14-kAR-96 28-FED-96 13-14R-96 = 28-FER-96 16-14R-g6 28-PED-96 13-kuR-96

\section{Your selection Criterin Hass}

Ieleace Mumber: $x$

Fren Reedived Date: $\$$

Cemponeses z-LR

Subalexion 10: $x$

Dfeptay Texe?
Protece yame 50.05. 04k9t-6147 
RELCASE MULER : 1000002055

PROJECT MUKE \& 50.05.08 93-614 CRUS I/D TREAT-PHUSE II

LA. SMMPLE ID USER WMPLE 1D SAMPLE POINT SUEFIX COXPONENT

RESULI_ UWIS LO SATE OAKPLED_ PERFORMED ASL

9.30 PH Un 20-FEB-96 16-MUR-96 28.9 Ppo 28-fEO-96 13-suk-96 a 9.28 PH Un 28-FEs-96 16-34R-96 : 32 pora 28-FEs-96 13-ruR-96

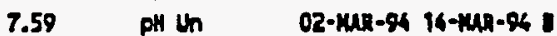
19 pon 02-ruk-96 13-141-96 \& 9.36 PH Un O2-MAk-96 16-Muk-96 .

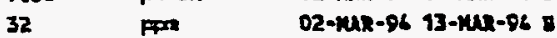
9.36 pH Un O2-ruR-g6 16-muR-9h ह 32 pow 02-ent-gs 13-2u1-96 ह 9.35 PH un 02-mak-96 16-201R-96

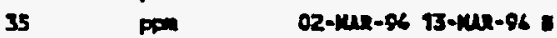
9.36 PH Un O2-Muk-96 $96-1428-96$ : 36 Ppo 02-MuR-96 13-7uk-96. 9.32 PH th 02-rike-gh is-melest E 37 pen 02-rur-g6 13-rulest 1 Pon U 01-rue-st 13-xuk-96 :

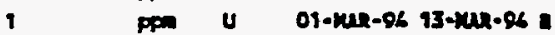
1 ppon $v$ 01-rexk-96 16-MuR-96: 1 ppe u 0z-ruh-gh 16-ruk-94 : 1 p oz-pur-gs 16-tur-gs 0 1 pos 4 oz-mul-os 16-ruk-se. 1 Ppon u 03-mun-gh 16-mul-gh : 1 ppa v 03-ruk-gh 14-ruk-gs :

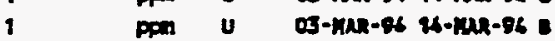
0.1 mo/L U 01-unt-p6 16-14ll-96 E 0.1 wall v 03-rule-gh 15-mak-96:

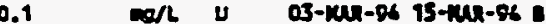

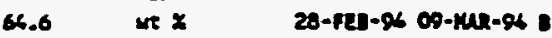
390 PPa d 28-FEl-D4 15-kll-g4 ह

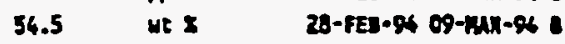
250 bond 28-FER-96 15-MAR-96 B

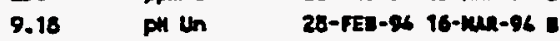
1.8 WE $X$ 28-FED-96 09-1012-96 37 PPe 28-PEL-96 1G'-nLL-96 56.6 ut 2 2B-FEI-86 09-kCR-96 180 pow d 28-ped-96 15-min-96

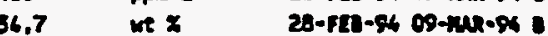
230 ppan d 28-FEs-gh 15-ruR-gh 52.0 ye $x$ of-rus-96 09+2ur-96 : 169 pon of 01-muk-96 16-kuk-4h a

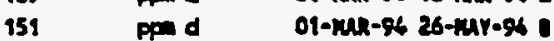
01.6 UE $X$ 02-mR -96 09-7un-96 B 840 pow d 02-mR-96 13-kuR-96 B

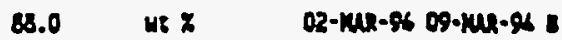
150 pon o D2-16R-96 18-kuR-96 B 78.3 HE $x$ 02-ruk-96 09-mur.96 ह
Your selection Critarie Usa:

Ralease Xunbars $x$

Iron Reeaived Outer $x$
Componentz $x-48$ Dieplay Texe?
Project Mane: S0.05.06xox-616x 
RELEASE MUKBER : 1000002055

PROJECT MANE : 50.05.08 93-616 CRUS 3/D TREAT-PHASE II

LAs SAYPLE_ID USER SUUOLE IP SAKPLE POIMI SUEEIX COMPOMEMT

INOREAMICB-IPH 200062965 96-616-1355-71 B1

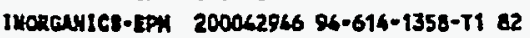

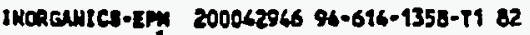
IMORGeNics-5PM 200062967 96-616-1360-11 6 I woraurics-EPM 200042947 96-616-1360- 116 Imoncuxics-EPM 200042948 96-616-1371-T1 80 IMORGanics-EPN 200062948 96-616-1371-T1 80 INDREANICS-EPX 200062949 94-616-1373-11 19 IMORGANICS-EPN 200062969 96-616-1373-T1 19 IKCOCAKICS-EPM - 200062950 96-614-1374-T190 THORCUNICs-EPM 200062950 96-616-1374-T190 IMOECANICT-EPH 200042951 96-616-1379-11 10 icorcenice-IPH 200042059 96-616-1379-T1 10 InORGAMICs-EPM 200042952 96-616-1386- 1129 IHORGANICS-EPM 200042952 96-616-1386-T1 29 INonGANICS-MVI 20004Z933 96-616-1362-T1 18 IHoraules-WVI 200062553 96-616-1342-T1 18 IKoRGante2-MVI 200062953 96-616-1342-T1 18 Imorcaulcs-MV1 200062953 96-616-1362-19 is Inorewics-MNI 200043933 94-616-1362-T9 18 Itoncurics-M/1 200062953 94-614-1362-T1 18 IMORGevics-MVI 200043953 94-614-1342-T1 10 Ihoagunics-MVI 200042953 94-616-1362-T1 18 Incraviles-WVI 200042953 96-616-1362-71 18 Inoreuntes-MVI 200062953 96-616-1362-71 18

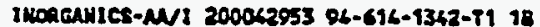
INORENICS-MVI 200028953 96-614-1362-T1 18 Ixoreunics-kPH 200042956 96-616-1342-19 18 IMoreanics-EPH 200062956 96-616-1362-TI 18 IMoreunics-WI 200042955 25-616-1377-T1 is tKonganiCs-N/I 200042955 96-616-1377-T1 18 IMOKCUNICS-M/1 200042955 94-614-1377-T1 18 JHORCNHICE-M/I 300062955 96-616-1377-T1 18

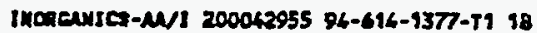

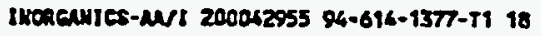
INoucuics-M/1 20002955 98-614-1377-71 18 IHoreauret-NI 200062955 96-614-1377-71 is

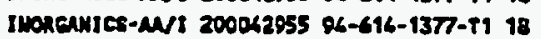
IHorearics-MVI 200042955 96-616-1377-T1 18 Imoneurics-NWI 200062955 96-614-1377-T1 18

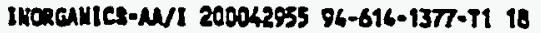
IHonewice-nWI 200042955 06-616-1377-T1 18 IHoreanics-EPM 200062957 94-616-1377-T1 18 IHonceNICA-EPW 200062957 96-614-1377-T1 18

(and

\begin{tabular}{|c|c|c|c|c|}
\hline $\begin{array}{l}\text { URAMIIUT } \\
\text { SOLIOS }\end{array}$ & $\begin{array}{l}760 \\
49.7\end{array}$ & we $x$ & & 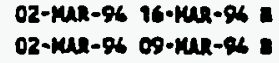 \\
\hline urenicur & 190 & pend & & 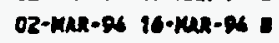 \\
\hline SOL.1DS & 54.1 & we $x$ & & $02-1402-96$ 09-14R-96 \\
\hline URANILH & 780 & ppnd & & $02-44 R-96+15-14 R-96=$ \\
\hline SOLIDS & 59.6 & ut $x$ & & $03-304-9609-1408-96$ I \\
\hline Uanuten & 393 & Fon & & $03-r u R-96 \quad 16-x u R-94=$ \\
\hline SOLIDS & 59.8 & wt $x$ & & $03-n u R-9409-x u s-96=$ \\
\hline UReNIUE & 230 & ppond & & $03-r e k-9626-r u k-96$ I \\
\hline souss & 56.4 & ut $x$ & & $03-\pi x k-96 \quad 09-\pi u z-96=$ \\
\hline unanicun & 140 & $\operatorname{pos} \alpha$ & & $03-M u R-96 \quad 16 \cdot \mathrm{MrR}-96=$ \\
\hline solids & 50.8 & ue $x$ & & $03-84 R-96 \quad 09-74 k 8-96=$ \\
\hline UREVILA & 100 & ppend & & 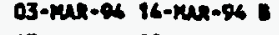 \\
\hline SOLIDS & 49.8 & we $z$ & & $03-m(1)-94 \quad 09-n / 12-94=$ \\
\hline uranium & 97 & ppond & & $03-r u R-96 \quad 16-x / 2-96=$ \\
\hline ANTIMOHY & 60.0 & $\mathbf{v g} / 2$ & U & 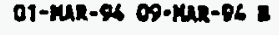 \\
\hline ARsEMIC & 91.6 & $\omega \mathrm{w} / \mathrm{L}$ & & $01-$ whe -20 16-4he -96 \& \\
\hline DERTLLIUN & 5.0 & $49 / L$ & u & $01-\pi / 2-9609-\pi / 2-96=$ \\
\hline chonilus & 5.0 & ug/L & $\mathbf{u}$ & 01-xuk-gh 09-xak-96 \\
\hline CHROArLu & 29.0 & $\omega / L$ & & $01-142 \pi-9609-212 k-96=$ \\
\hline COPPER & 96.8 & $45 / 6$ & & $01-72 k-9610-212-96=$ \\
\hline LEAD & 89.7 & $\mathbf{u g} / \mathbf{L}$ & & $01-2 u n-86$ 12-2uk-86 = \\
\hline MICKEL & 40.6 & $\mathbf{w} / 6$ & & $01-20 k-96609-\times 1 k 2-96=$ \\
\hline SELENIU & 5.0 & $40 / 6$ & u & $01-k e r-9629 \cdot 24 k-96=$ \\
\hline SILVER & 16.6 & $\omega / 2$ & & $01-m e n-96$ og-zur-g6 \\
\hline THALLILY & 100 & $42 / L$ & $v$ & 01- $24 R-96$ 19-APR-g6 B \\
\hline 2rue & 156.2 & $40 / 6$ & & $01-\operatorname{cun}-96$ 15-ruR-26 $=$ \\
\hline PH & 9.36 & phe un & & $01-\mathrm{rrR}-9409-\mathrm{xR2}-96=$ \\
\hline verextun & 13 & $\operatorname{mom}$ & & $01-r 4 R-96$ co-ruk-g6 = \\
\hline artinowr & 60.0 & $\operatorname{Lg} 0 / 2$ & u & $03-n k R-9609-242-96=$ \\
\hline ARSENIC & 10.0 & $40 / 2$ & $\boldsymbol{u}$ & $03-k 42-26,16-4 h+26=$ \\
\hline OERYLLJUN & 5.0 & vor & u & 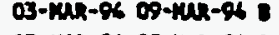 \\
\hline centux & 5.0 & 4a/t & $u$ & 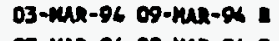 \\
\hline CHROHJUA & 38.2 & $\omega \mathrm{L} / \mathrm{L}$ & & 03-KAR-st 09-MuR-96 = \\
\hline COPPER & 139.2 & Los & & 03-HAk-96 10-*un-os = \\
\hline LEND & & L/ & & $03-x 4 k-96$ \\
\hline LEAD & 72.6 & $\omega / L$ & & 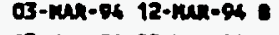 \\
\hline MICXELL & 41.9 & $\omega / L$ & & 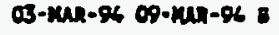 \\
\hline SELENIUN & 5.0 & $u=/ 6$ & $\mathbf{u}$ & 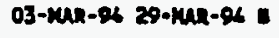 \\
\hline SILVER & 20.0 & ug/L & & $03 \cdot 14 R-96$ 09-nuk-96 \\
\hline TMastiux & 100.0 & 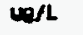 & u. & $03-112 R-9620-202 x-96=$ \\
\hline ZIME & 196.9 & $40 / 6$ & & $03-3 \mu R-94$ 15-ruk-96 = \\
\hline PH & 9.63 & ph U & & $03-x u R-96$ co-16n-96 \\
\hline URANiLm & 15 & $\operatorname{pem}$ & & $03-2 u R-96$ os-1un-26 = \\
\hline
\end{tabular}

Your selection criterie wass

Release Nutrbari $x$

Frea Recelved Dages $x$
Components X-LR subaiestion ID: $X$ Dleplay Texts N

DATE DATE TASK UMITS LQ SAMPLER PERFORGED ASL 
FEB- 3-95 FRI 16:47 FERMCO ANALYTICAL FAX NO. 5137386667

P. 04

DATI 02-rES-95

SLGQURY REPORT

PAet 18

THEe 11:52:33

(PRELIMIURRY)

RELEASE MURER \& 1000002116

ProdECT HAKT : 50.05.08 93-696 CQUS I/D TREAT-PHASE II

녹

1XoraurCs-IPH 200044720 96-696-1390-70 2 IHORGAUSCS-EPH 200056720 94-614-1390-TO 2 IMORECHIC5-EPA 200066720 94-614-1390-70 2 INORGAUICS-EPM 200066721 24-614-1388-71 82 IKOREAHIC5-EPX 200066721 96-616-1388-11 82 IMORGNICS-EPX 200044722 94-614-1389-TO 1 IHOACUMICS-EPH 200044722 94-614-1389-10 1 IMOREAMJCI-EPH 200066722 96-616-1389-70 1 IHORGertC3-EPK 200046723 96-614-1396-50 81 INorearice-IPH 200046723 96-616-1396-70 81 IKONGUNICS-EPH 200044724 94-616-1397-TO 6 IKORCANICS-EPM 200044724 94-614-1397-TO 6 IMOUGAUICS-EPW 200044725 94-614-1344-TO 80 IKOnGauiCs-EPW 200044725 94-614-1344-TO 80 IHONCWNICE-EPB 200064726 96-614-1346-TO 19 IHORECHICA-EPM 200066726 96-\$16-1346-TO 19 IKoweurtCs-EPH 200046727 96-616-1393-T0 12 IMOnaurice-FPK 200044728 96-614-1340-TO 5 IHonautes-LPW 200044728 94-614-7360-70 5 InOUEUVICS-EPM 200046728 94-614-1360-TO 5 Inokaniles-EPM 200044729 94-614-1340-70 5 IMONCUMICS-EPH 200046730 94-614-1341-TO 8ATL thoncuintc5-EPH 200046730 94-674-1361-T0 ourt IHoncurict-EPH 200046731 96-616-1342-T0 RI IMoncunict-IPW 200046732 94-616-1395-70 13 Imorcuxtcs-EPH 200044733 96-614-1399-10 i5 IHoneduICt-IPH 20004776 94-616-1361-T0 aurs IHOAGANICS-EPH 200046734 94-616-1341-TO oArs

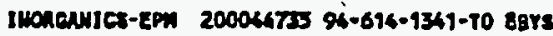
IMORCuHIC1-EPA 200046735 96-616-1361-T0 abre

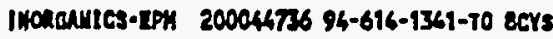
INOAGAICA-EPH 200044736 94-616-1369-TO 8CTS

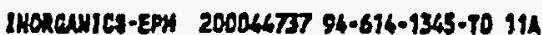

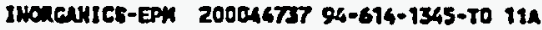

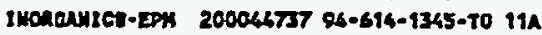
INorauxice-Em 20004673 96-616-1361-TO aurs InORCUHICT-EPH 200046759 96-616-1361-T0 EsY5 3HOACUNIC5-EPH 200046740 96-614-1341-T0 8CTS

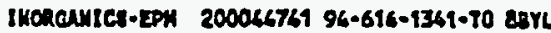
Inoneusses-IPH 200064769 96-616-1361-70 89Y IHORCWNICs-IPX 200044742 96-616-1361-T0 sert rHonerutcs-EPH 200046742 96-616-1361-T0 ecrL IHDeauics-EPH 200044743 94-616-1361-70 855 InonauntCE-EPM 200046743 94-614-1341-70 8E5 IHOACUHTC5-EPH 200046764 94-614-1341-70 8F5

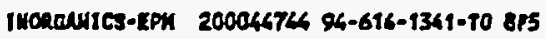
IHONGANICS-EPM 200047745 94-614-1361-TO $8 E 30$
COMPONENT

saldos

URANiUn

URewiun

SOLIDS

URANIUA

sol 105

uranizur

URenitu

Solios

urexicur

SOLIDS

veanium

Sot.10s

URewiLa

solios

urenitury

Exaxitum

PH

SOLIDS

vakiun

DENSITY

PH

URaurium

URevilum

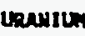

veruilus

SOLIDS

LEANIIU

collos

venus:

SOLIDS

Uarilui

PH

sorios

uraniux

Dexsity

DEMSITY

DELSITY

PH

consilar

คH

UReurius

PH

coresicum

PH

urentum

DATE DATE TASK

RESULT UWITS LO SAMPLED DERFORHEP ASL

94.3 we

32 PPO d

31 ppond

46.9 WE $X$

169 pand

80.7 wt $x$

525 ppond

679 ppa of

76.7 แล $x$

1260 pen d

65.1 we *

535 ppon d

45.2 us $z$

120 ppon of

48.3 ut $x$

215 pon d

7.31

1.1

pm $u$

07-MUR-96 16-RuR-96 :

07-MAR-94 23-KAR-96 :

07-mRR-96 18-APR-96 =

07-nuR-96 16- सuk-96 =

07-2uR-96 12-1PR-96 =

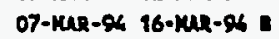

07-nche-96 13-ApR-96 :

$07-1402-96$ 15-N32-96 0

07-ruk-96 96-per-96 a

07-ruR-gh 12-102-96

07-ruR-96 16-kuk-96 :

07-kuR-o6 12-APR-P6 E

og-klak-96 $26-124 k-96=$

o9-kuR-96 23-4uk-96 a

09-kche-96 16-nke-96 =

09-14R-96 12-172-96 a

07-ruR-gh 23-rur-96 a

08-mur-94 22-ruk-96 =

PH un

wt $x$

08-1ere-96 $16-\mathrm{xuR}-96$ a

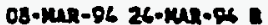

$1.02 \quad \mathrm{~g} / \mathrm{ml} \quad 08-\mathrm{knR}-96$ 05-Np2-96

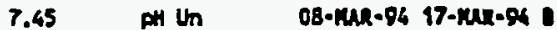

2.5 pom os-mak-9h zh-mek-96

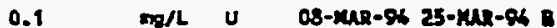

0.2 pan o7-ruR-96 25-iell-96:

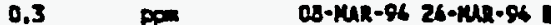

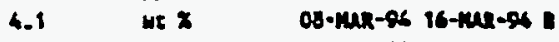

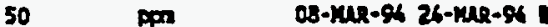

3.1 we $x$ os-rul-gs 16-kuR-g6 :

50 Dop 08-vuR-96 26-14kR-96 :

1.2 we $\mathrm{D}$ 08-7uk-96 16-\%ul-96

65 08-Mak-96 26-mak-94

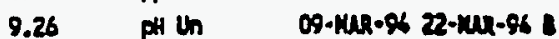

1.9 We $x$ o9-xuR-gh 16-nue-gh

36 pon 09-mur-gh 26-mak-96.

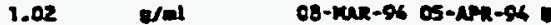

1.03 D/at OS-ruR- 96 OS-APR-96:

1.03 g/at o8-vele-96 os-epg-94

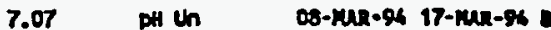

3 Ppa 08-rer-96 25 -kuR-96 a

7.10 pH in os-muR-94 17-MuR-os :

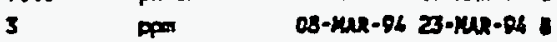

9.29 pH Un 08-rur-96 17-ruR-96:

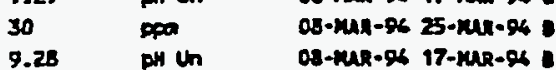

cosponentes $x-18$

Sumission ID: $x$

29 ppe

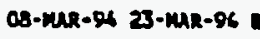

9.26 pH in

03-muk-96 17-xul-96 B

Your salection Criterie Was

Reterse Ncubar: $X$.

Prom nceelved dazes $x$

Dlepler Texe?

(1)


$\begin{array}{llll}\text { FEB- 3-95 FRI 16:49 FERMCO ANALYTICAL } & \text { FAX NO. } 5137386667 & \text { P. } 06\end{array}$

$\begin{array}{ll}\text { DATE } & 02-8 E B-95 \\ \text { TIKE } & 11: 52,33\end{array}$

DATE $02-8 E B-95$
TIKE $11: 52,33$

SLFURY REPORT

(PRELIMJMARY)

RELEASR HUAER : 1000002252

PROSECT WAYE I S0.05.03 93-616 CLUS I/O TREAT-PHASE II

LAB

SAKPLE ID USER SAKPLC ID SAMPLE POIMT SURFIX COMPONEMT

\begin{tabular}{|c|c|c|c|}
\hline RESII T & WNITS & $\begin{array}{l}\text { DATE } \\
\text { SAMPLED }\end{array}$ & $\begin{array}{l}\text { DATE TASX } \\
\text { PERFOUXEO }\end{array}$ \\
\hline
\end{tabular}

IKorGau1cs-EPH 200048499 96-616-1637 i1 15 INORCuNICB-EPH 200045500 96-616-1638 TI 8Y8 IKORGANICS-EPH 200046500 94-616-1638 71 8Y8 IKOAGAYICS-EPM 200048501 94-614-1438 II aYS IHORGANICS-EPH 200068502 9h-614-1438 II BTL IMORECHICA-EPM 200068502 96-614-1438 TI BYL JKOrCAYICD-EPM 200068503 96-616-1453 it in IHCRCantCR-EPH 200048504 96-616-1456 1114 IMancanics-EPM 200046505 94-614-1657 I1 16 IMORCANIC5-EPA 200048506 94-614-1458 it 17 JWORGuiset-EPK 200048507 96-616-1438 I1 825 IMOReunscs-EPW 200046507 96-616-1438 I1 828 IHOtcunics-EPH 200048308 96-616-1438 11821

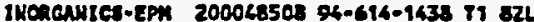
Imoreusics-EPM 200040508 96-616-1438 it a2L Imoreuntcs-EPH 200048509 96-616-1438 T1 828 IHoraukics-2PW 200045310 96-616-1438 i1 85 Inoucuiscs-EPW 200048510 94-616-1438 it as IMORGaNiCs-EPM 200045511 96-616-1438 I1 815 IUDenaures-EPK 200068519 \%6-614-1431 11813 Imoreuxics-EP 200048512 96-616-1638 i1 230

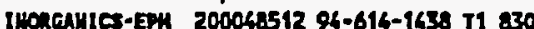
IHORCWNICs-tiph 200048513 94-616-1436 i1 Eso INoravitcs-EPH 200048313 96-616-1638 11850

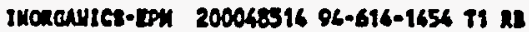
IKonceutcs-IPH 200046515 06-616-1439 I1 11A Inoncavics-EPA 200048515 94-614-1439 I1 11A IHORGuMtes-EPH 200040515 96-614-1439 i1 11A Thou Guxtes-IPX 200048521 96-616-1469 I1 19 InORGeuICs-EPH 200040521 94-616-1641 T1 19 IMONCAMICS-EPM 200048522 96-614-1442 T6 27 IHonexuICs-EPM 200048522 94-616-1462 T6 27 INORGANICS-EPW 200068522 96-614-1442 T6 27 twonsurica-ED 200068523 96-614-1444 To 82 IHOACuICE-IPH 200040523 94-616-1446 t8 82 IMORCUNICS-EPH 200068526 96-614-1446 II 90 Ironcuntcs-EPH 200048526 96-616-1446 T1 90 IMONGAIC8-EDN 200048525 94-614-1468 II 10

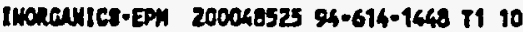
IHoreunies-EPH 200068523 96-614-1660 1910 IHONGUHICE-EPH 200048526 94-614-1459 11 82 IKoncunICs-EPH 200046526 96-616-1459 it 82

\begin{tabular}{|c|c|c|c|c|}
\hline $\begin{array}{l}\text { URAHILA } \\
\text { solios }\end{array}$ & $\begin{array}{l}1 \\
4.3\end{array}$ & $\begin{array}{l}\text { pess } \\
\text { ut } x\end{array}$ & $\mathbf{u}$ & 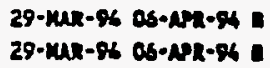 \\
\hline URANILY & 102 & Pm & & 29-KUR-96 OS-APR-OK E \\
\hline DEMSITY & 1.04 & g/al & & $29 \cdot k \mu k-96$ os-13n-sh \\
\hline PH & 7.10 & PH Un & & $29-\pi u R-96$ OS- $102-96=$ \\
\hline LReMILA & 30 & ppese & & $29-201-9606-201-96$ a \\
\hline LRAMILK & 0.1 & $\omega \sigma / L$ & $\mathbf{u}$ & $30-\mu h R-86$ OS-RPR-96 I \\
\hline urenitum & 1 & $\operatorname{pon}$ & $\mathbf{u}$ & $30-x u R-96$ os-APR-9h \\
\hline URentur & 9 & pon & u & 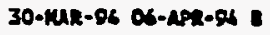 \\
\hline URAMIUN & 1 & ppe & $\mathbf{u}$ & 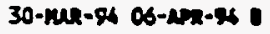 \\
\hline SOLtos & 7.3 & we $x$ & & $29-x u R-96$ os $-2 P R-96=$ \\
\hline urenitur & 103 & ppos & & 29-1LR-96 OS-APR-96 B \\
\hline PH & 9.49 & DN UN & & $29-x u R-9606-102-96=$ \\
\hline SOLIOS & 1.8 & we $x$ & & $29-\operatorname{man}-96$ 06-12R-26 = \\
\hline уесинй & 87 & pom. & & 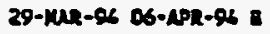 \\
\hline DENBITY & 1.05 & Q/al & & $29-\operatorname{knR}-96$ o5-ark-96 = \\
\hline DH & 9.41 & ph th & & $29-201-9606-18 R-96=$ \\
\hline venitum & 69 & ppom & & $29 \cdot$ ret-96 06-art-96 = \\
\hline DH & 9.61 & ph un & & 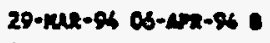 \\
\hline URENIUN & 76 & ppo & & $29-x u R-9406-\mu-2 k-96=$ \\
\hline $\mathbf{P r}$ & 9.40 & pH Un & & $20 \cdot x h-\alpha k$ as-aph-os $=$ \\
\hline urentum & 78 & ppon & & 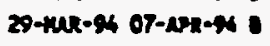 \\
\hline & 9.40 & PH Un & & $29-m e R-96$ OS-APR-96 \\
\hline Lentum & 22 & pem & & $29 \cdot \operatorname{mak}-26$ o6-19k-96 \\
\hline URERIUN & 0.1 & $\mathbf{m g} / \mathrm{L}$ & $\mathbf{u}$ & $30-21 k-96$ as-act-96 0 \\
\hline $\mathbf{P H}$ & 9.40 & on th & & 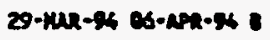 \\
\hline $\operatorname{soc} 103$ & 2.0 & we $x$ & & $29 \cdot 10 k-9406-\sin -96=$ \\
\hline URuxiur: & 6 & pan & & $29-24 x-96 \quad 07-2 x-96=$ \\
\hline solios & 56.2 & we $x$ & & 29-1uk-96 07-APR-9h B \\
\hline coneriun & 296 & pp & & 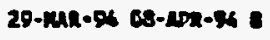 \\
\hline scours & 38.1 & $\omega t x$ & & $29-202-9607-27 t-260$ \\
\hline vacuitum & 129 & ppo & & $29-212 R-9643-12 R-96=$ \\
\hline Uenesiun & 525 & ppo d & & $29-211 x-96 \quad 13-202-96=$ \\
\hline sensos & 38.8 & we $x$ & & $29-x w k-9607-29 k-96=$ \\
\hline Urention & 277 & pm & & $29-12 R-96$ 04-NPR-96 E \\
\hline socios & 52.6 & $w=x$ & & $20-x u 2-96 \quad 07-107-96=$ \\
\hline urenicur & 186 & $\operatorname{pana} d$ & & 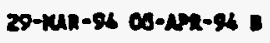 \\
\hline SOLIDS & 47.4 & wo $\mathrm{x}$ & & $30 \cdot m k R-56$ 07-2pR-96 \\
\hline Uentlum & 166 & $p \operatorname{don}$ & & $30-x c k-9600-c 2 k-96=$ \\
\hline uravitur & 198 & ppond of & & $30-x u R-94$ 26-xur-96 \\
\hline SOLIDS & 65.6 & ME $x$ & & $31-1212-9607-192-96=$ \\
\hline URAMtLr & 267 & pen d & & $31-302-9608-252-96=$ \\
\hline
\end{tabular}

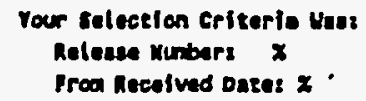

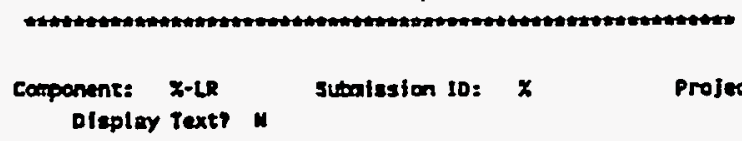


DATE O2-FEB-95

TINS 11:52:33

RELERSE MUKBER : 1000002342

PROJECT WUN

: 50.05.08 93.616 CRUS I/D TREAT-PHASE II

1 an

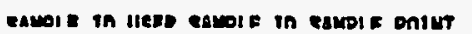

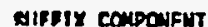

SUWCURY REPORT (PRELIMINARY)
DMEE 29

OATE

OATE TASK

RESULT UNITS LO SAKPLED PERFOREEO ASL 
RELEASE MUAER : 1000002362

PROJECT WAME : 50.05.08 93-616 CRUS 1/0 TREAT-PHASE 11

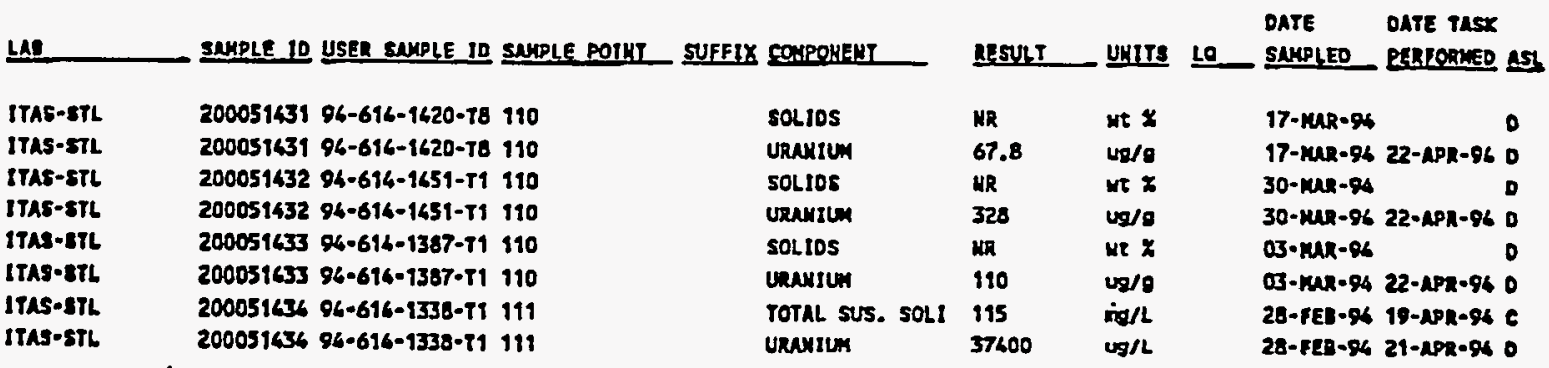

Your ealection critaris bas:

Releses Nutbers $z$

Fran areaived Dates $\mathbf{x}$

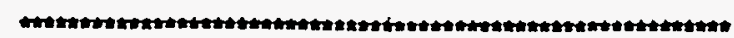

Components X-LR

Disploy Textr $n$
Subalssion 10: $z$

Project Mane: $50.05 .00 \times 59 \pi-614 x$ 
RELERSE MLABER : 1000002365

PROSECT WUATE : 50.05.08 93-616 CRUS 1/0 TREAT-PHASE II

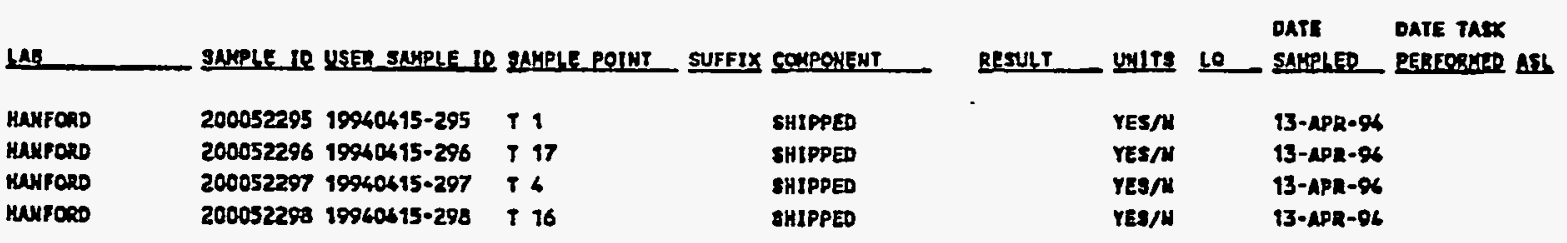

Your selection Critaria thes: Relense Nubers $z$ Fron Recoived Doter $x$

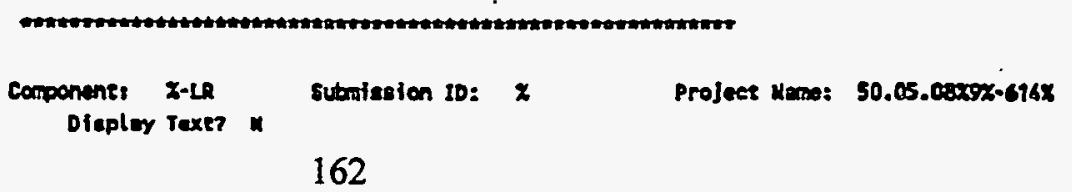


MELEASE MLUBER \& 1000003657

PROJECT WMAE \& 50.05.08 93-614 CRUS 1/D TREAT-PHASE II

4. SMMPLEID USER SAMPLE ID SMMPLE POINT SUFFIX COMPONEHT

\section{WotochenICAL} wotochisureul MolochentCuL NDIOCHENCLL MDIOCHEMICAL RHOLOCHEMSCAL neprochenten RNolochentent MAD IOCHEMICAL NLDIOCHEMTCAL Mubrockentcal MUDIOCHERICAL RADIOCKENICAL motochentCal

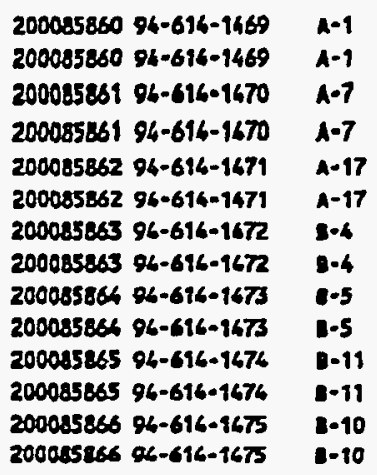

MLPHA

QETA

ALPMI

BEin

M.PMA

UETA

ALPHA

LETA

ALPHA

IETA

ALPHA

IETA

ALPHA

IETR
DATE DATE TASK RESULT UWIS LO SAMPLED PAREORAEP ASI

470 PCI/s

$420 \quad \mathrm{PCI} / \mathrm{g}$

PCi/g

Aci/g

pCi/s

pCi/s

petso

PCi/g

pciss

$\mathrm{pCl} / \mathrm{\theta}$

pcisg

pcise

PCi/o

pCis/s

$16-100-96$ 17-2100-96: 16-AVE-96 17-N166-94 :

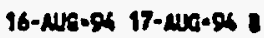
16- NGG-96 17- Nus-96: $16-1 \mathrm{NC}-96$ 17- $1 \mathrm{NC}-96$ : 16-ave-os 17-uve-g6:

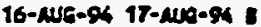
16-4l6e-96 17-406-94 16-100-96 17-eve-ge $16-100-84$ 17- 1700-94 16-160-96 17-ave-94 =

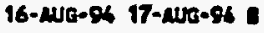
16- $16100-96$ 17- $1700-96$

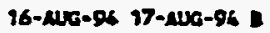

Your seleotion criteris Mas: nalease thebars $x$ fron Reealived Dares $x$
Compenents $x-1$ Dlaplay Text?
Sumiasion ID:

$x$

Projest Muset 50.05.00x52-614X 
DATE O2-FES-95

SUHWARY REPORT

DACE 25

TINE $11: 52: 33$ (PRELIATHARY)

RELEASE RUNBER : 1000003896

PROJECT HUKE $=$ 50.05.08 $93-616$ CQUS 1/D TREAT-PHASE 11

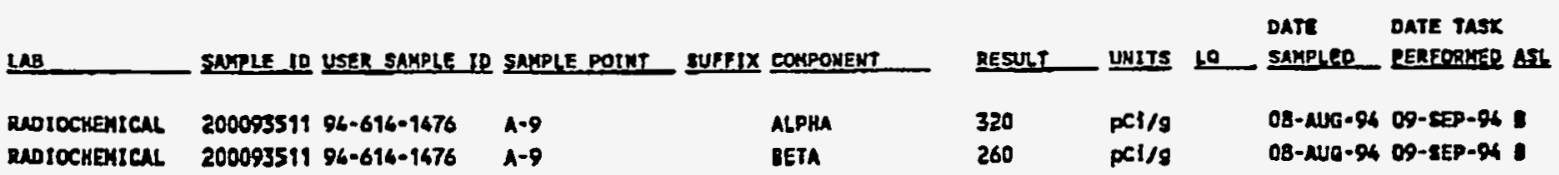

rour Seleetion Crizerfa tast Relenen inemer: $x$ Pron Recalved Date: $x$

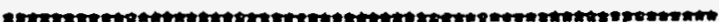

coaponenes $x$-LR subateaton $10: x$

Project wenes 50.05.00x9\%-614\%
164 
RELEASE MLHAER : 1000004140

PROJECT MHME : $30.05 .0893-616$ CRUS S/O TREAT-PHASE II

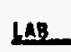
SMYPLE IO USER EMMPLE ID SAMPLE POIMT SURFIX COMPOMEMT

motockentche 200100014 \$6-616-1481 72851 WOPYOCHEMICAL 200100016 96-616-1681 72951 RADIOCHEKICAL 200100020 96-616-1506 Y2 \$50 RADROCHEMICAL 200100020 96-614-1506 I2 550 RNDTOCHEHICAL 200100021 96-614-1513 T2 S51 RNOLOCHEMICAL $20010002196-616-1513$ T2 351 IHORGANICS-EPH 200100216 94-614-1477 T2 sia IHORewitcs-EPW 200100216 96-614-1477 12 sia IMONCANICS-EPN 200100233 94-614-1670 72 s18 IMOACUYICS-EPH 200100233 94-616-1678 12 51B IMORCUHIC8-EPH 200100236 96-614-1479 T2 SIC IMORGANICE-IPH 200100236 96-614-1470 T2 SIC IHORGuIIC8-EPX 200100235 96-614-1486 Y2 S81 IKORGANICS-EPH 200100235 94-614-1486 T2 S81 IMOREUNIC8-EPM 200100236 96-616-1490 72 S70 IMORCAHICS-EPH 200800236 96-616-1690 72570

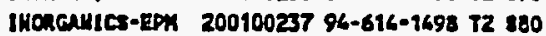
IHOACNHICS-EPN 200100237 94-616-1698 I2 280 IRORGuMrCs-EPK 200100238 $04-616-150072890$ IMORCaNiCs-EPM 200100238 $96-616-1500$ i2 390 IHORGANICS-EPH 200100239 96-616-1502 TZ 810A IHOACANICS-EPH 200100239 94-616-9502 T2 s10A IHCRCANIES-EPN 200100240 94-614-1503 T2 5108 InORanics-Ex 200100260 94-616-1503 T2 s100 IWOACAHICS-EPH 200100241 96-616-1506 T2 \$10C IHCACUHICS-EPH 200100261 96-616-1504 728106

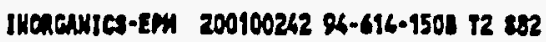
IMORCUNICS-EPM 200100262 94-616-1508 $\mathrm{T2} 582$ INORGauiet-LPW 200100263 96-614-1509 T2 S1A IMORCWHICs-EPH 200100263 96-616-1509 T2 51A IHORGuNICe-EPH 200100266 96-614-1510 T2 S18 IHORCANICS-EPW 200100264 Q4-616-1510 T2 s10 IHOREUMICS-EPM 200100245 96-616-1511 T2 s1C IHORQUHICS-EPM 200100245 96-616-1519 T2 S1C IWONCAH1CJ-EPH 200100246 96-616-1529 12860 IMOAEANICS-EPH 200100246 94-616-1529 T2 860 IWOAdHICA-IPA 200100252 94-614-1682 T2 פ2 InORGAurcs-zPH 200100252 94-616-1482 T2 s2 IHORECHICS-EPH 200100262 \$4-616-1516 T2 \$2 IKOACANICS-EPA 200100262 96-616-1516 $72 \$ 2$ IKONCANICs-Em 200100286 Q4-616-1487 T2 seAYL THOAGHTCS-EPH 200100285 \$4-616-1487 T2 saArh

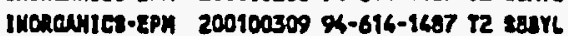

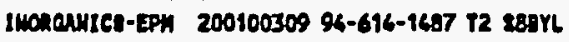

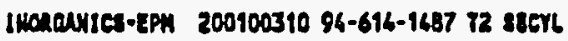
INoncuutcs-IPH 200100310 96-614-1487 T2 s8ctL IKORGANICS-EPH 200100311 96-614-1487 72 Se460L

vour solection criterle wasz

Roluse Mubert $x$

Prom Recoived bates $x$

\begin{tabular}{|c|c|c|c|}
\hline $\begin{array}{l}\text { ALPHA } \\
\text { DETA }\end{array}$ & $\begin{array}{l}360 \\
320\end{array}$ & $\begin{array}{l}p C 1 / s \\
\text { PCI/O }\end{array}$ & $\begin{array}{l}29-5 E P-96 \text { 05-0CT-94 } \\
29-8 E P-96 \text { 05-CCT-96 }\end{array}$ \\
\hline ALPHA & 53 & pci/s & $03-061-96$ 05-0CT-Q6 \\
\hline BEJA & 130 & PCi/g & $05-0 c t-94$ os-oct-96 $=$ \\
\hline MLPKa & 450 & $\infty i / g$ & 05- \\
\hline BETA & 380 & DCI/o & $03-0 c T-96$ 05-0ct-96 = \\
\hline MOISTURE & 8.1 & wE $\mathbf{z}$ & $29-\operatorname{sep}-9606-0 c t-960$ \\
\hline Urexisus & 570 & pond & $29-5 E P-9613-001-968$ \\
\hline MOISTURE & 9.3 & we $z$ & $29-9 E P-96$ O6.0CT-96 = \\
\hline URANILM & 550 & ppo of & $29-$ st5-94 13-oct-96 \\
\hline MOISTURE & 11.7 & we $x$ & 29-sep-96 O6-0CT-96 D \\
\hline Urensium & 480 & $\operatorname{pos} d$ & $29-\operatorname{sep}-96 \quad 13-\propto c t-96=$ \\
\hline MOISTURE & 18.9 & ut $x$ & $29-\operatorname{sep} \cdot 96$ 06-0CT-96 = \\
\hline consicen & 920 & Dpon d & 28-sEP-94 13-ccr-96 \\
\hline MOISTURE & 32.6 & we $x$. & 30-szP-gh Ob-oct-gh \\
\hline Uavion & 140 & $\infty$ & 30-IEP-96 13-DCT-g6 = \\
\hline MoIstuaE & 32.6 & $\operatorname{sex} x$ & $\begin{array}{l}30-\text { รEP-96 } 06-007-96= \\
30-\text { IEP-96 } 13-007-96\end{array}$ \\
\hline MOISTURE & 35.3 & wE $x$ & 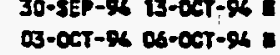 \\
\hline URuNiux & 89 & $\cos d$ & $03-0 c t-96$ 13-0ct-96 = \\
\hline MOISTURE & 38.9 & ut $x$ & $03-067-96$ o6-0ct-96 = \\
\hline Granium & 85 & pen d & $03-0<1-96$ 13-0<t-96 = \\
\hline MOISTURE & 37.3 & we $z$ & $03-067-9406-0 C T-96$ ] \\
\hline urewitis & 100 & ppon d & $03-\infty c 7-94$ 13-xct-ss \\
\hline MOISTURE & 37.4 & we $\mathbf{x}$ & $03-0 C 5-96 \quad 06-00 T-96$ \\
\hline 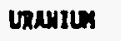 & 76 & pen d & 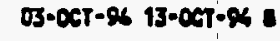 \\
\hline MISTURE & 45.1 & ye $x$ & $03-007-9606-047 \cdot 96$ \\
\hline unerizer & 140 & $\cos d$ & 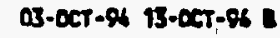 \\
\hline woleture & 16.2 & $4 \pm x$ & O3-oct-96 os-oct-96 = \\
\hline $\begin{array}{l}\text { Laumitum } \\
\text { notstune }\end{array}$ & $\begin{array}{l}910 \\
13.8\end{array}$ & $\cos _{\text {we } x} x$ & 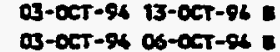 \\
\hline ureanitun & 950 & pean d & $03-\infty c t-06 \quad 13-\infty c 7-96$ \\
\hline WOISTURE & 12.7 & we $x$ & $03-0 \mathrm{CT}-96 \quad 06 \cdot 00 \mathrm{~T}-96 \mathrm{C}$ \\
\hline unartum & 790 & pen d & $03-0<T-96$ 13-வCT-96, \\
\hline MOISTURE & 40.3 & ut $x$ & $03-0 C T-96$ 0S-0CT-96 = \\
\hline URamicen & 390 & $\operatorname{cosec} d$ & $03-0 C T-96 \quad 13-007-96$ \\
\hline MOISTURE & 2.0 & st $x$ & 29-SEP-96 D6-DCT-96 \\
\hline UenNICH & 51 & $p=d$ & $29-85 P-96 \quad 13-\infty \mathrm{CT}-96$ \\
\hline Molstuak & 24.3 & wT \& & $03-0 c r-96$ as-oct-o6 = \\
\hline Lanizium & $\pi$ & pos d & $03-\infty c T-96$ t3- \\
\hline PH & 7.30 & Dit & 29-SEP- 96 05- 0 CT- \\
\hline ventiven & 2.2 & $\mathbf{m} / \mathbf{L}$ & 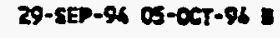 \\
\hline $\mathbf{P H}$ & 7.27 & PN Un & $29-\operatorname{seP}-96$ C5-0CT-96 = \\
\hline verustim & 2.3 & $\boldsymbol{m} / \mathbf{L}$ & 29-SEP-86 05-0CT-96 I \\
\hline DH & 7.26 & put in & $29-\operatorname{SEP}-96$ 05-0CT-O6 = \\
\hline Gavitur & 2.3 & $\mathbf{m} / \mathbf{L}$ & 29-SEP-96 03-.CT-96 D \\
\hline PM. & 9.46 & pti un & $29-\sec -96 \quad 00-\infty C T-96$, \\
\hline & & & \\
\hline 8 & & jeet Mand & $50.05 .02 \times 9 x-6168$ \\
\hline
\end{tabular}


RELEASE Mmben \& 1000004160

PROSEET WUKE \& 50.05.08 93-614 CRUS I/O TREAT-PHASE II

LAB SUMPLE IP USER SAHPLE ID SAMPLE POIMT SUFFIX COUPONENT

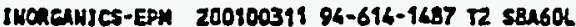
INORCQNICS-EPH 200100311 96-614-1487 T2 SEA60L INORGAICS-EPW 200100312 96-616-1687 T2 $38860 \mathrm{~L}$ IMORGANICS-EPM 200100312 94-614-1407 T2 SEB60l INOAGAYICS-EPH 200100312 96-616-1487 T2 38B60L INOREenICs-EPH 200100313 96-614-1487 T2 S8C60L IMORGurtes-EPH 200100313 96-616-1487 12 sec60h INOEGANICA-EPW 200100313 96-614-1487 I2 S8E60L IMOrGantes-EPW 200100314 96-616-1489 T2 $311 \mathrm{~A}$ IMORGNics-EPN 200100316 94-616-1689 72 517A IHCAEAMJCS-EPW 200100316 96-614-1489 T2 \$19A THORGuics-EPH 200100375 96-616-1499 T2 3118 Imorounics-EPN 200100313 96-616-1691 128110 troreuxics-IPH 200100315 96-616-1691 T2 8118 inoreuics-2m 200100316 96-616-1695 12 sapq82 IMOnGUICs-EPH 200100316 94-614-1495 12 san18t 1monasures-IPW 200100316 96-616-1695 T2 schist Imorewics-5PH 200100317 96-616-1696 72 SB8186

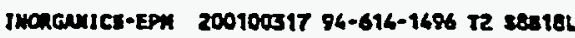
IWORCANICS-EPW 200100317 94-614-1696 T2 se818L IHORCWICS-EPM 200100318 94-616-1497 T2 S8C184

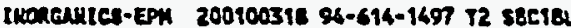
IMORGUICS-EPM 200100318 96-616-1497 72 sec181 Imoreculcs-IPH 200100319 96-616-1501 728110 Imoracuxies-LPM 200100319 96-616-1501 72 2110 I Moteunics-EPM 200100319 96-616-1501 T2 8110 Imouenites-EPN 200100320 96-616-1507 72 \$11E IMORCANICS-EPM 200100320 96-614-1507 T2 \$11E IMOHGANICS-EPK 200100320 54-614-1507 T2 S11E I102GANICs-EPW 200100321 96-616-1520 12 sart INORCuHICs-EPH 200100321 96-616-1520 i2 seurL INORENICS-EPK 200100321 96-614-1520 T2 sBuYL IHORCHILS-EPH 200100322 94-616-1521 T2 starL 1MORGANICs-EPX 200100322 96-616-1521 12 searL

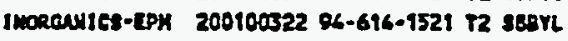
INORGAMICs-5PH 200100323 96-616-1522 82 s8crL INORGAKICS-EPA 200100323 96-616-1522 T2 sact IMOKCANICS-EPX 200100323 94-614-1522 T2 sBcrL 1Kokevics-EPH 200100326 94-614-9326 12 s2usol

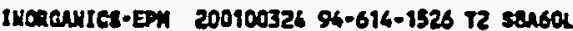
IMORGANICS-EPX 200100326 96-616-1526 72 sensol INCRGANICS-EPA 200100325 96-616-1527 T2 58850L IHOReunies-EPW 200100325 96-614-1527 12 s8860l IKORCUNICS-EPM 200100325 96-616-1527 t2 s806011 IMOREAMICS-EPA 200100326 96-616-1528 72 S8C60L Thon Guvics-EPH 200100326 96-616-1521 T2 SBC60L INORCANICS-EPK 200100326 96-616-1528 T2 s8C60L

\begin{tabular}{|c|c|}
\hline SOLIOS & 0.6 \\
\hline URAMIUA & 31.1 \\
\hline PH & 9.65 \\
\hline solids & 1.0 \\
\hline URANIU: & 30.3 \\
\hline PH & 9.46 \\
\hline solios & 0.6 \\
\hline unaritur & 31.6 \\
\hline PH & 9.67 \\
\hline solios & 1.61 \\
\hline UReNIIUA & 29.2 \\
\hline PH & 9.53 \\
\hline soulos & 1.73 \\
\hline unantuy & 7.3 \\
\hline PH & 9.40 \\
\hline SOLIDS & 1.9 \\
\hline LRNUIL & 1.5 \\
\hline PH & 9.48 \\
\hline $\sec 10 s$ & 1.9 \\
\hline URAMILM & 1.6 \\
\hline PH & 9.48 \\
\hline sollos & 1.9 \\
\hline Unentix & 1.5 \\
\hline PH & 9.69 \\
\hline sectos & 0.3 \\
\hline URANIT & 1.6 \\
\hline PH & 9.76 \\
\hline ecclos & 0.1 \\
\hline URAyiux & 3.8 \\
\hline PH & 8.02 \\
\hline seutas & 0.06 \\
\hline URAMIUA & 16.6 \\
\hline PH & 7.96 \\
\hline solios & 0.1 \\
\hline URANIUN & 16.6 \\
\hline PH & 7.98 \\
\hline $\operatorname{coc} 10 s$ & 0.1 \\
\hline urenium & 15.3 \\
\hline PH & 9.67 \\
\hline solios & 1.8 \\
\hline crenisu & 18.0 \\
\hline PH & 9.47 \\
\hline solids & 2.8 \\
\hline trakiten & 86.9 \\
\hline PH & 9.66 \\
\hline soctos & 3.0 \\
\hline venakiun & 87.2 \\
\hline
\end{tabular}

DATE OATE TASK RESULT UHITS LO SAMPLED PERFEREED ASL

29-sta-o6 10-00T-94 29-4еp-gh 09-00t-94 29-5EP-gS 06-CCT-9S 29-StP-94 10-0.7-93 29-xep-94 00-0CT-94 29-SEP-96 05-0CT-96 : 29--5eP-94 10-0CT-96 I 29-JEP-94 09-0CT-96 = 29-IEP०وS Q4-0CT-96 : 29-รEP-96 10-0.7-\% $29-35$ - 98 10-007-96 30-IEP-OS OY-CeT-96 30-EEP-96 10-0.97-94 30-8EP-96 10-0ct-96 30-1EP-\% C8-0ct-94 30-รEP-16 10-0ल7-04 30-9EP-96 10-0CT-96 30-Ex-94 08-0.t-96 = 30-xep-94 10-0ct-96 30-IEP-S6 10-COT- $\%$ 30-SEP-96 03-00T-06 30-3EP-96 10-0CT-96 30-SEP- Y4 10-0CT -94 03-0eT-os 0s-cot- $\alpha$ 03-00T-96 10-0.96-96 03-0ct-94 10-cet-96 03-0ct-94 as-0.t- 46 03-0ct-96 10-097-94 03-cGT-46 10-0.t-gs 03.067-04 08-00T-94 8 03-0c7-94 10-00T-96 03-0ct-96 00-0eT-96 E 03-0CT-OS D-0.0T-gs E 03-0c7-06 10-0ct-os = 03-0ct-96 10-0CT-o6 03-ect-98 02.0CT-96 ह 03-0CT-96 10-00T- 96 03-0cT-96 10-0ct-96 a 03-0ct-86 08-0ct-24 as-cot-\% 10.0ct-\% a 03-0ct-os 10-0ct-96 03-0ct-96 08-0ct-\%6 03-0CT-96 10-0CT-96 a 03-0ct-96 10-0ct-96 03-0eT-96 c5-0et-g6 a 03-0CT-96 10-0CT-96 03-0et-94 10-0ct-96 = vour setestion Criterte Was: Release Nuber: $x$

Fron neeoived Date: $x$
Component: $x-L e$ Displey rexer H oubaisaton s0: $x$ $\mathbf{x}$

Project rane: $50.05 .00059 x-674 x$ 
RELEASE MLYMER \& 1000004140

PRONECT WANT I 30.05.08 93-614 CRUS i/O TREAT-PHASE II

4h. SMMPLE ID USER RMPLE TO SMYPLF PORMT SUFFIX COMPONEHT

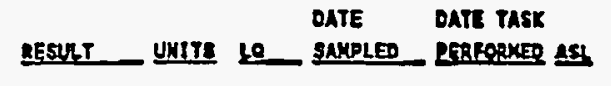

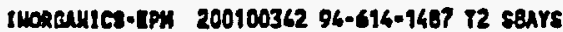
IHoncurics-2PH 200100362 96-616-1487 I2 sBurs IHoucultes-IPM 200100342 96-616-1487 12 saurs In REANICS-EPM 200100343 94-616-1487 72 s83Y IHOACANICS-EPH 200100343 94-616-1687 T2 stave IMAICUICS-EPH 200100343 94-616-1487 72 s88rs JHoncurict-EPH 200100366 96-616-1487 T2 stcrs Imonautcs-IDM 2001003e6 96-616-1687 T2 s8crs Iworanitce-EPh 200100346 96-616-1487 T2 secre

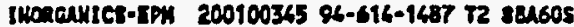

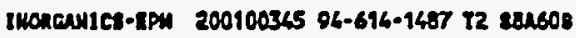
Irotanitcs-รPY 200100345 94-616-1487 72 subos

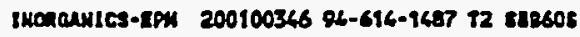
IMORGAMICS-EPH 200100346 94-616-1487 IZ 888608 IHORCANICS-EPM 200100346 98-616-1607 T2 s6es0s thoneurtes-EPM 200100347 94-614-1487 12 s8c60s

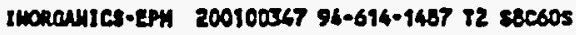
IHoweuntes-IPW 200100367 96-616-1487 72 sac6os IKCRGAHICs-Im 200100348 96-616-1683 t2 selze IMOReANICs-EPH 200900348 96-614-1600 12 souze IHentanics-1m 200100348 96-616-1480 12 seuzs IWOACANJC5-EPM 200100349 96-616-9488 72 20028 IMCNCAVICS-EPH 200100349 94-616-1688 T2 3882s IWonensics-EPH 200100349 94-614-1488 12 s812s Inoucultes-Em 200100330 94-614-1488 I2 s8czs IMORCuntes-Em 200100350 \$4-616-1483 12 sac2s Ixoreunics-em 200100350 96-616-1400 72 s8c7s

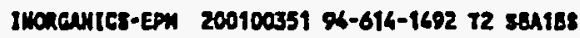
1Honcunres-EPM 200100351 \%4-616-14\%2 T2 sou1as Inoncurics-IPH 200100351 96-614-1492 72 senies

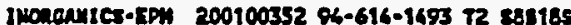
IHOREAVICS-EPH 200100352 \$4-616-1693 T2 E8A18s IHOACAVICL-EPH 200100352 94-616-1493 72 s83185 IKoneunics-5PM 200100353 96-614-1496 T2 sectes Inoneanics-Em 200100353 96-616-1694 72 sectes IMORGuHCS-EPH 200100353 06-616-1696 72 stC1ES

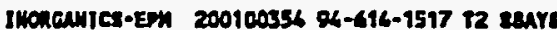
Inoncautcs-egh 200100356 96-616-1517 T2 surs IMoneautcs-EDM 200100356 \%6-616-9517 T2 seArs Imoncuxjes-Eph 200100355 96-696-9518 i2 sepre IHoueurics-EPM 200100355 94-614-1518 T2 sa17s IHorautes-tPM 200100355 96-616-1518 12 seprs

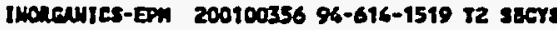
tweneurics-EPn 200100356 94-614-1319 12 sects

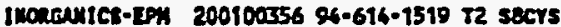

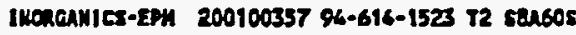

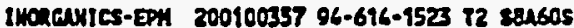
Components $x$-LR Dieploy Texe? N

\begin{tabular}{|c|c|c|c|}
\hline $\begin{array}{l}\text { DELSITY } \\
\text { SOLIOS }\end{array}$ & $\begin{array}{l}1.06 \\
8.4\end{array}$ & $\begin{array}{l}\text { g/al } \\
\text { we } x\end{array}$ & $\begin{array}{l}29-9 E P-96 \text { 11- CCT-96 } \\
29-15 P-96 \text { 10-0cT-96 }\end{array}$ \\
\hline URAHILA & 51.5 & $m / 2$ & $29-\operatorname{sep}-9 \phi 10-0 c t-9 \phi=$ \\
\hline DEKSITY & 1.03 & $g / m l$ & 29-SEP-96 11-0CT-96 \\
\hline solios & 8.6 & we $\mathbf{x}$ & 29-EEP-96 $10.001-96$ E \\
\hline URANILA & 50.0 & $\omega / L$ & 29-sep-96 10-0c7-96 \\
\hline DEISITY & 1.03 & $g / m l$ & 29-step-96 11-0ct-96 D \\
\hline solios & 6.5 & wt $x$ & $29-\operatorname{sep}-96 \quad 10-0 \mathrm{ct}-96=$ \\
\hline $\begin{array}{l}\text { ERANTIN } \\
\text { OENSITY }\end{array}$ & $\begin{array}{l}31.3 \\
1.08\end{array}$ & g/al & 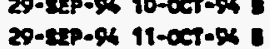 \\
\hline SOLIDS & 8.7 & ue $x$ & $29-\operatorname{sep}-9610-007-94=$ \\
\hline URakion & 51.6 & $\boldsymbol{\infty} / \mathbf{L}$ & $29-\operatorname{sep}-94 \quad 10-0<1-96=$ \\
\hline DEHEITY & 1.12 & g/al & 29-sEP-96 11-DCT-96 \\
\hline solids & 0.8 & we $x$ & 29-JEP-96 10-0CT-96 = \\
\hline Lrentlow & 48.1 & $\infty$ & $29-255-9408-061-96=$ \\
\hline DEMSITY & 1.10 & g/al & $29-\operatorname{sep}-9611-\infty \mathrm{CT}-96=$ \\
\hline soltos & 8.7 & He $x$ & 29-sEp-94 10-0ct-94 = \\
\hline URenilu & 45.9 & $m / 2$ & $29-\operatorname{sep}-9408-00 t-941$ \\
\hline DEMSIT & 1.05 & $\mathrm{Iml}$ & 30- IEE-96 $11-00 \mathrm{CT}-96=$ \\
\hline sotidos & 7.9 & we $x$ & 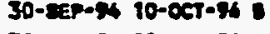 \\
\hline Lenentum & 14.7 & $\mathbf{m} / \mathbf{L}$ & $30-8 E 2-9400-00 t-96$ \\
\hline DEMSITY & 1.07 & $g / m l$ & $30-\operatorname{sep}-9611-06 \mathrm{CT}-96=$ \\
\hline 50L105 & 7.8 & $\omega x$ & $30-\operatorname{sep}-94 \quad 10-0<7-96=$ \\
\hline venutur & 15.2 & $\mathbf{m / L}$ & 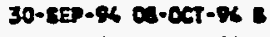 \\
\hline DEMSITY & 1.07 & $g / \mathrm{ml}$ & $30-\operatorname{seg}-96 \quad 11-\infty T-96=$ \\
\hline solitos & 8.3 & uE $x$ & $30 \cdot$ SEP-96 $10 \cdot 0 \mathrm{CP} \cdot 94=$ \\
\hline GRavilur & 16.9 & $\mathbf{m} / \mathbf{L}$ & $30-28 p-9600-\infty 67-94$ L \\
\hline OENSITY & 1.06 & g/al & $30-$ SEP-96 $11-0 C T-96$ \\
\hline sol.105 & 8.3 & we $x$ & $30-8 E P-96 \quad 10-067 \cdot M 4$ \\
\hline Uenertur & 6.3 & $m / L$ & $30-58 p-96 \cos -\cot -96=$ \\
\hline OENSITY & 1.06 & s/al & $30-\operatorname{sep}-94 \quad 11-\infty \mathrm{ct}-96=$ \\
\hline solios & 8.1 & we $x$ & $30-5 E 5-96 \quad 10-0 \mathrm{CT}-96=$ \\
\hline uranicur & 11.5 & $\mathbf{m} / \mathbf{6}$ & $30-850-9603-007-96=$ \\
\hline DEMSITY & 1.06 & $g / a t$ & $30-85 P-96$ 11-06T-86 E \\
\hline soulds & 7.4 & we $\mathbf{x}$ & 30-8EP-QK $10-0 \mathrm{CT}-86=$ \\
\hline urentiun & 16.5 & $\boldsymbol{m} / \mathbf{L}$ & 30-5EP-96 DE-0CT-84 E \\
\hline DENSITY & 1.06 & g/al & $03-D C T-8611-\infty \mathrm{CT}-96$ \\
\hline sol.10s & 6.9 & $w \pi$ & $03-00 \mathrm{~T}-96$ 10-0ct-94 = \\
\hline unatiur & 120 & $\mathbf{m} / \mathrm{l}$ & $03-007-8603-067 \cdot 96=$ \\
\hline DEMSITY & 1.03 & $g / a l$ & $03-00 T-9411-0 C 1-A 4=$ \\
\hline SOLIOS & 5.3 & we $x$ & O3-0CT-96 10-0CT-gS E \\
\hline ueensium & 91.1 & $m / L$ & $03-0 C T-9608-007-96=$ \\
\hline DEMEITY & 1.06 & $\boldsymbol{g} / \mathbf{m b}$ & $03-0 c t-9611-0<T-96=$ \\
\hline solidos & 8.3 & we $X$ & 03-סCT-94 10-0CT-86 $=$ \\
\hline Lenaviun & 120 & $m / L$ & $03-0<t-96$ OB-06T-96 = \\
\hline DExsity & 1.06 & $g / a d$ & 03-0CT-96 11-DCT-96 \& \\
\hline soụtos & 7.6 & ae $x$ & $03-\infty 07-96 \quad 10-\infty 07-94=$ \\
\hline
\end{tabular}

your selection Criteerto thas: Ralases vubers $x$ Pron Reeofived oator $x$

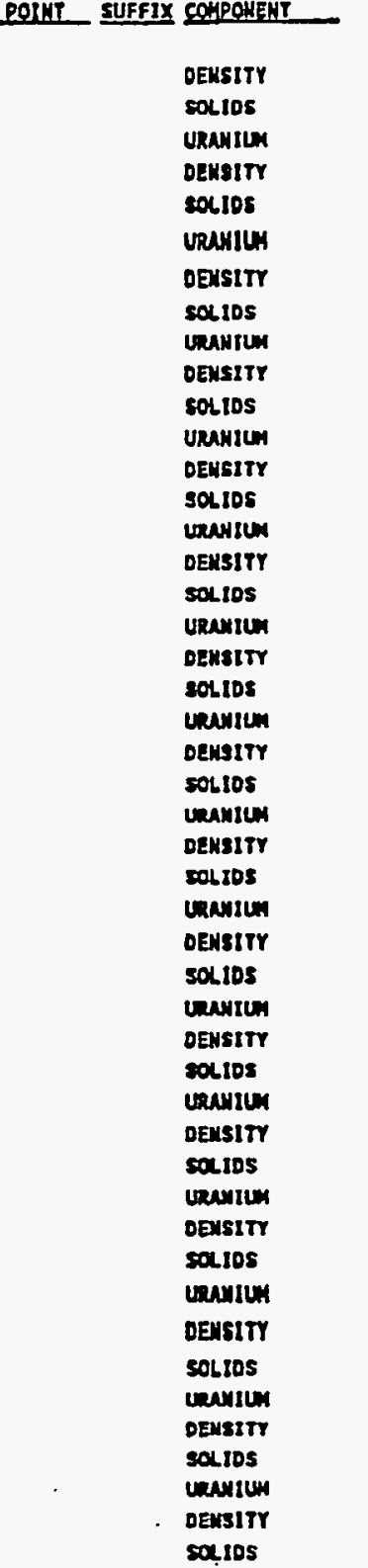


RELEASE MUMBER : 1000006160

PROJECT WNE \& 50.05.08 93-696 CRUS 1/D TREAT-PHASE I1

$4 A B$ GAKRLE IO USER SAKPLE ID SAKPLE POIKT SUEEIX COMPONEKT

RESULT UHITS Le SAKPLED REROALE ASL

IHONGNICS-EM 200100357 94-614-1523 72 s8460s IMORCNICS-EPW 20070035B 96-614-1524 T2 58860S IRORGawiCs-Em 200100358 96-616-1526 T2 588605 INORCANICS-EPH 200100358 94-616-1526 T2 s8860s INORCANICS-EPH 200100359 94-614-1525 T2 s8c60s IMOREAUICS-EPX 200100359 94-616-1525 T2 sec60s IMCReANIES-EPH 200100359 94-614-1525 T2 sec60s mase eprethosco 200100362 9h-616-1502 72 \$10A Mas spectnosco 200100362 \%-614-1502 $\mathrm{T}$ sioh MAs SPECTROSCO 200100362 94-614-1502 t2 s10h MAss SPECTROSCO 200100362 94-614-1502 t2 s10ג KAst speetnosco 200100613 96-614-1503 t2 s10a kuss spectnosco 200100413 96-616-1503 T2 s108 WASS EPECTROSC0 200100613 94-616-1503 T2 s108 Kuse SPECTROSCO 200100413 94-616-1503 72 s108 MAS spectRosto 200100616 96-614-1506 T2 s10C Muss spretrosco 200100416 96-616-1506 T2 s10C MASS SPEETROsco 200100616 94-616-1506 $\mathrm{T2}$ s106 MUS EPETINosco 200100416 Q6-616-1506 72 s106 Iworeutes-5PH 200100615 96-616-1428 $\mathrm{r}$ sBA2L

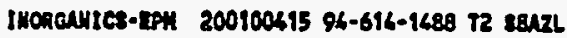
Inonenucs-IPW 200100415 9h-616-148s T2 senzL 1woredutes-5PH 200100616 96-616-14E8 T2 s89zL. InoRnumes-EPH 200100\$16 96-616-1488 T2 18824

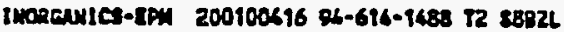

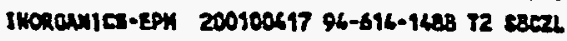

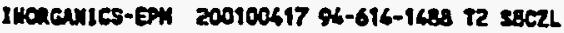

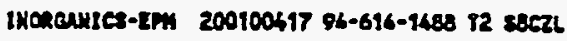
INCReArics-EPH 200100518 94-614-1690 T2 s11C Imoxeutes-EPA" 200100618 96-616-1699 T2 S1TC twoncuntcs-EPX 200100618 96-616-9499 T2 s1tc

\begin{tabular}{|c|c|c|c|}
\hline verutrun & 125 & $m / L$ & $03-0 c T-96$ as-oct-or \\
\hline DENSITY & 1.05 & g/al & $03-007+96 \quad 89-0 c T-96$ \\
\hline SOLIDS & 7.6 & we $x$ & $03-00 t-94 \quad 10-00 T-96$ \\
\hline URANIUM & 122 & $\mathbf{m a / h}$ & $03-0 \mathrm{cT}-96$ 08-0ct-94 \\
\hline DEWSITY & 1.02 & g/al & $03-007-96 \quad 11-007-96=$ \\
\hline solios & 5.1 & we $x$ & $03-00 \mathrm{r}-96 \quad 10.0 \mathrm{ct}-96$ \\
\hline URANIU世 & 93.1 & $9 / \mathrm{h}$ & $03-007-96$ 085-0ct-94 \\
\hline URAKTIX 234 & 30.9 & $\mathrm{pel} / \mathrm{s}$ & $03-001-96$ 17-0ct-96 \\
\hline URANIUN 235 & 1.3 & $\mathrm{PCi} / \mathrm{m}$ & 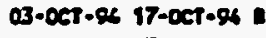 \\
\hline URnuIU: 236 & 0.4 & pcise & $03 \cdot 007-9617-007-06$ \\
\hline URAKIUA 238 & 28.4 & pes/s & $03 \cdot 00 \mathrm{0}-06$ 17-007-96 \\
\hline URNIIUA 236 & 37.5 & $\mathrm{PCl} / \mathrm{g}$ & $03-00 t-96$ 17-0ct-96 \\
\hline Lanture 235 & 1.5 & $\mathrm{pCi} / \mathrm{s}$ & $\alpha 3-\infty c t-96 \quad 17-0 c t-96=$ \\
\hline ventitus 236 & 0.5 & Dite & $03-007-96$ 17-0.7-96 = \\
\hline vansun 238 & 33.4 & $\mathrm{pct} / \mathrm{e}$ & $03-007-96 \quad 17-001-96=$ \\
\hline URAKILA 236 & 27.0 & pcis/s & $03-007-94$ 17-007-94 \\
\hline LNANIU: 235 & 1.1 & $\mathrm{pcise}$ & $03-00 T-96 \quad 17-007-96$ \\
\hline Unentun 236 & 0.6 & $D C t / s$ & $\alpha 3-\operatorname{cct}-9617-\infty \cos -96=$ \\
\hline LRNIIU: 238 & 24.7 & pet/o & $03-$ act-os 17-0ct-ob \\
\hline PH & 9.50 & on un & 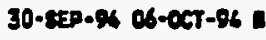 \\
\hline solios & 2.0 & $\operatorname{mex}$ & $30-\operatorname{sep}-9410-005-86$ \\
\hline Unarsicy & 7.2 & $m / 2$ & $30-\operatorname{sep}-46$ 03-0ct-96 \\
\hline PH & 9.50 & PH Un & $30-\operatorname{cop}-9606-001-96$ \\
\hline SOLIOS & 2.5 & wr $x$ & $30-5 E P-94 \quad 10-00 T-96$ \\
\hline unesiun & 6.6 & $\infty / 6$ & $30-8 E P-9403-007-96$ \\
\hline PH & 9.48 & ph th & $30-525-9606-007-96=$ \\
\hline sotios & 2.4 & wז $x$ & $30-8 E$-96 10-0.91-96 \\
\hline Unaniun & 7.2 & $m / L$ & 30-รEP-g6 CS-c0t-96 \\
\hline PH & 9.46 & PH un & $30-849-96$ 06-0ct-94 \\
\hline SoLIDS & 1.6 & we $x$ & 30-rep-Y4 10-cet-96 \\
\hline URAnIUA & 1.7 & $\infty / 2$ & $30-\operatorname{cep}-94$ 08-0ct-96 \\
\hline
\end{tabular}

Your selfazion Criserto Vast retease ulubers $x$ Pron Recelved bate: $\mathrm{x}$

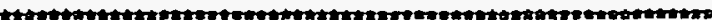

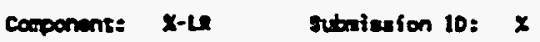

Display Texe?
Projece Hame: 50.05.08xpx-616x 


\section{REstLY}

\section{7}

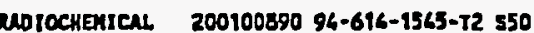
MOIOCKEMICAL 200100890 94-616-1565-72 550 IHOACUNICS-EPN 200101024 94-614-1530-72 S81 IHOReuntCl-EPX 200101026 96-616-1530-T2 S81 IMORGUHICR-EPM 200101023 96-676-1534-12 570 1Koranice-EPH 200101025 96-616-1534-T2 870 IHORCANICS-EPH 200101026 94-616-1537-12 580 INOAGUNICS-EPM 200101026 94-616-1537-T2 S80 IHOAGANICS-EPH 200101027 $26-616$-1539-12 590 IHOREANIC5-EPH 200101027 96-614-1539-12 590 IKOXCUHTCS-EDX 200101028 94-616-1561-12 S10A IHORGAHICE-EDY 200101028 96-616-1561-T2 S10A MUSs EPECTROsCo 200101029 96-616-1541-72 s10A muss sprctrosco 200101029 96-616-1541-12 s10A mass aPECTROSCO 200101029 96-616-1561-72 s104 muss spretrosco 200101029 96-616-1561-T2 stah miss spectroseo 200101029 96-616-1541-12 s10A JHoncunics-EPM 200101030 94-616-1362-T2 s10B ithoncunics-Em 200101030 96-614-1562-12 \$10 MASt sPECTROsCO 200101031 94- ¿16-1542-J2 stas mass sPECTROSCE 200101031 94-614-1342-12 \$10B MASS EPECTROSCO 200101031 96-616-1542-72 8100 uUSE EPECTROsco 200101031 94-614-1542-72 s109 MUSS SPECTROSCO 200101031 94-616-1562-72 S108 IHOACANICS-EPH 200101032 96-614-1543-T2 SI0C IHoncuxics-Em 200109032 94-614-1563-12 S10C MUSB EPECTEOSCO 200101033 96-616-1563-72 s10C MAss apectroseo 200101033 96-616-1543-72 S106 Wuls specthoseco 200101033 94-616-1563-12 stoc muse epetruosec 200101033 96-614-1543-72 s10C mase apictro:sco 200101033 26-616-1543-72 \$106 ImonCAHICs-EPM 200101036 96-616-1532-72 219 IHoncuHIC5-EPX 200101036 96-614-1532-72 \$19 IMORCAHICS-EPA 200101035 96-616-1531-72 811A IHORGNICS-EPA 200101035 94-614-1531-72 s11A IHoneanics-EPh 200101035 94-616-1531-t2 si14 IMOnauics-Em 200101036 94-614-1533-12 souzs 1HORCuIICS-EPM 200101036 96-616-1533-12 sanzs IHorGWVICI-EPY 200101036 96-616-1533-12 2anzs tноnеuиtes-EPM 200101037 96-616-1533-72 96020 IMCRCuHICs-EPX 200101037 94-616-1333-72 c8921 IWORGUNICS-EPH 200101037 96-614-1533-12 S3825 IKOARANICI-EPM 200101038 96-616-1533-72 s8C25 Imoneantet-EPH 200101039 96-614-1533-r2 s8czs Inorauntes-IPM 200101038 96-616-1533-12 sec25 IKORENICS-EPH 200101039 94-616-1533-12 SBN2L IHORGANICS-EPh 200101039 94-616-1533-12 seuzL

1533 12 senzL

\begin{tabular}{|c|c|c|c|}
\hline ALPHA & 47 & $\mathbf{D i} / \mathrm{s}$ & $05-067-96 \quad 07-0 C T-96$ \\
\hline BETA & 360 & $\mathbf{p C I} / \mathbf{Q}$ & $05-0 c 7-96 \quad 07-007-96=$ \\
\hline WOISTURE & 12.1 & we $x$ & $06-067-96 \quad 11-\infty C T-96=$ \\
\hline URuitum & 156 & $\operatorname{pan} \alpha$ & OL-0CT-94 14-0ct-96 = \\
\hline MOISTUAE & 39.9 & ue $x$ & $06-0 \mathrm{cT}-96,11-0 \mathrm{cT}-96=$ \\
\hline Lantur & 163 & pand & $06-0<7-9616-0 c 7-96$ \\
\hline MOISTURE & 39.4 & we $x$ & 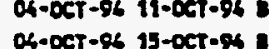 \\
\hline $\begin{array}{l}\text { URenIILA } \\
\text { MOISTURE }\end{array}$ & $\begin{array}{l}150 \\
43.5\end{array}$ & pped $x$ & $\begin{array}{l}06-\infty C T-96 \quad 15-\infty C T-96 \\
05-\infty C T-96 \text { 11--CCT-96 }\end{array}$ \\
\hline uranter & 114 & poso of & 05-0et-96 16-0ct-96 = \\
\hline MOISTURE & 46.5 & we $X$ & $05-007-96119-0 \mathrm{cT}-96 \mathrm{~B}$ \\
\hline URaniLi: & 980 & pon d & $05-00 \mathrm{ct}-96$ 16-0cT-96 \\
\hline HOISTURE & 45.56 & we $x$ & $05-\infty C T-54 \quad 17-0 C T-96=$ \\
\hline vernitum 236 & $6.4 E+01$ & pei/g & $05-0 C 7+96 \quad 15-05 E-96=$ \\
\hline urentitun 235 & $2.6 E+\infty 0$ & pCi/s & $05-0 C T-96$ 15-0EE-96 = \\
\hline VReNILA 236 & $8.3 E-01$ & peiso & CS-DCT-9S 15-DEC-9S E \\
\hline Uravicun 238 & $6.0 E+01$ & $\mathrm{PCI} / \mathrm{a}$ & 05-0CT-OS 15-0EC-94 B \\
\hline MoIstuRE & 46.1 & ut $x$ & $05-\infty 07-9611-007-96=$ \\
\hline vedirtun & 114 & ppond & $05-0 c 7 \cdot 06$ 16-0ct-94 \\
\hline nolsture & & $t x$ & $03-0 c 7-94$ 12-oct-gs \\
\hline LRENILA 236 & & $\mathrm{PCI} / \mathrm{s}$ & 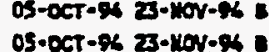 \\
\hline LRABILA 235 & & Diso & 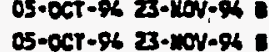 \\
\hline 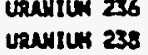 & & $\begin{array}{l}\mathrm{PCI} / \mathrm{q} \\
\mathrm{pCt} / \mathrm{g}\end{array}$ & $\begin{array}{l}\text { 05-0cT-96 23-10V-96 } \\
05-0 \mathrm{CT}-96 \text { 23-1100V-96 }\end{array}$ \\
\hline molstuRE & 45.8 & it $x$ & $05-0 \mathrm{CT}-96,11-0 \mathrm{cT}-86=$ \\
\hline Lenculus & 113 & $\operatorname{pos} d$ & 05-cCt-g6 14-0T-96 = \\
\hline MIITURE & & we $x$ & $\begin{array}{l}05-0 C T-96 \quad 12-\infty C T-96 \\
03-0 c 7-9423-10 V-96=\end{array}$ \\
\hline Urowith 236 & & pelis & $05-0 c t-\beta 423-100.94=$ \\
\hline URentur 235 & & & s-a \\
\hline URentuir 236 & & $\mathbf{P C l} / \mathbf{A}$ & $05-\infty \mathrm{ct}-9623-10 \mathrm{~V}-96$ \\
\hline 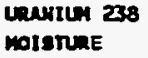 & 78.6 & $\begin{array}{l}p C l / 0 \\
\text { ve } x\end{array}$ & $\begin{array}{l}\text { 05-0CT-96 23-10V-96 = } \\
\text { O6-DCT-96 11-0CT-96 }\end{array}$ \\
\hline veanting & 21900 & ppon of & OC-OCT-96 15-OCT-96 = \\
\hline PH & 9.48 & PN Un & $04-0 c t-16 \infty 8-\infty 0 T-96=$ \\
\hline SOL1DS & 1.52 & we $x$ & $06-0 c t-96$ 10-0CT-96 \\
\hline Leantü & 81.0 & a & $\alpha G-0 C T-9411-\alpha C T-94=$ \\
\hline $\mathbf{P H}$ & 9.52 & ptt un & $06 \cdot 0 \mathrm{ct} \cdot 94 \quad 12-0 \mathrm{cT} \cdot 94 \mathrm{C}$ \\
\hline 501105 & 7.5 & we $x$ & $06-\infty c t-94 \quad 10-\infty c t-96$ \\
\hline URARILA & 35.1 & $m / L$ & $04-0 c T-96 \quad 10-0<T-96=$ \\
\hline PH & 9.30 & oft in & O4-oct-96 12-Der-96 I \\
\hline solios & 7.5 & ut $z$ & Ch- $-0 \mathrm{~T}-96 \quad 10-0 \mathrm{CT}-96=$ \\
\hline veantum & 40.2 & $\omega / L$ & $\alpha 4-\infty<T-\alpha 6$ 11- \\
\hline & 9.52 & pan Un & ab-oct-96 12-act-96 \\
\hline s0L10s & 7.0 & ut $\mathbf{x}$ & ab-oct-86 10-cct-96 \\
\hline weamiun & 68.7 & $\boldsymbol{m o / L}$ & C6-0CT-96 11-0CT-96 \\
\hline PH & 9.52 & phl In & $06-0 c t-96 \quad 12 \cdot 0 C T-96=$ \\
\hline solibs & 1.9 & wE $x$ & OS- $-0 \mathrm{CT}-96 \quad 10-0 \mathrm{CT}-96=$ \\
\hline
\end{tabular}

vour selection critorle tast

Malease Murber: $x$

from Recelved oater $x$

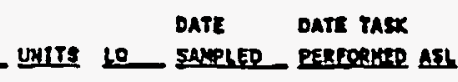

xi/

PCI/O

we $x$

ue $x$

pas of

we $x$

ppen a

ue $x$

peso

ppo

peise

peis

peiso

$\boldsymbol{x} x$

peise

peiso

pet/I

we $x$

pei/s

peirs

pCl/s

peirs

ppon of

Pat in

we $x$

in $x$

$m$

oft in

ut $\pi$

$\infty$

pot un we $x$
$05-067-96$ 07-0CT-96 ab-0e7-os 11-0et-96 OS-DCT-94 16-DCT-96 : 06-0CT-96 11-0CT-96: O6-OCT-96 16-0CT-96 : -0c7-96 19-0ct-96: 04-0CT-96 15-0ct-96 Cc7-96 11-0ct-96 05-cet-94 16-0ct-9s 05-0CT-96 16-0CT-94 OC-0CT-94 17-0CT-96. C5.DCT-OS 15-0Ee-gs 05 -0ct-os 15-0EC-94 E 5-0CT-96 11-DCt-gh 05-oct-94 23-HOV-M B oct-96 23-rov-sh 5-oct-96 11-0ct-96 : 05-cer-g6 14-0ct-96 = -0CT-96 12-0ct-96 ह $03-0 \mathrm{ct}-94$ 23-10V-96 = 05-cct-91 23-kOV-sh E

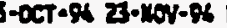
-0CT-96 23-inov-96 a6-0ct-gh 10-0ct-96 : ar-oct-gs 11-0ct-gh

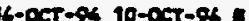
4-0CT-94 10-0CT-96 (2)T-96 12-0CT-96 at-oct-of 11-0ct-gh -cet-96 12-0CT-96 06-0cT-96 12-0CT-96 as-oct -96 10-ect-os

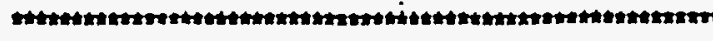

Cocponents $x$-LR Subviestion ID: $x$ Dieplar rexe? * 
$\begin{array}{lll}\text { FEB- 3-95 FRI 17:01 FERHCO ANALYTICAL } & \text { FAX NO. } 5137386667\end{array}$

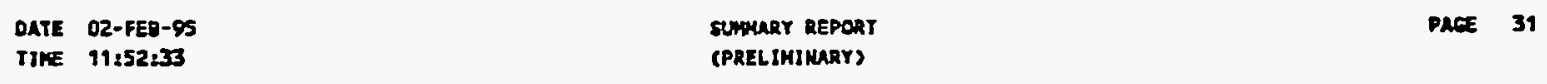

RELEASE MUHER : 1000006169

PROJECT WUAT : 50.05.08 93-616 CRUS I/O TREAT-PHASE 11

LAR SWMPLE IO USER SAMPLE ID SAMPLE POIMI SUFFIX COMPONEWT

DATE DATE TASX

IMORCANICS-EPH 200101039 94-614-1533-72 sonzL IMORGUNIGS-EPK 200101060 96-616-1533-12 5892L IVARCuNICS-EPW 200701040 96-614-1533-T2 5832L IMORGHICS-EDH 200101040 96-614-1533-72 5882L IHORCANICS-EPH 200101041 94-616-1533-T2 SBC2L IMORCWICS-EPN 200101041 94-614-1533-72 s8C2L IHORGANICS-EPH 200101041 94-614-1533-72 sac21. IMOREUICS-EPA 200101042 94-614-9535-T2 \$11B Juoraurics-EPH 200101042 96-616-1535-72 \$110 INORENICS-EPH 200101062 96-616-1535-T2 5118 IHORGANICS-EPH 200101043 94-616-1536-72 381183 trorcenics-teph 200101063 96-616-1536-72 san14s INOREUHICS-EPH 200101043 96-616-1536-12 s84185 IHORGNITES-EPH 200101046 96-614-1536-12 EBDies thorgunies-EP! 200101066 96-614-1536-T2 S8018s tHoRGU1CE-EPH 200101066 96-674-1536-72 589185 Imonounics-EPA 200101045 96-616-1536-72 s8CTEs IMOREAUICS-EAH 200101045 94-616-1536-72 S8C188 IMoreanics-EMA 200901065 96-616-1536-T2 s8c185

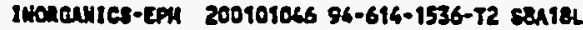
INORCuNIEs-EPW 200101066 96-614-1536-72 SBA18L INORGuHIC8-EPH 200101066 96-616-1536- R2 S8A182 1morenules-1PW 200901067 96-616-1536-72 s88186 IKORGANICS-EPA 200101067 94-616-1536-12 283101 IHONGUHCS-EPI 200101067 94-616-1536-12 s81186 JHCREuHICS-EPA 200101040 64-616-1536-52 s8C186. IHOReWHICE-EPA 200101040 44-616-1536-72 sac1al

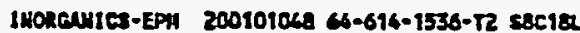
IWORGuHICS-EPH 200101069 96-616-1538-12 s11c

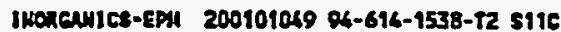
IHORGNICS-EPN 200101049 94-616-1538-T2 3116 IKongules-EPH 200101050 \$4-614-1540-12 5110 IHOREUHIEs-EPH 200101050 94-614-1540-T2 5110 IHolesuircs-EPH 200101050 96-616-1540-12 \$110 1KORCANICS-EPA 200101051 96-616-1547-12 229 IHCRENICS-EPH 200101051 96-616-1567-T2 S29 INCRENHICS-EPH 200101051 94-616-1567-72 529 IMonounies-Em 200101052 96-616-1546-72 FB IHOReuntes-EPH 200101053 96-616-1549-72 RB INCRCuntCs-EPH 200101061 96-616-1550-72 s11E JWORQUHICS-EPA 200101069 96-616-1550-12 s118 IHORGANICS-EPA 200101061 96-616-1550-12 311E

\begin{tabular}{|c|c|c|c|c|}
\hline IRNNIUN & 56.8 & $\operatorname{mg} / \mathrm{L}$ & $04-007-96$ & $11-005-96$ \\
\hline $\mathrm{PH}$ & 9.52 & pH un & $06-067-96$ & $12-\cot -96$ \\
\hline SOLIDS & 1.9 & we $x$ & $O 4-0 c t-06$ & $10.001-96$ \\
\hline LRaviluy & 29.6 & $n 0 / L$ & $04-007-96$ & $11-007-9$ \\
\hline PH & 9.52 & on Un & $04-0 \mathrm{CT}-96$ & $12-087-06$ \\
\hline sot.10s & 2.0 & we $x$ & $06-007-96$ & $10-001-94$ \\
\hline URAKIUA & 29.2 & $m / 6$ & $06-00 \mathrm{CT}-94$ & $11-007-94$ \\
\hline$P H$ & 9.54 & pH th & $04-00 T-96$ & $12 \cdot 051 \cdot 8$ \\
\hline socios & 2.3 & we $x$ & $06-001-\infty 6$ & $10-0 \mathrm{ct}-96$ \\
\hline uresitus & 26.6 & $00 / 6$ & ah-oct-94 & $11-\cot -96$ \\
\hline PH & 9.46 & DH Un & $06-\infty \mathrm{CT}-96$ & $12-005-96$ \\
\hline solids & 7.1 & ve $x$ & $06-0 c t-94$ & $10-\operatorname{coc}-9$ \\
\hline URNILA & 22.9 & $m / L$ & $06-007-24$ & $11-00 \mathrm{cos}$ \\
\hline PH & 9.46 & pH in & $06-\infty \mathrm{cr}-94$ & $12-0 \mathrm{ct}-\mathrm{xt}$ \\
\hline soLidos & 5.2 & ut $x$ & $06-0 c t \cdot 94$ & $10-\cot -94$ \\
\hline crenius & 25.9 & $\omega / L$ & $06-00 T-96$ & $11-\cot -94$ \\
\hline $\mathbf{P H}$ & 9.65 & pH un & $06-\cot -96$ & $12-00 t-96$ \\
\hline solios & 7.9 & wr $x$ & $0 b-0 c t-96$ & $10-007-06$ \\
\hline inantus & 20.8 & 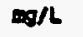 & $04-00 T-96$ & $11-00 t-94$ \\
\hline PH & 9.46 & pH Un & $06-007-94$ & $08-00 t-24$ \\
\hline SOLIOS & 2.15 & we $\mathrm{x}$ & $06-0 \mathrm{CT}-94$ & $10-00 \mathrm{ct}-96$ \\
\hline unensty & 6.9 & $\boldsymbol{m a / h}$ & $06-00 \mathrm{c}-96$ & $11-0,5-96$ \\
\hline PH & 9.66 & or un & $04-007-96$ & $12-0.07-96$ \\
\hline solsos & 2.1 & wt $x$ & $06-0 c T-\alpha$ & $10 \cdot 0 \mathrm{ct}-94$ \\
\hline inerite & 3.8 & $m / L$ & $04 \cdot 007-96$ & $13-\infty \mathrm{ct}-9 \mathrm{~A}$ \\
\hline PH & 9.46 & pin un & $06-007-96$ & $12-007-94$ \\
\hline SoLtDs & 2.2 & we $x$ & $06-001-96$ & $10-\cot -\%$ \\
\hline unarivy & 3.0 & $n / L$ & $a c-O C T-96$ & $13-005-26$ \\
\hline PH & 9.68 & pti un & $04-0 C T-96$ & $12 \cdot-097-84$ \\
\hline solios & 2.0 & ut $x$ & OS-0CT-96 & $10-007-2 \%$ \\
\hline InNyIM & 3.4 & $m / 6$ & $04-0 c T-8$ & $13 \cdot 041 \cdot 45$ \\
\hline DH & 9.72 & ph th & $06-0 c T-96$ & $12 \cdot 0 \mathrm{cr} \cdot \mathrm{q}$ \\
\hline sotios & 0.2 & we $x$ & $06 \cdot 00 t-84$ & $10-007-94$ \\
\hline cramics & 1.9 & $m / 2$ & $06-0,5-96$ & 13-0.0T-86 \\
\hline PH & 9.73 & N In & os-oct- -96 & $12-007-06$ \\
\hline souros & 0.1 & $\boldsymbol{w} x$ & $05 \cdot 0 \mathrm{CT}-4$ & $10-009-94$ \\
\hline unaveum & 0.5 & $a / b$ & $05-007-\infty 6$ & $13-00 t-94$ \\
\hline uncuitu & 0.2 & wort & $05 \cdot 0 \mathrm{CT}-96$ & $10-00 \mathrm{-g}$ \\
\hline varitu & 0.2 & $m / 2$ & 05-0ct-96 & $10-0 \mathrm{CT}-96$ \\
\hline PH & 9.76 & ph un & CS-oct-96 & $12-\infty 0 T-96$ \\
\hline sotios & 0.1 & we $X$ & $05-001+96$ & $10-007-96$ \\
\hline umanises & 0.6 & $n d / 6$ & $05-007-96$ & $11 \cdot 007-96$ \\
\hline
\end{tabular}

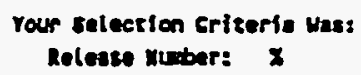


RELEASE MUNBER : 100000424

PRONET HUHE I 50.05.08 93-614 CRUS I/O TREAT-PHASE II

4 스.

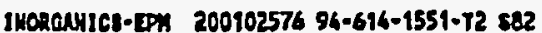
INOaGuHICS-5PM 200102576 P4-616-1551-72 s82 IKORGANIES-EPM 20010257 94-616-1552- 12 s1A IHORCUNICS-EPM 200102577 94-616-1552-72 sia IKOREWHICS-EPH 200102578 94-616-1553-72 S18 INARAKICl-EPH 200102579 96-694-1553-72 818 IWOACANICS-EPH 200102579 94-616-9556-12 51C INCReANiCS-EPW $20010257894-616-1556-12$ stC IMORGuMics-EPK 200102580 94-696-1557-72 82 IHOR GuICE-IPM 200102580 96-616-1557-72 82 IMONCA4ICS-EPH 200102581 96-616-1561-T2 881 IHOnearics-EPM 200102581 94-614-1561-T2 so1 IHCRCUNICS-EPM 200902582 94-616-1562-T2 360

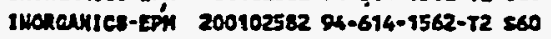
IHONGUHICS-EPM 200102583 96-616-1565-T2 870 IHonsuric8-EPM 200102533 96-616-1565-12 870 IHonavutes-1PM 200102586 96-616-1568-T2 180 IHEACurics-EPA 200102546 94-616-1560-T2 880 Inoneunics-18n 200102585 96-616-1571-12 590 Imoreanics-5PH 200102583 96-616-1571-12 990 imonawics-em 200102586 96-616-1573-T2 s10u InORGUIIES-EPH 200102586 96-616-1573-T2 s10A MISS SPECTROSCO 200102587 94-616-1573-T2 310A mase aprctrosco 200102587 94-614-1573-T2 s194 mass eptetrosec 200102587 96-616-1373-t2 s10a mast sptetrosco 200102587 94-614-1573-T2 ston muss ztretrosec 200102387 96-616-1573-72 510R

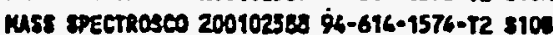
MUS5 EPECTROSCO 200102583 96-616-1376-52 5109 Mass APECTROSE0 200102583 96-616-1574-72 5104 Mhss epEeTRoseo 200102583 96-614-1574-T2 \$108 MUSS SDECTROSCO 200102388 96-616-1574-72 $\$ 100$

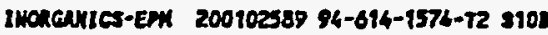
IMONGAHICS-EPH 200102589 96-616-1574-T2 s10 russ spretkosed 200102590 94-616-1575-72 s10C mase epectroseo 200102390 96-616-1573-72 8106 mass spectrose0 200102590 \&6-616-1575-72 stoc MAss s9ECTROsco 200102390 96-616-1575-12 \$106 MAS1 EPECTIOSCO 200102590 96-616-1575-T2 s10C IMCHeniles-EPH 200102591 94-616-1573-12 510C Inoncuitc8-Ith 200102591 96-614-1575-72 510C russ spectrosec 200102392 06-516-1562-72 $\$ 29$ mass EPECTROsec 200102392 o6-616-1582-T2 820 Mus: BPECTROsCo 200102592 94-616-1582-12 820 mss spectrosco 200102592 96-614-1582-72 529 mass spictionco 200102592 98-616-1582-72 529 Inoncentes-59M 200102593 \%6-616-1582-72 529

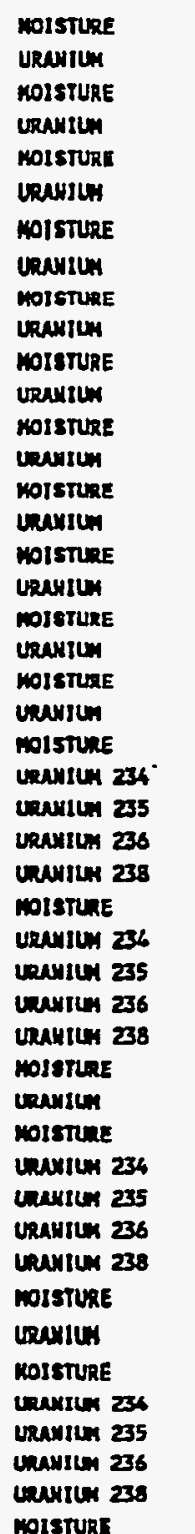

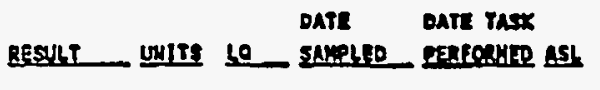

8.4 Ppa
525 ppom 11.2 ur $x$ $530 \quad$ ppon 12.2 at $x$ 488 Ppan 6.9 we $=$ 166 ppon 12.0 we $x$ 122 pan 33.6 uE $x$ 112 Ppe 36.5 we $x$ 71 prom 35.6 ut $\%$ 74 pom 37.6 ur $x$ 55 ppos 43.0 we $x$ $49 \quad \mathrm{pom}$ 43.3 uT $x$ $13.9 \mathrm{pCi} / \mathrm{g}$ 0.69 pci/s 0.21 pCl/s $16.6 \quad$ PCI/O 43.1 ut $\mathrm{X}$ 16.0 DCI/9 0.60 pei/g 0.21 pCi/s $16.0 \mathrm{pCI} / \mathrm{9}$ 42.6 we $x$ 68 ppa 63.6 ut $x$ $16.5 \mathrm{pCl} / \mathrm{O}$ 0.71 pelis $0.26 \quad 01 / 9$ 16.6 pei/s 43.1 Me $K$ 69 pp 63.2 we $x$ 13.1 pel/s 0.56 DC1/9 0.20 pCi/o 15.7 peile 43.2 we $x$ we $x$

Your solection Criteris was,

Roloase Numberz $x$

Prom Resaived ontes $x$
$11-$ oct-96 19-0ct-96

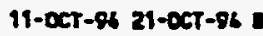
$11-00 \mathrm{~T}-96$ 19-00T-96 $11-007-96$ 29-0ct-96 11-0CT-96 19-0CT-94 : $11-0$ ct-94 21-0ct-94 $11-007-96$ 19-0ct-9s 8 $11-0 \mathrm{cT}-94$ 21-0cT-94 $11-001-94$ 10-0cT-96 : 11-oct-96 21-0ct-96 11-0cT-96 19-00T-96 : $11-001-96$ 21-0ct-96 : $11-0 c 7-94$ 10-0ct-gh D 11 - oct-96 21-0ct-94 12-DCt-96 19-0ct-96 : $12-\infty \mathrm{ct}-96$ 21-बet-9s : 13-0ct-96 19-8ct-96 : 13-0ct-96 21-0eT-94 $13-0 \mathrm{ct}-96$ 19-0ct-96. 13-0ct-96 21-0eT-96 = 13-0et-9s 19-0et-gs :

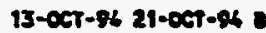
13-oct-8s 19-0ct-94: 13-Det-56 21- wor-gs :

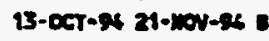

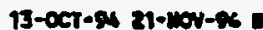
13-0et-as 27-100-9s a 13-0ct-96 19-0ct-96 : 13-0ct-as 21-wor-94 13-cet-9s 21-xav-96 1 $13-\cot -96$ 21- $210 \mathrm{~N}-96 \mathrm{a}$ 13-0cT-96 21-w0V-96 13-DCt-A6 19-DCT-9s: 13-oct-96 21-0cT- 06 : 13-0ct-96 19-0cT-96 :

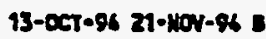
13-0ct-96 21-1104-96 a $13-\operatorname{cct}-96$ 21- $120 \mathrm{xt}-0 \mathrm{x}$ : 13-0ct-96 21- $10 \mathrm{Or}-94 \mathrm{~s}$ : 13-0ct-14 19-0ct-94 1 13-0CT-94 21-0ct-96 $13-0 \mathrm{ct}-96$ 19-0ct-96 13-0ct-96 24-100v-06 = 13-0et-96 21-WOV-96 : 13-0CT-96 21- $\mathrm{NOV}-06 \mathrm{C}$

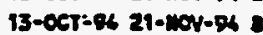
13-0CT-94 19-0CT-94 : 
RELEASE MUAER : 1000004266

PRDECT WNK I 50.05.08 93.614 ERUS 1/0 TREAT-PHASE 11

LAB ILPLE ID USER SAHPLE ID SAMPLE POILT SUPEIX EOAPOAENT

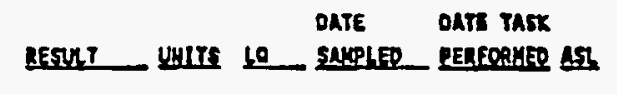

INORENICS-EPH 200102593 \$4-614-1582-72 \$29 INCheAuICs-EPH 200102596 96-614-1559-72 seurs IHORENICS-EDA 200102596 96-616-1559-72 sats IMOREurtes-EPA 200102594 94-614-1559-72 stars

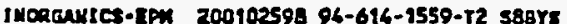

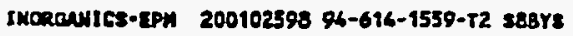
IROReuntCS-IFA 200102598 96-616-1559-T2 sB8VS InoneAutce-594 200102599 94-616-1559-12 s8crs tкоREAKJCs-EPH 200102599 94-616-1959-72 ssers INoneukieI-EPH 200102599 96-614-1559-72 ssers

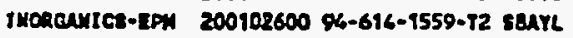
INORGNICS-EPA 200102600 94-614-1550-12 saAL IHoreurics-EPH Z00102600 96-616-1559-72 s8AKL

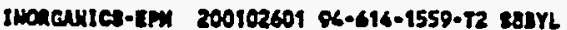

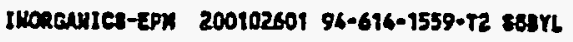
IMoreuites-EPN 200102601 96-616-1559-r2 sesth IMcrearics-EFM 200102602 96-616-1559-72 s8ch IHonewres-EFN 200102602 96-614-1559-12 sech Inomouics-Zen 200102602 96-616-1559-12 s8ert

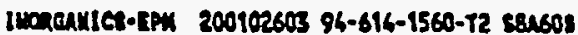

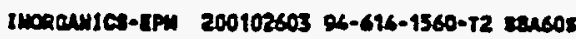
fwomanics-EPY 200102603 96-616-1560-T2 sausos

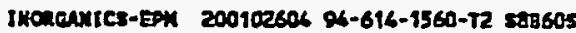
IHoneantes-Em 200102604 96-614-1560-12 s81960s Imoncantcs-zph 200102604 94-616-1560-72 sossos Iwonenxres-Em 200102605 96-614-1560-72 s8c60s IwoneNrTC5-EPA 200102605 96-69-1560-72 sec60s InOREUICs-EPN 200102605 96-616-1560-tz \$8c60s IHORCANICI-EPH 200102606 94-616-1560-72 sBu6OL IHonenics-Em 200102sas 95-614-1560-12 s8u60t Inonenites-tEPM 200102606 96-614-1560-72 s2usOL twonautet-ten 200102607 94-616-1560-72 ssar tworeAurcs-EPM 200102607 Q4-616-1560-12 sa8rL IWoneNICS-EPM 200102607 94-616-1560-72 sart IMonewicL-EPM 200102608 96-614-1560-T2 s8CrL INonexures-ED 200102603 $\$ 4-614-1560-72$ s8cTL

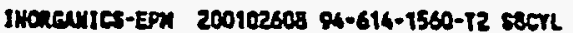
twoneutcs-EP 200102609 96-614-1563-72 \$11A Inonentcs-tan 200102609 96-616-1563-72 s114 IMONENICS-EPH 200102609 94-614-1563-12 \$11A IMorautcs-[DP 200102610 96-614-1566-72 sans Imoreutcs-ton 200102610 96-616-1564-72 98128 twonentcs-EPn 200102610 94-616-1566-T2 sanzs InO2ANICS-EPX 200102611 94-614-1564-T2 seazs Imoneuytcs-EPn z00102611 96-616-1564-T2 se8zs

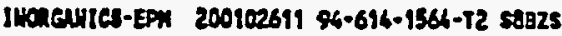

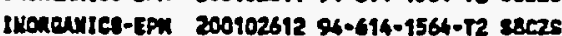
OENSITY

ventuy DENSITY SOLIDS Uncuicu OEMSITY SOL108 urentur DEMSITY colids unusut PH solios truntur PY sectos unamius PH sol.tos unsilun DEusITY

solios cunsuin OENSITY sotids tanity DEAsITY coulos valion Pท soldos unatu PH sotios unesice คH coltos unastu: OENSITY cotios unavtum DEUSITY corsos unaricy oEMSITY

collos unerius
67 1.027

4.96

39.0

1.042

5.49

37.8

t. 043

5.57

36.1

8.12

0.05

10.6

8.27

0.03

10.6

8.26

0.06

11.1

1.060

7.46

36.0

1.057

7.58

36.9

1.057

7.45

37.2

9.46

1.40

28.7

9.45

1.39

28.2

9.46

1.60

27.1

1.012

1.35

27.0

1.050

0.10

8.6

1.069

6.13

0.3
Ppin

$9 /$ al

ut $x$

mon

orel

we $x$

mo/c

g/al

we $x$

$\mathrm{nos} / \mathrm{L}$

pid Un

we $\pi$

$\mathrm{mall}$

pul un

ue $x$

Dag/6

pill Un

ut $x$

na/t

oral

ut $x$

$\mathrm{mat}$

g/al

ue $\mathrm{X}$

$m / 6$

g/al

ue $\mathrm{x}$

and

pH in

we $x$

Eo/ $/ 2$

pu un

we $x$

no/l

on un

wr $x$

Do/s

o/ml

we $x$

$m / L$

arat

wt $x$

$-9 / 2$

a/al

we $x$

ar 13-0c7-94 21-0ct-st

$11-0 \mathrm{ct}-9420-0 \mathrm{ct}-96$ 11-0ct-96 17-0CT-96 11-0ct-94 19-0CT-96 $11-0 \mathrm{Tt}-\mathrm{gh} 20$-0ct-96 $11-0 \mathrm{CT}-96$ 17-0CT-96 $19-007-96$ 19-00t-94 $11-0 \mathrm{CT}-96$ 20-0CT-96 8 $11-0 \mathrm{CT}-94$ 17-0CT-96 11-oct-96 19-0eT-9s E 11-007-96 20-0ct-gs 11-00T-94 17-007-06 E $11-007-\% 6$ 19-00T-94 11-0CT-96 20-0cT-96 11-0et-96 17-0et-94 8 $11-007-96$ 19-0ct-44 e $11-007-96$ 20-0ct-9s 11-007-\% 17-0m-9s $11-00 t-\mathrm{M}$ 11-0eT-9s 0 $11-007-94$ 20-097-94 11-0ct-96 17-0et-96 = 11-0eT-94 19-0eT-16 e $11-0 \mathrm{cT}-9420-0 \mathrm{~T}-96$ : $11-00 T-96$ 17-0ct-os $11-007-46$ 19-0ct-gh $11-00 T-\% 6$ 20-00T-OS 11-0ет-96 17-00T-96 11-0ct-\%5 19-00T-96 $11-007-\alpha$ 20-0eT-\% 11-007-96 17-00T-\% $11-0 \mathrm{ct}-\mathrm{N6}$ 19-00T-94 11-001-94 20-007-96 : 11-DCT-O4 17-00T-96 19-0ct-96 19-0et-94 11-0ct-os 21-0et-gs 11-0et-o6 17-00t-9s 11-0लT-96 19-0c7-94 $11-0 \mathrm{CT}-94$ 20-0CT-94 11-0ct-96 17-0ct-06 11-0CT-94 19-0大 - 96 12-0ct-96 20-0ct-94 12-0ct-94 17-cct-94 12-0ct-94 19-0et-94 : $12-00 t-96$ 20-ect-84 12-00T-Q6 17.00T-Q6 12-0ct-96 19-007-96 12-0ct-96 20-0et-96
Tou selection cetearle thas
Roleace hubars $x$

From necelived Dates $\%$ components: $x-18$

Disploy Text? sutenisston $102 \%$ 
FEB- 3-95 FRI 17:05 FERMCO ANALYTICAL

FERYCO ANALYTICAL

DATE 02-FE-95

TIKE 11152,33

RELEASE WWIER \& 1000004244

PROLECT MAYE \&50.05.05 93.614 eRUS I/D TREAT-PHASE II
SURECRY REPORT

FAX NO. 5137386667

P. 13

(PRELIMIKARY)
Pret 36

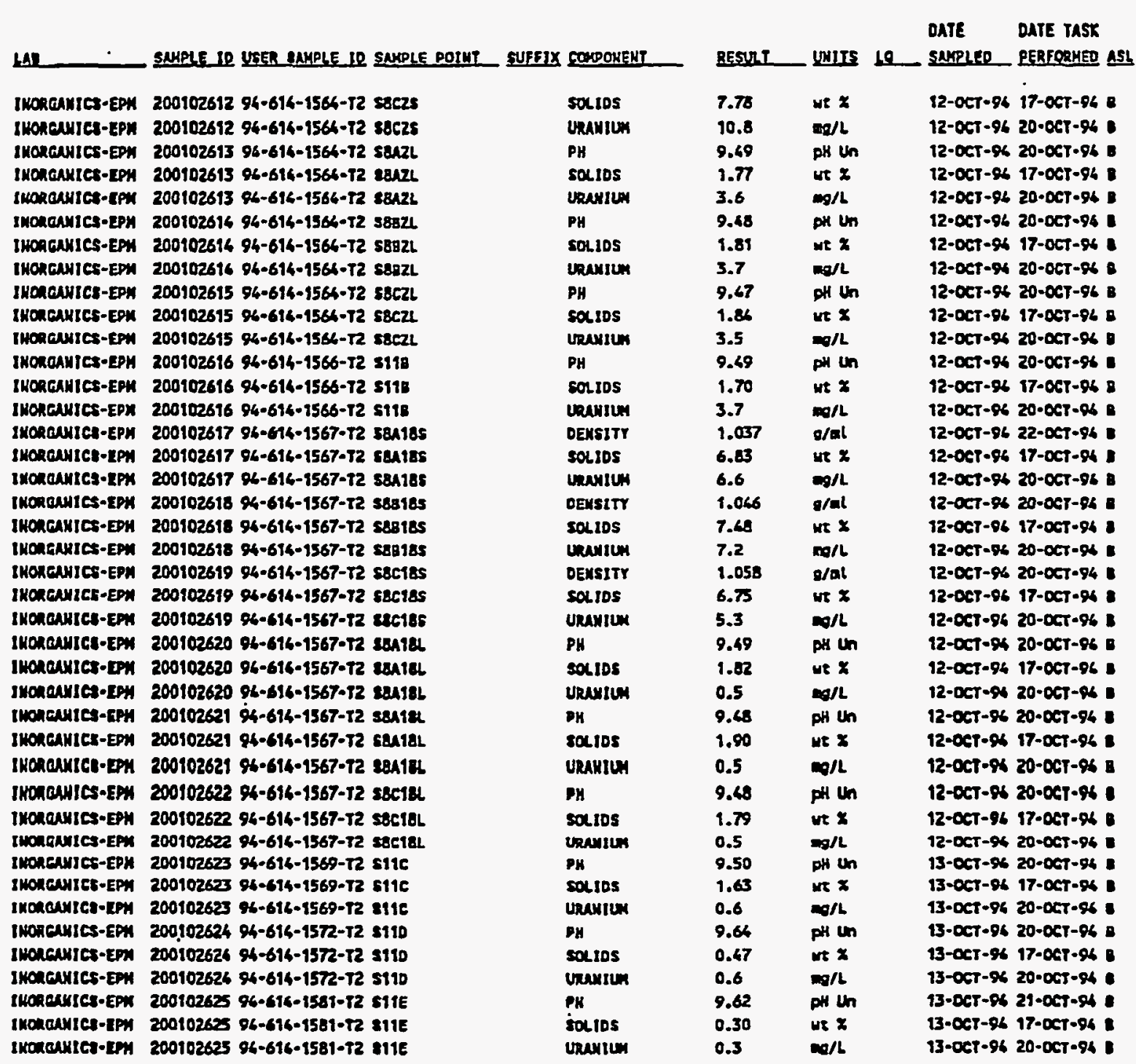

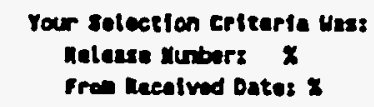

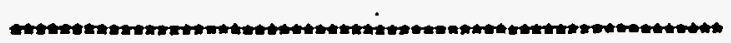

\begin{tabular}{|c|c|c|c|c|}
\hline $\begin{array}{l}\text { Component: } \\
\text { Diseley }\end{array}$ & $\begin{array}{l}y-2 \mathrm{R} \\
\text { Text? }\end{array}$ & subraistion 10: & $\mathbf{x}$ & Proleet yeso: $50.05 .0005 x-614 x$ \\
\hline
\end{tabular}




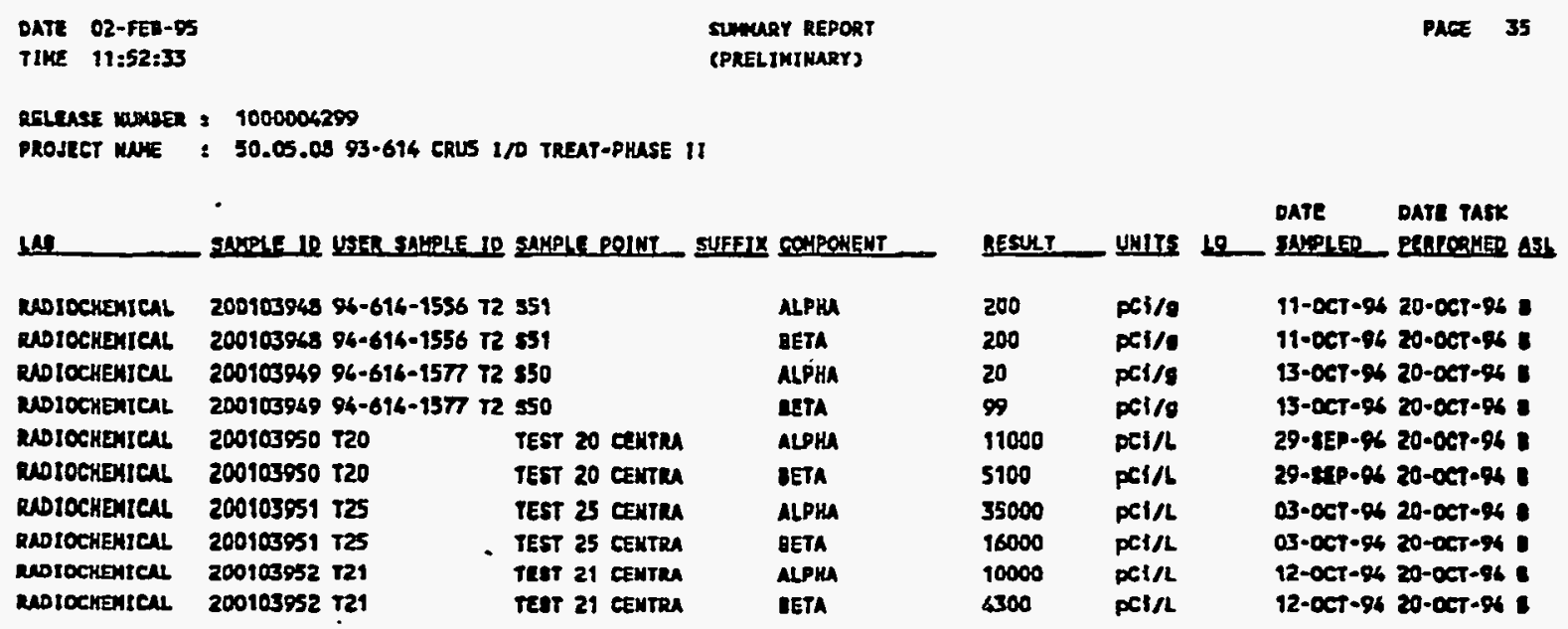

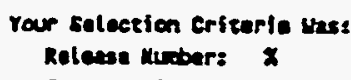

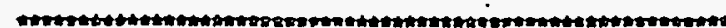

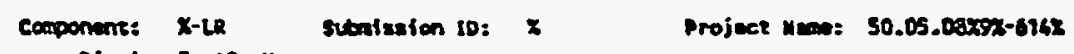



HA

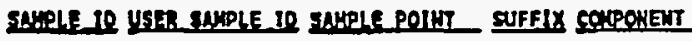

IHoneurtcs-IPH 200105971 96-616-1505-12 in Ikonauics-EPW 200103971 96-616-1583-12 iA Iroreurtce-EPH 200103973 96-616-1591 12 axs thoacautcs-ED 200103973 96-616-1591 12 aurs I Horeanics-EPM 200103973 94-614-1591 t2 eArs INOACWNics-EPH 200103977 94-616-1586-72 18 IHCaeurics-IPH 200103977 94-614-1586-12 18 Inorautcs-IPH 200103972 96-616-1585-T2 iA Inoneusitcs-5PM 200103970 96-616-1585-T2 iA Ixoncuntcs-tow 200103970 96-616-1603-72 81 Inoncurtcs-em 200103970 96-616-1603-72 81 IHodeurles-LPX 200103920 96-616-1604-12 22 IHorculcs-EPH 200103980 96-616-1604-12 82 JKonculles-LH 200103981 96-616-1605-7260 TwoncAures-EPW 200103981 94-616-1605-12 60 IHONCunICS-EPA 200103982 94-614-1617-T270 InOACuNICs-EM 200103982 94-614-1617-12 70 IHonesules-IPH 200103965 96-614-1592 12 80YS Inoreunics-EPN 200103985 96-616-1592 12 Ears

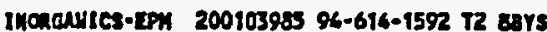
Inoneunics-1PM 200103986 96-616-1593 $\mathrm{TZ}$ 8CY5 Imoncunies-zan 20010398s 96-616-1593 72 eers IHouchilcs-em 200103986 96-616-1593 T2 8crs Imoncunjer-Em 2001059a7 94-616-1596 12 aArL IWORGUICS-EMI 200103997 96-616-1596 72 8ATL

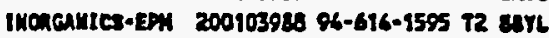
Imoncellics-EMH 200103985 94-616-9595 12 err IHOACUIICA-EPH 200103989 94-614-1596 T2 8CYL IHorcuxics-Em 200103969 94-614-1396 T2 8CTL IHOACurics-Em 200103990 96-616-1597 T2 axsos

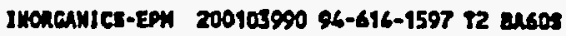
IHCReurics-EPM 200103990 96-616-1597 T2 as60s Imoreuice-2PM 200103991 96-614-1598 72 82605 IMorquulez-EPH 200103991 96-616-1590 T2 03608 IHORENICS-EDA 200103991 96-616-1598 T2 co60s

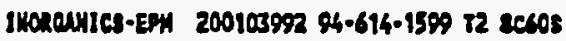
IHoncurtes-LPW 200103992 94-616-1599 T2 8c60s 1woncurics-tePH 200103992 96-616-1599 12 Ec605 InOUCANIES-EPW 200103993 96-616-1600 r2 MBOL IHOREANICS-EPH 200103993 94-614-1600 T2 EUSOL

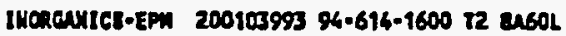

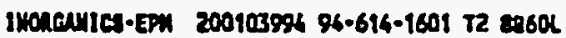
Inoicurtes-IPW 200103996 94-616-1601 7283602 1Houculies-EPK 200103996 96-616-1601 72 8060L IKonGAMICR-IPH 200103995 96-614-1602 T2 EC6OL imonewHites-EMN 200103995 94-616-1602 T2 8C60L I Wenceurics-EPM 200103995 96-616-1602 T2 BC6OL casponenti $x=18$

norsture

vanius

oexsity

salsos

ventux

nolgtune

varulles

molsture

ueeniux

moreture

urenium

MoIsture

vecusiun

MOIsTURE

sranius

moleture

uresisur

oExsity

solios

URevilum

Oemsity

serios

varuitur

PH

URenitux

PH

ceevisian

PH

Lensium

ozmsjtr

solids

Lremiun

DEMsitr

costos

urevitury

DEMstTY

socios

uresitux

PH

solios

unevilu

PH

SOLios

volution

DH

socios

ureanitur

Componentt $X \cdot L R$ Olsplay Text?
Sutniesion 10: $x$

$x$

DATE DATE TASX

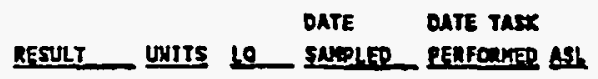

๑.5

$1.35 \quad g / a 1$

0.07 we $x$

$119.7 \quad 0 / 1$

11.66 we $x$

1300 Pare

91.01 WE $X$

600 Dom

22.67 ut $x$

580 - pan

50.66 . wt $\%$

33 mon

36.78 we $x$

162 Ppam

33.60 wr $X$

113 (3)

$1.07 \mathrm{~g} / \mathrm{al}$

1.33 we $x$

$16.7 \mathrm{~m} / \mathrm{h}$

$1.05 \quad \mathrm{a} / \mathrm{mb}$

0.99 ws $x$

$17.3 \quad 0 / 6$

7.92 pt in

$2.9 \quad 0 / 1$

7.09 PH th

$2.6 \mathrm{~mol}$

8.03 pH in

$2.3 \quad \mathrm{~m} / \mathrm{L}$

$1.08 \mathrm{~g} / \mathrm{ml}$

2.16 we $X$

$61.4 \quad 0 / 6$

$1.10 \mathrm{~g} / \mathrm{ml}$

4.00 uE $x$

$41.9 \mathrm{~m} / \mathrm{c} / \mathrm{L}$

1.09 g/nl

2.10 ue $\mathrm{x}$

$61.5 \quad 0 / 2$

0.45 pH Un

1.70 we $x$

$39.3 \mathrm{mg}$

9.45 PH th

1.76 at $x$

36.0 as

9.46 pH un

1.86 we $\alpha$

$36.2 \mathrm{~m} / \mathrm{h}$
$18-007-96$ 21-0c7-96 s

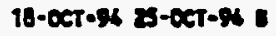

$18-0 \mathrm{cT}-94$ 85-0ct-96 : . 18-0c1-96 21-0ct-96 = 18-0c7-9s 23-0ctass : 18-oct-96 21-oct-gh E 18-0ct-96 23-0ct-96 : 11-0.07-06 21-0.07-84 : 18-0et-96 zs-cet-96 : 18-0cT- 96 21-0ct- 36 ह 18-067-96 25-007-96 : 18-0et-96 2h-0et-gs : 18-0ct-96 25-0ct-96 1 19-0c7-96 26-0.c7-96 = 19-0CT-96 25-0CT-96 E 19-0CT-96 21-cot-96 1 19-0et-96 25-0ect-96 : 18-CCT-94 Z5-0et-96 E 18-0ct-94 21-00t-96 : 18-0ct-94 21-0ct-96 : 18-0ct-96 23-00T-96 :

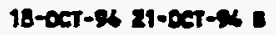

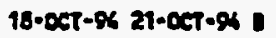

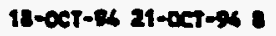

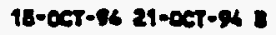

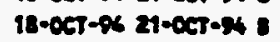
18-cet-96 21-ect-96 : 18-0ct-ss 21-0ct-96

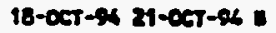
18-0CT-96 23-0CT-94 I 16-0cT-96 21-cet-94 : $18-\operatorname{cct}-9626-\cot -960$ 18-0ct-96 35-xct-96 78-cet-96 21-0et-86 : 18-0et-96 26-0ct-96 110-01-As 85-oct-gh 18-0ct-gh 21-0ct-94: 18-Dct-gs 2h-0cT-96 : 18-0ct-96 26-0ct-os a 18-0ct-96 21-0et-96 : 18-0CT- 96 21-0et-96 18-0CT-96 25-06T-84 :

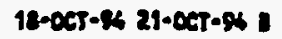

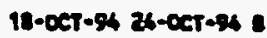
18-00t-96 Z5-0ct-96 : 18-0CT-96 21-0ct-96: $18-007-86$ 26-0cT-86 a
Vour selcetion critarlo Mas

Relesse number: $x$

Fro Recaived Dates $x$ 
RELEASE MUKBER : 1000004309

PROSECT WAKE \& 50.05.08 93-696 CQUS I/D TREAT-PHASE II

LAB SAMPLE ID USER HNMLE IR SAMPLE POIMT SULFIX COMPOMEMT

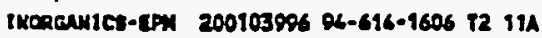
INORENIICS-EPH 200103996 96-616-1606 72 11A

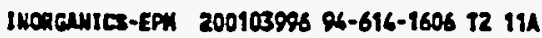
INORGUICS-EPh 200103997 94-616-1607 12 8428 Imoncautes-EPM 200105997 94-616-9607 T2 euze

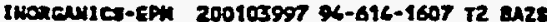
INOREANICS-EPM 200103998 94-616-1603 T2 8325 IMPREAHICS-EPW 200103998 96-616-2608 T2 8825 IMcacentcs-EPW 200103998 96-616-9608 T2 6928 Imonecuntet-5PH 200103909 96-616-1609 72 2028 I wOReurics-EPM 200103999 06-616-1609 T2 8028 IHorsaxics-8PW 200103999 96-616-1609 I2 8029

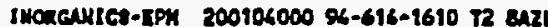
Imoreuntes-EDW 200104000 96-616-1610 72 8uzL IHONGWICS-EMH 200104000 94-614-9610 t2 u2t. IHCReAlles-EPM 200104001 96-614-1611 12 832L

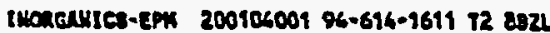
twoncuitcs-8PM 200104001 96-616-1611 72 B226

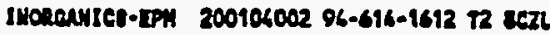
IMoncuntce-Em 200104002 94-614-1612 728024 INERGAMIES-EPW 200104002 94-616-1612 T2 8C24 uDLOCHEMICAL 200104006 94-616-1587-12 31 rorockiateAt 200106006 94-616-1587-12 51 Imoteunice-EPM 200106005 96-616-1588-12 2 IMORGAHICS-EPH 200104005 94-616-1584-T2 2 IKCRENIES-EFH 200104006 94-616-1580-12 19

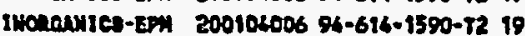

PH

solios

uRAxiบ

DEASIT

sol 10s

unakicu

DENSITY

solios

LAHILY

DENSITY

sotros

unanten

PH

sol.105

unatyiu

PH

solits

unANIU

PH

seltos

unexten

ALPKA

SETA

misture

vanity

moisture

imakity
Date bute tasx RESULT UHITS 10 SAMPLTD EERFORHED ASL

9.6

pH un

we $x$

ng/6

a $/ m$

we $x$

$\operatorname{mg} / \mathrm{L}$

$g / n t$

we $\boldsymbol{x}$

$\operatorname{marl}$

$g / a b$

we $x$

$m / L$

pH Un

ut $x$

$m / 6$

pit un

we $x$

$m / 6$

on Un

we $x$

$a / L$

pet/s

pcils

ux $x$

prin

we $x$

ppon
19-0CT-96 25-001-94 19-0CT-96 21-0CT-960 19-0ct-94 24-0CT-96 19-0CT-96 25-0eT-06 19-0ct-96 21-0ct-96 0 19-0ct-96 24-0er-96 = 10-0ct-96 25-0cr-96 = 19-0ct-96 21-0et-g6 8 19-0ct-gh z5-oct-94 19-0CT-94 z5-00T-96 19-0ct-96 21-0CT-96 e 19-0ct-9s 23-0eT-06 : $19-067-96$ 25-0CT-96 = 19-0et-96 21-00T-94 19-0.5-94 $25 \cdot 0 \mathrm{CT} \cdot 84$ 19-0еT-9s 25-00T-96 0 19-00T-96 21-0.5T- $94=$ 19-0ct-\% 25-0ct-94

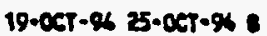
19-00T-96 21-00p-Q6 19-0cT-96 25-0eT-96 = 18-сCT-96 24-0ет-96 a 18-DCT-\%

18-0eT-96 36-00T-95 18-0ct-94 25-0cT-96 18-0cT-94 21-0eT-94 $18-0, T-96$ 25-0CT-96 8

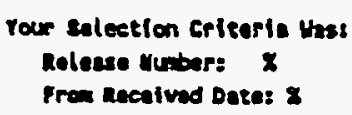

14.

Compenent: X-1R

Subatesion ID: $x$

Projece meane: $50.05 .00 \times 95 x-614 x$ 
RELEASE MUNBER : 1000006369

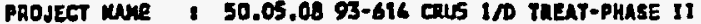

LA

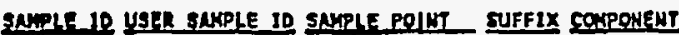

Imonautce-IPH 200104288 96-616-1675 72118 IHonduICS-EPH 200104288 96-616-1615 T2 118 Iwonerutcs-EPH 200104288 96-616-1615 1211 IMORGAHICS-EPH 200104209 94-614-1616 J2 aA1as

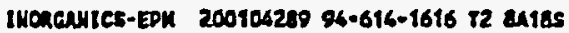
InONGANICF-EPM 200104289 94-614-1616 T2 EA18s IMONGUICS-EPM 200104290 94-616-1617 T2 88185

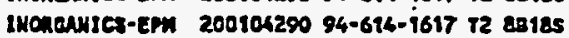
IHencutc5-EPH 200104290 94-614-1617 T2 8818s Iworaures-RPH 200106291 96-616-1618 72 reis5 IMoneulct-1PH 200104291 96-616-1618 T2 ac188 IwOnGAMTCS-EPH 200104291 94-616-1618 T2 8C185 IHonenic5-EDN 200104292 96-614-1619 T2 8h181. Incneutcs-EPH 200106292 96-696-1619 T2 ah1al INOAGUtCs-EPH 200106292 96-614-1619 72 EA18L IHenentes-Em 200104293 96-614-1620 T2 8B18L thoncautes-Em 200104293 94-614-1620 12 En18L IMONeUHIC5-EPM 200104293 94-614-1620 T2 8818L

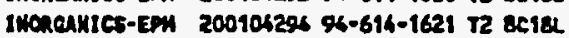
IHoneurics-EM 200104294 94-614-1621 t2 ac1al

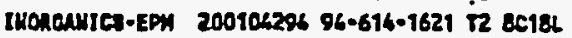

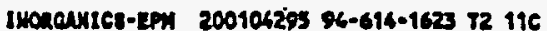
Imoraxics-Ion 200104295 96-816-1623 i2 116 Inomeules-tm 200104X8 96-616-1623 T2 11c

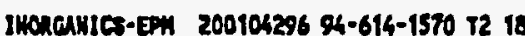
IHONeNICS-Em 20010429 \%-614-1570 72 18 twoneurJes-2WI 200106297 94-614-7570 72 18

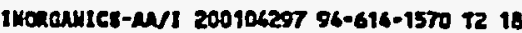
IMonauics-MNI 200104297 \%-616-1570 12 18 Inoncules-M/1 200104297 94-614-1570 72 18 IMonanice-MVI 200104297 94-614-4570 T2 18

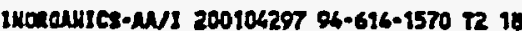
Imoneanice-MV1 200104797 94-614-1570 t2 18 Ithonewice-pNI 200106297 94-614-1570 T2 18 IHoneusics-MVI 200106297 96-614-7370 T2 16

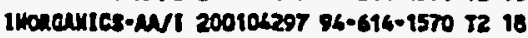
IwonenyIE-MNI 200104297 96-616-1570 72 18

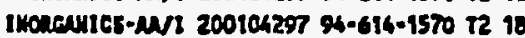
Imomeanies-MNI 200104297 94-616-9570 I2 18 Inoteurics-M/1 200104297 94-616-3570 T2 18

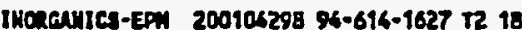
Imonaules-IPH 200104298 94-614-1627 r2 18 Inonautce-NVI 200106299 94-616-1627 T2 18

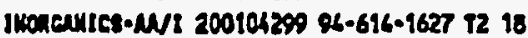
IHoneuics-M1 200104299 94-616-1627 t2 18 Iwoneunics-MV/ 200106290 96-616-1627 T2 18

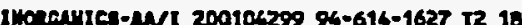

P

PH

sotios

venium

DEUSITY

solios

uncrity

DENSITY

sotios

URentLis

oenstrt

SoLios

ueantus

PH

colidos

earitu

DH

solios

ventur

PH

solids

variun

PH

soltos

uncultu

pH

convitu

axtimony

arsentc

matu

IERTLLION

craviun

CHRonitu

copper

LESO

LEN

HICXel

SELENIU

gILVR

THaLlion

atke

PH

uncuitu

AMTIrour

AREENIC

cenrliza

eaphrus

chromtly

\author{
DATE DATE tasK
}

9.68 pH Un $19-00 T-9631-001-96$ I

1.71 we $x$

$3.1 \quad 9 / 6$

$1.06 \mathrm{~g} / \mathrm{al}$

3.38 we $\%$

$9.7 \quad 0 / 6$

$1.07 \mathrm{~g} / \mathrm{ml}$

6.67 we $x$

9.5 norl

$1.08 \mathrm{~g} / \mathrm{at}$

3.05 we $x$

$11.6 \quad \mathrm{mg} / \mathrm{h}$

9.46 PH un

1.77 ut $\mathrm{z}$

$0.6 \mathrm{mo} / \mathrm{L}$

9.66 pH th

1.76 we $z$

0.6 of

9.65 Dif in

1.72 we $x$

0.6 ag/

9.67 py th

1.74 ut $x$

$0.6 \quad \mathrm{~m} / \mathrm{h}$

9.48 of in

10.1 arl

$12.0 \quad-/ k g u$

2.0 ag/kg U

voto molkg

1.0 mot $\mathrm{u}$

$1.0 \quad 0 / k 0$ U

2.0 mork u

5.0 eo/kg U

volo moge

$1.65 \quad 0 / k 9$

8.0 a 1 (ing

$1.0 \mathrm{mos} U$

$2.0 \mathrm{mo/kg} U$

$2.0 \mathrm{mo} / \mathrm{k} \mathrm{u}$

4.0 nolkg U

9.53

3.1

240

py Un

moll

und $U$

19-0CT-96 26-0eT-96 B

19-0CT-96 27-0C7-94 =

19.06T-86 31-0cT-\% a

19-0c7-96 26-007-96

19-0ct-gs 27-0ct-\%6

19-0ct-o6 31-oct-96

19-0CT-96 26-0ct-96 E

19-0CT-96 27-0CT-94

10-0cT-96 31-0cT-96 :

19-0c7-96 26-0ct-06 a

19-0CT-96 27-0CT-94

10-oct-94 20-0ct-06 :

19-0CT-96 26-0CT-96 =

19-0ct-96 27-0cT-96 B

10-0ct-96 28-0ct-96

19-cot-96 26-0ct-96

19-0ct-96 27-0cT-96

19-0) -96 27-0ct-86

19-0cT-96 26-0ct-9h

$19-06 T-96 \quad 27-0 \mathrm{CT}-96 \mathrm{O}$

19-0CT-96 28-0ct-94 =

19-0लT-96 26-0लT-96

19-0.cT-96 27-067-96

13-007-96 37-0.47-94

13-0ct-g6 23-0ct-gs

13-0st-96 as-nov-96

13-0et-as 03-mor-gh

13-cet-96 01-nON-96 E

13-0ct-96 01-40y-94 a

13-0eT-96 01-ixor-94

13-0ct-9s 01-Mov-gh

13-0ct-96 01-10V-96 a

13-cet-9h 01-kov-gh

13-0CT-96 ce-Nov-g6 :

33-0eT-96 01-mov-9s :

13-0CT-94 03-YOW-06

13-00t-96 01-10y-96

13-0ct-96 04-wor-96

33-0et-96 01-Nov-9s

20-cet-94 31-0ct-96

20-0eT-96 27-00t- $\%$

20-00T-\% 3i-0et-96

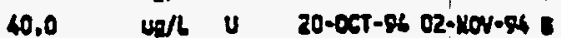

$20 \mathrm{ug} / \mathrm{s} \quad 20$-0ct-96 31;0ct-94

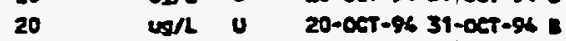
$60.0 \quad 4 / 1$
Your setection Gritaria Hass Roleve Nubers $\$$

Iran heod lued bates $x$ component: $x-4$

Dlepley Texe?
Schission 10, *

2

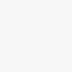

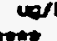


RELEASE WHABE : 1000004360

PROJECT Whe : 50.05.08 93-616 CRUS 1/0 TREAT-PHUSE 11

LB

IAKLE_ID USFR_SAMPLE ID SALLE POIMT SUFEIX COMPOHFH

Imongevics-M/1 200106290 $96-616-1627$ i2 18 Irosenutes-MVI $200104290 \%-616-1627$ T2 18 Inorountes-N1 200106299 96-616-1627 r2 18 Jucredites-Mvi 200104299 $96-616-1627$ r2 18 Inoratice-MNI 200106290 96-616-1627 7218 ,

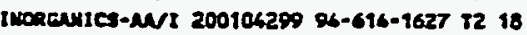
IMCReAMICS-MNI 200104299 94-616-1627 T2 18 IHCRENICU-EP 200104300 94-614-1629 T2 110 Inorcuntes-tPX 200104300 96-614-1629 T2 110 Inomantes-tsh 200104300 96-616-1629 T2 110 INORGULICS-EPH 200104301 96-616-1630 T2 I1E IWoreutcs-2PH 200104301 96-616-1630 T2 11E IHodaurce-5PH 200106301 96-616-1630 T2 11E INonGUICS-EPM 200104302 96-616-1625 T2 RB Inoncunic8-EPH 200104303 96-616-1626 T2 Fo 1hosentes-5PH 200106312 96-616-1622 T2 80 Imonenulcs-zPu 200104312 96-616-1622 i2 80 Inonentcs-EPN 200104313 96-616-1628 12 90

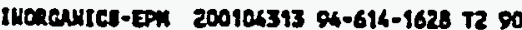
Inoncurtes-2PM 200104316 96-614-1626 T2 82

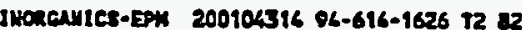
Imovarics-IPN 200104315 86-676-1636 T2 82 Imonawtcs-5:H 200104315 96-616-1636 T2 82 Inonentes-Lin 200106316 94-614-1632 T2 I0A Inoneutcs-Em 200104316 94-614-1632 72 10A Iworevites-EPM 200104317 96-614-1633 72 100 thomantes-Em 200104357 94-616-1633 12 I08 IHoreanics-ePN 200104318 96-616-1634 T2 10E

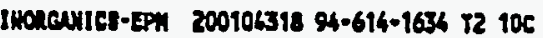
Mrs erectiosed 200104319 96-616-1632 t2 ion ust epectioseo 200106319 94-614-1632 т2 s04 mss spzetroseo 200104319 94-614-1632 T2 IaA

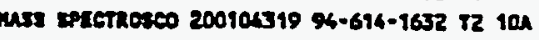
uss spectikosed 200104319 96-616-1632 72 I0A MSS SPECTROsco 200104320 94-616-1633 12 103 ust epeetrosco 200104320 94-614-1633 T2 108 wes SPECTROSc0 200104320 96-616-1633 r2 103 MAse spectrosco 200104320 96-616-1633 I2 105 uss spetrioson 200104320 94-676-1653 t2 108 was sectrosco $20010632194-614-1634$ T2 $10 \mathrm{C}$ MAs spectRose0 $20010432196-616-1636$ 12 106

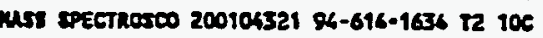
uss epterkesco 200104321 94-614-1634 T2 10C kass epectheseo 200104321 06-616-1036 $r 2$ 10C UbrochentcAl zo0104322 94-616-1635 T2 50 woIOCHEMICAL 200105322 94-614-1635 T2 50
Your selection Griearia thes

Nolesse Nubers $x$

Prom Recelved Dater $x$

\begin{tabular}{|c|c|c|c|c|}
\hline COPper & 100 & $\omega g / L$ & $\mathbf{U}$ & $20-007-9631-007-94$ \\
\hline IES & 12.0 & $40 / 2$ & $\mathbf{u}$ & $20-007-06 \quad 31-007-26$ \\
\hline MICXEL & 160 & $48 / L$ & $\mathbf{u}$ & $20 \cdot 007-9639 \cdot 009-96$ \\
\hline selentur & 20.0 & $\log / 6$ & $\mathbf{U}$ & $20-06 T-9631-0.67-96$ \\
\hline SILVER & 40.0 & $u g / L$ & $\mathbf{u}$ & $20.007-9631-007-96$ \\
\hline THacLIUM & 10.0 & $\operatorname{ug} / 2$ & $\mathbf{u}$ & 20-0cT-96 ab-210v-96 \\
\hline ZINC & 80.0 & $40 / 2$ & $\mathbf{u}$ & 20-0c7-94 31-0ct-94 \\
\hline PH & 9.63 & PH in & & $20-0 \mathrm{ct}-9627-0 \mathrm{ct}-96$ \\
\hline col10s & 0.40 & we $x$ & & $20-057-9626-067-86$ \\
\hline Unation & 0.6 & $9 / 2$ & & $20 \cdot 001-9427-00 T-94$ \\
\hline PH & 9.52 & pH Un & & $20-\cot -96$ 21-00t-96 \\
\hline solios & 0.18 & wt $x$ & & $20-007-9426-007-96$ \\
\hline URANILY & 0.1 & $m / L$ & & $20-007-9427-007-96$ \\
\hline umitu & 0.1 & orll & $\mathbf{u}$ & $20-001-9625-00 \mathrm{ct}-96$ \\
\hline Gunite & 0.1 & $\boldsymbol{\omega} / \mathrm{L}$ & $u$ & $20-0<5-96 \quad 23-067-96$ \\
\hline Hotstune & 31.28 & we $x$ & & $20-0 \mathrm{CT}-9626-007-96=$ \\
\hline unturs & 75 & $\operatorname{pon} d$ & & $20-00 \mathrm{~T}-9629-00 \mathrm{~T}-96$ \\
\hline notstune & 35.71 & wet $\mathbf{x}$ & & $20-0 c T-\alpha 3-02 T-94$ \\
\hline unaritu & 69 & Pp d & & $20 \cdot 0 \mathrm{cr} \cdot \% 428-0 \mathrm{cT} \cdot 96$ \\
\hline morstune & 56.16 & we $x$ & & $20-0 \mathrm{CT}-9626-0 \mathrm{CT}-96$ \\
\hline vantus & 360 & Dind & & $20-6 C T-9628-0 C T-94$ \\
\hline NOISTURE & 49.23 & we $\mathbf{x}$ & & $20-00 \mathrm{CT} \cdot 96 \mathrm{26-00T-96}=$ \\
\hline Ganick & $\mathbf{B}$ & Ppon d & & 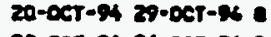 \\
\hline motstuns & 39.39 & $x$ & & $20-007-9426-001-94=$ \\
\hline conitin & $\$ 6$ & popd & & $20-0 \mathrm{CT}-9629-0 \mathrm{cT}-94$ \\
\hline mistune & 42.10 & $4 x$ & & $20-007-9626-007-94$ \\
\hline encurtin & 45 & Fond & & $20-00 T-9429-00 t-96$ \\
\hline MIGTURE & 61.59 & we $\%$ & & $20-0 \mathrm{CT}-96$ 26-0CT-24 \\
\hline LAMIUY & 68 & $p+d$ & & $20-007-9629-0 \mathrm{cT}-96$ \\
\hline WISTURE & 39.66 & we 8 & & $20-007-9626-007-\% 6$ \\
\hline ventux 236 & $1.95 \times 01$ & pei/a & & $20-0 C T-96$ 13-DEC-96 D \\
\hline trante: 235 & $9.68-01$ & pct/o & & $20-00 T-96$ I3-DEC-94 \\
\hline conium 236 & $1.9 t-01$ & PCl/s & & $20-0 c t-96 \quad 13-0 E c-94$ \\
\hline unetiun 238 & $2.22 * 01$ & pciss & & $20-007-96 \quad 13-5 E C-94$ \\
\hline Noistune & 42.22 & wt $x$ & & $20-00 \mathrm{ct}-9626-0 \mathrm{cT}-96 \mathrm{~J}$ \\
\hline UANIIE 236 & $1.68+01$ & $\mathrm{pCi} / \mathrm{e}$ & & $20-0 c t-9623-086-96$ \\
\hline unargur 235 & 8.6E-01 & PCI/s & & $20.067-96$ 13.016-94 \\
\hline URANIL 236 & 2.GE-01 & pef/o & & $20-007-96 \quad 13-086-96$ \\
\hline LaNIU: 238 & 2.2E+01 & DCt/o & & $20-007-9613-026-94$ \\
\hline MISTIXE & 42.15 & wr $x$ & & $20-0 c t-9626-0 c 7-960$ \\
\hline LeNIIUA 234 & $2.55+01$ & pet/s & & $20-067-96$ 13-DEC-96 0 \\
\hline Uxaxita 235 & $1.05 \circ 00$ & pel/s & & $20-007-96$ 13-DEC-96 0 \\
\hline IRANIUA 236 & $1.95-01$ & pot/a & & $20-0 \mathrm{CT}-96$ 13-DEC- $06=$ \\
\hline URant1M 238 & 2.JE+01 & pci/e & & $20-0051-96$ 13-0ES-94 0 \\
\hline ALPE & 50 & pet/s & & $20-0 \mathrm{ct} \cdot 9425-0 \mathrm{ct}-94$ \\
\hline ETA & 120 & $0 \mathrm{CI} / 9$ & & $20-0 \mathrm{CT}-9623-0 \mathrm{CT}-\% 6 \mathrm{~B}$ \\
\hline
\end{tabular}

DATE DATE TASX

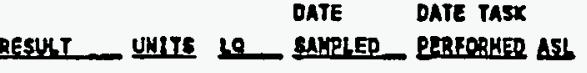

Componants $x$-LR shatesion ID: $x$ Display Texe? $n$
Project neme1 50.05.0069x-614x 
RELTASE MMER \& 1000004656

PROLECT wUE \& 50.05.08 93.616 CRUS $1 / 0$ TREAT-PHASE II

LAB

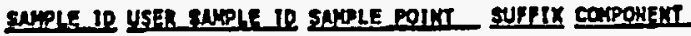

RDIOCHEHICUL 200193920 96-696-1580-12 721 NDIOCHENICLL 200113920 \$4-616-1560-72 121

1327 RECONDS DRIUTED

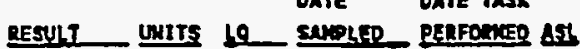

ENO OF REPORT

Tour selection Criterie uses Roleses Mubery $X$ Fren Received Ontas $\star$
$9.3 \quad \mathrm{PC1} / \mathrm{M} \quad 12 \cdot 0 \mathrm{CT}-9629 \cdot \mathrm{NOW} \cdot 94 \mathrm{~s}$

5.7 PCI/m 12-0c7-96 29-Kov-9s

\begin{tabular}{|c|c|c|}
\hline $\begin{array}{l}\text { ALPHA } \\
\text { IETA }\end{array}$ & $\begin{array}{l}9.3 \\
5.7\end{array}$ & $\begin{array}{l}\mathrm{pci} / \mathrm{m} \\
\mathrm{pci} / \mathrm{m}\end{array}$ \\
\hline
\end{tabular}

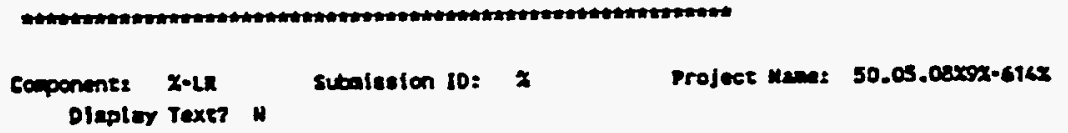



APPENDIX D

DETAILED MATERIAL BALANCES 
$$
\text { . }
$$ 


\section{APPENDIX D \\ DETAILED MATERIAL BALANCES}

The detailed material balance results are shown in Appendix $D$. These detailed balances list the amounts of solids and uranium in each stream. Tables D-1 through D-8 apply to Tests 0 through 19. Material balances for the final four Phase II tests are presented in Tables D-9 and D-10. The reactor and the centrifuge material balances for solids are shown in Table D-1 for the storage pad soil and in Table D-2 for the incinerator area soil. The overall material balances for solids are shown in Table D-3 for the storage pad soil and in Table D-4 for the incinerator area soil. The reactor and the centrifuge material balances for uranium are shown in Table D-5 for the storage pad soil and in Table D-6 for the incinerator area soil. The overall material balances for uranium are shown in Table D-7 for the storage pad soil and in Table D-8 for the incinerator area soil. The soil and uranium overall material balances for the final four tests are given in Tables D-9 and D-10, respectively. 
Table D-1

CENTRIFUGE MATERIAL BALANCE FOR SOLIDS STORAGE PAD SOIL

\begin{tabular}{|c|c|c|c|c|c|c|c|}
\hline & Tes! 4 & Test 5 & Tos! 6 & Test 8 & Test 16 & Test 17 & Test 19 \\
\hline Feed Soil (lbs) & 393.76 & 299.05 & 299.17 & 321.86 & 365.83 & 308.29 & 309.36 \\
\hline Colld- of & & & & & & & \\
\hline Sollds out (los) & & & & & & & \\
\hline TrommelHe日 & 12.43 & 14.9 & 11.9 & $\frac{25.9}{21.8}$ & 17.1 & $\frac{12.2}{28 .}$ & $\frac{11.34}{16.07}$ \\
\hline Centrate & 62.5 & $\overline{45.3}$ & 46.2 & 42.7 & 2.9 & 48.9 & $\frac{76.91}{36.7}$ \\
\hline Wet Cake & 241 & 182.2 & 208.2 & 192.5 & 269.3 & 168.6 & $\frac{30.1}{191.22}$ \\
\hline (Samples) & & & & & & & \\
\hline Foed Soll & 8.97 & 9.92 & 9.46 & 9.09 & 9.2 & 70.74 & 10.04 \\
\hline Total Solids out (bs) & 324.8 & 252.32 & 275.76 & 297.89 & 298.5 & 269.14 & 266.27 \\
\hline Solids Loss (bs) & 68.86 & 46.73 & 23.41 & 29.97 & 67.43 & 39.15 & 43.09 \\
\hline \% Solids Recovery & $82.51 \%$ & $84.37 \%$ & $92.18 \%$ & $90.69 \%$ & $81.57 \%$ & $87.30 \%$ & $86.07 \%$ \\
\hline
\end{tabular}

REACTOR MATERIAL BALANCE FOR SOLIDS STORAGE PAD SOIL

\begin{tabular}{|c|c|c|c|c|c|c|c|}
\hline & Test 4 & Test 5 & Test 6 & Test 8 & Test 16 & Test 17 & Test 19 \\
\hline Feed Soil (lbs) & 393.76 & 299.05 & 299.17 & 321.96 & 365.93 & 308.29 & 309.36 \\
\hline \multirow{2}{*}{\multicolumn{8}{|c|}{ Solids Out (bs) }} \\
\hline & & & & & & & \\
\hline Trommel He日 & 12.43 & 14.9 & 37.9 & $\frac{25.9}{21.8}$ & 17.1 & $\frac{72.2}{28.7}$ & $\begin{array}{l}11.34 \\
16.97\end{array}$ \\
\hline Reactor Slurry & 246 & 195.3 & 212.5 & 188 & 156.7 & 213.1 & 177 \\
\hline (Samples) & & & & & & & \\
\hline Feed Soll & 8.97 & 9.92 & 9.46 & 9.09 & 9.2 & 70.74 & 70.04 \\
\hline Altrition Scrubber & 0.62 & 0.58 & 0.59 & 4.29 & 21.25 & 6.32 & 5.3 \\
\hline Total Solids Out (lbs) & 268.02 & 220.7 & 234.45 & 249.08 & 204.25 & 271.06 & 220.65 \\
\hline Solids Loss (bs) & 125.74 & 78.35 & 64.72 & 72.88 & 161.68 & 37.23 & 88.71 \\
\hline \% Solids Recovery & $68.07 \%$ & $73.80 \%$ & $78.37 \%$ & $77.36 \%$ & $55.82 \%$ & $87.92 \%$ & $71.32 \%$ \\
\hline
\end{tabular}


Table D-2

CENTRIFUGE MATERIAL BALANCE FOR SOLIDS

NGINERATOR AREA SOIL

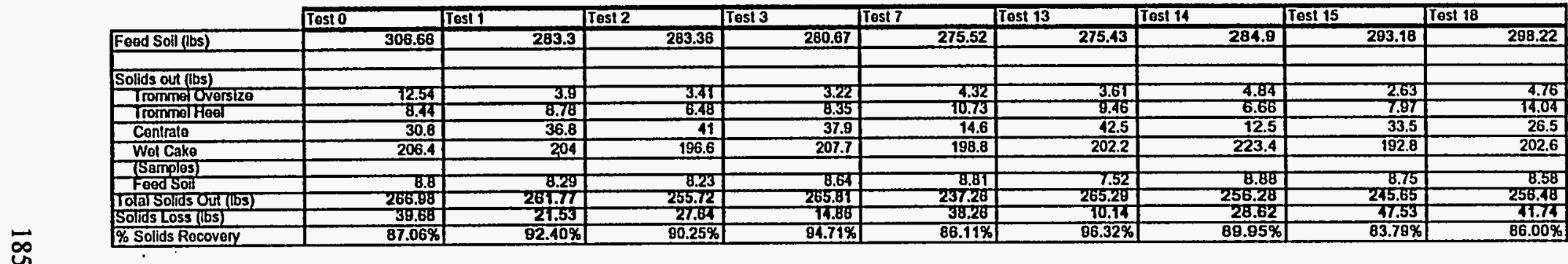

REACTOR MATERIAL. BALANCE FOR SOLIDS

INCINERATOR AREA SOIL

\begin{tabular}{|c|c|c|c|c|c|c|c|c|c|}
\hline & Testo & Test 1 & Tost 2 & Tost 3 & Test 7 & Test 13 & Test 14 & Test 15 & TOSt 18 \\
\hline Food Soil (1bs) & 306.68 & 283.3 & 283.38 & 280.67 & 275.52 & 275.43 & 284.8 & 203.18 & 288.22 \\
\hline & & & & & & & & & \\
\hline Solids out (bs) & & & & & & & & & \\
\hline Trommol Uversize & 12.54 & 3.8 & $3.4 \pi$ & 3.22 & 4.32 & 3.67 & 4.84 & 2.63 & 4.76 \\
\hline Trommol hool & 8.44 & 8.78 & 6.48 & 8.35 & 10.73 & 9.46 & 6.66 & 7.97 & 14.04 \\
\hline Reactor Slumy & 148 & 197.8 & 192.6 & 202.4 & 151 & 197.5 & 216 & 169.8 & 169.4 \\
\hline (Samplas) & & & & & & & & & \\
\hline $\begin{array}{l}\text { Foed Soll } \\
\text { Altilon Scowber }\end{array}$ & 28.84 & $\frac{8.29}{0.59}$ & $\frac{8.23}{3.86}$ & $\frac{8.64}{4.3}$ & 7.81 & $\frac{7.52}{5.47}$ & $\frac{8.88}{8.31}$ & $\frac{8.15}{6.51}$ & $\frac{8.58}{8.64}$ \\
\hline Total Solids Out (lbs) & 203.82 & 219.38 & 214.58 & 226.91 & 188.1 & 223.5 & 244.69 & 185.66 & 205.42 \\
\hline Solids Loss (bs) & $\frac{202.04}{102.84}$ & $\frac{63.84}{61}$ & 68.78 & 53.78 & 89.42 & 51.03 & 40.21 & 07.52 & 82.8 \\
\hline \% Solids Rocovery & $68.46 \%$ & $77.43 \%$ & $75.73 \%$ & $80.85 \%$ & 67.55x & $81.15 \%$ & $\overline{85.80 \%}$ & $66.74 \%$ & $68.88 \%$ \\
\hline
\end{tabular}


Table D-3

OVERALL MATERIAL BALANCE FOR SOLIDS

STORAGE PAD SOIL

\begin{tabular}{|c|c|c|c|c|c|c|c|}
\hline & Test 4 & Test 5 & Test 6 & Test 8 & Test 16 & Test 17 & Test 19 \\
\hline Foed Soil (lbs) & 393.76 & 299.05 & 299.17 & 321.96 & 365.93 & 308.29 & 309.36 \\
\hline Treated Sold (Ibs) & 202.76 & 185.8 & 787.94 & 126.16 & 209.33 & 196.7 & 757.84 \\
\hline By-product Solids (bs) & & & & & & & \\
\hline Trommeloversize & $\sqrt{2.43}$ & 74.9 & 17.9 & 25.9 & 17.1 & 12.2 & 11.34 \\
\hline Trommel Heel & & & & 21.8 & & 28.7 & 36.97 \\
\hline Vibrating screen Oversiz & 4.14 & 1.93 & 3.56 & & & & \\
\hline $\begin{array}{l}\text { Centrifuge Purge } \\
\text { CentrateNo. } 1\end{array}$ & 165 & 348 & 151 & 28.4 & 34 & 5508 & 33 \\
\hline Cenlralono. 2 & 98.3 & 17 & $\frac{13.1}{1.5}$ & $\frac{14.35}{5.66}$ & $\begin{array}{r}2.4 \\
0.64\end{array}$ & $\frac{55.98}{9.37}$ & $\frac{70.81}{28.32}$ \\
\hline Centrale No. 3 & 10.60 & 4.70 & 0.01 & 3.08 & 0.56 & $\frac{3.31}{2.92}$ & \\
\hline Cenirifuge Heal & & & & 41.9 & & 13.92 & 33.97 \\
\hline (Samples) & & & & & & & \\
\hline Feed Soll & 8.97 & 9.92 & 9.46 & 9.09 & 9.2 & 70.74 & 70.04 \\
\hline Altrition Scrubber & 0.62 & 0.58 & 0.59 & 4.29 & 21.25 & 6.32 & \\
\hline Reactor & 0.2 & 0.3 & 0.3 & 0.57 & 0.5 & 0.7 & 0.4 \\
\hline Centrifuge Wet Cake & & & & 0.83 & & & 0.99 \\
\hline Tolal By-product Solids & 77.76 & 81.13 & 42.42 & 215.87 & 51.65 & 140.85 & 211.14 \\
\hline Gross Solids Out (bs) & 274.52 & 266.93 & 230.358 & 342.03 & 260.98 & 337.55 & 368.98 \\
\hline Chamicals (bbs) & & & & 110 & 200.50 & $\frac{201.00}{77}$ & $\frac{500.98}{78}$ \\
\hline Net Solids out (bs) & 274.52 & 266.93 & 230.358 & 232.03 & 260.98 & 260.55 & 290.98 \\
\hline Solids Loss (16s) & 179.24 & 32.12 & 68.812 & 89.93 & 704.85 & 47.74 & 18.38 \\
\hline PercentRecovery & 69.72 & 89.26 & 77.00 & 72.07 & 71.32 & 84.51 & 94.06 \\
\hline
\end{tabular}




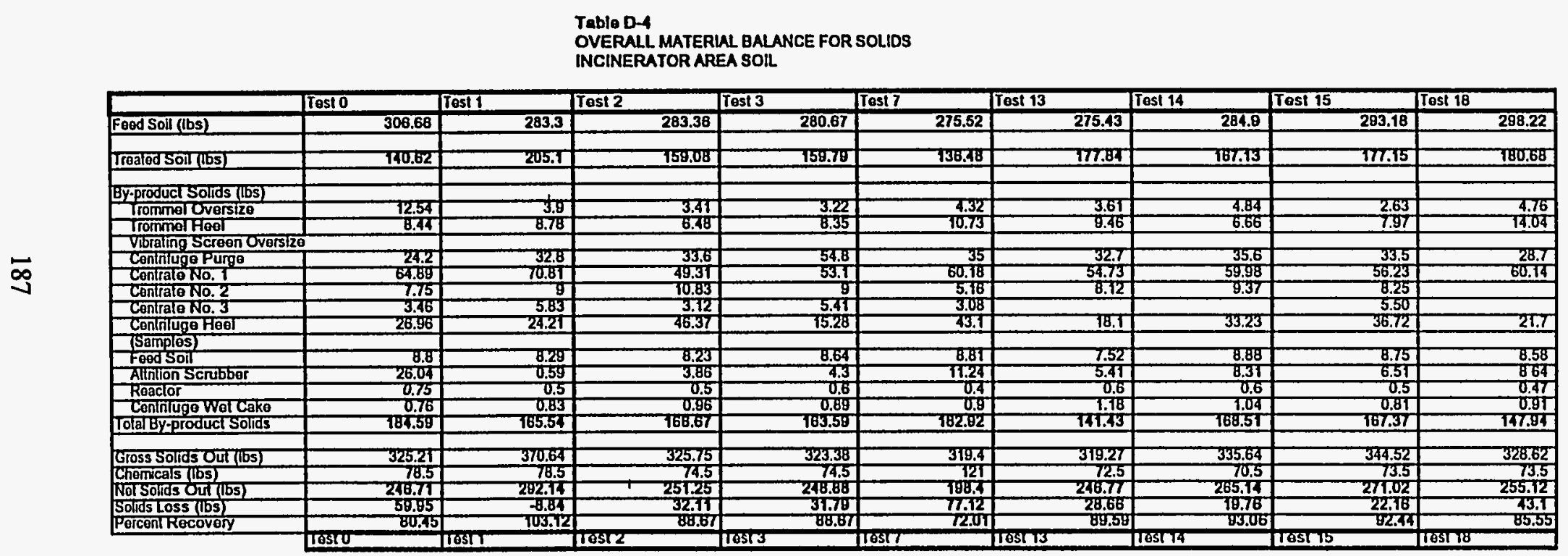


TABLE D-5

CENTRIFUGE MATERIAL BALANCE FOR URANIUM

STORAGE PAD SOIL

\begin{tabular}{|c|c|c|c|c|c|c|c|}
\hline & Test 4 & Test 5 & Test 6 & Test 8 & Test 16 & Test 17 & Test 19 \\
\hline Uranium in Feed (ibs) & 0.584300 & 0.574200 & 0.541500 & 0.550600 & 0.6733300 & 0.505600 & 0.570400 \\
\hline Uranium out (ibs) & & & & & & & \\
\hline Trommel Oversize & 0.01865 & 0.023 & 0.0165 & 0.02214 & 0.0159 & 0.0128 & 0.0044 \\
\hline Trommel Heel & 0.000000 & 0.000000 & 0.000000 & 0.004360 & 0.000000 & 0.012400 & 0.002986 \\
\hline Centrate & & 0.1393 & & 0.1748 & 0.1734 & 0.1985 & 0.1805 \\
\hline Wel Cake & 0.2905 & 0.1731 & & 0.2445 & 0.399 & 0.2072 & 0.2295 \\
\hline (Samples) & & & & & & & \\
\hline Feed Soil & 0.073300 & 0.019600 & 0.017100 & 0.015500 & 0.016900 & 0.017600 & 0.016600 \\
\hline Total Uranium Out (bs) & 0.32245 & 0.355 & 0.0336 & 0.4613 & 0.6052 & 0.4485 & 0.433986 \\
\hline Uranium Loss (lbs) & 0.26185 & 0.2192 & 0.5079 & 0.0893 & 0.0681 & 0.0571 & 0.076414 \\
\hline Percent Uranium Recovery & $55.19 \%$ & $61.83 \%$ & $6.20 \%$ & $83.78 \%$ & $89.89 \%$ & $88.71 \%$ & $85.03 \%$ \\
\hline
\end{tabular}

REACTOR MATERIAL BALANCE FOR URANIUM STORAGE PAD SOIL.

\begin{tabular}{|c|c|c|c|c|c|c|c|}
\hline & Test 4 & Test 5 & Test 6 & Test 8 & Test 16 & Test 17 & Test 19 \\
\hline Uranium in Feed (bs) & 0.584300 & 0.574200 & 0.541500 & 0.550600 & 0.673300 & 0.505600 & $0.510400^{\circ}$ \\
\hline \multicolumn{8}{|l|}{ Uranium out (lbs) } \\
\hline neloversize & 0.01865 & 0.023 & 0.0165 & 0.02214 & 0.0159 & 0.0128 & 0.0044 \\
\hline Trommel Hee & 0.000000 & 0.000000 & 0.000000 & 0.004360 & 0.000000 & 0.012400 & 0.002986 \\
\hline Reactor Slurry & 0.5676 & 0.4984 & 0.3995 & 0.3774 & 0.4398 & 0.3916 & 0.3676 \\
\hline \multicolumn{8}{|l|}{ (Samples) } \\
\hline Feed Soll & 0.013300 & 0.019600 & 0.017100 & 0.015500 & 0.016900 & 0.077600 & 0.016600 \\
\hline Attrition Scrubber & 0.000485 & 0.000549 & 0.000600 & 0.005447 & 0.031900 & 0.004678 & 0.006154 \\
\hline Uranium Out (lbs) & 0.600035 & 0.541549 & 0.4337 & 0.424847 & 0.5045 & 0.439078 & 0.39774 \\
\hline Uranium Loss (ibs) & -0.015735 & 0.032651 & 0.1078 & 0.125753 & 0.1688 & 0.066522 & 0.11266 \\
\hline Percent Uranium Recovery & $102.69 \%$ & $94.31 \%$ & $80.09 \%$ & $77.16 \%$ & $74.93 \%$ & $86.84 \%$ & $77.93 \%$ \\
\hline
\end{tabular}

$\checkmark$ 
TABLE D-6

CENTRIFUGE MATERIAL. BALANCE FOR URANIUM.

INCINERATOR AREA SOIL.

\begin{tabular}{|c|c|c|c|c|c|c|c|c|c|}
\hline & Test 0 & Tost 1 & Test 2 & Test 3 & Test 7 & Test 13 & Test 14 & Tost 15 & Test 18 \\
\hline Uranium in Feed (bs) & 0.1855800 & 0.206800 & 0.185500 & 0.202800 & $0.308600^{\circ}$ & 0.2178000 & 0.215400 & 0.204300 & 0.221600 \\
\hline Uranium out (bs) & & & & & & & & & \\
\hline Trommoloversize & 0.0004 & 0.000935 & 0.002593 & 0.00008 & 0.001726 & $0.00015 T$ & 0.000726 & 0.0005 & 0.001619 \\
\hline TrommelHeal & 0.009618 & 0.006850 & 0.006028 & 0.006212 & 0.023060 & 0.010220 & 0.004925 & 0.005738 & 0.071230 \\
\hline Centrate & 0.0729 & 0.0538 & 0.0459 & 0.0758 & 0.0875 & 0.068 & 0.0042 & 0.0634 & 0.0589 \\
\hline Wel Cake & 0.1104 & 0.1306 & 0.116 & 0.1169 & 0.1868 & 0.1193 & 0.1743 & 0.1079 & 0.1103 \\
\hline (Samples) & & & & & & & & & \\
\hline Feodsoll & 0.005300 & 9.006100 & 0.005700 & 0.006200 & 0.010000 & 0.006000 & 0.006700 & 0.006700 & 0.006400 \\
\hline Tolal Uranium Out (lbs) & 0.198618 & 0.188285 & 0.176221 & 0.205102 & 0.309086 & 0.203671 & 0.190851 & 0.183638 & 0.188449 \\
\hline Uranium Loss (lbs) & -0.012818 & 0.008515 & 0.018279 & -0.002292 & -0.000486 & 0.014229 & 0.024549 & 0.020662 & 0.033151 \\
\hline
\end{tabular}

REACTOR MATERIAL BALANCE FOR URANIUM

INCINERATOR AREA SOIL

\begin{tabular}{|c|c|c|c|c|c|c|c|c|c|}
\hline & Testo & Test 1 & Test 2 & Test 3 & Test 7 & Test 13 & Test 14 & Test 15 & Test 18 \\
\hline Uranium in foed (Ibs) & 0.185800 & 0.206800 & 0.185500 & 0.202900 & 0.308600 & 0.2178000 & $0.215400^{\circ}$ & 0.204300 & $0.221600^{\circ}$ \\
\hline \multicolumn{10}{|l|}{ Uranium out (lbs) } \\
\hline Trommeloversize & 0.0004 & 0.000935 & 0.002593 & 0.00008 & 0.007726 & 0.000151 & 0.000726 & 0.0005 & 0.001619 \\
\hline TrommelHeel & 0.009678 & 0.006850 & 0.006028 & 0.006212 & 0.023060 & 0.010220 & 0.004925 & 0.005738 & 0.011230 \\
\hline Reactor Slurry & 0.1722 & 0.1577 & 0.173 & 0.1519 & 0.222 & 0.1301 & 0.1511 & 0.1697 & 0.1754 \\
\hline \multicolumn{10}{|l|}{ (Samples) } \\
\hline Feed Soll & 0.005300 & 0,006700 & 0.005700 & 0.006200 & 0.010000 & 0.006000 & 0.006700 & 0.006700 & 0.006400 \\
\hline iscrubber & 0.073930 & 0.000381 & 0.002276 & 0.002421 & 0.070570 & 0.003190 & 0.006481 & 0.003643 & 0.003023 \\
\hline Total Üraniúm Out (lbs) & 0.201448 & 0.171866 & 0.189597 & 0.166813 & 0.267356 & 0.149661 & 0.169932 & 0.185681 & 0.197672 \\
\hline Uranium Loss (bs) & -0.015848 & 0.034834 & 0.005903 & 0.036087 & 0.041244 & 0.068239 & 0.045468 & 0.018619 & 0.023928 \\
\hline Percent Uranlum Recovery & $108.42 \%$ & $83.16 \%$ & $96.98 \%$ & $82.21 \%$ & $86.64 \%$ & $68.68 \%$ & $78.89 \%$ & $80.89 \%$ & $89.20 \%$ \\
\hline
\end{tabular}


TABLE D-7

OVERALLL MATERIAL BALANCE FOR URANIUM

STORAGE PAD SOIL

\begin{tabular}{|c|c|c|c|c|c|c|c|}
\hline & Test 4 & Test 5 & Test 6 & Test 8 & Test 16 & Test 17 & Test 19 \\
\hline Uranium in Feed (IDS) & 0.584300 & $0.574200^{\circ}$ & 0.541500 & 0.550600 & 0.673300 & $0.505600^{\circ}$ & $0.570400^{\circ}$ \\
\hline Uranium in Treated Soll (ibs) & 0.0278 & 0.0216 & 0.0242 & 0.01577 & 0.0262 & 0.0256 & 0.0287 \\
\hline By-Product Uranium (bs) & & & & & & & \\
\hline Trommel Oversize & 0.01865 & 0.023 & 0.0165 & 0.02214 & 0.0159 & 0.0128 & 0.0044 \\
\hline Trommel Heel & & & & 0.004360 & & 0.012400 & 0.002986 \\
\hline Vibrating Screen Oversize & 0.001050 & 0.000309 & 0.000700 & & & & \\
\hline Centrifuge Purge & & & & 0.01 & & & 0.01741 \\
\hline Centrate No. 1 & 0.444000 & 0.386500 & 0.286600 & 0.339900 & 0.383200 & 0.297400 & 0.297400 \\
\hline Centrate No. 2 & 0.057450 & 0.052480 & 0.040820 & 0.031150 & 0.052500 & 0.031240 & 0.119000 \\
\hline Centrate No. 3 & 0.013270 & 0.008747 & 0.007809 & 0.003082 & 0.021200 & 0.004665 & 0.000000 \\
\hline Centrifuge Heel & 0.000000 & 0.000000 & 0.000000 & 0.030000 & & 0.002645 & 0.009071 \\
\hline (Samples) & & & & & & & \\
\hline Feedsoll & 0.013300 & 0.019600 & 0.017100 & 0.015500 & 0.016900 & 0.017600 & 0.016600 \\
\hline Attrition Scrubber & 0.000485 & 0.000549 & 0.000600 & 0.005447 & 0.031900 & 0.004678 & 0.006154 \\
\hline Reactor & 0.001030 & 0.001655 & 0.007471 & 0.007139 & 0.001443 & 0.001278 & 0.000975 \\
\hline Centrifuge Wet Cake & & & & 0.000171 & & & 0.000232 \\
\hline Total Byproduct Uranium (lbs) & 0.549235 & 0.492840 & 0.371600 & 0.462889 & 0.523043 & 0.384706 & 0.474228 \\
\hline Tht & 757 & D.5यदयत & 0305800 & 0278659 & 0540243 & 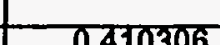 & 7.5्रकरक \\
\hline Uranium Loss (lbs) & 0.073265 & 0.059760 & 0.145700 & 0.077941 & 0.124057 & 0.095294 & 0.007472 \\
\hline Precent Uranium Recovery & $97.73 \%$ & $89.59 \%$ & $73.09 \%$ & $86.93 \%$ & $81.57 \%$ & $81.15 \%$ & $98.54 \%$ \\
\hline
\end{tabular}


TABLE D-8

TABLEAL MATERIAL BALANCE FOR URANIUM

INCINERATOR AREA SOIL

\begin{tabular}{|c|c|c|c|c|c|c|c|c|c|}
\hline & Test 0 & Test 1 & Test 2 & Test 3 & Test 7 & Test 13 & Test 14 & Test 15 & Test 18 \\
\hline [Uranium in Feed (Ibs) & 0.185800 & 0.206800 & 0.185500 & 0.202800 & 0.3086000 & 0.2178000 & 0.215400 & 0.204500 & 0.221600 \\
\hline [Uranium in Treated soil (IBS) & 0.01687 & 0.02256 & 0.0207 & 0.0185 & 0.03958 & 0.0283 & 0.03671 & 0.02976 & 0.0154 \\
\hline & & & & & & & & & \\
\hline By-Product Uranium (bs) & 0.0004 & 0.000935 & 0,002593 & 0,00008 & 0.007726 & 0.000151 & 0,000726 & 0.0005 & 0001679 \\
\hline Trommel he日l & 0.009678 & 0.006850 & 0.006028 & 0.006212 & $\frac{0.001126}{0.023060}$ & $\frac{0.000151}{0.010220}$ & $\frac{0.000 / 26}{0.004925}$ & 0.005738 & $\frac{0.001619}{0.011230}$ \\
\hline Vibrating screen Oversize & & & & & & & & & \\
\hline Centrifuge Purge & 0.0052 & 0.00705 & 0.00723 & 0.0137 & 0.0197 & 0.00818 & 0.00818 & 0.00569 & 0.0037 \\
\hline CentrateNo. 1 & 0.123000 & 0.127400 & 0.114300 & 0.717100 & 0.138100 & 0.112500 & 0.126600 & 0.124950 & 0.139300 \\
\hline Centrateno.2 & 0.075490 & 0.012000 & 0.017970 & 0.012000 & 0.033570 & 0.070830 & 0.012500 & 0.013750 & \\
\hline Centrifuge Heel & 0.006202 & 0.004775 & 0.010850 & 0.003819 & 0.015950 & 0.003400 & 0.005615 & 0.008299 & 0.004339 \\
\hline (Samplos) & & & & & & & & & \\
\hline Foed Soll & 0.005300 & 0.006100 & 0.005700 & 0.006200 & 0.010000 & 0.006000 & 0.006700 & 0.006700 & 0.006400 \\
\hline Altrition Scrubber & 0.013930 & 0.000387 & 0.002276 & 0.002421 & 0.010570 & 0.003190 & 0.006487 & 0.003643 & 0.003023 \\
\hline Reactor & 0.000870 & 0.000464 & 0.000469 & 0.000488 & 0.000676 & 0.000244 & 0.000463 & 0.000514 & 0.000384 \\
\hline Cenirifuge Welcake & 0.000099 & 0.000120 & 0.000138 & 0.000126 & 0.000377 & 0.000244 & 0.000283 & 0.000737 & 0.000098 \\
\hline Total Byproduct Uranium (bs) & 0.183566 & 0.177246 & 0.164618 & 0.164853 & 0.260878 & 0.154959 & 0.172473 & 0.172064 & 0.170083 \\
\hline Totaluranium out (bs) & 0.200436 & 0.183806 & 0.185378 & 0.1833553 & 0.300398 & 0.183259 & 0.189183 & 0.201824 & 0.185493 \\
\hline Uranium Loss (16s) & -0.014636 & 0.012894 & 0.010182 & 0.019547 & 0.008202 & 0.034641 & 0.026217 & 0.002476 & 0.036107 \\
\hline Precent Uranlum Recovery & $107.88 \%$ & $83.72 \%$ & $04.79 \%$ & $80.37 \%$ & $97.34 \%$ & $84.10 \%$ & $87.83 \%$ & $98.79 \%$ & $83.71 \%$ \\
\hline
\end{tabular}


Table D-9. Overall material balances for soil final four Phase $\mathbf{I}$ tests

\begin{tabular}{lcccc}
\hline & \multicolumn{4}{c}{ Quantity of soil (lb) } \\
\cline { 2 - 5 } & Test 20 & Test 21 & Test 22 & Test 25 \\
\cline { 2 - 5 } Feed soil & 340.4 & 293.2 & 332 & 282.5 \\
Treated soil & 205.2 & 165.6 & 255.8 & 144.2 \\
By-product solids & & & & \\
$\quad$ Trommel & 14.1 & 1.8 & 12.3 & 14 \\
oversize & 12.6 & 22.4 & 18.6 & 21.5 \\
$\quad$ Trommel heel & 86.2 & 73.7 & 0 & 67.3 \\
$\quad$ Reactor sample & 13.2 & 14.1 & 20.3 & 10.5 \\
$\quad$ Centrifuge heel & 12 & 11.4 & 11.6 & 11.2 \\
$\quad$ Other samples & 138.1 & 123.4 & 62.8 & 124.5 \\
Total by-product & & & & \\
solids & 343.3 & 289 & 318.6 & 268.7 \\
Total solids out & $(2.9)$ & 4.2 & 13.4 & 13.8 \\
Solids loss (gain) & 100.9 & 98.6 & 96 & 95.1 \\
\hline Percent recovery & & & & \\
\hline
\end{tabular}


Table D-10. Overall material balances for uranium final four Phase $\mathrm{I}$ tests

\begin{tabular}{lcccc}
\hline & \multicolumn{4}{c}{ Quantity of uranium (lb) } \\
\cline { 2 - 5 } & Test 20 & Test 21 & Test 22 & Test 25 \\
\hline Uranium in feed soil & 0.1900 & 0.1507 & 0.1855 & 0.2495 \\
Uranium in treated soil & 0.0179 & 0.0083 & 0.0171 & 0.0164 \\
By-product uranium & & & & \\
Trommel oversize & 0.0007 & 0.0003 & 0.0004 & 0.0011 \\
Trommel heel & 0.0116 & 0.0027 & 0.0108 & 0.0033 \\
Reactor sample & 0.0391 & 0.0300 & & 0.0890 \\
Centrates & 0.1072 & 0.0852 & 0.1256 & 0.2952 \\
Centrifuge heel & 0.0018 & 0.0010 & 0.0017 & 0.0013 \\
Other samples & 0.0067 & 0.0058 & 0.0060 & 0.0306 \\
Total by-product uranium & 0.1671 & 0.1250 & 0.1445 & 0.4205 \\
Total uranium out & 0.1850 & 0.1333 & 0.1616 & 0.4369 \\
Uranium loss (gain) & 0.0050 & 0.0174 & 0.0239 & $(0.1874)$ \\
Percent recovery & 97.4 & 88.5 & 87.1 & 175 \\
\hline
\end{tabular}



ORNL/TM-12960

\section{INTERNAL DISTRIBUTION}

1. M. R. Ally

2. A. Q. Armstrong

3. H. L. Boston

4. A. G. Croff

5. N. H. Cutshall

6. D. M. Douthat

7. M.P. Elless

8. B. D. Faison

9. D. D. Gates

10. J. R. Hightower

11. A. J. Kuhaida, Jr.

12. S. Y. Lee

13. A. P. Malinauskas

14. A. J. Mattus
15. L. E. McNeese

16. L. L. Oakes

17. J. G. Pruett

18. S. M. Robinson

19. D. S. Shiner

20. B. P. Spalding

21. S. H. Stow

22. J. S. Watson

23-25. J. H. Wilson

26. Central Research Library

27. ORNL Laboratory Records Department

28. ORNL Laboratory Records-RC

29. ORNL Patent Section

30. ORNL Y-12 Technology Library

\section{EXTERNAL DISTRIBUTION}

31. Y. Acar, Electrokinetics Inc., Louisiana Business and Tec Center, South Stadium Drive, Suite 102, Baton Rouge, LA 70803-6100

32. R. Bahorich, Scientific Ecology Group, 1501 Ardmore Blvd., Forest Hills, PA 15221

33. J. Barthel, Rust Remedial Services, 1597 Cole Blvd., Bldg. 15, Suite 350, Golden, CO 80401

34. V. Ceci, BDM Federal, Bellemeade 1, 20251 Century Blvd., Germantown, MD 20874

35. W. A. Bliss, Reynolds Electrical Eng. Co. Inc., P. O. Box 98521, MS-428, Las Vegas, NV 89193-8521

36. J. R. Brainard, LANL-INC-4, MS-C36, Los Alamos National Laboratory, Los Alamos, NM 87545

37. E. T. Bramlitt, Defense Nuclear Agency, Field Command, FCDNA/FCEH, 1680 Texas St. S. E. Kirtland AFB, NM 87117-5669

38. D. Brettschneider, FERMCO, P.O. Box 398704, Cincinnati, OH 45239-8704

39. M. Bricka, USAE WES, 3909 Halls Ferry Rd., WESEE-R, Vicksburgh, MS 39180

40. K. Brierly, British Nuclear Fuels plc, R220 Risley, Warrington, Cheshire, United Kingdom, WA3 6AS

41. E. C. Buck, Argonne National Laboratory, Chemical Technology Division, 9700 South Cass Avenue, Argonne, IL 60439

42. J. L. Burnett, ER-142, G-339/GTN, Office of Basic Energy Sciences, U. S. Department of Energy, 19901 Germantown Road, Germantown, MD 20545

43. J. Caldwell, Jacobs Engineering Group, 251 S. Lake Avenune, Pasadena, CA 91101

44. D. J. Chaiko, Argonne National Laboratory, Chemical Technology Division, 9700 South Cass Ave., Bldg. 205, Argonne, IL 60439-4837 
45. P. Colomobo, Brookhaven National Laboratory, Bldg. 703-50 Rutherford, Upton, NY 11973

46. R. H. Condit, Lawrence Livermore National Laboratory, P.O. Box 808, Livermore, CA 94550

47. J. Corone, Ames Laboratory, 329 Wilhelm Hall, Iowa State University, Ames, IA 50011

48. C. Cox, USEPA National Air \& Radiation, Environmental Laboratory, 1504 Avenue A, Montgomery, AL 36115-2601

49. J. C. Cunnane, Chemical Technology Division, Argonne National Laboratory, 9700 South Cass Avenue, Argonne, IL 60439

50. A. Dietrich, Scientific Ecology Group, 1501 Ardmore Blvd., Forest Hills, PA 15221

51. D. Dougherty, Halliburton NUS, 10200 Bellaire, Haouston, Texas 77072-5299

52. L. Dworjahyn, Westinghouse SRL, Savannah River Site/Bldg. 779-2A, Aiken, SC 29808

53. M. Eagle, U.S. EPA, 401 M Street SW, RSD-6603J, Washington, DC 20460

53. S. Fauver, DOE-HQ, EM-424, Trevion II Bldg., Washington, DC 20585-0002

55. D. Foust, General Electric Co., Corporate R\&D, P. O. Box 8, Bldg. K-1, RM 5A24, Schenectady, NY 12301

56. A. J. Francis, PI Brookhaven National Laboratory, 1 South Technology St., Bldg 318, Upton, NY 11973

57. M. Fuhrmann, Brookhaven National Laboratory, Bldg. 830, Upton, NY 11973

58. D. M. Gerrick, FERMCO, P. O. Box 398704, MS 52-5, Cincinnati, OH 45239-8704

59. M. J. Geyer, FERMCO, P. O. Box 398704, MS 81-3, Cincinnati, OH 45239-8704

60. M. Ghosh, Dept of Civil and Environmental Engineering, University of Tennessee, 219B Berkins Hall, Knoxville, TN 37996-2010

61. D. Gombert, Westinghouse Idaho Nuclear Co., Site Remediation, P. O. Box 4000, Idaho Falls, ID 83402-4000

62. R. A. Graves, ISOTRON Corporation, 13152 Chef, New Orleans, LA 70124

63. B. Gupta, Manager, Waste Management Prgrms, National Renewable Energy Laboratory, 1617 Cole Boulevard, Golden, CO 80401

64. K. Hain, U. S. Department of Energy, EM-55, RM-422, Trevion II Blvd., Washington, DC 20585-0002

65. G. F. Hall, Lockheed Env Systems \& Tech, 900 Grier Dr., Suite B, Las Vegas, NV 89119

66. A. Hanson, New Mexico State University, Dept. Of Civil Engineering, Engineering Complex II, Box 3CE, Los Cruces, NM 88003

67. J. Hart, U. S. Department of Energy, FUSRAP, MS-EW93, P. O. Box 2001, Oak Ridge, TN 37831-8723

68. B. Hass, Ames Laboratory, 329 Wilhelm Hall, Iowa State University, Ames, IA 50011

69. S. Hay \& Associates, S. Cohen \& Associates, Inc., 1418 I-85 Parkway, Montgomery, AL 36016

70. J. E. Helt, Chemical Technology Division, Argonne National Laboratory, 9700 South Cass Avenue, Argonne, IL 60439

71. D. Herman, FERMCO, P.O. Box 398704, Cincinnati, OH 45239-8704

72. P. Hopper, Scientific Ecology Group, Inc., P. O. Box 2570, 1560 Bear Creek Rd., Oak Ridge, TN 37831

73. C. S. Hultman, BNFL Inc., 5655 South Yosemite, Suite 100, Englewood, CO 80111

74. R. Jacobson, Desert Research Institute, P.O. Box 19040, Las Vegas, NV 89132-0040

75. G. Y. Jordy, Director, Office of Program Analysis, , Office of Energy Research, ER-30, G-226, U.S. Department of Energy, Washington, DC 20545 
76. D. L. Keairns, Westinghouse Science and Technology Center, 1310 Beulah Road, Pittsburgh, PA 15235-5098

77. P. C. Keegan, Scientific Ecology Group, 1501 Ardmore Blvd., Pittsburgh, PA 15221

78. D. Kelsh, Science Applications Intl. Corp., 555 Quince Orchard Rd., Suite 500, Gaithersburg, MD 20878

79. T. R. Krause, Chemical Technology Division, Argonne National Laboratory, 9700 South Cass Avenue, Argonne, IL 60439

80. M. A. Kristich, FERMCO, P. O. Box 398704, MS 52-5, Cincinnati, Ohio 45239-8704

81. E. J. Lahoda, Westinghouse Electric Science \& Tech. Center, 1310 Beulah Rd., Pittsburgh, PA 15235-5098

82. E. R. Landa, U.S. Geological Survey, Water Resources Division, 431 National Center, MS-4432, Reston VA 22092

83. E. R. Lindgren, Sandia National Laboratories, P. O. Box 5800, Albuquerque, NM 87185-5800

84. H. L. Lomasney, ISOTRON Corporation, 13152 Chef Hwy, New Orleans, LA 70129

85. J. L. Malhotra, DOE/Morgantown Energy. Technical Center, P. O. Box 880, Collins Ferry Rd., Morgantown, WV 26507-0880

86. M. Malone, U. S. Department of Energy, EM-551, Trevion II Blyd., Washington, DC 20585-0002

87. G. Maraman, Argonne National Laboratory, P. O. Box 6974, Oak Ridge, TN 37831

88. C. Mason, Los Alamos National Laboratory, P. O. Box 1663, MSJ-534, Los Alamos, NM 87545

89. J. Mather, DOE-HQ, EM542, Trevion II Bldg., Washington, 20585-0002

90. E. Milicic, Westinghouse Remediation Services ATLANTA, 675 Park North Blvd., Building F, Suite 100, Clarkston, GA 30021-1962

91. F. L. Miller, Jr., Desert Research Institute, P. O. Box 19040, Las Vegas, NV 89132-0040

92. L. A. Moschuk, AECL Technologies, 9210 Corporate Blvd., Suite 410, Rockville, Maryland 20850

93. K. Motyl, EG\&G Rocky Flats, P.O. Box 464, Golden, CO 8042-0464

94. P. R. Mulik, Westinghouse Science and Technology Center, 1310 Beulah Road, Pittsburgh, PA 15235-5098

95. T. M. Murarik, AWC-Lockheed, P.O. Box 96118, Las Vegas, NV 89193

96-98. K. R. Nuhfer, FERMCO, P. O. Box 398704, MS 82-1, Cincinnati, OH 45239-8704

99. A. Patrinos, Director, Environmental Sciences Division, Office of Health and Environmental Research, ER-74, U.S. Department of Energy, Washington, DC 20585

100. M. Peterson, PNL, Battelle Pacific NW Laboratory, P.O. Box 999, MS-INP-41, Battelle Blvd, Richland, WA 99352

101. P. J. Pettit, FERMCO, P.O. Box 398704, Cincininati, OH 45239-8704

102. A. D. Pflug, Argonne National Laboratory, 9700 S. Cass Ave., CID-900, Argonne, IL 60439-4832

103. K. L. Pylka, FERMCO, P.O. Box 398704, MS 81-3, Cincinnati, OH 45239-8704

104. L. Rogers, EG\&G, Energy Measurements, Inc., P.O. Box 1912, MS-RSL-11, 316 East Atlas Circle, Las Vegas, NV 89030

105. R. R. Ryan, EG\&G Rocky Flats, P. O. Box 4013, T 130-A, LATO, Golden, CO 80401-0013

106. M. Salisbury, FERMCO, P.O. Box 398704, Cincinnati, OH 45239-8704 
107. D. Sanning, U.S. Environmental Protection Agency, 26 W. Martin Luther King Drive, RM-218, Cincinnati, OH 45219

108. J. Schwing, FERMCO, P. O. Box 398704, MS 81-2, Cincinnati, OH 45239-8704

109. B. Seay, U. S. Department Of Energy, P. O. Box 2001, Oak Ridge, TN 37831-8723

110. R. Jeff Serne, Geochemistry Section, Geosciences Department, Battlelle Pacific Northwest Lab, P.O. Box 999, Richland, WA 990352

111. W. E. Sisk, U. S. Army Environmental Center, ENAEC-TS-D, Bldg. E4460, Aberdeen Proving Grounds, MD 21010-5401

112. M. Skriba, Fluor Daniel Environmental Services, Inc, 3333 Michelson Drive, Irvine, CA 92730

113. S. C. Slate, Pacific Northwest Laboratory, MSIN KI-19, Office of Environmental Technology, P.O. Box 999, Richland, WA 99352

114. R. F. Smiecinski, U. S. DOE/NV, 2765 S. Highland, Las Vegas, NV 89193-8518

115. R. Stead, FERMCO, P. O. Box 398704, MS 81-2, Cincinnati, OH 45239-8704

116. J. Steel, Waste Env. Remediation Prgrms, Savannah River Site, Bldg. 773-A, A208, Aiken, SC 29802

117. G. Subbaraman Rockendyne Division, Rockwell Internaltioal/ETEC, Energy Technology Eng., Center, P. O. Box 7930, Canoga Park, CA 91309-7930

118. J. R. Suitlas, Brown \& Root Environmental, Foster Plaza 7, 661 Anderson Drive, Pittsburgh, PA 15220

119. N. Swift, Bradtec - US, 1010 Huntcliff Trail, Suite 1350, Atlanta, GA 30350

120. C. L. Tellez, Lockeed, Manager, Projects, 900 Grier Drive, Suite B, Las Vegas, NV 89119

121. V. Tidwell, Sandia National Laboratory, Department 6115, 1515 Eubank Blvd. S. E., Albuquerque, NM 87185

122. R. Warner, DOE-Fernald, MS-45, P.O. Box 398704, Cincinnati, Ohio 45239-8704

123. L. Worl, Los Alamos National Laboratory, Nuclear Materials Technology Div., NMT-3, MS-E511, Los Alamos, NM 87545

124. P. J. Yerace, U. S. Department of Energy, FERMCO, P. O. Box 398704, MS-45, Cincinnati, Ohio 45239-8704

125. D. A. York, Los Alamos National Lab, MEE-4, MS G787, P.O. Box 1663, Los Alamos, NM 87545

126-127. Office of Scientific and Technical Information, P.O. Box 62, Oak Ridge, TN 37831 